VICTOR CHIARONI GALVÃO

VALIDAÇÃO DE UM INSTRUMENTO PARA CARACTERIZAÇÃO DE CULTURA DE SEGURANÇA DE ALIMENTOS PARA O PORTUGUÊS BRASILEIRO

São Paulo

2018 


\section{VALIDAÇÃO DE UM INSTRUMENTO PARA CARACTERIZAÇÃO DE CULTURA DE SEGURANÇA DE ALIMENTOS PARA O PORTUGUÊS BRASILEIRO}

Dissertação apresentada ao Programa de Pós-Graduação em Epidemiologia Experimental e Aplicada às Zoonoses da Faculdade de Medicina Veterinária e Zootecnia da Universidade de São Paulo para a obtenção do título de Mestre em Ciências

\section{Departamento:}

Medicina Veterinária Preventiva e Saúde Animal

\footnotetext{
Área de concentração:

Epidemiologia Experimental e Aplicada às Zoonoses
}

Orientadora:

Prof ${ }^{a}$. Dra. Simone de Carvalho Balian

De acordo:

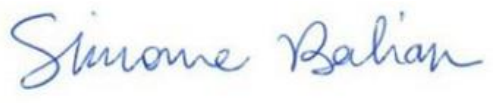

Orientadora

\section{São Paulo}

2018

Obs: A versão original encontra-se disponível na Biblioteca da FMVZ/USP 
Autorizo a reprodução parcial ou total desta obra, para fins acadêmicos, desde que citada a fonte.

\section{DADOS INTERNACIONAIS DE CATALOGAÇÃO NA PUBLICAÇÃO}

(Biblioteca Virginie Buff D’Ápice da Faculdade de Medicina Veterinária e Zootecnia da Universidade de São Paulo)

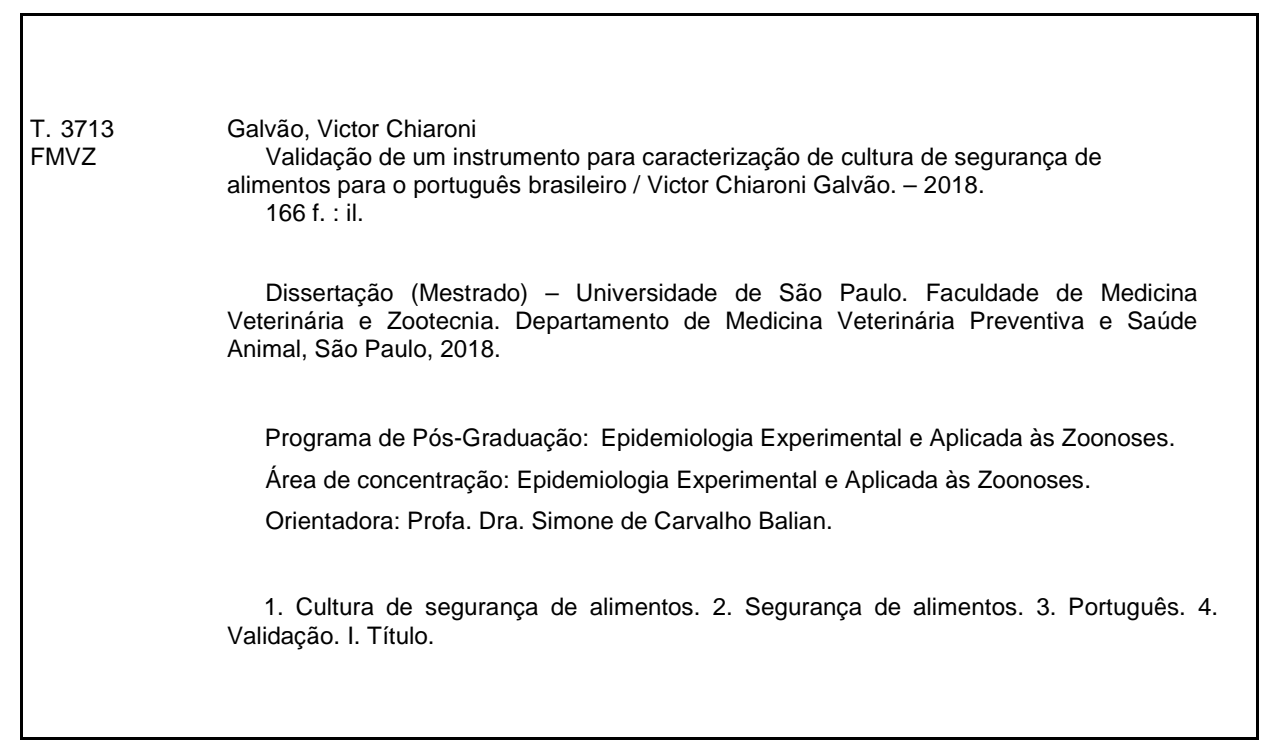

Ficha catalográfica elaborada pela bibliotecária Maria Aparecida Laet, CRB 5673-8, da FMVZ/USP. 
llimo(a). Sr(a).

Responsável: Simone De Carvalho Balian

Area: Epidemiologia Experimental Aplicada As Zoonoses

Equipe envolvida: Victor Chiaroni Galväo - executor (fmvz-usp):

Titulo do projeto: "VALDAÇÃO DE UM INSTRUMENTO PARA CARACTERIZAÇĂO DE CULTURA DE SEGURANÇA DE ALIMENTOS PARA O PORTUGUES BRASILEIRO".

\section{Parecer Consubstanciado da CEUA FMVZ}

A Comissão de Ética no Uso de Animais da Faculdade de Medicina Veterinária e Zootecnia da Universidade de São Paulo, na reuniāo de 17/10/2018, ANALISOU e APROVOU o protocolo de estudo acima referenciado. A partir desta data, é dever do pesquisador: 1. Comunicar toda e qualquer alteraçăo do protocolo.

2. Comunicar imediatamente ao Comite qualquer evento adverso ocorrido durante o desenvolvimento do protocolo.

3. Os dados individuais de todas as etapas da pesquisa devem ser mantidos em local seguro por $\mathbf{5}$ anos para possivel auditoria dos órgãos competentes.

4. Relatórios parciais de andamento deverão ser enviados anualmente à CEUA até a conclusāo do protocolo.

$$
\text { (Onnelies Tealon. }
$$

Profa. Dra. Anneliese de Souza Trald Presidente da Comissão de Etica no Uso de Animais Faculdade de Medicina Veterinária e Zootecnia da Universidade Faculdade de Medicina Veterinária e Zootecnia da Universidade de São Paulo

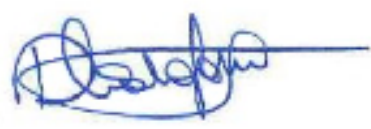

Roseli da Costa Gomes Secretária

de Sāo Paulo 
Autor: GALVÃO, Victor Chiaroni

Título: Validação de um instrumento para caracterização de cultura de segurança de alimentos para o português brasileiro

Dissertação apresentada ao Programa de Pós-Graduação em Epidemiologia Experimental e Aplicada às Zoonoses da Faculdade de Medicina Veterinária e Zootecnia da Universidade de São Paulo para obtenção do título de Mestre em Ciências.

Data:

\section{Banca Examinadora}

Prof. Dr.

Instituição: Julgamento:

Prof. Dr. Instituição: Julgamento:

Prof. Dr. Instituição: Julgamento: 


\section{Dedicatória}

Dedico esta dissertação a Nosso Senhor Jesus Cristo pelas mãos da Virgem Maria, nossa Mãe santíssima.

Tuus totus ego sum, et omnia mea tua sunt. 


\section{Agradecimentos}

Agradeço a Deus por ter concedido a mim a Graça de viver e de sustentar o meu ser para que eu contribua com o seu projeto eterno.

Aos instrumentos de Deus: Nossa Senhora de Fátima, São Padre Pio de Pietrelcina, Santa Teresinha do Menino Jesus, São Luís Gonzaga, Santa Teresa d'Ávila, os Três Arcanjos, meu Anjo da Guarda, Pe. Anderson Bernardes Banzato e Pe. Paulo Ricardo de Azevedo Júnior.

A toda a minha Família, em especial minha Mãe Claudia, Pai Ricardo e Irmãos Dante, Ricardo e Júlia pelo suporte emocional, afetivo e material.

À Vanessa, companheira de minha vida.

À Professora Simone, fonte da qual me alimento em todos os sentidos da vida. A senhora é um exemplo de ser humano e professor/orientador para mim.

Ao Professor Olavo de Carvalho pelos ensinamentos e esclarecimentos do meu raciocínio sobre as coisas.

À empresa participante do projeto, em especial à Julia, Carla, Jaqueline, Ilana, Vanessa, Elaine, Cristina, Beth, Karina e Clarice.

Aos Professores das disciplinas que cursei durante a pós-graduação, em especial ao Profo Fábio Gregori pelas conversas, receptividade e conselhos.

Aos Colegas de Pós que convivi nesse período, em especial ao Werner Souza Martins pelas conversas e companheirismo nesse período.

À Sandra Abelardo Sanches pelo carinho, amizade e auxílio no laboratório e durante a pós-graduação.

Aos Funcionários do VPS: Renatinho, Washington, Sheila, Gisele, Carolzinha, Rose, Danival, Vanessa e Antônio.

Ao Euro de Barros Couto Junior e a Regina Albanese Pose pelos conselhos e orientações em estatística. 
Aos alunos da Graduação (Vet USP 80) pelo carinho, aprendizado e amizade durante o Programa de Aperfeiçoamento de Ensino da USP (PAE).

À FMVZ-USP que me forneceu tanto na pós-graduação quanto na graduação conhecimento, recursos/infraestrutura e pessoas incríveis que formaram o que sou hoje.

À Nação brasileira e a população do Estado de São Paulo que fomentam a pesquisa científica através da sua contribuição de impostos.

À CAPES, órgão financiador do projeto.

O presente trabalho foi realizado com apoio da Coordenação de Aperfeiçoamento de Pessoal de Nível Superior - Brasil (CAPES) - Código de Financiamento 001. 


\section{Resumo}

GALVÃO, V. C. Validação de um instrumento para caracterização de cultura de segurança de alimentos para o português brasileiro. [Validation of an instrument to characterize the food safety culture in Brazilian Portuguese]. 2018. $166 \mathrm{f}$. Mestrado (Mestre em ciências) - Faculdade de Medicina Veterinária e Zootecnia, Universidade de São Paulo, São Paulo, 2018.

Este estudo tem o objetivo de validar um instrumento (questionário) em português do Brasil para avaliação de cultura de segurança de alimentos (CSA). O cenário do estudo foi composto por áreas de manipulação de alimentos prontos para consumo de uma rede de lojas de hipermercado (RLH). A empresa possuía 2204 colaboradores de manipulação de alimentos em 28 lojas hipermercado. Foi realizada uma revisão da literatura científica nacional e internacional para identificar qual instrumento se adequa melhor segundo a realidade brasileira para autoavaliação da percepção dos colaboradores que manipulam alimentos a respeito da CSA. Os critérios para escolha do instrumento foram a disponibilidade do questionário para ser avaliado, a explicação dos elementos que compõem a CSA, itens condizentes com o dia a dia de manipulação de alimentos e limite de até 50 itens. Um instrumento de 31 itens e escala Likert de sete pontos foi escolhido. O processo de validação do instrumento baseou-se no trabalho de Borsa et. al. (2012) que estabeleceram seis passos: tradução do instrumento para o novo idioma, síntese das versões traduzidas, avaliação da síntese por experts, avaliação pelo públicoalvo, backtranslation (retradução) e estudo piloto. Uma entrevista com um responsável pela segurança de alimentos da RLH foi coletada para obter outra fonte de informação sobre a CSA. O instrumento foi aplicado em 383 participantes de 15 lojas da RLH. Após a aplicação empírica do instrumento na RLH sucederam-se análises estatísticas descritivas e multivariadas dos dados. $O$ instrumento foi validado para diagnosticar CSA em português brasileiro após as etapas descritas. Os resultados das respostas do instrumento demonstraram que a CSA possui tendência positiva. A entrevista corroborou as respostas dos participantes e mostrou uma CSA desenvolvida.

Palavras-chave: Cultura de Segurança de Alimentos. Segurança de Alimentos. Português. Validação. 


\begin{abstract}
GALVÃO, V. C. Validation of an instrument to characterize the food safety culture in Brazilian Portuguese. [Validação de um instrumento para caracterização de cultura de segurança de alimentos para o português brasileiro]. 2018. 166 f. Mestrado (Mestre em ciências) - Faculdade de Medicina Veterinária e Zootecnia, Universidade de São Paulo, São Paulo, 2018.
\end{abstract}

This study aims to validate an instrument (questionnaire) in Brazilian Portuguese for assess food safety culture (FSC). The study scenario was composed of ready-to-eat food handling areas of a hypermarket chain network (HCN). The company had 2204 food handling workers in 28 hypermarket stores. A review of national and international scientific literature was carried out to identify which instrument is best suited to the Brazilian reality for the self-assessment of food handlers' perception of FSC. The criteria for choosing the instrument were the availability of the questionnaire to be evaluated, the explanation of the elements that make up the FSC, items consistent with the day to day food handling and limit of up to 50 items. An instrument of 31 items and a seven-point Likert scale was chosen. The validation process of the instrument was based on the work of Borsa et. al. (2012), which established six steps: translation of the instrument into the new language, synthesis of translated versions, evaluation of synthesis by experts, evaluation by the target audience, backtranslation and pilot study. An interview with an HCN food safety representative staff was collected for another source of information about FSC. The instrument was applied to 383 participants from $15 \mathrm{HCN}$ stores. After the empirical application of the instrument in the $\mathrm{HCN}$, descriptive and multivariate statistical analyzes of the data were succeeded. The instrument was validated to diagnose FSC in Brazilian Portuguese after the steps described. The results of the instrument responses showed that the FSC has a positive trend. The interview corroborated participants' responses and showed a FSC developed.

Keywords: Food Safety Culture. Food Safety. Portuguese. Validation. 


\section{LISTA DE FIGURAS}

Figura 1 - Posicionamento esquemático da cultura de segurança de alimentos (adaptado de Nyarugwe et. al., 2016) - São Paulo, 2018

Figura 2 - Hierarquia de funções da Rede de Lojas Hipermercado no Brasil, dividida em nível administrativo e loja hipermercado - São Paulo, 2018

Figura 3 - Fluxograma da metodologia da validação do questionário para diagnóstico de Cultura de Segurança de Alimentos - São Paulo, 2018

Figura 4 - Procedimentos para adaptação cultural de instrumentos psicológicos segundo Borsa et. al.(2012)

Figura 5 - Distribuição espacial de doze lojas da rede hipermercado no município de São Paulo - São Paulo, 2018

Figura 6 - Distribuição espacial de três lojas da rede hipermercado em três municípios da Região Metropolitana de São Paulo - São Paulo, 2018 66

Figura 7 - Total de participantes na pesquisa, segundo seu Cargo ou Função Setor da Empresa - São Paulo, 2018

Figura 8 - Participantes da pesquisa categorizados em Operadores de Loja e Gerenciadores, subdivididos segundo os setores de manipulação de alimentos - São Paulo, 2018

Figura 9 - Organograma internacional da Segurança de Alimentos na empresa participante do estudo sobre CSA - São Paulo, 2018 


\section{LISTA DE QUADROS}

Quadro 1 - Elementos de cultura de segurança de alimentos, de acordo com diferentes autores, ano de publicação, contexto e área adaptada ou instrumento - São Paulo, 2018

Quadro 2 - Distribuição das quinze lojas da rede de lojas hipermercado segundo os seus respectivos Responsáveis Técnicos, Coordenadores de Região e Localização nas Figuras 5 e 6 - São Paulo, 2018

Quadro 3 - Testes KMO e Bartllet's para verificar a adequação dos dados para início da Análise Fatorial Exploratória - São Paulo, 2018

Quadro 4 - Comunalidades para Análise Fatorial Exploratória, segundo software SPSS - São Paulo, 2018

Quadro 5 - Resultados da variância total explicada para Análise Fatorial Exploratória, segundo software SPSS - São Paulo 2018

Quadro 6 - Matriz de componentes não rotacionados para Análise Fatorial Exploratória, segundo software SPSS - São Paulo, 2018

Quadro 7 - Matriz de componentes rotacionados para Análise Fatorial

Exploratória, segundo software SPSS - São Paulo, 2018

Quadro 8 - Matriz de componente não rotacionado para Análise Fatorial

Confirmatória, segundo software SPSS - São Paulo, 2018 93

Quadro 9 - Matriz de componentes rotacionados para Análise Fatorial Confirmatória, segundo software SPSS - São Paulo, 2018.

Quadro 10 - Média dos escores em Cultura de Segurança de Alimentos para cada loja, Responsável Técnico (RT) e Coordenador de Região (CR) - São Paulo, 2018 


\section{LISTA DE GRÁFICOS}

Gráfico 1 - Grau de Concordância (Frequência absoluta) de cada item do Questionário sobre Cultura de Segurança de Alimentos - São Paulo, 2018

Gráfico 2 - Grau de Concordância (Frequência relativa) de cada item do Questionário sobre Cultura de Segurança de Alimentos - São Paulo, 2018

Gráfico 3 - Média, Desvio padrão e Moda das respostas em escala Likert de cada item do questionário sobre Cultura de Segurança de Alimentos - São Paulo, 2018

Gráfico 4 - Média dos Escores de Cultura de Segurança de Alimentos para cada Zona do Município de São Paulo e Grande São Paulo - São Paulo, 2018 


\section{LISTA DE TABELAS}

Tabela 1 - Resultados do tamanho da amostra conforme Cochran - São Paulo, 2018

Tabela 2 - Perfil sócio-demográfico dos participantes do estudo ( $n=383)$ - São Paulo, 2018 68

Tabela 3 - Resultados de Frequência absoluta e relativa, Moda e Mediana para cada ponto da escala Likert - São Paulo, 2018

Tabela 4 - Resultado da média da Moda para cada Fator de CSA em cada loja São Paulo, 2018

Tabela 5 - Média, Desvio Padrão e Moda de cada Fator de Cultura de Segurança de Alimentos - São Paulo, 2018

Tabela 6 - Valores de alfa de Cronbach para consistência interna de um questionário - São Paulo, 2018

Tabela 7 - Composição de fatores e itens de Ungku Fatimah e do presente estudo após AFE e AFC - São Paulo, 2018.

Tabela 8 - Resultados de Análise Fatorial Exploratória e rearranjo dos itens conforme os fatores dos autores de Cultura de Segurança de Alimentos - São Paulo, 2018

Tabela 9 - Resultados de Análise Fatorial Confirmatória e rearranjo dos itens conforme os fatores dos autores de Cultura de Segurança de Alimentos

- São Paulo, 2018 100

Tabela 10 - Frequência absoluta e Escore para as variáveis demográficas - São Paulo, 2018 104

Tabela 11 - Valores de Correlação de Spearman para Variáveis Demográficas São Paulo, 2018 108 
APPCC Análise de Perigos e Pontos Críticos de Controle

BPF Boas Práticas de Fabricação

$\mathrm{CAB} \quad$ Central Administrativa Brasil

$\mathrm{CN} \quad$ Cultura Nacional

CO Cultura Organizacional

CR Coordenadores de Região

CS Cultura de Segurança

CSA Cultura de Segurança de Alimentos

DG Diretor Geral

DL Diretor de Loja

DPRP Diretoria de Prevenção de Riscos e Perdas

DSACQ Departamento de Segurança de Alimentos e Controle de Qualidade

DTA Doenças Transmitidas por Alimentos

ES Estagiário

FLV Frutas, legumes e verduras

GC Gerenciador

GE Gerente Especialista

OP Operador de Loja

RLH Rede de lojas Hipermercado

RT Responsável Técnico

SA Segurança dos Alimentos

TCLE Termo de Consentimento Livre e Esclarecido 


\section{SUMÁRIO}

1 INTRODUÇÃO

$\begin{array}{lll}1.1 & 19\end{array}$

1.2 CONCEITO DE SEGURANÇA DE ALIMENTOS 21

1.3 CONCEITO DE CULTURA DE SEGURANÇA DE ALIMENTOS 22

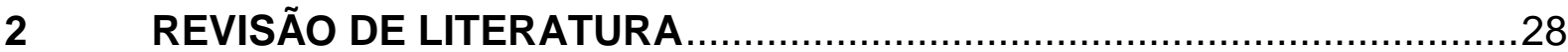

2.1 AUTORES E ABORDAGENS PARA CSA 28

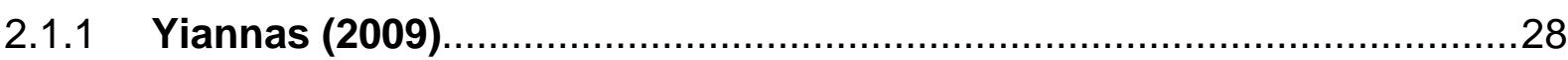

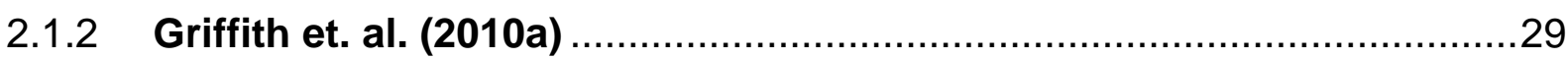

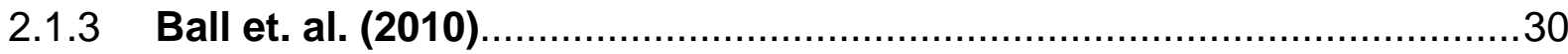

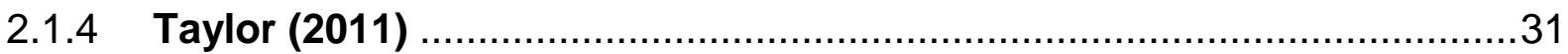

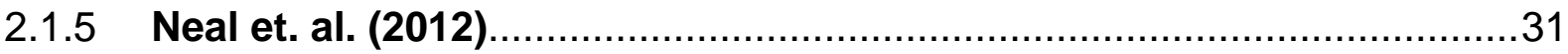

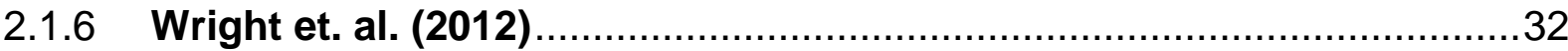

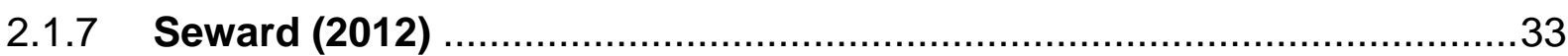

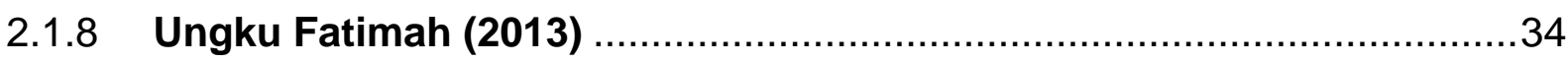

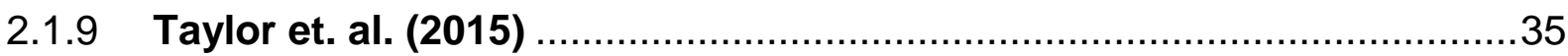

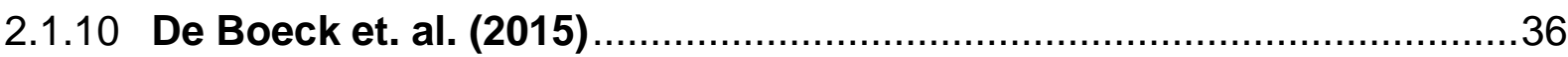

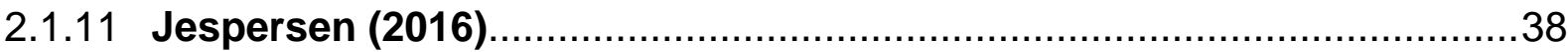

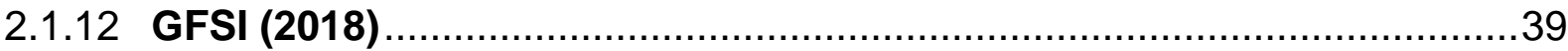

2.2 RESUMO DOS ELEMENTOS DE CSA 40

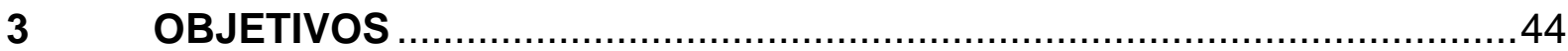

3.1 OBJETIVO PRINCIPAL 44

3.2 OBJETIVOS ESPECÍFICOS 44

4 METODOLOGIA

4.1 COMISSÃO DE ÉTICA 45

4.2 O CENÁRIO DO ESTUDO 45

4.3 DESENHO DO ESTUDO 49

4.4 CÁLCULO DO TAMANHO DA AMOSTRA 54

4.5 ANÁLISE DE DADOS 56 
5. RESULTADOS

5.1 ADAPTAÇÃO DO INSTRUMENTO DE PESQUISA 59

5.1.1 Tradução do questionário, sua síntese e avaliação dos experts ...........59

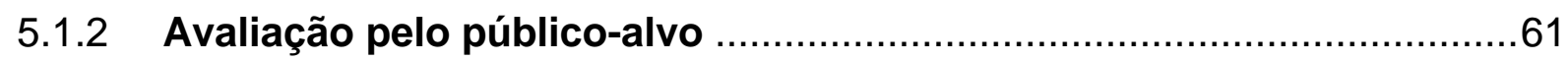

5.1.3 Backtranslation e avaliação do autor original do instrumento...............61

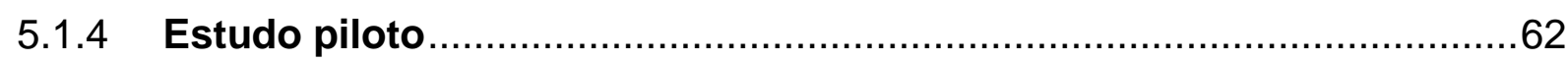

5.2 RESULTADOS DA LOCALIZAÇÃO ESPACIAL DAS LOJAS 64

5.3 RESULTADOS DA SEÇÃO DEMOGRÁFICA DO QUESTIONÁRIO 64

5.4 RESULTADOS DA SEÇÃO SOBRE CSA DO QUESTIONÁRIO 74

5.4.1 Resultados das frequências absolutas e relativas .................................74

5.4.2 Resultado dos itens e fatores de CSA por meio de Média e Desvio

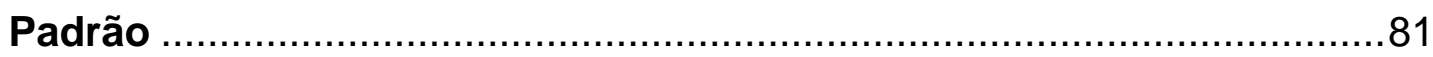

5.4.3 Resultado da consistência interna do questionário ...............................86

5.4.4 Análise Fatorial Exploratória e Confirmatória da escala Likert ..............87

5.4.5 Escores de CSA para cada variável demográfica e para cada loja ......104

5.4.6 Análise de correlação de Spearman entre as variáveis demográficas e os Escores de CSA. 108

5.5 ENTREVISTA COM RESPONSÁVEL PELA SEGURANÇA DE ALIMENTOS DA EMPRESA PARTICIPANTE 109

5.5.1 História do departamento de qualidade e segurança de alimentos da empresa participante do estudo. 109

5.5.2 Cultura de segurança de alimentos sobre a perspectiva do departamento de qualidade e segurança de alimentos da empresa participante do estudo

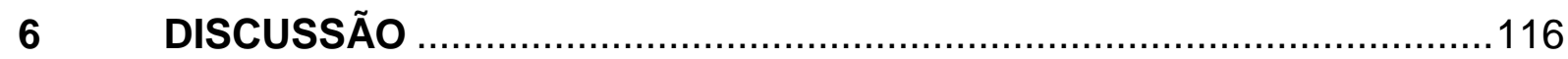

6.1 ADAPTAÇÃO CULTURAL DO INSTRUMENTO 116

6.2 VALIDAÇÃO DO INSTRUMENTO 120

6.3 ESCALA LIKERT DE MENSURAÇÃO 123

6.4 A CULTURA DE SEGURANÇA DE ALIMENTOS DA EMPRESA PARTICIPANTE

6.5 A INFLUÊNCIA DA CULTURA BRASILEIRA E CULTURA NACIONAL SOBRE OS PARTICIPANTES DA PESQUISA 
7 CONCLUSÃO.

139

7.1 CONCLUSÕES GERAIS

7.2 REFLEXÕES E LIMITAÇÕES DO ESTUDO

REFERÊNCIAS 


\section{INTRODUÇÃO}

\subsection{JUSTIFICATIVA}

Apesar da maioria das empresas de alimentos possuírem sistemas para controlarem os seus processos tanto de fabricação quanto de manuseio e distribuição, estes sistemas não têm se mostrado suficientes para minimizar a ocorrência de doenças transmitidas por alimentos (DTA).

Os estudos da Organização Mundial da Saúde (OMS) sobre o impacto global das DTAs entre 2007 e 2015 estimaram que 31 perigos (incluindo vírus, bactérias, protozoários e helmintos) causaram 600 milhões de DTA globalmente (em um intervalo de incerteza de 420-960 milhões) e 420000 mortes (OMS, 2015). Em 2015, apenas nos Estados Unidos houve 902 casos de surtos de doenças, resultando em 15.202 doentes, 950 hospitalizações e 15 mortes (CDC, 2015). Na União Europeia, segundo relatório de síntese sobre zoonoses, agentes zoonóticos e surtos de origem alimentar, foram mais de 300.000 casos confirmados de DTAs com mais de 300 mortes confirmadas (EFSA, 2014).

No Brasil, segundo a Secretaria de Vigilância em Saúde (SVS), entre 2000 e 2017 houve um total de 12.660 surtos notificados, 239.164 doentes, afetando 2.372.132 pessoas e 186 óbitos causados por DTA (BRASIL, 2018). Esses números brasileiros podem estar subestimados conforme argumenta Ferreira (2017), pois há uma potencial subnotificação do próprio sistema de vigilância, a não conclusão dos processos de investigação dos surtos e outros fatores.

No período de 2000 a 2010 as legislações europeias passaram por mudança, tornando-se harmoniosas e baseadas em risco, em boas práticas e análise de perigos e pontos críticos de controle, configurando-se nos chamados sistemas de gestão de segurança de alimentos (DE BOECK et al., 2015). Porém, tais sistemas não estão sendo capazes de garantir a prevenção do aparecimento de surtos de DTA (GRIFFITH, 2006; EFSA; ECDC, 2014; CDC, 2015). Quando da investigação dos fatores determinantes da ocorrência de surtos, encontram-se erros de manipulação de alimentos e não cumprimento de normas de segurança de alimentos (POWELL, 2011; WRIGHT, 2012). 
Percebe-se que algum aspecto nos sistemas de controle ainda está deficiente, pois apesar das boas condições estruturais, equipamentos e conhecimento técnico por parte dos manipuladores, não se consegue reduzir as DTAs como desejado. A construção, manutenção e caracterização da Cultura de Segurança de Alimentos (CSA) é um instrumento de vanguarda que vem sendo estudado para completar o sistema de autocontrole dos processos produtivos e minimizar a ocorrência de DTAs.

Alguns autores vêm demonstrando que os esforços para desenvolver e implementar uma CSA são capazes de melhorar o desempenho produtivo das empresas e fornecer o entendimento sobre como o comportamento de segurança influencia nos resultados, evidenciando que esses conceitos são essenciais para a prevenção das DTAs e para o bom desempenho competitivo das empresas. Também é crescente a percepção de que a CSA representa fator altamente influente na ocorrência de surtos de DTAs, porém ainda são escassos os trabalhos publicados sobre sua análise, aplicação e uso, principalmente no Brasil.

Segundo Griffith (2010a), existem quatro etapas para se avaliar a CSA em uma organização. A primeira etapa é decidir quais fatores comporão o conceito de CSA que serão avaliados. Daí deriva o método a ser utilizado para avaliar a empresa por meio desses fatores.

O método de avaliação da CSA, segunda etapa, pode assumir caráter qualitativo ou quantitativo, nos quais ambos possuirão vantagens e desvantagens. Os qualitativos podem incluir entrevistas em grupos, grupo focal de discussão e entrevistas pessoais. Os métodos quantitativos podem incluir a aplicação de questionários (GRIFFITH, 2010a).

A terceira etapa é decidir em qual nível hierárquico será focada as energias de investigação, pois em cada nível existe a sua especificidade, além de que ocorre variação de empresa para empresa ou as vezes entre unidades de uma mesma organização (GRIFFITH, 2010a). Por fim, é necessário decidir como os dados serão analisados (quarta etapa). Isto depende de como os resultados serão usados e para quem serão apresentados.

Griffith (2010a) defende que a razão para avaliar ou diagnosticar a CSA de uma organização permitirá:

- avaliar a conformidade potencial com sistemas de gestão de segurança para evitar erros / custos com DTA; 
- ajudar a aumentar a conscientização sobre segurança de alimentos;

- comparar e melhorar as funções e processos de uma determinada empresa (benchmarking)/ comparação de sítios de localização/ comparação entre unidades;

- informar decisões sobre treinamento / ação corretiva;

- promover compromisso; e

- identificar fraquezas e avaliar riscos.

Em relação ao pesquisador que conduziu este trabalho, posso afirmar que o tema CSA é importante no dia a dia. Vivenciei momentos em certas organizações em que havia os controles sobre toda a produção de alimentos, mas as pessoas envolvidas não estavam comprometidas com a SA ou não entendiam o seu valor e, por isso, as taxas de sucesso nesse quesito não eram adequadas.

No Brasil, este estudo representa uma das primeiras iniciativas sobre o tema de CSA. Esta é uma oportunidade de mostrar aos gestores de qualidade de alimentos, proprietários de empresas e consultores o que significa a CSA, para que serve e como pode ser diagnosticada nas empresas. As conclusões que poderão ser retiradas do presente estudo poderão contribuir no avanço do conhecimento científico para a redução da ocorrência de DTAs no contexto nacional.

\subsection{CONCEITO DE SEGURANÇA DE ALIMENTOS}

Para entender sobre CSA, primeiramente é importante conceituar Segurança de Alimentos (SA). Segundo o Codex Alimentarius (2009), SA é uma garantia de que os alimentos não causarão danos ao consumidor quando for preparado. Além disso, o produto deve estar de acordo com o uso pretendido. Para World Health Organization (2006) e a Pan American Health Organization (2016), Segurança de Alimentos compreende o conjunto de medidas que asseguram alimentos que não causarão qualquer dano ao consumidor quando preparados/consumidos como o esperado. Em seu prefácio, o Food Code criado pelo Food and Drug Administration - FDA (2017) apresenta a Segurança de Alimentos como uma responsabilidade compartilhada entre indústria de alimentos e 
governo para garantir que o consumidor receba um alimento seguro, livre de transmitir agentes patogênicos, preparado em ambiente limpo e sem adulteração.

O Código Sanitário de Animais Terrestres (2011), desenvolvido por uma comissão de especialistas em Segurança de Alimentos pertencentes a World Organization for Animal Health descreve no item 6.1.3 que:

A segurança de alimentos e a qualidade dos alimentos são
asseguradas por uma abordagem integrada e multidisciplinar,
considerando toda a cadeia produtiva de alimentos. Eliminar ou
controlar os riscos alimentares na sua origem, ou seja, uma
abordagem preventiva é mais eficaz na redução ou eliminação do
risco de efeitos indesejáveis para a saúde do que depender do
controle do produto final, tradicionalmente aplicado através de uma
"verificação de qualidade" final. As abordagens da segurança de
alimentos evoluíram nas últimas décadas, passando de controles
tradicionais baseados em boas práticas (Boas Práticas Agrícolas,
Boas Práticas de Higiene, etc.), através de sistemas mais específicos
de segurança alimentar baseados na análise de perigos e pontos
críticos de controlo (HACCP) usando análise de risco de segurança
de alimentos.

Segundo as definições descritas acima, a SA está estruturada em práticas e procedimentos que devem ser seguidos em um ambiente de produção ou preparação de alimentos.

Porém, o conceito de segurança dos alimentos está intrinsicamente ligado à CSA. Pois, quem executa as ações necessárias para manter a segurança dos alimentos são as pessoas inseridas no processo. A CSA direciona o foco ao ser humano na produção de alimentos, demonstrando os comportamentos e atitudes para alcançar alimentos com baixo risco de contaminação. A CSA compreende a dimensão subjetiva, ou seja, o outro lado da moeda da segurança dos alimentos, fazendo a sustentação ou dando o suporte às práticas e procedimentos do dia a dia. No próximo item, o conceito de CSA será demonstrado em detalhes.

\subsection{CONCEITO DE CULTURA DE SEGURANÇA DE ALIMENTOS}


O conceito de CSA originou-se de dois outros conceitos, principalmente: cultura organizacional (CO) e cultura de segurança (CS) (GRIFFITH, 2010b; YIANNAS, 2009). A CO dedica-se a compreender como os colaboradores de determinada organização a percebem. Foi descrito por Schein (2004, p.17) como:

o aprendizado compartilhado acumulado de um determinado grupo, abrangendo comportamentos, emoções e elementos cognitivos do funcionamento psicológico total dos membros do grupo. Para que tal aprendizagem compartilhada ocorra, deve haver um histórico dessa experiência compartilhada que, por sua vez, implica alguma estabilidade de associação no grupo. Dada essa estabilidade e uma história compartilhada, a necessidade humana de estabilidade, consistência e significado fará com que os vários elementos compartilhados se formem em padrões que eventualmente podem ser chamados de cultura.

A definição de Schein (2004) distingue uma organização de outra. Este sistema de premissas compartilhadas pode ser representado por um conjunto de características-chave que a organização valoriza, conforme percebido por cada membro individualmente.

Já o conceito de CS advém de diversas áreas do conhecimento como enfermagem, ergonomia e medicina ocupacional (GRIFFITH, 2010b; YIANNAS, 2009). Outra área que utiliza o conceito de CS é a energia nuclear a qual não apenas os conhecimentos técnicos são úteis para a diminuição de risco de acidentes, mas também da busca do entendimento do comportamento das pessoas e das organizações (GRIFFITH, 2010b). Uma das definições mais aceitas de CS foi elaborada pelo órgão público do Reino Unido chamado Health and Safety Executive (2008), que define a CS de uma organização o:

[...] produto de valores, atitudes, percepções, competências e padrões de comportamento individuais e grupais que determinam o compromisso e o estilo e a proficiência de um gerenciamento de saúde e segurança de uma organização. As organizações com uma cultura de segurança positiva são caracterizadas por comunicações baseadas na confiança mútua, por percepções compartilhadas da importância da segurança e pela confiança na eficácia das medidas preventivas. 
A CSA é uma forma específica de CO que representa como uma organização trata a segurança dos alimentos. Foi conceituada por Griffith; Livesey e Clayton (2010b, p.435) como:

a agregação das atitudes, valores e crenças predominantes, relativamente constantes, aprendidas, compartilhadas, que contribuem para os comportamentos de higiene usados dentro de um ambiente particular de manuseio de alimentos.

De acordo com Yiannas (2009), CSA é formada por pensamentos, atitudes e comportamentos humanos em um ambiente de produção de alimentos, sejam esses elementos humanos individuais ou grupais. Portanto, cada colaborador possui uma parcela de responsabilidade sobre a CSA que por sua vez impactará em um alimento seguro. A somatória dos esforços sobre a SA é mais importante que cada indivíduo em si, pois os pensamentos, atitudes e comportamentos, quando compartilhados, se reforçam dia a dia. Resumindo, Yiannas define a CSA como sendo: "o modo como fazem as coisas", ou seja, o modo como uma organização faz a SA.

A adaptação de conceitos de CS ou Safety Culture para CSA ou Food Safety Culture foi proposta para a gestão da segurança de alimentos e na prevenção de DTAs (YIANNAS, 2009; GRIFFITH, 2010a). Os pesquisadores afirmam que a importância da CS na melhoria dos comportamentos de segurança dos trabalhadores nas áreas de segurança e saúde ocupacional é um conceito similar que pode ser aplicado à cadeia dos produtos alimentícios (YIANNAS, 2009; GRIFFITH, 2010a). Os pesquisadores reconhecem que os problemas da SA na indústria são parcialmente causados por problemas comportamentais, incluindo aqueles envolvendo CO (YIANNAS, 2009; GRIFFITH, 2010a), por isso não basta possuir sistemas de gestão de SA para garantir um alto nível de SA baseado apenas em gestão de processos, é essencial focar nas pessoas que estão envolvidas neles (YIANNAS, 2009; DE BOECK et al., 2015).

Recentemente em uma revisão de literatura, Nyarugwe et. al. (2016) propôs o conceito de 'cultura nacional' para descrever a CS e CO, concomitantemente. $\mathrm{O}$ autor justifica sua proposta dizendo que o individuo carrega consigo os valores influenciados pela sua 'cultura nacional' e a forma como estes se 
encaixam na cultura da organização na qual ele trabalha pode representar diferenças no desempenho das organizações nos diferentes países.

Nyarugwe et. al. (2016) são também concordantes, afirmando que os sistemas de gestão de SA, que estão inseridos nos sistemas de qualidade de uma organização, dão suporte à CSA e esta última está atrelada a CS, no seu âmbito mais abrangente, e que ambas estão inseridas na $\mathrm{CO}$, conforme ilustra a Figura 1. É possível também observar na figura que a organização como um todo está inserida em uma determinada Cultura Nacional que possui as sua características próprias, ou seja, valores, crenças, atitudes e comportamentos que irão influenciar toda a organização, inclusive a CSA.

Figura 1 - Posicionamento esquemático da cultura de segurança de alimentos (adaptado de Nyarugwe et. al., 2016) - São Paulo, 2018

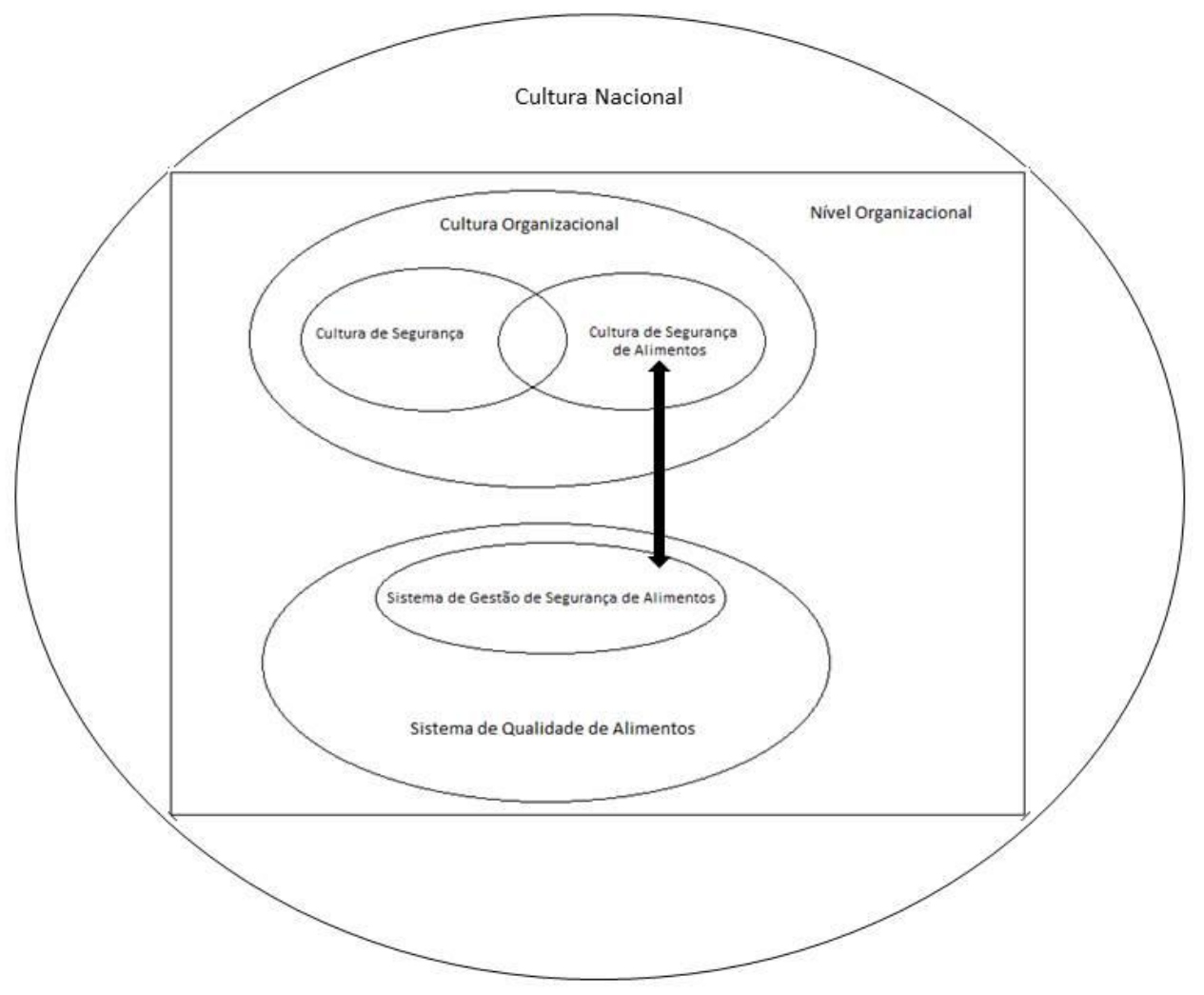

Fonte: (GALVÃO, V. C., 2018).

A CSA tem sido cada vez mais reconhecida como uma ferramenta de diminuição de risco emergente de surtos de DTAs em organizações de serviços de alimentação (GRIFFITH, 2010b). Segundo Seward (2012), uma forte CSA nas 
realidades de produção de alimentos ajudará a guiar as decisões do dia a dia, as ações e os comportamentos o que permitirá uma produção de alimentos mais segura.

Uma pobre CSA reflete em deficiências no compromisso de gerenciamento, nas prioridades e no apoio organizacional, as quais têm sido sugeridas como fatores de risco significativos para a ocorrência de DTAs, como já ocorrido em várias empresas de alimentos, como por exemplo a Peanut Corporation of America e Maple Leaf Foods, Inc., conforme citam Powell et. al. (2011).

Taylor (2011) estabelece o conceito de CSA a partir da perspectiva da indústria de alimentos, definindo-a como as "atitudes, valores e práticas predominantes relacionadas à segurança dos alimentos que são ensinadas, direta e indiretamente, a novos funcionários”.

Em 2015, De Boeck (2015) realizou um trabalho relacionado à CSA. Segundo a visão do autor, a CSA muitas vezes é confundida com o Clima de Segurança de Alimentos que, por sua vez, é entendido como a percepção dos funcionários sobre a situação dentro de uma organização, uma "foto instantânea" que reflete aspectos importantes da CSA de uma organização. Para o autor

A cultura de segurança de alimentos pode ser definida como a
interação do clima de segurança de alimentos, tal como é percebido
pelos funcionários e gestores de uma empresa (a chamada 'rota
humana'), o contexto em que uma empresa opera, o atual Sistema
de Gestão de Segurança de Alimentos implementado e a
consistência de atividades de controle e garantia (a chamada 'rota
técnico-gerencial') obtendo uma certo resultado microbiológico.

Jespersen (2016) também contribuiu para compreender a CSA. A autora define CSA como a interligação entre três perspectivas teóricas: cultura organizacional, ciência dos alimentos e ciência cognitiva social. Sabendo que a CO já foi descrita, faz-se necessário conhecer brevemente as outras teorias.

Ciência dos alimentos significa o arcabouço teórico específico dos alimentos associado aos riscos de consumir alimentos e como medir ou avaliar isso. A ciência cognitiva social está ligada a definir, medir e prever comportamentos 
humanos. Os métodos da ciência cognitiva social podem ser aplicados especificamente para medir a intenção de uma organização, um gerente, uma equipe e um indivíduo de realizar comportamentos dentro do escopo das próprias regras e valores da organização (JESPERSEN, 2016).

A Global Food Safety Initiative's (2018) é uma colaboração global dos atores (indústria, regulatório, pesquisa, etc.) da cadeia de produção de alimentos e se dedica ao avanço da Segurança de Alimentos. A organização acredita que para ser bem-sucedida e sustentável, a segurança dos alimentos deve ir além das regulamentações formais para viver dentro da cultura de uma empresa.

Recentemente, a GFSI (2018) propôs uma definição de CSA através do seu grupo técnico de trabalho. Segundo a organização CSA é definida como "os valores compartilhados, crenças e normas que afetam a mentalidade e 0 comportamento em relação à segurança dos alimentos em toda a organização".

Com base em alguns dos elementos culturais encontrados na literatura sobre segurança e saúde no trabalho, os pesquisadores propuseram componentes da CSA aplicáveis à indústria de alimentos (YIANNAS, 2009; GRIFFITH; LIVESEY; CLAYTON, 2010a; TAYLOR, 2011; BALL, 2010; NEAL, 2012; WRIGHT, 2012; UNGKU FATIMAH, 2013; TAYLOR, 2015; DE BOECK, 2015; JESPERSEN, 2016; GFSI, 2018).

Fica claro que o conceito de CSA ainda está em fase de construção na literatura científica. Vários autores identificam-na de formas diferentes através de estudos exploratórios a campo, nas realidades de empresas. Como veremos mais à frente, alguns autores, já citados aqui, propuseram alguns elementos que formariam a CSA. 


\section{REVISÃO DE LITERATURA}

\subsection{AUTORES E ABORDAGENS PARA CSA}

Esta etapa da dissertação discorreu sobre os elementos formadores de CSA. Como esse tema ainda é recente na literatura científica não há consenso sobre quais são os elementos que compõem a CSA. Houve pesquisadores que se debruçaram para descobrir quais são esses elementos que foram apresentados a seguir. Os elementos de CSA podem ser chamados de outros nomes como componentes, elementos e fatores. A maioria dos trabalhos utilizaram questionários para identificar os elementos que compõem a CSA. Os questionários foram chamados no presente estudo também por instrumento ou ferramenta.

A seguir serão apresentados alguns autores e suas respectivas abordagens sobre CSA, bem como a descrição dos fatores que compõem a CSA.

\subsubsection{Yiannas (2009)}

Com base nas pesquisas feitas por Whiting e Bennett (2003) sobre como 65 empresas líderes em CS nos Estados Unidos desenvolveram sua cultura, Yiannas (2009) analisou os componentes relevantes de uma CSA e sugeriu cinco componentes essenciais:

(I) Liderança: distinguiu o gerenciamento da SA da liderança em SA e destacou o papel dos líderes em influenciar os outros e liderar o caminho para 0 manuseio seguro de alimentos;

(II) Confiança dos colaboradores: ressaltou a importância de ganhar a confiança dos colaboradores e defende que esta deve ser alcançada e mantida através do diálogo constante;

(III) Apoio à gestão: Cada colaborador deve apoiar a gestão sobre a construção da CSA que, por sua vez, impactará em um alimento seguro;

(IV) Responsabilidade: refere-se à garantia pela própria organização que os colaboradores saibam quais as expectativas que se depositam sobre eles 
em relação à $S A$, uma medida tomada para que os resultados sejam alcançados; e

(V) Compartilhamento de conhecimento e informação: deve ser feito com frequência por uma organização, usando múltiplas mensagens e abordagens para incentivar colaboradores para a ação.

\subsubsection{Griffith et. al. (2010a)}

Griffith et al. (2010a) revisaram a literatura no campo das ciências de segurança para identificar componentes de CSA e propôs seis dimensões para esta:

(I) Estilo e sistema de gestão: as percepções dos trabalhadores em relação ao sistema e ao estilo de gestão são influenciadas pelas atividades coordenadas para direcionar ou controlar a segurança dos alimentos, procedimentos documentados, os comportamentos praticados e 0 envolvimento da administração nas operações diárias;

(II) Liderança: este componente identifica se as equipes são alavancadas pelo(s) seu(s) líder(es) para executar e cumprir os padrões de segurança de alimentos dos negócios;

(III) Comunicação: pode ser avaliada pela qualidade dessa comunicação, de cima para baixo e de baixo para cima, isto é verticalmente, bem como da transferência de informações de segurança de alimentos entre os colegas de trabalho (horizontalmente);

(IV) Compromisso: o compromisso percebido de SA dos empregados é medido pela forma como os valores e crenças organizacionais quanto à segurança de alimentos estão alinhados com os deles. Os valores associados às recompensas, aos papéis, à satisfação no trabalho e ao empoderamento são subcomponentes do compromisso percebido;

(V) Ambiente: o componente ambiental é referido como estruturas e processos organizacionais visíveis que caracterizam as dimensões internas do negócio. Fatores tangíveis, complacência, padrões, grau de excelência, consistência e suporte organizacional são elementos relevantes no suporte ao ambiente percebido pelos colaboradores; e 
(VI) Percepção/consciência/comportamento de risco: são as percepções dos colaboradores sobre o comportamento de risco, ou seja, estão relacionadas ao risco de contaminação dos produtos, da disposição dos trabalhadores, humor, feedback de desempenho, confiança e estratégia de comunicação de risco.

\subsubsection{Ball et. al. (2010)}

Ball et al. (2010) desenvolveram um instrumento para avaliação do clima de SA com o objetivo de investigar os principais fatores que influenciavam trabalhadores de um frigorífico a seguir procedimentos de SA. A ferramenta consistiu em 65 itens capazes de medir cinco fatores no local de trabalho:

(I) Comprometimento da unidade de trabalho: relacionado ao comprometimento dos trabalhadores. Por isso, há grande influência do supervisor da unidade (líder) que pode estar comprometido ou não. Para isso acontecer, o supervisor deve estabelecer uma comunicação que reforce a SA;

(II) Compreensão pessoal: os trabalhadores devem compreender que eles influenciam a SA através das suas tarefas diárias, assim precisa-se conhecer as razões de tarefas como trocar de luvas, etc.;

(III) Treinamento em Segurança dos Alimentos: para haver a compreensão de cada indivíduo sobre a SA é necessário treinamentos tanto para as pessoas que trabalham no local quanto para aquelas que irão ser incorporadas na organização;

(IV) Comprometimento da gestão: a gestão administrativa da organização demonstra que está comprometida com a SA por meio de suas ações gerencias, seus líderes e do suporte ambiental (equipamentos, utensílios, etc.) para toda a organização;

(V) Infraestrutura: o sistema de gestão de SA, isto é, Boas Práticas de Fabricação, APPCC, etc., estão de acordo com o esperado; e 
(VI) Comportamento de Segurança de Alimentos: demonstrações de comportamentos positivos ou negativos em relação à SA.

\subsubsection{Taylor (2011)}

Outros pesquisadores consideraram a CSA como um conceito amplo e multidimensional, que poderia ser ampliado para um ambiente multicultural. Ao incluir elementos relevantes da cultura de gestão, negócios internacionais e psicologia, Taylor (2011) propôs que a CSA seja influenciada por 20 subfatores em quatro fatores amplos, interconectados e interdependentes. Porém, neste trabalho há poucas informações sobre cada fator e seus 20 subfatores. Os quatro fatores são:

(I) Conhecimento;

(II) Psicológicos e atitudinais;

(III) Externos; e

(IV) Comportamentais.

\subsubsection{Neal et. al. (2012)}

Neal (2012) encontraram dois fatores ao avaliar a CSA em restaurantes usando a ferramenta de Ball (2010). As percepções dos empregados sobre a CSA foram comparadas com base na sua demografia. Não foram encontradas diferenças significativas nas percepções dos colaboradores em relação aos fatores: compromisso da unidade de trabalho, infraestrutura e treinamento em segurança dos alimentos. Os fatores que foram associados aos restaurantes por Neal (2012) são:

(I) Comprometimento da gestão;

(II) Comportamento de Segurança de Alimentos dos colaboradores. 


\subsubsection{Wright et. al. (2012)}

Devido à demanda da Food Standars Agency (Agência Reguladora de Alimentos) do Reino Unido, Wright et. al. (2012) desenvolveram um instrumento para micro e pequenas empresas para diagnosticar CSA e categorizar os estabelecimentos, conforme o nível de cumprimento em SA. Wright (2012) estabelece oito fatores que compõe a CSA. A partir deles, criaram um instrumento de avaliação contendo 34 questões abertas. A intenção da elaboração deste instrumento foi auxiliar os inspetores a entender as atitudes em relação à $S A$, ao comportamento de higiene e ao tipo de conselhos que podem ser fornecidos durante as fiscalizações para ajudar a influenciar as atitudes e, em última análise, a cultura dentro de uma empresa de alimentos. No curso de seu trabalho, o autor vai além e propõe cinco categorias para cada fator de CSA que após serem avaliados pelo instrumento desenvolvido esses estabelecimentos se enquadrariam em: a) Calculistas amorais, b) Dependentes, c) Duvidosos, d) Cumpridores Proativos e e) Líderes. Neste trabalho iremos adotar a categoria Líder, pois constitui-se como um conceito ideal de CSA. Portanto, os oito fatores são descritos como se segue:

(I) Prioridades e atitudes em relação a higiene dos alimentos: a organização considera que a higiene alimentar é uma das principais prioridades, um fator crítico de sucesso empresarial e algo em que deve ser considerado excelente;

(II) Percepção e conhecimento de risco em higiene dos alimentos: a organização acredita que a intoxicação alimentar ou outro incidente similar poderia causar um grande impacto adverso nos negócios, além de prejudicar muitas pessoas;

(III) Confiança da empresa nos pré-requisitos de Segurança dos Alimentos: a organização acredita que sistemas como o APPCC, quando aplicados adequadamente, são essenciais para o negócio e que eles efetivamente controlam os riscos; 
(IV) Propriedade empresarial sobre higiene dos alimentos: a organização verifica e melhora ativamente a higiene dos alimentos na ausência de inspeção ou requisitos de terceiros. Enxerga a higiene alimentar como um risco para os negócios em que eles devem ser excelentes;

(V) Competência, aprendizagem, treinamento, conhecimento: muito bem informado sobre os perigos, métodos mais recentes de controle de risco, bem como a presença de uma gestão altamente treinada e bem informada;

(VI) Liderança em higiene dos alimentos: a organização incentiva frequentemente os funcionários a aplicar procedimentos de higiene alimentar, explica por que isso é necessário e parabeniza as boas práticas;

(VII) Envolvimento dos colaboradores na revisão e desenvolvimento de práticas de higiene dos alimentos: a organização procura ativamente as percepções dos funcionários sobre como melhorar a higiene alimentar; e

(VIII) Comunicação e confiança para se envolver em higiene dos alimentos e questões de relatório: os funcionários se sentem totalmente livres para relatar problemas e confiam na administração para responder positivamente.

\subsubsection{Seward (2012)}

Seward (2012) desenvolveu uma ferramenta de diagnóstico de CSA para a indústria de alimentos. $O$ instrumento é focado em trabalhadores e supervisores que estão cotidianamente ligados aos processos fabris e que praticam os comportamentos seguros para produzir alimentos. $O$ instrumento possui 15 afirmações em escala Likert de quatro pontos, baseados em quatro fatores de CSA descritos a seguir:

(I) Cultivar: o líder é responsável por desenvolver e comunicar o comprometimento necessário para a SA, os objetivos em SA, garantindo que esses objetivos serão cumpridos; 
(II) Educar: trabalhadores de todos os níveis hierárquicos devem ter todo o conhecimento e habilidade necessários para promover e executar boas decisões e práticas em SA.

(III) Investigar: é imperativo procurar o que não queremos ver e agir de acordo com as descobertas que não atendem às nossas expectativas. Também é importante incorporar o conhecimento dos avanços científicos e industriais descobertos durante a investigação.

(IV) Elevar e melhorar: as falhas do sistema são levadas a sério e são usadas como oportunidades de melhoria contínua.

\subsubsection{Ungku Fatimah (2013)}

Ungku Fatimah (2013), em sua dissertação pela lawo University, desenvolveu uma ferramenta para diagnosticar CSA. A pesquisa da autora utilizou uma abordagem metodológica mista qualitativa e quantitativa $A$ autora realizou revisão de literatura sobre o assunto, grupo focal $(n=33)$ e questionário em escala ( $n=400$ ) em 37 hospitais e 24 escolas que possuíam foodservice. Na primeira fase, grupo focal, método qualitativo de coleta de dados, foi conduzido com um grupo selecionado de colaboradores de manipulação de alimentos para avaliar a percepção de CSA nas organizações. Um questionário, abordagem quantitativa, foi desenvolvido com base nos resultados do grupo focal e administrado na segunda fase do estudo. O questionário foi utilizado para coletar dados empíricos sobre as percepções dos colaboradores em relação à CSA e utilizou escala Likert (1932) de sete pontos, variando de 1- "Discordo fortemente" a 2- "Concordo fortemente" e o ponto intermediário é "Neutro". Estava incluso no questionário uma seção com perguntas demográficas e da organização. Foram definidas 31 afirmações (itens) e seis fatores de CSA:

(I) Apoio dos gerentes e colaboradores: atividades coordenadas ou políticas e procedimentos para direcionar ou controlar a SA e o apoio dos colaboradores em relação à prática de manipulação segura de alimentos no local de trabalho; 
(II) Comunicação: esse construto avalia as percepções dos funcionários em relação à qualidade da transferência de mensagens e conhecimentos sobre SA entre a gerência, a equipe supervisora e os manipuladores de alimentos;

(III) Autocomprometimento: este constructo avalia se as percepções dos funcionários em relação aos valores e crenças dos funcionários sobre SA estão alinhadas com aqueles da organização;

(IV) Suporte do ambiente: esse conceito avalia as percepções dos funcionários em relação à disponibilidade e à qualidade da infraestrutura que dão suporte à CSA;

(V) Pressão no trabalho: esse construto avalia as percepções dos funcionários em relação a vários aspectos da pressão associada ao preparo de alimentos que afeta práticas seguras de manipulação de alimentos; e

(VI) Julgamento baseado em risco: este construto avalia as percepções dos funcionários sobre a conscientização de riscos organizacionais e as decisões de tomada de risco em relação à $S A$.

\subsubsection{Taylor et. al. (2015)}

Taylor et. al. (2015) desenvolveram um novo modelo de CSA através de anos de experiência na indústria de alimentos. O modelo foi baseado em estudos sobre cultura e psicologia organizacional. O modelo apresenta quatro fatores cujos quais são divididos em quatro subfatores cada, totalizando 16 subfatores em cada fator. Os fatores são:

(I) Pessoas:

- $\quad$ Empoderamento: capacitar as pessoas para tomarem ações em SA;

- $\quad$ Reforço: reforçar as práticas de SA;

- $\quad$ Trabalho em equipe: a efetividade das equipes de SA e APPCC; 
- Treinamento: a efetividade dos treinamentos e comunicações sobre SA;

(II) Processo:

- $\quad$ Controle: o nível de controle da gestão em SA;

- Coordenação: a coordenação da SA através de toda a organização;

- Consistência: o nível de consistência e cumprimento das práticas de SA;

- $\quad$ Sistemas: a efetividade do Sistema de Gestão de Segurança de Alimentos;

(III) Propósito:

- $\quad$ Visão: o papel da SA na visão de longo prazo da empresa;

- $\quad$ Valores: o papel da SA nos valores fundamentais da empresa;

- $\quad$ Estratégias: o direcionamento estratégico para SA;

- $\quad$ Objetivos: a definição e gestão de objetivos de SA; e

(IV) Pró-atividade:

- $\quad$ Consciência: ter consciência do status externo e questões sobre $\mathrm{SA}$;

- $\quad$ Previsão: ter previsão sobre os riscos para a SA;

- Mudança: estar pronto para mudança e inovação quando requerido;

- Aprendizado: capacitar a aprendizagem organizacional sobre SA.

\subsubsection{De Boeck et. al. (2015)}

De Boeck et. al. (2015) desenvolveram um instrumento de avaliação de clima de CSA. Foram utilizados vinte especialistas no assunto para avaliar os fatores e as afirmações do instrumento. Posteriormente foi aplicado em quarenta e oito 
colaboradores de uma empresa distribuidora de carnes. Os fatores deste questionário relacionavam:

(I) Liderança: o líder influencia os liderados a segui-lo, motiva-os a trabalharem de modo higiênico e seguro, deixa claro quais as expectativas em relação à $\mathrm{SA}$, escuta os seus liderados a respeito de melhorias que eles propõem;

(II) Comunicação: é baseado na interação/troca sociais entre líderes e liderados. Uma alta interação entre essas partes produz um melhor engajamento sobre higiene e SA. Por isso, é necessário comunicação regular com os trabalhadores. A comunicação dos líderes também deve ser clara e compreensível e adaptada ao nível educacional do receptor. O canal de comunicação deve ser aberto do trabalhador para o líder, bem como haver discussões sobre a higiene do local e dos alimentos. A organização deve apresentar outras formas de comunicar a SA através de pôsteres, símbolos, ícones, etc.;

(III) Comprometimento: o comprometimento começa com o líder demonstrando grande apreço ou importância pela SA. Consequentemente, os liderados irão valorizar a higiene e SA e demonstrarão isso através do seu comportamento e declarações;

(IV) Recursos: se os funcionários tiverem tempo suficiente para trabalhar de maneira higiênica e segura, perceberão que há apoio (financeiro, prático, psicológico e emocional) para questões relacionadas à higiene e à $S A$ da organização. O número de funcionários para realizar comportamentos seguros, as condições de trabalho (bom espaço de trabalho, bons equipamentos e utensílios) e educação/treinamento em boas práticas também são importantes nesse fator; e

(V) Consciência de risco: os riscos devem ser conhecidos pelos funcionários para que possam levá-los em conta em suas decisões diárias de trabalho. Isto reflete se a administração e os funcionários sentem que podem confiar no desempenho do sistema de gerenciamento de SA da organização. A atmosfera será menos estressante e os funcionários sentirão que a organização está fazendo um bom trabalho. Essa confiança pode ser 
motivadora para permanecer comprometida com a higiene e SA. Assim, os líderes terão uma visão realista dos riscos envolvidos e os funcionários poderão ajudar os seus colegas de trabalhos caso verifiquem perigos para o alimento nos procedimentos.

\subsubsection{Jespersen (2016)}

Jespersen (2016) desenvolveu cinco fatores de CSA. Os fatores são categorizados em um modelo de maturidade de CSA de cinco categorias (duvidoso, reativo, conhecedor, preditivo e internalizado), ou seja, cada fator elaborado pelo autor se enquadra em uma das categorias. A conduta é semelhante a Wright (2012) que além de elaborar fatores para CSA também objetiva categorizar os estabelecimentos de alimentos que participaram do estudo. Neste trabalho iremos adotar os fatores segundo a ótica da categoria "Internalizada". Os fatores de Jespersen são:

(I) Valor percebido: a melhoria e o crescimento contínuo dos negócios são possibilitados pela SA;

(II) Sistema de pessoas: a direção estratégica é definida em toda a organização, com responsabilidades definidas, responsabilidades e segurança dos alimentos como um dos facilitadores de negócios. Definição preventiva e melhoria contínua de comportamentos, consequências e ferramentas específicas de SA;

(III) Pensamento sobre os processos: a varredura do horizonte e a melhoria contínua são usadas para identificar riscos. Os riscos informam o desenvolvimento e / ou melhoria dos planos de mitigação. Os planos de mitigação estão integrados no sistema global de gestão de negócios;

(IV) Tecnologia ativa: sistemas integrados de informação global estão em vigor na organização, tornando-a rápida para adaptar, melhorar e usar fluxos de trabalho automatizados; e 
(V) Ferramentas e infraestrutura: o investimento em ferramentas e infraestrutura é avaliado a longo prazo e priorizado junto com outros investimentos de negócios.

\subsubsection{GFSI (2018)}

Recentemente, a GFSI lançou um documento chamado "Cultura de Segurança de Alimentos: posicionamento da Global Food Safety Initiative's". Neste material, a organização global propõe cinco fatores de CSA, baseado nas pesquisas científicas:

(I) Visão e Missão: a liderança organizacional define o tom e a direção de sua CSA. A visão corporativa e as declarações de missão não precisam mencionar especificamente a SA, embora sua importância deva ser refletida nas comunicações da empresa. Ter um direcionamento para seguir ajuda a estabelecer uma boa CSA porque requer uma visão clara, compartilhada e incorporada em toda a organização. Este fator é dividido em três subfatores: Estrutura do negócio, valores e propósito; Definindo direções e expectativas; e Liderança e mensagem.

(II) Pessoas: as pessoas são um componente crítico para CSA. O comportamento e as atividades dos funcionários, desde os processos na fazenda até o atendimento aos clientes, contribuem para a SA e, potencialmente, diminuem ou aumentam o risco de doenças transmitidas por alimentos. É importante estabelecer uma estrutura formal de SA com papéis e responsabilidades individuais claramente definidos. Os principais elementos dessa dimensão incluem desde educar os funcionários e reforçar o bom comportamento até criar uma governança e métricas adequadas. $\mathrm{Na}$ medida em que as pessoas têm o poder de promover a SA, haverá impacto na capacidade de sua organização de se adaptar, melhorar e sustentar sua CSA. Uma boa comunicação garante que as mensagens relacionadas à SA sejam compreendidas por todos dentro da organização. Este fator é dividido em cinco subfatores: Público-alvo (stakeholders); Governança; 
Comunicação; Aprendizagem organizacional; Incentivos, recompensas e reconhecimento.

(III) Consistência: refere-se a garantir o alinhamento das prioridades de SA com as pessoas, tecnologia, recursos e processos, para aplicar efetivamente um programa de SA e apoiar sua cultura. Este fator é dividido em três subfatores: Responsabilidade; Mensuração de desempenho; Documentação.

(IV) Adaptabilidade: refere-se à habilidade da organização se ajustar às mudanças de influências e condições. Este fator é dividido em três subfatores: Expectativas de Segurança de Alimentos e estado atual; Agilidade; Mudança, gestão de crises e resolução de problemas.

(V) Perigos e Consciência de risco: todos os funcionários precisam de uma visão geral básica dos riscos para reconhecer a responsabilidade decorrente de estar em uma cadeia produtiva na qual os clientes consomem o produto. Além disso, cada funcionário e departamento deve entender suas respectivas responsabilidades relacionadas à SA. Todos tem um papel, e reconhecer riscos potenciais é tão importante desde o nível do alto executivo sênior quanto para trabalhadores de linha. Este fator é subdividido em três subfatores: Educação e informações fundamentais sobre perigos; Engajamento dos funcionários; Verificar perigos e consciência de risco.

\subsection{RESUMO DOS ELEMENTOS DE CSA}

Em suma, os pesquisadores adaptaram o conceito e as escalas de medição da CO e CS em vários outros campos para entender os fatores que afetam a CSA conforme síntese apresentada na Quadro 1. As avaliações da CSA ajudam a organização entender por que os colaboradores não realizam práticas seguras de manuseio de alimentos no trabalho (YIANNAS, 2009; BALL; WILCOCK; COLWELL, 2010; GRIFFITH; LIVESEY; CLAYTON, 2010a; TAYLOR, 2011).

Os esforços para estabelecer e avaliar uma cultura positiva em matéria de SA e para melhor definir o seu papel na melhoria das práticas de SA podem ser 
facilitados pela sua mensuração. Recentemente um estudo com 19 mil colaboradores de panificadoras, processadores de alimentos e produtos cárneos no Canadá, desenvolveu uma ferramenta para avaliar o grau de maturidade da CSA implantada como uma medida importante no processo de prevenção de DTAs (JESPERSEN et. al., 2016).

Quadro 1 - Elementos de cultura de segurança de alimentos, de acordo com diferentes autores, ano de publicação, contexto e área adaptada ou instrumento - São Paulo, 2018

\begin{tabular}{|c|c|c|c|c|}
\hline $\begin{array}{l}\text { Autor/ano } \\
\text { publicado }\end{array}$ & $\begin{array}{l}\text { País de } \\
\text { origem da } \\
\text { pesquisa }\end{array}$ & Contexto & $\begin{array}{c}\text { Área } \\
\text { adaptada/instrumento }\end{array}$ & $\begin{array}{l}\text { Elementos de Cultura de } \\
\text { Segurança de Alimentos }\end{array}$ \\
\hline Yiannas (2009) & $\begin{array}{l}\text { Estados } \\
\text { Unidos }\end{array}$ & $\begin{array}{l}\text { Varejo e Indústria } \\
\text { Foodservice }\end{array}$ & Cultura de Segurança & $\begin{array}{l}\text { (I) liderança, (II) confiança dos } \\
\text { colaboradores, (III) apoio à gestão, (IV) } \\
\text { responsabilidade e (V) compartilhamento de } \\
\text { conhecimento e informação. }\end{array}$ \\
\hline $\begin{array}{l}\text { Griffith et al. } \\
(2010)\end{array}$ & Reino Unido & $\begin{array}{l}\text { Indústria de } \\
\text { Alimentos }\end{array}$ & Cultura de Segurança & $\begin{array}{l}\text { (I) estilo e sistemas de gestão, (II) liderança, } \\
\begin{array}{ll}\text { (III) comunicação, (IV) compromisso, (V) } \\
\text { ambiente } & \text { (VI) } \\
\text { percepção/consciência/comportamento de } & \text { de } \\
\text { risco. } & \end{array}\end{array}$ \\
\hline $\begin{array}{l}\text { Ball et al. } \\
(2010 b)\end{array}$ & Canadá & $\begin{array}{l}\text { Indústria de } \\
\text { Processamento de } \\
\text { Carnes }\end{array}$ & $\begin{array}{l}\text { Instrumento de clima de } \\
\text { Segurança de Alimentos }\end{array}$ & $\begin{array}{l}\text { (I) comprometimento da unidade de } \\
\text { trabalho; (II) compreensão pessoal; (III) } \\
\text { treinamento em segurança dos alimentos; } \\
\text { (IV) comprometimento da gestão; (V) } \\
\text { infraestrutura; e (VI) comportamento de } \\
\text { segurança de alimentos. }\end{array}$ \\
\hline Taylor (2011) & Reino Unido & $\begin{array}{l}\text { Multi-cultural } \\
\text { Indústria de } \\
\text { alimentos }\end{array}$ & $\begin{array}{l}\text { Gestão, } \quad \text { Negócios } \\
\text { internacionais e Psicologia }\end{array}$ & $\begin{array}{l}\text { (I) conhecimento, (II) } \\
\text { psicológicos/atitudinais, (III) externos e (IV) } \\
\text { comportamentais. }\end{array}$ \\
\hline $\begin{array}{l}\text { Neal et al. } \\
\text { (2012) }\end{array}$ & $\begin{array}{l}\text { Estados } \\
\text { Unidos }\end{array}$ & Restaurante & $\begin{array}{l}\text { Instrumento de clima de } \\
\text { Segurança de Alimentos }\end{array}$ & $\begin{array}{l}\text { (I) comprometimento da gestão e (II) } \\
\text { comportamentos de segurança de alimentos } \\
\text { dos colaboradores. }\end{array}$ \\
\hline $\begin{array}{l}\text { Wright et. al. } \\
\text { (2012) }\end{array}$ & Reino Unido & $\begin{array}{l}\text { Micro e pequenas } \\
\text { empresas }\end{array}$ & $\begin{array}{l}\text { Instrumento de Cultura de } \\
\text { Segurança de Alimentos }\end{array}$ & $\begin{array}{l}\text { (I) prioridades e atitudes em relação a } \\
\text { higiene dos alimentos; (II) percepção e } \\
\text { conhecimento de risco em higiene dos } \\
\text { alimentos; (III) confiança da empresa nos } \\
\text { pré-requisitos em segurança dos alimentos; } \\
\text { (IV) propriedade empresarial sobre higiene } \\
\text { dos alimentos, (V) competência, } \\
\text { aprendizagem, treinamento, conhecimento; } \\
\text { (VI) liderança em higiene dos alimentos; } \\
\text { (VII) envolvimento dos colaboradores na }\end{array}$ \\
\hline
\end{tabular}




\begin{tabular}{|c|c|c|c|c|}
\hline $\begin{array}{l}\text { Autor/ano } \\
\text { publicado }\end{array}$ & $\begin{array}{l}\text { País de } \\
\text { origem da } \\
\text { pesquisa }\end{array}$ & Contexto & $\begin{array}{c}\text { Área } \\
\text { adaptada/instrumento }\end{array}$ & $\begin{array}{l}\text { Elementos de Cultura de } \\
\text { Segurança de Alimentos }\end{array}$ \\
\hline & & & & $\begin{array}{l}\text { revisão e desenvolvimento de práticas de } \\
\text { higiene dos alimentos e (VIII) comunicação } \\
\text { e confiança para se envolver em higiene dos } \\
\text { alimentos e questões de relatório }\end{array}$ \\
\hline Seward (2012) & $\begin{array}{l}\text { Estados } \\
\text { Unidos }\end{array}$ & $\begin{array}{l}\text { Indústria de } \\
\text { alimentos }\end{array}$ & $\begin{array}{l}\text { Instrumento de Cultura de } \\
\text { Segurança de Alimentos }\end{array}$ & $\begin{array}{l}\text { (I) Cultivar; (II) Educar; (III) Investigar e (IV) } \\
\text { Elevar e melhorar. }\end{array}$ \\
\hline $\begin{array}{l}\text { Ungku Fatimah } \\
\text { (2013) }\end{array}$ & $\begin{array}{l}\text { Estados } \\
\text { Unidos }\end{array}$ & $\begin{array}{l}\text { Foodservice em } \\
\text { hospitais e escolas }\end{array}$ & $\begin{array}{l}\text { Instrumento de Cultura de } \\
\text { Segurança de Alimentos }\end{array}$ & $\begin{array}{l}\text { (I) Apoio dos gerentes e colaboradores; (II) } \\
\text { comunicação; (III) auto comprometimento; } \\
\text { (IV) suporte do ambiente; (V) pressão no } \\
\text { trabalho e (VI) julgamento baseado em } \\
\text { risco. }\end{array}$ \\
\hline $\begin{array}{l}\text { Taylor et. al. } \\
\text { (2015) }\end{array}$ & Abu Dhabi & $\begin{array}{l}\text { Indústria de } \\
\text { alimentos }\end{array}$ & $\begin{array}{lr}\text { Cultura } & \text { organizacional, } \\
\text { Gestão, } & \text { Negócios } \\
\text { internacionais e Psicologia }\end{array}$ & $\begin{array}{l}\text { (I) pessoas; (II) processo; (III) propósito e } \\
\text { (IV) pro-atividade. }\end{array}$ \\
\hline $\begin{array}{l}\text { De Boeck et. al. } \\
\text { (2015) }\end{array}$ & Bélgica & $\begin{array}{l}\text { Indústria de } \\
\text { alimentos }\end{array}$ & $\begin{array}{l}\text { Instrumento de clima de } \\
\text { Cultura de Segurança de } \\
\text { Alimentos }\end{array}$ & $\begin{array}{l}\text { (I) liderança; (II) comunicação; (III) } \\
\text { comprometimento; (IV) recursos e (V) } \\
\text { consciência de risco. }\end{array}$ \\
\hline $\begin{array}{l}\text { Jespersen } \\
(2016)\end{array}$ & Canadá & $\begin{array}{l}\text { Indústria de } \\
\text { alimentos }\end{array}$ & $\begin{array}{l}\text { Cultura organizacional, ciência } \\
\text { dos alimentos e ciência } \\
\text { cognitiva social }\end{array}$ & $\begin{array}{l}\text { (I) valor percebido; (II) sistema de pessoas; } \\
\text { (III) pensar sobre os processos; (IV) } \\
\text { tecnologia ativada e (V) ferramentas e } \\
\text { infraestrutura. }\end{array}$ \\
\hline GFSI (2018) & $\begin{array}{l}\text { Colaboração } \\
\text { internacional } \\
\text { de vários } \\
\text { países }\end{array}$ & $\begin{array}{l}\text { Toda a cadeia de } \\
\text { alimentos }\end{array}$ & $\begin{array}{l}\text { Cultura de Segurança de } \\
\text { Alimentos }\end{array}$ & $\begin{array}{l}\text { (I) visão e missão; (II) pessoas; (III) } \\
\text { adaptabilidade; (IV) consistência e (V) } \\
\text { perigos e consciência de risco. }\end{array}$ \\
\hline
\end{tabular}

Fonte: GALVÃO (2018).

Observa-se que o conceito de CSA foi sendo construído ao longo do tempo, havendo contribuições de diferentes autores internacionais. Os autores construíram elementos ou fatores de CSA em diferentes pontos da cadeia produtiva de alimentos (indústria, foodservice, etc.), variando de dois a oito fatores, para diagnosticar ou avaliar a CSA dos estabelecimentos. A finalidade dos autores é melhorar a SA dos produtos através da identificação dos valores, crenças, atitudes e comportamentos das pessoas inseridas no processo. 
A presente pesquisa ao se propor validar, no Brasil, um dos instrumentos elaborados pelos autores acima citados contribui com a epistemologia sobre o tema e disponibiliza uma ferramenta no idioma português para os proprietários de estabelecimentos de alimentos ou gestores organizacionais de SA. 


\section{OBJETIVOS}

\subsection{OBJETIVO PRINCIPAL}

Validar um instrumento em português do Brasil para avaliação de Cultura de Segurança de Alimentos - CSA.

\subsection{OBJETIVOS ESPECÍFICOS}

- Selecionar, a partir da literatura científica disponível, um questionário para diagnosticar a CSA.

- Aplicar o questionário selecionado e validado para analisar as percepções dos colaboradores de estabelecimentos que comercializam alimentos prontos para consumo sobre a CSA.

- Avaliar a confiabilidade e validade do questionário que será utilizado.

- Descrever as percepções dos colaboradores quanto à CSA com base nas características das atividades que desempenham na organização. 


\section{METODOLOGIA}

\subsection{COMISSÃO DE ÉTICA}

O presente estudo foi realizado em acordo com a Comissão de Ética da FMVZ - USP. Foi estruturado um Termo de Consentimento Livre e Esclarecido (TCLE), apresentando à empresa do estudo, contido no Apêndice $\mathrm{A}$ e a Carta de Aceite da organização participante, disponível no Apêndice B. A submissão do presente estudo visa proteger os participantes de pesquisa quanto a sua saúde, direitos e segurança. Para garantir que os participantes estavam livres de riscos ou desconforto, o TCLE foi apresentado, bem como o propósito deste estudo, além de assegurar a confidencialidade das respostas dos participantes. Para a consulta do processo referente ao presente estudo, procurar por número de protocolo CEUAx № 7453230318, junto à FMVZ-USP.

O estudo também foi submetido ao Conselho Nacional de Saúde através da Plataforma Brasil (www.plataformabrasil.saude.gov.br). A finalidade dessa plataforma é avaliar os projetos que são submetidos por lá de maneira que os procedimentos metodológicos que envolvam diretamente a coleta de dados de seres humanos não acarretem riscos maiores do que os encontrados na vida cotidiana dos participantes (BRASIL, 2016). Para a consulta do processo referente ao presente estudo, procurar por número de protocolo CAAE: 95202318.5.0000.5422.

\subsection{O CENÁRIO DO ESTUDO}

O cenário deste estudo compreendeu colaboradores das áreas de manipulação de alimentos prontos para consumo de uma Rede de Lojas Hipermercado (RLH) multinacional. A empresa possuía 2204 colaboradores de manipulação de alimentos em 28 lojas hipermercado no município de São Paulo e da região Grande São Paulo.

Os colaboradores, chamados Operadores de loja (OP), são divididos em setores produtivos conforme a finalidade do mesmo. Cada setor possui um Gerenciador (GC), colaborador encarregado de supervisionar os OP e também realizar manipulação de alimentos. Um degrau acima na hierarquia está o Diretor de 
Loja (DL), encarregado por todas as operações da loja hipermercado (produção de alimentos, estoques, vendas, etc.). Paralelo a essa hierarquia no nível da loja, está estruturada a equipe de segurança de alimentos formada por um Responsável Técnico (RT) e um Estagiário (ES). O RT é um prestador de serviço em segurança dos alimentos nas lojas e são auxiliados por ES ainda cursando o ensino superior cuja graduação deve conter a atribuição de RT de loja hipermercado.

Ainda sobre a hierarquia, todas as lojas estão subordinadas aos Coordenadores de Região (CR). Para cada CR é designado um conjunto de lojas que podem abranger bairros, municípios e estados do Brasil. Os CR fazem parte do Departamento de Segurança de Alimentos e Controle de Qualidade (DSACQ) encabeçado por um Gerente Especialista (GE) nesse assunto. Acima do departamento está a Diretoria de Prevenção de Riscos e Perdas (DPRP), envolvida com a administração de todas as lojas, abarcando outras áreas administrativas da empresa, e que possui um Diretor Geral (DG). Essa diretoria atua em conjunto com outras diretorias da empresa formando a Central Administrativa Brasil (CAB) da empresa. Tanto o GE quanto o DG são responsáveis por todas demais lojas existentes no Brasil. Na Figura 2 há a esquematização da hierarquia da empresa no Brasil.

O tamanho da amostra foi obtido a partir do tempo possível para realização da pesquisa, bem como o número de lojas disponibilizadas pela $R L H$, devido à logística da própria rede, uma vez que os colaboradores participantes interromperam as suas atividades por alguns minutos para responderem 0 instrumento (ou questionário), interferindo nos processos de operação dos setores. 
Figura 2 - Hierarquia de funções da Rede de Lojas Hipermercado no Brasil, dividida em nível administrativo e loja hipermercado - São Paulo, 2018

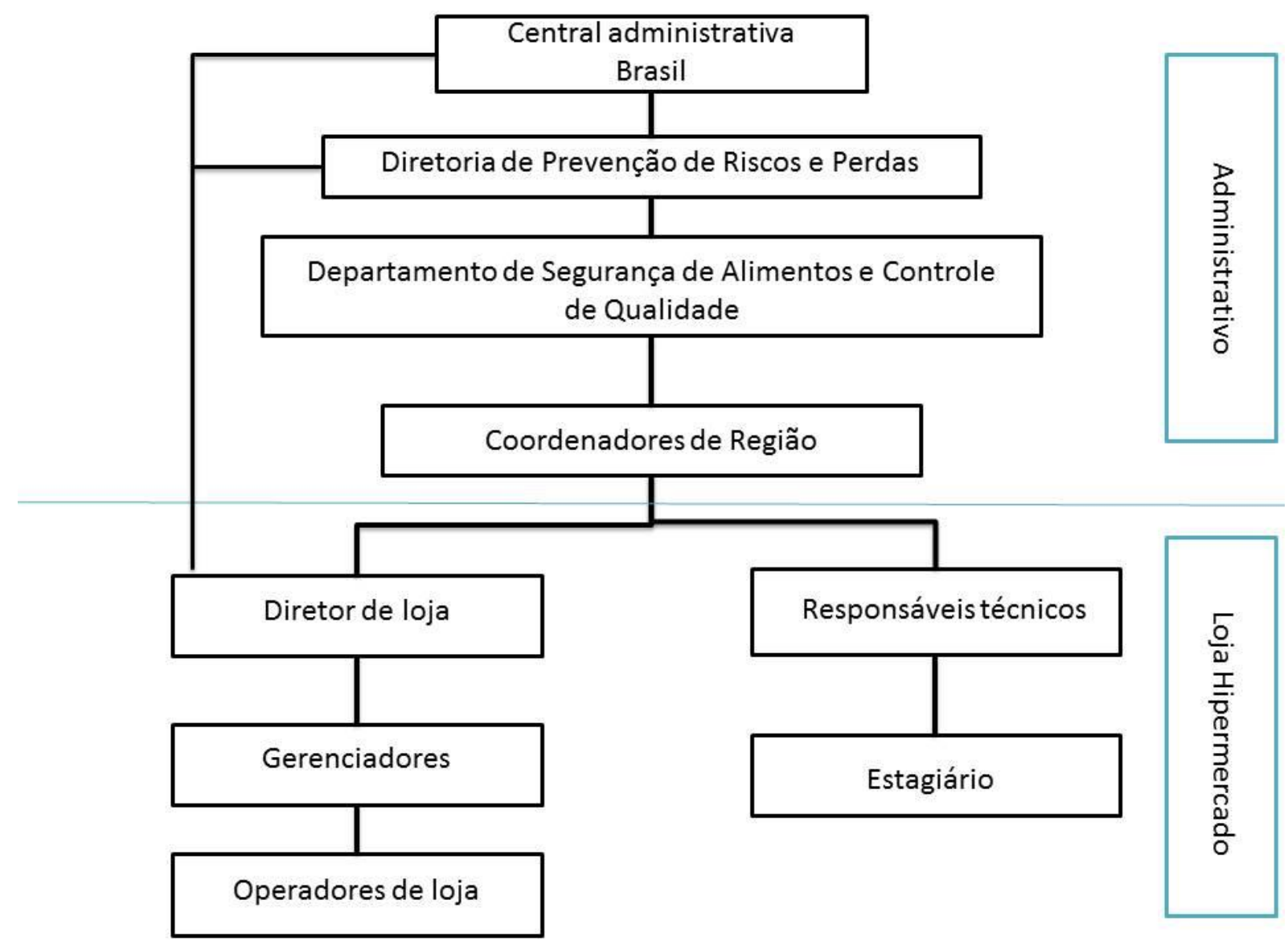

Fonte: (GALVÃO, V. C., 2018).

Os setores da RLH cujos colaboradores fizeram parte do estudo são: açougue, peixaria, salsicharia (embutidos e derivados lácteos), padaria, frutas/legumes/verduras (FLV) e cafeteria.

O setor de açougue eram expostos a venda cortes de animais de abate como bovino, suíno, ave e outros. Existem cortes pré-preparados e embalados e aqueles a partir da solicitação do cliente. Uma parte da matéria prima chega congelada embalada a vácuo e pode seguir para venda direta ou pode ser fracionada. Há também a manipulação de carcaças suínas, as quais são divididas em cortes para venda. Os cortes cárneos são acondicionados em freezers de acordo com a temperatura estabelecida pelo fornecedor e/ou especificada em legislação.

A peixaria funciona similar ao açougue, o pescado pode ser vendido em cortes pré-preparados ou cortes a pedido do cliente ou vendidos inteiros (eviscerados ou não). Os pescados ficam dispostos em bancada com gelo, abastecida conforme a necessidade dos produtos. As lojas trabalham com diversas 
espécies de pescado entre peixes, crustáceos, moluscos e etc. Alguns chegam congelados, outros refrigerados e outros frescos.

$\mathrm{Na}$ salsicharia, eram vendidos embutidos cárneos e derivados lácteos de diferentes composições e sabores. O cliente poderia comprar peças inteiras dos produtos ou pedir para os colaboradores fracionarem os produtos em determinado peso.

A padaria possuía uma grande variedade de preparações de massas. As receitas variavam de preparações salgadas a doces. Eram utilizadas diferentes matérias primas específicas de panificação e confeitaria. Os produtos eram produzidos nas lojas em equipamentos industriais de grande capacidade de operação. Os produtos são pré-preparados nas lojas e expostos para venda. O cliente pode solicitar aos colaboradores quais produtos quer adquirir.

O setor de Frutas Legumes e Verduras (FLV) manipula poucos produtos. Poucas preparações eram realizadas nas lojas, são elas: "salada de fruta" (variados tipos de frutas cortados em cubos e posteriormente embalados) e "mix de salada" (folhas e legumes cortados e embalados). A maioria dos produtos era vendida in natura. Os colaboradores são treinados para exporem à venda produtos conforme o grau de maturação.

O setor de Cafeteria apresentava uma ampla gama de salgados e doces prontos para o consumo. Realizava-se ali a preparação de lanches com diversos recheios. Além disso, era servido aos clientes um leque de opções de bebidas quentes e frias.

Todas as lojas possuem outros colaboradores que também estavam envolvidos com alimentos, porém esses alimentos não necessitam de manipulação para serem vendidos ao cliente. São produtos embalados nas indústrias fornecedoras à RLH. Esses colaboradores eram incumbidos de apenas retirar os produtos do estoque e colocá-los nas gondolas do hipermercado. Portanto, o risco de contaminação desses produtos é baixo e por isso os colaboradores dessas outras áreas não são o alvo dessa pesquisa.

Quanto à manipulação de alimentos, as lojas da RLH participantes da pesquisa mantinham treinamentos em SA todos os meses do ano para os colaboradores dos setores descritos acima. As normas de SA presentes nas RLH foram elaboradas tanto pela empresa (para melhorar sua eficiência de controle sobre os produtos e manter a qualidade dos mesmos, de acordo com manuais de 
fotos de identidade e qualidade desenvolvidos pela RLH) quanto pelas legislações sanitárias vigentes no Município, no Estado e na esfera Federal.

Além disso, as lojas eram auditadas pelo menos uma vez ao mês por uma empresa especializada em SA para averiguar as realidades de manipulação de alimentos, higiene, controle de pragas, controle de temperatura, validade de produtos, rotulagem de produtos e etc., ou seja, conforme as normas da empresa e das legislações.

Os treinamentos eram criados no DSACQ. Esse departamento possui a atribuição de cuidar da segurança dos alimentos como um todo e de todas as lojas, através de documentos, análises estatísticas e ações de inspeção sanitária realizadas pelos RTs. Os RTs não fazem parte da empresa de auditoria em segurança dos alimentos.

A RLH realizava periodicamente análise laboratoriais de seus produtos, sejam os manipulados nas lojas ou enviados embalados prontos para o consumo. As análises visam a pesquisa de agentes patogênicos e contaminantes (microbiológica), bem como análises físico-químicas.

Segundo representante do DSACQ, cada loja possuía em torno de setenta colaboradores de manipulação de alimentos dos setores citados acima, divididos em dois turnos de trabalho de oito horas cada. Não foi possível que todos os colaboradores de cada loja participassem da pesquisa, pois não era possível liberar todos os colaboradores das atividades dos setores ao mesmo tempo. Ao pesquisador foi permitido visitar uma loja por semana durante oito meses entre agosto de 2017 e abril de 2018.

\subsection{DESENHO DO ESTUDO}

Neste trabalho foi realizado um estudo de campo para aplicação de um instrumento (ou questionário) de diagnóstico de CSA (GUILLEMIN; BOMBARDIER, 1993; LAKATOS; MARCONI, 2003; GIL, 2008). O tipo de amostra é não probabilística e de conveniência (LEVY; LEMESHOW, 1999). O fluxograma da metodologia pode ser visualizado na Figura 3.

Figura 3 - Fluxograma da metodologia da validação do questionário para diagnóstico de Cultura de Segurança de Alimentos - São Paulo, 2018 


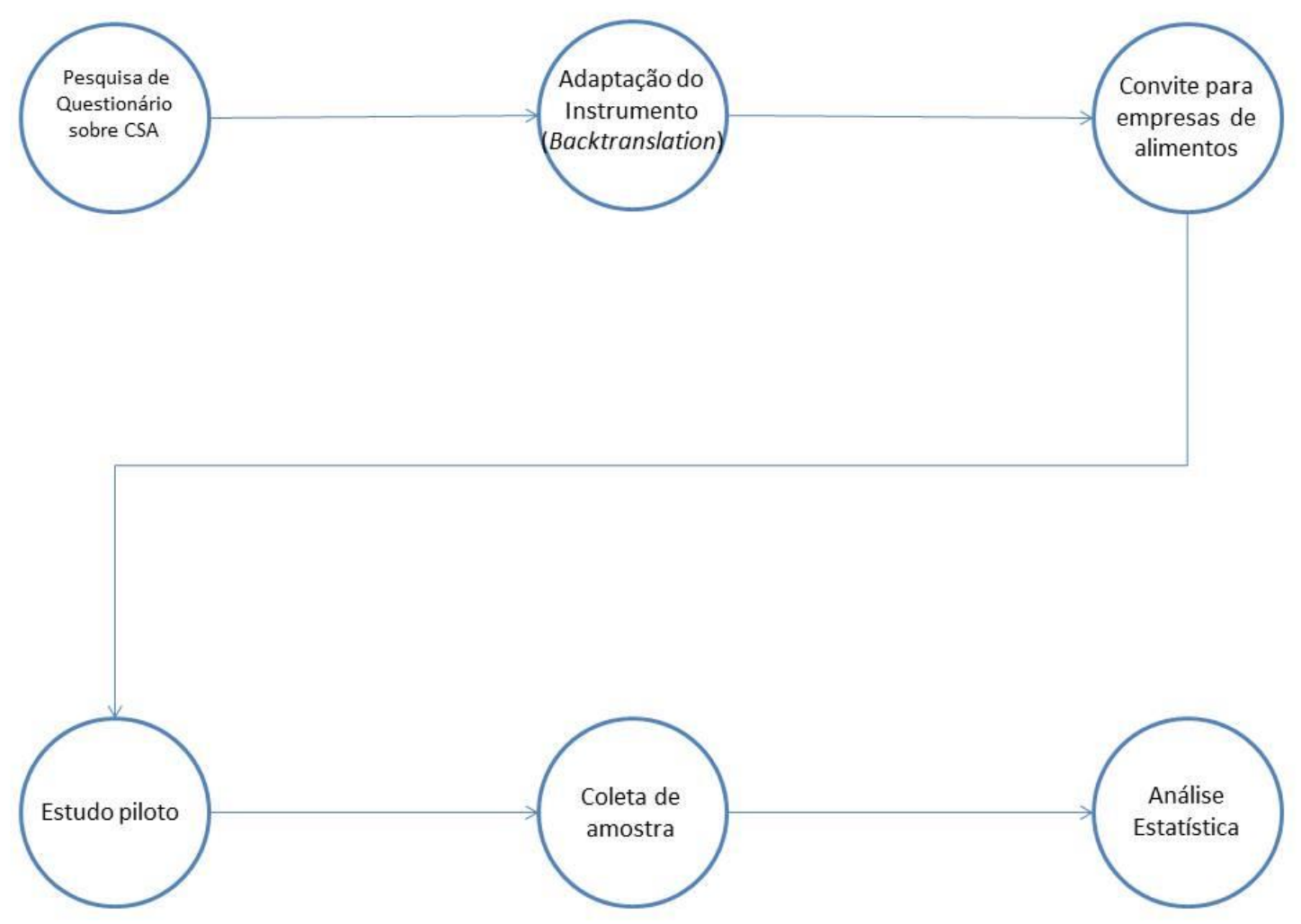

Fonte: (GALVÃO, V. C., 2018).

Foram pesquisadas diferentes bases nacionais de dados (LILACS, SciELO e Periódicos CAPES) para identificar se havia estudos que utilizavam um instrumento de CSA no Brasil. Não foram encontrados tais estudos até o momento, por isso, partiu-se para bases de dados estrangeiras (Scopus, Sciencedirect, Pubmed e Web of Science).

Ao investigar a literatura cientifica estrangeira foram levantados estudos que utilizaram instrumentos que avaliaram a CSA em organizações (BALL, 2010; TAYLOR, 2011; NEAL, 2012; WRIGHT, 2012; SEWARD, 2012; UNGKU FATIMAH, 2013; DE BOECK, 2015; JESPERSEN, 2016; GRIFFITH, 2017). Foram utilizados dois meses para a compilação dos trabalhos. Os trabalhos estavam em um período de tempo de sete anos, ou seja, entre 2010 a 2017. Os critérios para a escolha do instrumento neste trabalho foram:

- Questionário disponível para ser avaliado;

- Explicação dos elementos que compõem a CSA;

- Itens condizentes com o dia a dia de manipulação de alimentos;

- Limite de até 50 itens. 
Dentre os estudos levantados, aquele desenvolvido por Ungku Fatimah (2013) foi o que possuia todos os critérios descritos acima. Ressalta-se que o conteúdo dos itens do referido autor constituem ações de preferências declaradas pelo participante em relação a determinado assunto, e não reveladas ou confirmadas na prática através da observação desse participante.

Posterior à escolha do instrumento, a próxima etapa da pesquisa, conforme figura do fluxograma, foram a adaptação e validação do intrumento para o português do Brasil. O motivo da especificação do processo de adaptação e validação ser para a o português brasileiro se deve, pois, existem outros países cujo idioma também é o português, mas como há diferenças de modos de raciocínio, expressões idiomáticas, de significação de palavras e culturais, decidiu-se especificar que os processos aconteceram para o português do Brasil. O processo de adaptação baseou-se no trabalho de Borsa et. al. (2012) que estabeleceram seis passos para adaptação de instrumentos:

(1) Tradução do instrumento para o novo idioma;

(2) Síntese das versões traduzidas;

(3) Avaliação da síntese por Experts;

(4) Avaliação pelo público-alvo;

(5) Backtranslation (retradução); e

(6) Estudo piloto.

Borsa et. al. (2012) ressaltam que antes de realizar a adaptação do instrumento é preciso solicitar a autorização de uso do questionário para o autor. $O$ contato foi feito por e-mail solicitando o uso. $O$ autor autorizou a utilização do instrumento, conforme apresentado no Apêndice $C$. Importante ressaltar que foram utilizados os itens validados pelo autor Ungku Fatimah (2013), total de 31 itens. A autorização do autor do instrumento é fundamental para dar continuidade às próximas etapas da adaptação.

A tradução do instrumento para o novo idioma (1), conforme Borsa et. al. (2012), foi realizada por dois tradutores bilíngues para minimizar os vieses linguísticos, psicológicos, culturais e de compreensão teórica e prática. A síntese das versões traduzidas (2) consiste em reunir as traduções em um único compilado de itens, avaliando as diferenças e discrepâncias semânticas, idiomáticas, conceituais, linguísticas e contextuais. A avaliação citada foi realizada por dois experts no assunto (Avaliação da síntese por experts - 3). A avaliação pelo público- 
alvo (4) destinou-se verificar se os itens, as instruções e a escala de resposta são compreensíveis pelo público-alvo de maneira que nessa etapa não é necessário procedimentos estatísticos. O Backtranslation (5) é uma forma de garantia da qualidade do processo de tradução, uma vez que o instrumento foi retraduzido para o inglês por dois profissionais bilíngues. O objetivo foi identificar discrepâncias entre essas duas versões que podem ser devidas a erros na tradução. Após a retradução fez-se uma síntese das duas versões, buscando uma equivalência conceitual. Com isso em mãos, o instrumento foi apresentado ao autor do instrumento original que não retornou suas considerações até o encerramento desta pesquisa. Por fim, o processo de adaptação visa um estudo piloto (6) para aplicar o instrumento "quase pronto" em uma pequena parcela do público-alvo. Foram utilizados nesta última etapa de adaptação vinte e nove participantes. O objetivo do estudo piloto foi avaliar a adequação dos itens quanto ao seu significado e dificuldade de compreensão. $O$ instrumento foi aplicado pelo próprio pesquisador presencialmente na loja. Para fins ilustrativos, a Figura 4 mostra metodologia em que este estudo se baseou para acontecer.

Conforme Borsa et. al. (2012), o estudo piloto foi conduzido para testar a compreensibilidade do instrumento pelos participantes e a operacionalização do estudo. Todos os participantes do estudo piloto foram recompensados ao final do preenchimento do instrumento com um bombom de chocolate como forma de agradecimento pela participação na pesquisa. Logo após esta etapa foi conduzida a coleta de dados da amostra do estudo.

Figura 4 - Procedimentos para adaptação cultural de instrumentos psicológicos segundo Borsa et. al.(2012) 


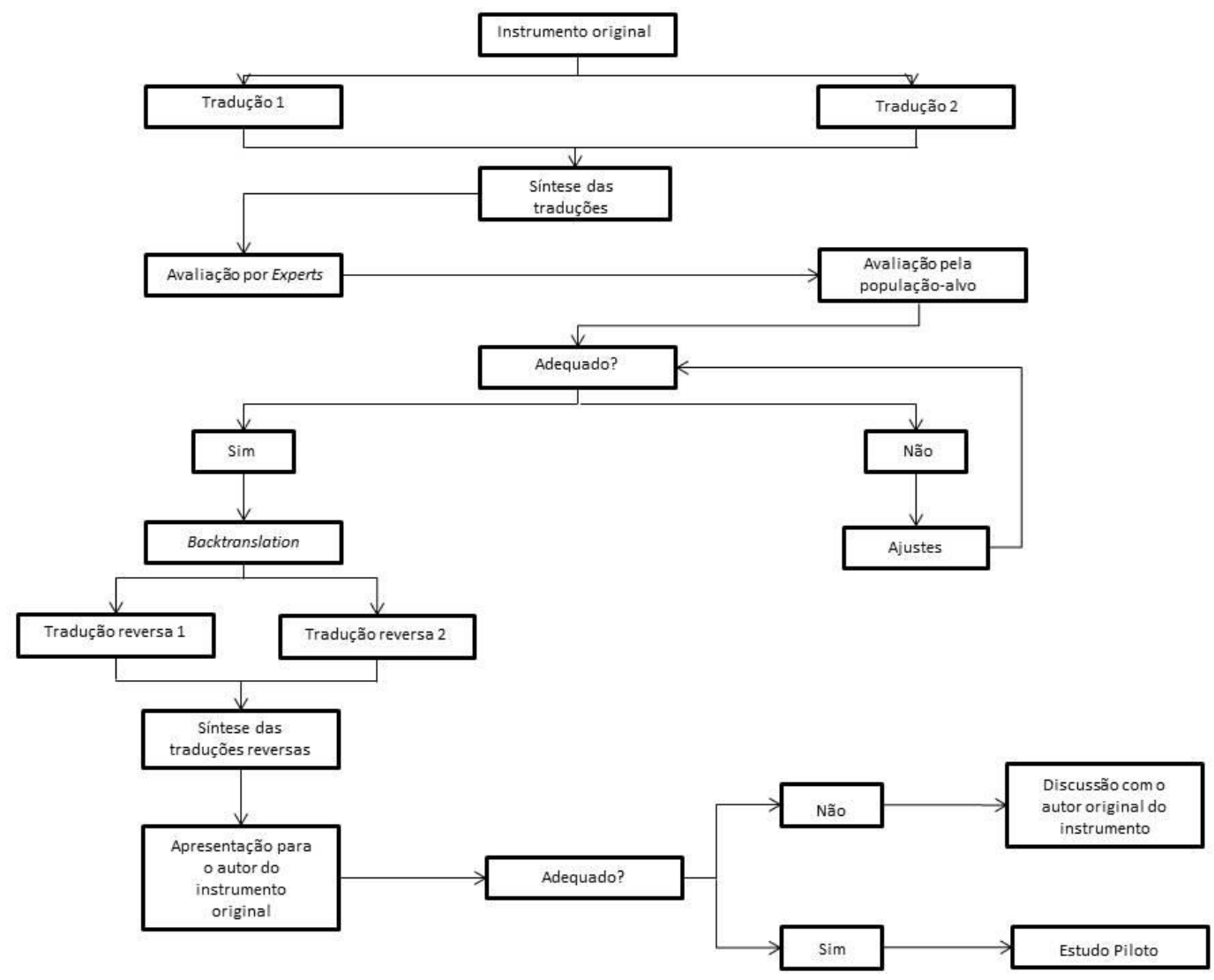

Fonte: (BORSA, 2012).

Após a etapa de escolha do instrumento e adaptação do instrumento, o próximo passo foi encontrar um cenário para aplicação do questionário. Foram feitos convites, por correio eletrônico, para empresas de alimentos nas quais havia realidades de processos de manipulação de alimentos prontos para o consumo, na cidade de São Paulo, Brasil, semelhantes aos que Ungku Fatimah (2013) trabalhou. Os convites foram feitos por correio eletrônico. Apenas uma empresa do setor de hipermercados aceitou participar do estudo.

Foi agendada uma reunião com o gestor de SA da organização para explicar os objetivos, propostas e etapas do estudo. Em contra partida, a empresa solicitou a não divulgação de seu nome, bem como o não preenchimento do TCLE por parte dos participantes que aceitassem colaborar com a pesquisa. Ficou então acordado entre as partes que, previamente ao convite de participação aos colaboradores, o pesquisador explicaria verbalmente sobre o que se trata o referido estudo, qual seria a participação de cada um, caso aceitasse, a inexistência de compromissos, a ausência de qualquer natureza de dano, comprometimento ou prejuízo para o coloborador e que, a qualquer momento, que julgasse válido poderia declinar de sua participação. 
Outra etapa do estudo foi uma entrevista semi-estruturada com uma pessoa responsável pela SA inserida no Departamento de Qualidade e Segurança de Alimentos (DSACQ) da empresa participante. O objetivo dessa etapa era identificar através das respostas da entrevistada elementos que caracterizem a SA da organização (JESPERSEN, 2017a). A entrevista é um dos elementos para caracterizar a CSA de um estabelecimento (NYARUGWE, 2017; JESPERSEN, 2017a). A entrevista foi registrada em áudio e posteriormente transcrita em texto. As questões da entrevista estão no Apêndice F.

Segundo Jespersen (2017a), a triangulação de informações que nos direciona para o diagnóstico de CSA é mais segura do que utilizar apenas um instrumento de geração de dados e informação. O autor defende que a) entrevista semi-estruturada, b) utilização de um instrumento de autorrelato da percepção dos colaboradores e c) avaliação documental dos registros em SA são maneiras de circundar a CSA a partir de diferentes abordagens e pontos de vista. Por isso, solicitaram-se os documentos de registro que revelam o cotidiano da SA da organização, tais como Relatórios de auditoria externa em SA, Minutos de reuniões sobre SA, Relatórios de inspeção interna e Registros de Boas Práticas de Fabricação. Mas, a empresa se recusou a fornecer os documentos.

\subsection{CÁLCULO DO TAMANHO DA AMOSTRA}

Segundo Munnich (2006, p.3), a amostragem consiste:

no ato de investigar parcialmente a população com o poder de generalizar o conhecimento adquirido na amostra para o conjunto da população, com uma margem de segurança dimensionável. A coleta de dados é, talvez, a parte mais importante da pesquisa, pois qualquer erro, engano ou viés presente na mesma se refletirá nas conclusões baseadas nessa coleta, seja na coleta realizada de forma censitária ou amostral.

Foi adotado, segundo Cochran (1986, p.75), a seguinte fórmula, para calcular o tamanho mínimo da amostra, para a coleta de dados proposta, a fim de cumprir os objetivos da pesquisa: 


$$
n=\frac{\frac{t^{2} \cdot P \cdot(1-P)}{d^{2}}}{1+\frac{1}{N} \times\left(\frac{t^{2} \cdot P \cdot(1-P)}{d^{2}}-1\right)}
$$

onde:

$\mathrm{N}$ - tamanho da população-alvo.

$\mathrm{n}$ - tamanho da amostra desejada.

t - abscissa da curva Normal determinada por uma área de tamanho a (alfa), que é o risco calculado, para que a margem de erro máximo adotado seja a menor possível; neste caso, $\mathrm{t}=1,96$.

d - margem de erro máximo adotado, ou, também chamada de precisão adotada; valores entre $1 \%$ e $20 \%$ são passíveis de adoção; o valor $5 \%$ (margem de erro), cuja precisão equivale-se a 95\% é um dos mais usuais. De qualquer modo, foi adotado 4 valores possíveis, para que um deles seja o escolhido pelo pesquisador: $5 \%, 10 \%$, $15 \%$ e $20 \%$, e foi feito o cálculo do tamanho da amostra para esses 4 valores.

P - proporção de ocorrência do fato observado; quando se desconhece, previamente, o valor populacional, adota-se $\mathrm{P}=50 \%(0,5000)$, o que permite a maximização do valor de ' $n$ '.

Neste estudo, adotou-se, de forma arbitrária, a chance de 50\% de ocorrer o fenômeno estudado. Porém, a abordagem dicotômica foi utilizada somente para o cálculo de tamanho de amostra, definida por Cochran (1986).

A interpretação da existência e diversidades na CSA da organização em suas diferentes lojas foi feita de natureza qualitativa, utilizando os autores selecionados para esse fim.

O tamanho da amostra foi calculado a partir do total de trabalhadores informado por represente legal da empresa, compondo um total de 2204 manipuladores de alimentos, distribuídos em 28 lojas em São Paulo.

Assim, substituindo-se os valores adotados na fórmula de Cochran citada anteriormente, temos que o tamanho da amostra será uma amostra de tamanho mínimo de 328 ( $d=5 \%), 93$ ( $d=10 \%), 42(d=15 \%)$ ou 24 ( $d=20 \%)$ elementos amostrais, como mostra a Tabela 1. Escolheu-se $n=328$, como a amostragem ideal, em virtude da viabilidade do trabalho e menor erro (d) estatístico. 
Tabela 1 - Resultados do tamanho da amostra conforme Cochran - São Paulo, 2018

\begin{tabular}{cccccccc}
\hline $\mathrm{t}$ & $\mathrm{t}^{2}$ & $\mathrm{P}$ & $1-\mathrm{P}$ & $\mathrm{d}$ & $\mathrm{d}^{2}$ & $\mathrm{n}$ \\
\hline 1,96 & 3,8416 & 0,5000 & 0,5000 & $\mathbf{0 , 0 5}$ & 0,0025 & $\mathbf{3 2 8}$ \\
1,96 & 3,8416 & 0,5000 & 0,5000 & $\mathbf{0 , 1 0}$ & 0,0100 & $\mathbf{9 3}$ \\
1,96 & 3,8416 & 0,5000 & 0,5000 & $\mathbf{0 , 1 5}$ & 0,0625 & $\mathbf{4 2}$ \\
1,96 & 3,8416 & 0,5000 & 0,5000 & $\mathbf{0 , 2 0}$ & 0,0400 & $\mathbf{2 4}$
\end{tabular}

Fonte: GALVÃO (2018).

\subsection{ANÁLISE DE DADOS}

As etapas estabelecidas por Borsa (2012) para adaptação cultural e validação de instrumentos psicológicos foram analisadas segundo critério qualitativo, ou seja, as versões produzidas pelos tradutores e retradutores foram avaliadas uma a uma para verificar o sentido, a forma, o conteúdo, e comparadas aos itens do autor original.

Os resultados do questionário tanto da seção demográfica quanto dos fatores de CSA foram apresentados e analisados pela estatística descritiva. Portanto, os resultados foram mostrados através das frequências absolutas e relativas, moda e mediana.

Análise fatorial exploratória e confirmatória foram realizadas utilizando o Statistical Package for the Social Sciences (SPSS, versão 18.0) com a finalidade de verificar a distribuição dos itens segundo as suas cargas fatoriais. A consistência interna (Alpha de Chronbach) foi calculada para avaliar se o instrumento mede o que pretende medir, ou seja, a CSA. O valor do alfa quanto mais próximo de 1 mais consistente 0 instrumento será. Realizou-se a análise descritiva dos dados demográficos e posterior estudo relacional (teste de Spearman) com as respostas dos participantes para confrontar as percepções dos colaboradores sobre a CSA com base nas suas características demográficas e funções de trabalho.

Além das análises estatísticas descritas acima, buscou-se expressar em números o grau de discordância ou concordância das respostas dos participantes. Assim, a CSA pôde ser classificada em positiva e negativa. A finalidade foi retribuir à empresa que cedeu espaço para realização da pesquisa o resultado do estado da 
CSA da organização. Os parágrafos a seguir dizem respeito de como foi realizada a análise da CSA para a organização.

A CSA positiva é a tendência de uma organização de alimentos possuir $S A$, em maior ou menor grau, em seus valores, crenças e atitudes que são expressas pelos comportamentos das pessoas. Já a CSA negativa é a tendência inversa da positiva, também em maior ou menor grau. Assim, quanto mais a SA se destaca nos valores, crenças, atitudes e comportamentos na organização haverá maior cumprimento das legislações sanitárias, alimentos mais seguros e melhoria de processos.

Para avaliar se a empresa possuía uma CSA positiva ou negativa, adotou-se o critério de somatório da escala Likert de cada participante e o estabelecimento da distância entre pontos da escala (distância sigma) através da média dos pontos - ambos os métodos elaborados por Likert (1932), de forma que o grau de concordância ou discordância obedeça um padrão positivo e um negativo de respostas dos fatores de CSA.

Portanto, entende-se por escore positivo aquele cujo valor está acima ou igual ao escore "Indiferente" mais quinze pontos. O escore negativo é aquele cujo valor está abaixo ou igual ao escore "Indiferente" menos quinze pontos. Portanto, um participante pode somar trinta e um pontos (caso tenha marcado em todos os itens a escala 1) ou até 217 pontos (no caso de ter marcado em todos os itens a escala 7). A Tabela 2 mostra os valores de escore para CSA positiva e negativa.

Houve a inversão dos itens 6, 30 e 31 cujo conteúdo original elaborado por Ungku Fatimah (2013) era negativo. Assim, cada item possuirá uma bidirecionalidade cujas extremidades representam a completude de cada aspecto.

Conforme Hair et. al. (2009), após a coleta de dados da amostra se houver participantes que não responderam mais de $50 \%$ dos itens, esse participante deve ser eliminado da análise estatistica. No presente estudo foram retirados 18 participantes da amostra, pois eles não atendiam ao critério de Hair (2009). 
Tabela 2 - Distância sigma de Likert (1932) para categorização das respostas dos participantes - São Paulo, 2018

\begin{tabular}{|c|c|c|c|c|c|c|c|}
\hline & \multicolumn{7}{|c|}{ Escala Likert e Distância sigma } \\
\hline & $\begin{array}{l}\text { Discordo } \\
\text { muito }\end{array}$ & $\begin{array}{l}\text { Discordo } \\
\text { moderadamente }\end{array}$ & $\begin{array}{l}\text { Discordo } \\
\text { pouco }\end{array}$ & Indiferente & $\begin{array}{l}\text { Concordo } \\
\text { pouco }\end{array}$ & $\begin{array}{l}\text { Concordo } \\
\text { moderadamente }\end{array}$ & $\begin{array}{l}\text { Concordo } \\
\text { muito }\end{array}$ \\
\hline $\begin{array}{l}\text { Escala Likert } \\
\text { (ancoragem } \\
\text { numérica) }\end{array}$ & 1 & 2 & 3 & 4 & 5 & 6 & 7 \\
\hline $\begin{array}{l}\text { Escore possível } \\
\text { caso o } \\
\text { participante } \\
\text { escolhesse apenas } \\
\text { uma escala como } \\
\text { resposta para } \\
\text { todos os } 31 \text { itens }\end{array}$ & 31 & 62 & 93 & 124 & 155 & 186 & 217 \\
\hline $\begin{array}{l}\text { Escore negativo e } \\
\text { positivo }\end{array}$ & & $\leq 109$ & & 124 & & $\geq 139$ & \\
\hline
\end{tabular}

Fonte: GALVÃO (2018). 


\section{RESULTADOS}

\subsection{ADAPTAÇÃO DO INSTRUMENTO DE PESQUISA}

O processo de adptação baseou-se no trabalho de Borsa et. al. (2012) que estabelece seis passos para adaptação de instrumento psicológicos: (1) tradução do instrumento para o novo idioma, (2) síntese das versões traduzidas, (3) avaliação da síntese por experts, (4) avaliação pelo público-alvo, (5) backtranslation e (6) estudo piloto. Portanto, nessa seção do trabalho serão apresentados os dados referentes a essa etapa.

\subsubsection{Tradução do questionário, sua síntese e avaliação dos experts}

Segundo Borsa (2012), a etapa de tradução tem por objetivo avaliar principalmente se durante a tradução do inglês para o português houve: perda do sentido original dos itens e diferenças na forma escrita. Vinte e cinco itens das duas traduções do questionário não apresentaram diferença de sentido do conteúdo dos itens.

O item 2 "I am encouraged to provide suggestions for improving food safety practices" houve uma diferença sutil entre as traduções dos avaliadores. $O$ avaliador A traduziu por "Eu sou encorajado...." enquanto que o avaliador B traduziu "Eu estou encorajado..." Devido ao verbo ser/estar, o item pode ser entendido de duas formas diferentes. No primeiro caso a intenção é que o participante é continuamente encorajado. No segundo, o participante pode entender que está encorajado naquele momento. Como a pesquisa é sobre CSA e não Clima de Segurança de Alimentos (DE BOECK, 2015), a finalidade foi caracterizar se o participante ao longo do tempo é encorajado. Portanto, a síntese das traduções ficou "Sou encorajado a dar sugestões para melhorar as práticas de segurança dos alimentos".

O item 4 "Management provides adequate and timely information about current food safety rules and regulations" apresentou divergência de sentido devido a palavra "timely". Essa palavra foi traduzida pelo avaliador A por "pontual" e pelo avaliador B por "no tempo certo". Como houve essa diferença de tradução, os experts decidiram pela seguinte síntese entre as duas traduções: " $A$ administração 
ou a gerência fornece informações sobre as normas e regulamentos de segurança alimentar vigentes".

O item 6 apresentou diferença entre os tradutores devido a uma expressão inglesa, "cover-up", assim identificada na afirmação: "I believe that written food safety policies and procedures are nothing more than a cover-up in case there is a lawsuit." A citada expressão foi traduzida pelo avaliador A por "acobertar" enquanto que o avaliador B por "proteger". Como a tradução do avaliador A poderia causar um mal-estar no participante da pesquisa, foi adotado a tradução do avaliador B. Dessa forma, o item ficou traduzido como se segue: "Acredito que as políticas e os procedimentos escritos de segurança de alimentos da empresa não são nada mais do que uma proteção caso haja um problema com a lei".

O item 12 apresentou diferença entre os avaliadores devido a palavra "clutter". Originalmente o item era descrito como "I keep my work area clean because I do not like clutter". Um dos tradutores fez a tradução da palavra acima como "talher". Porém, não era esse o sentido do item. Por isso, o item foi traduzido como "Eu mantenho minha área de trabalho limpa porque eu não gosto de desordem".

Com relação ao item 30, o avaliador B apresentou tradução mais ajustada ao propósito do instrumento, em relação ao avaliador $\mathrm{A}$. O item, originalmente, foi escrito "When there is pressure to finish food production, managers sometimes tell us to work faster by taking shortcuts with food safety". A ideia de shortcut na afirmação significa encurtar ou pular alguma etapa. Por isso, e devido a grande maioria dos participantes serem de baixa escolaridade, a síntese desse item ficou "Quando estamos sob pressão para terminar a produção de alimentos, os gerentes às vezes nos dizem para trabalhar mais rápido, 'pulando' algumas regras de segurança dos alimentos".

O item 31 "I am sometimes asked to cut corners with food safety so we can save costs when preparing food" foi traduzido de maneira muito parecida pelos avaliadores. A expressão "cut corners" foi traduzida por "economizar". Porém, como o item se refere a segurança de alimentos, o sentido dessa expressão seria parecido ao item 30, ou seja, cortar regras, burlar, não praticar as regras de segurança de alimentos. Por isso, a síntese do item ficou "Às vezes me pedem para "cortar caminho" em relação à segurança dos alimentos durante a produção dos alimentos para que possamos economizar custos". 
Em relação à forma escrita dos itens, eles foram avaliados segundo a ordem dos termos, a pontuação da oração e presença de palavras diferentes. Foram realizadas alterações nesse quesito de forma escrita para ajustar ao vocabulário da maioria dos participantes que são pessoas com até ensino médio. Os resultados tanto do sentido dos itens quanto da forma escrita estão no Apêndice $F$.

\subsubsection{Avaliação pelo público-alvo}

Esta etapa da metodologia de Borsa (2012) foi aplicada em um conjunto de pessoas que compõem a amostra. $O$ instrumento foi avaliado por elas em relação à compreensão dos itens, as instruções de preenchimento, diagramação e formatação do documento.

Portanto, as pessoas participantes dessa etapa foram de uma loja da RLH. Houve um participante para cada função ou cargo dentro da loja: 1 OP, 1 GC, 1 ES e 1 RT. Todos os participantes afirmaram que os itens estavam compreensíveis, as instruções eram claras, a diagramação e formatação do instrumento eram satisfatórias e objetivas. Um dos participantes sugeriu a substituição da palavra "sexo" para "gênero", presente na seção demográfica do instrumento, pois existem pessoas de orientações sexuais diferentes e isto poderia inibi-las.

\subsubsection{Backtranslation e avaliação do autor original do instrumento}

Assim como dito na metodologia desse trabalho, o objetivo do Backtranslation (retradução) foi identificar discrepâncias entre essas duas versões que podem acontecer devido a utilização de significados diferentes entre os retradutores.

Porém, é possível notar no Apêndice $F$ que não houve discrepâncias de sentido. Além disso, os retradutores utilizaram diferentes palavras com os mesmos significados daquelas presentes na versão original, apesar de desconhecerem o instrumento de Ungku Fatimah.

A síntese das retraduções não apresentou dificuldade para ser realizada devido à alta semelhança entre as versões. Uma vez pronta e avaliada pelos experts em CSA, a síntese foi enviada ao autor original do questionário para que ele avaliasse e apresentasse discordâncias, concordância, sugestões, críticas, etc. do 
instrumento. Até o momento da redação da dissertação não houve retorno do autor com as suas considerações.

\subsubsection{Estudo piloto}

O estudo piloto foi conduzido com os colaboradores em uma das lojas da RLH participante do estudo no município de São Paulo. Um total de 29 pessoas, não inclusas na amostra total, participou do estudo piloto. O instrumento foi aplicado pelo próprio pesquisador presencialmente na loja.

O piloto proporcionou avaliar na prática a operacionalização da aplicação do questionário, ou seja, quanto tempo cada participante completou o questionário e o entendimento do vocabulário dos itens. Os participantes levaram em torno de quinze minutos, em média, para o preenchimento dos itens. Além disso, eles foram estimulados a sugerir críticas e sugestões para a melhoria do instrumento aplicado.

Antes que os colaboradores preenchessem o questionário, o pesquisador informou que a pesquisa era anônima e de participação voluntária. Houve explicação sobre o preenchimento do questionário e, para aqueles que aceitaram participar da pesquisa, foi dado a cada colaborador um bombom como gesto de agradecimento pela participação.

Os colaboradores realizaram a pesquisa em sala de treinamento com arcondicionado sobre mesas acompanhadas de cadeiras. Em cada loja os colaboradores foram alocados em turmas de cinco a dez pessoas para 0 preenchimento do questionário. As turmas foram organizadas pelos RTs de cada loja, sendo que a composição delas possuíam colaboradores de diferentes setores. Ocorreu dessa maneira, pois cada setor necessitava de pelo menos dois colaboradores para fazer acontecer a operação comercial da loja, ou seja, para o setor não ficar deficiente no atendimento ao público (clientes) e as tarefas de manipulação de alimentos, higienização e outras, os colaboradores foram enviados às salas de treinamento em turmas mistas.

Durante o preenchimento da seção demográfica do questionário, seção esta discursiva, alguns colaboradores deixaram itens em branco ou a resposta não condizia com o item. Por isso, o pesquisador adotou a prática de explicar item a item da seção demográfica para os participantes da amostra. 
A seção dos itens sobre CSA também houve falhas de preenchimento, principalmente dos itens sete ao vinte (Apêndice D), pois estes itens estavam na segunda página da primeira folha (o questionário foi impresso em duas folhas frente e verso, unidas por grampo, ou seja, quatro páginas por questionário). Portanto, o pesquisador decidiu que era necessário pedir que o participante da pesquisa, durante a fase de coleta de amostra, verificasse se ele completou todos os itens do questionário.

Finalmente, em conversa com os colaboradores, o pesquisador decidiu trocar o item da seção demográfica "Experiência nesta empresa" por "Experiência na Empresa X". Os participantes do estudo piloto relataram que as perguntas eram pertinentes à realidade de manipulação de alimentos e que o bombom pela participação na pesquisa era estimulante.

O estudo piloto também possuiu a função de ensaio para o pesquisador, ou seja, a maneira como a pesquisa seria conduzida durante a coleta de amostra. Portanto, a experiência adquirida nessa etapa foi fundamental para a coleta de dados da amostra.

Assim, adotou-se os seguintes procedimentos na coleta de amostra: o instrumento foi aplicado pelo próprio pesquisador presencialmente em cada loja que participou do estudo, foi informado que a pesquisa era anônima e de participação voluntária, houve explicação sobre o preenchimento do questionário tanto da parte demográfica quanto dos itens sobre CSA, foi mostrado aos participantes que o questionário possuía duas folhas, frente e verso, e solicitado que os mesmos conferissem se haviam preenchido todo 0 instrumento antes de entregar ao pesquisador e, para aqueles que aceitaram participar da pesquisa, foi entregue um bombom de chocolate. 


\subsection{RESULTADOS DA LOCALIZAÇÃO ESPACIAL DAS LOJAS}

Um total de 383 questionários foram preenchidos em quinze lojas da RLH participante. Em média foram vinte e seis questionários preenchidos por loja (\%).

A distribuição das lojas está discriminada nas figuras abaixo. A Figura 5, mostra o município de São Paulo dividido em cinco zonas (Central, Norte, Leste, Sul e Oeste) nas quais cada uma das zonas é subdividida em bairros. A localização das lojas que participaram da pesquisa está indicada na figura através de uma seta vermelha.

Figura 5 - Distribuição espacial de doze lojas da rede hipermercado no município de São Paulo - São Paulo, 2018 


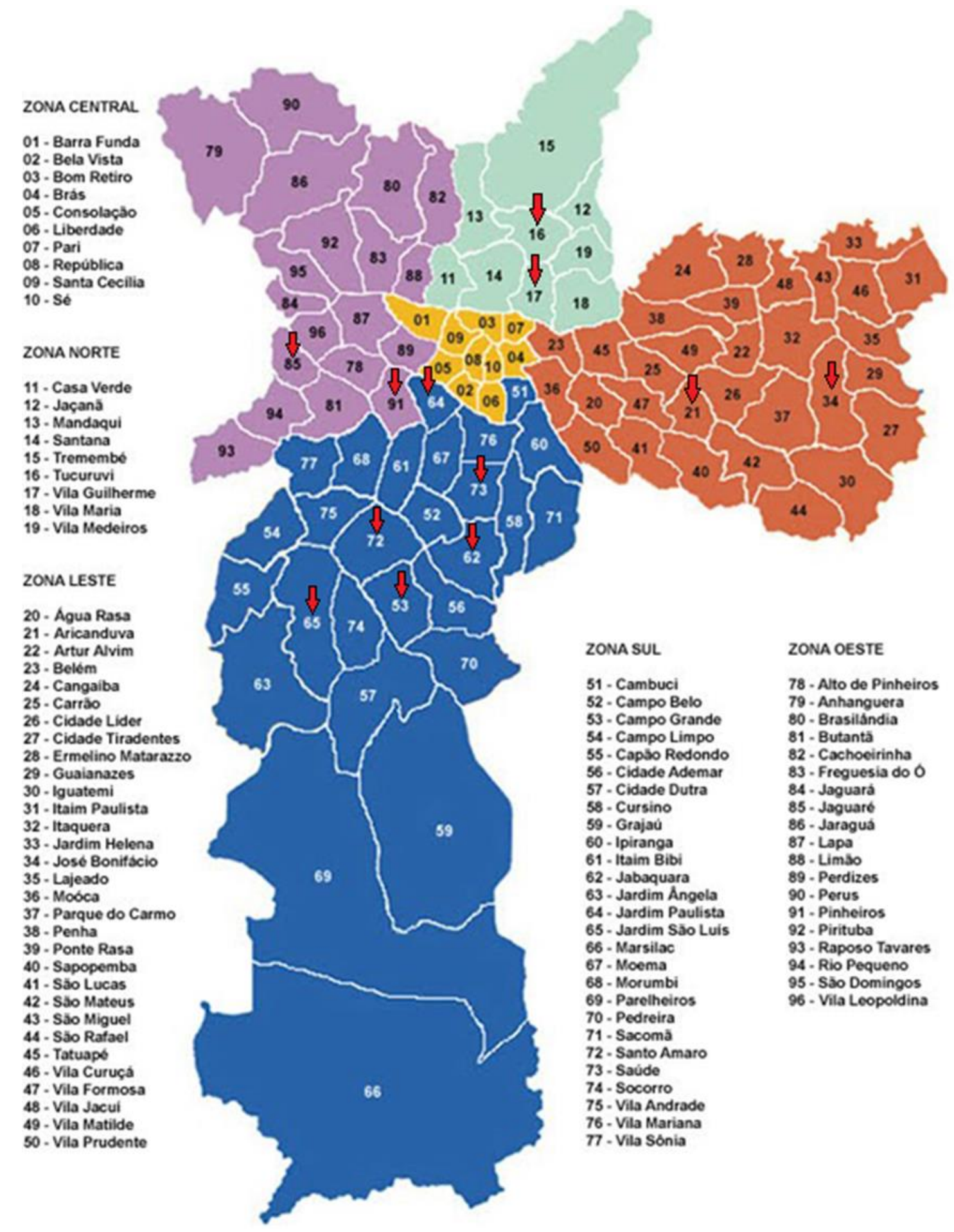

Fonte: (GALVÃO, V. C., 2018).

Nota: a imagem original, sem adição de setas vermelhas, acima pode ser encontrada no sítio eletrônico <http://www.mapas-sp.com/bairros.htm>

Participaram do estudo duas lojas nas zonas norte, leste e oeste totalizando seis lojas nessas regiões. A zona sul foi a mais numerosa em termos de lojas participantes (seis ao todo). Na zona Central não houve lojas da RLH que 
participaram do estudo. A localização de todas as lojas da RLH não foi disponibilizada pela empresa.

Na Figura 6, apresenta-se o mapa da Grande São Paulo, apontando a participação de três lojas em três municípios, indicados pela seta vermelha: Osasco, Diadema e Guarulhos.

Figura 6 - Distribuição espacial de três lojas da rede hipermercado em três municípios da Região Metropolitana de São Paulo - São Paulo, 2018

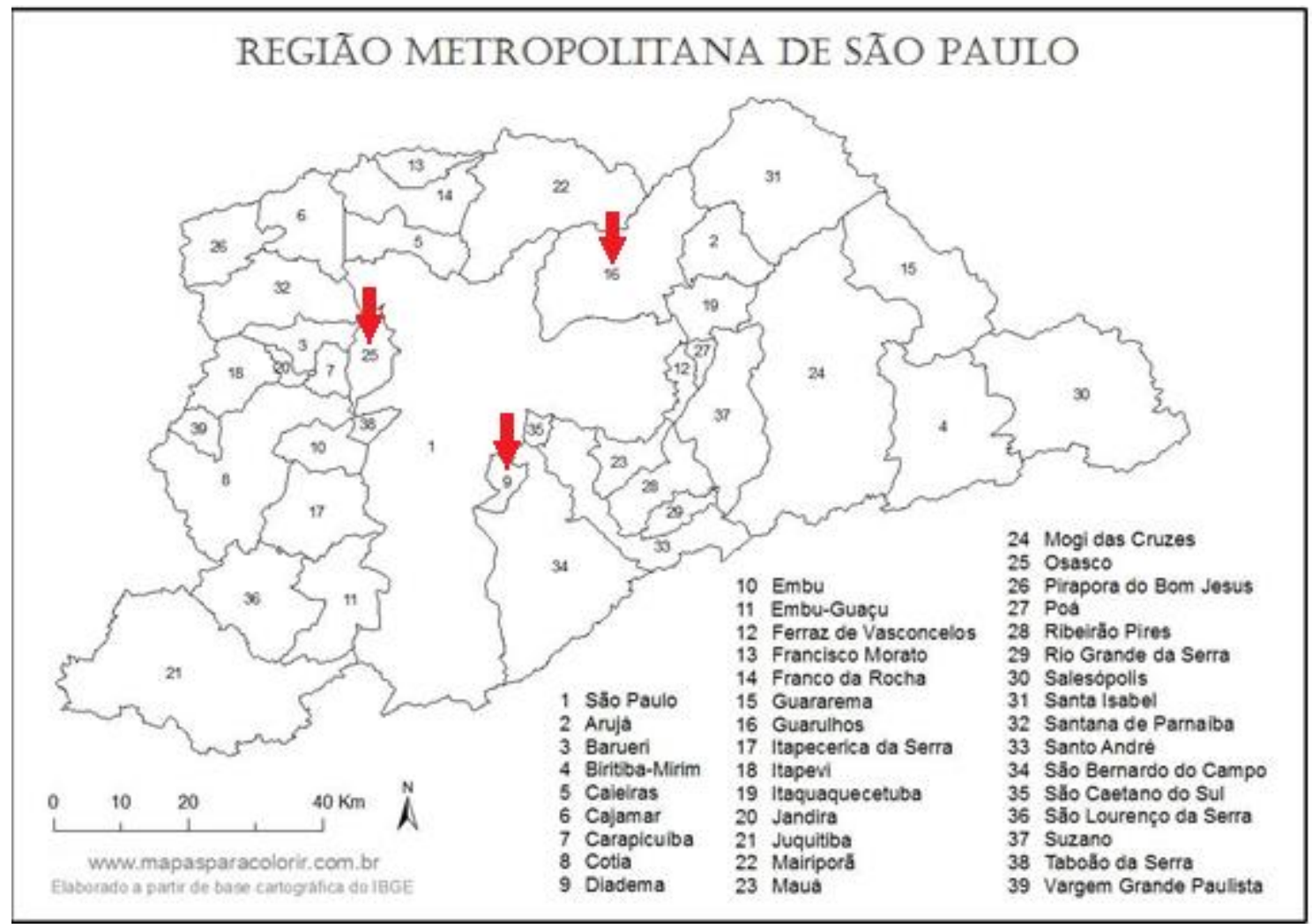

Fonte: (GALVÃO, V. C., 2018).

Nota: a imagem original, sem adição de setas vermelhas, acima pode ser encontrada no sítio eletrônico <http://www.mapasparacolorir.com.br/mapa/estado/sp/estado-sao-paulomesorregiao-metropolitana.png>

A distribuição espacial das lojas da RLH se dá pelo fato que, conforme dito na metodologia anteriormente, cada CR possui um conjunto de lojas para supervisionar. Os CR que participaram da pesquisa serão referidos como CR1 e CR2. O CR1 coordena cinco lojas (números até 10 serão escritos por extenso e números acima de dez em algarismos arábicos para esse tópico do trabalho), enquanto que o CR2 coordenava dez lojas. As lojas de CR1, segundo a sua 
localização nos mapas, foram: Guarulhos, Tucuruvi, Vila Guilherme, Aricanduva e José Bonifácio. Já as lojas de CR2 estavam localizadas em: Jabaquara, Saúde, Jardim São Luís, Santo Amaro, Diadema, Campo Grande, Osasco, Jaguaré, Pinheiros e Jardim Paulista.

As lojas descritas acima necessitam de um RT por se tratar de estabelecimentos comerciais de alimentos, conforme a Portaria CVS 5, de 09 de abril de 2013, do Centro de Vigilância Sanitária, vigente até o presente momento da execução da pesquisa, nos artigos 16 ao 19 (BRASIL, 2013). Sete RTs participaram do estudo. Todos formados em Medicina Veterinária. Essa categoria profissional possui atribuição de responsabilidade técnica de estabelecimentos comerciais de alimentos. Segundo o Conselho Regional de Medicina Veterinária de São Paulo, esta classe pode comprometer o seu tempo profissional em no máximo 48 horas semanais para atendimento das necessidades do estabelecimento (CRMV-SP, 2014). Por isso, os sete RTs se distribuíram entre as lojas da RLH participante do estudo, a fim de assumirem a parte técnica do estabelecimento.

Adotando o mesmo procedimento dos CR, os RT serão identificados por números. O RT1 era responsável pela loja de Guarulhos; RT2 pelas lojas Aricanduva, Vila Guilherme e Tucuruvi; RT3 pela loja de José Bonifácio; RT4 pelas lojas de Jabaquara, Saúde e Jardim São Luís; RT5 pelas lojas de Santo Amaro, Diadema e Campo Grande; RT6 pela loja de Osasco; RT7 pelas lojas de Jaguaré, Pinheiros e Jardim Paulista. No Quadro 2, está contida a distribuição das lojas segundo os RTs e CRs.

Quadro 2 - Distribuição das quinze lojas da rede de lojas hipermercado segundo os seus respectivos Responsáveis Técnicos, Coordenadores de Região e Localização nas Figuras 5 e 6 - São Paulo, 2018

\begin{tabular}{|c|c|c|c|c|c|}
\hline \multirow{2}{*}{$\begin{array}{c}\text { Coordenadores de } \\
\text { Região }\end{array}$} & $\begin{array}{c}\text { Responsável } \\
\text { Técnico }\end{array}$ & $\begin{array}{c}\text { Lojas da Rede } \\
\text { Hipermercado }\end{array}$ & Figura & $\begin{array}{c}\text { Número } \\
\text { no mapa }\end{array}$ & $\begin{array}{c}\text { Zonas do } \\
\text { Município de SP }\end{array}$ \\
\cline { 4 - 6 } & RT1 & Guarulhos & 6 & 16 & - \\
\cline { 3 - 6 } & \multirow{3}{*}{ RR1 } & Aricanduva & 5 & 21 & ZL \\
\cline { 3 - 6 } & & Vila Guilherme & 5 & 17 & ZN \\
\cline { 3 - 6 } & \multirow{2}{*}{ RT3 } & Tucuruvi & 5 & 16 & ZN \\
\hline \multirow{2}{*}{ CR2 } & \multirow{2}{*}{ RT4 } & José Bonifácio & 5 & 34 & ZL \\
\cline { 3 - 6 } & & Jabaquara & 5 & 62 & ZS \\
\hline
\end{tabular}




\begin{tabular}{|c|c|c|c|c|c|}
\hline \multirow{3}{*}{$\begin{array}{c}\text { Coordenadores de } \\
\text { Região }\end{array}$} & \multirow{2}{*}{$\begin{array}{c}\text { Responsável } \\
\text { Técnico }\end{array}$} & $\begin{array}{c}\text { Lojas da Rede } \\
\text { Hipermercado }\end{array}$ & \multicolumn{3}{|c|}{ Localização } \\
\cline { 3 - 5 } & \multirow{3}{*}{ RT5 } & Jardim São Luís & 5 & 65 & Número \\
no mapa & $\begin{array}{c}\text { Zonas do } \\
\text { Município de SP }\end{array}$ \\
\cline { 3 - 6 } & & Santo Amaro & 5 & 72 & ZS \\
\cline { 3 - 6 } & RT6 & Campo Grande & 5 & 53 & ZS \\
\cline { 3 - 6 } & \multirow{2}{*}{ RT7 } & Osasco & 6 & 25 & - \\
\cline { 3 - 6 } & & Jaguaré & 5 & 91 & ZO \\
\cline { 3 - 6 } & Pinheiros & 5 & 85 & ZO \\
\cline { 3 - 6 } & Jardim Paulista & 5 & 64 & ZS \\
\hline
\end{tabular}

Fonte: GALVÃO (2018).

Legenda: Coordenadores de Região - CR; Responsável técnico - RT; ZL - Zona Leste; ZN - Zona Norte; ZO - Zona Oeste; ZS - Zona Sul.

\subsection{RESULTADOS DA SEÇÃO DEMOGRÁFICA DO QUESTIONÁRIO}

As análises de frequência absolutas e relativas foram conduzidas para avaliar os dados demográficos, conforme apresentados na Tabela 2. A frequência absoluta se refere a quantidade de respostas para cada variável demográfica, enquanto a frequência relativa foi calculada a razão entre quantidade de respostas e o total de respondentes. Nota-se que a maioria dos participantes eram homens $(50,91 \%)$. Aproximadamente $95 \%$ dos participantes estavam entre 21 e 55 anos de idade, sendo o grupo 21-25 anos o com maior representatividade $(21,15 \%)$.

Tabela 2 - Perfil sócio-demográfico dos participantes do estudo ( $n=383$ ) - São Paulo, 2018

\begin{tabular}{lcc} 
Características & $\mathrm{n}$ & $\%$ \\
\hline Sexo & & \\
Feminino & 182 & $47,52 \%$ \\
Masculino & 195 & $50,91 \%$ \\
Idade & & \\
$18-20$ anos & 11 & $2,87 \%$ \\
$21-25$ anos & 81 & $21,15 \%$ \\
$26-30$ anos & 59 & $15,40 \%$ \\
$31-35$ anos & 65 & $16,97 \%$ \\
$36-40$ anos & 59 & $15,40 \%$
\end{tabular}




Características
$41-45$ anos
$46-50$ anos
$51-55$ anos
$56-60$ anos
$61-65$ anos
$66-70$ anos
$71-75$ anos
$76-80$ anos

\begin{tabular}{cc}
$\mathrm{n}$ & $\%$ \\
\hline 37 & $9,66 \%$ \\
30 & $7,83 \%$ \\
20 & $5,22 \%$ \\
7 & $1,83 \%$ \\
3 & $0,78 \%$ \\
1 & $0,26 \%$ \\
0 & $0,00 \%$ \\
0 & $0,00 \%$
\end{tabular}

Origem de nascimento

Norte

$0,52 \%$

Nordeste

$36,29 \%$

Centro-Oeste

$0,00 \%$

Sudeste

$57,70 \%$

Sul

DF

Estrangeiro

$1,83 \%$

$0,00 \%$

$0,78 \%$

\section{Escolaridade}

Primário incompleto

$0,26 \%$

Primário completo

$0,52 \%$

Fundamental incompleto

$2,09 \%$

Fundamental completo

$9,14 \%$

Médio incompleto

$6,79 \%$

Médio completo

$60,57 \%$

Superior incompleto

$9,14 \%$

Superior completo

$7,31 \%$

Pós-graduado

$0,52 \%$

Ensino Técnico

$0,52 \%$

Experiência na área de alimentos (anos ou meses)

Sem experiência prévia em outra empresa

$35,25 \%$

$<6$ meses

$3,66 \%$

6 meses a 1 ano

$7,05 \%$

1-2 anos

$12,27 \%$

3-5 anos

6-10 anos

$4,88 \%$

11-15 anos

16-20 anos

$11,23 \%$

21-25 anos

26-30 anos

31-35 anos

$3,66 \%$

$2,09 \%$

$0,78 \%$

$0,52 \%$

$0,26 \%$

\section{Experiência na "Empresa X" (anos ou meses)}

$<6$ meses

1-2 anos

3-5 anos

6-10 anos 


\begin{tabular}{|c|c|c|}
\hline Características & $\mathrm{n}$ & $\%$ \\
\hline $11-15$ anos & 37 & $9,66 \%$ \\
\hline $16-20$ anos & 32 & $8,36 \%$ \\
\hline $21-25$ anos & 12 & $3,13 \%$ \\
\hline $26-30$ anos & 5 & $1,31 \%$ \\
\hline $31-35$ anos & 0 & $0,00 \%$ \\
\hline \multicolumn{3}{|l|}{ Cargo ou Função } \\
\hline Operador de loja (total) & 324 & $84,59 \%$ \\
\hline Peixaria & 26 & $6,79 \%$ \\
\hline Padaria & 72 & $18,80 \%$ \\
\hline Salsicharia & 48 & $12,53 \%$ \\
\hline Açougue & 66 & $17,23 \%$ \\
\hline FLV & 29 & $7,57 \%$ \\
\hline Cafeteria & 16 & $4,18 \%$ \\
\hline Não identificou o setor & 67 & $17,49 \%$ \\
\hline Gerenciador (total) & 33 & $8,61 \%$ \\
\hline Peixaria & 4 & $1,04 \%$ \\
\hline Padaria & 5 & $1,31 \%$ \\
\hline Salsicharia & 2 & $0,52 \%$ \\
\hline Açougue & 5 & $1,31 \%$ \\
\hline FLV & 4 & $1,04 \%$ \\
\hline Cafeteria & 0 & $0,00 \%$ \\
\hline Não identificou o setor & 13 & $3,39 \%$ \\
\hline Estagiário de Segurança de alimentos & 12 & $3,13 \%$ \\
\hline Responsável técnico & 7 & $1,82 \%$ \\
\hline
\end{tabular}

Fonte: GALVÃO (2018).

Quanto à origem dos trabalhadores, a maioria pertencia à região Sudeste $(57,70 \%)$ e Nordeste $(36,29 \%)$ do Brasil. Ainda, dois colaboradores da região Norte, nenhum do Distrito Federal e Centro-Oeste. Três colaboradores apresentaram-se estrangeiros, vindos do Haiti.

O item relativo à escolaridade nos mostra que a maioria dos participantes do estudo possuíam ensino médio completo $(60,57 \%)$ e poucos apresentaram ensino médio incompleto (6,79\%). Apesar de apresentar valores menos representativos, este estudo mostra que $9,14 \%$ dos participantes possuíam ensino superior incompleto e vinte e oito pessoas $(7,31 \%)$ conseguiram concluir ensino superior. Entretanto, os dados mostram que cerca de doze por cento dos participantes possuíam nível escolar fundamental, em que aproximadamente nove por cento completaram essa etapa escolar. Apenas um participante afirmou possuir 
nível primário incompleto e dois afirmaram ter completado o primário. Dois participantes afirmavam ter cursado ensino técnico (mas não discriminaram em qual área de formação) e outros dois participantes realizaram curso de pós-graduação.

Ao ser perguntado se o participante da pesquisa possuía alguma experiência pregressa na área de alimentos, o intuito desse questionamento foi verificar se o colaborador tem alguma experiência com a manipulação de alimentos. Uma parte considerável dos participantes afirmou não ter experiência anterior em manipulação de alimentos (35,25\%). Abaixo de seis meses de experiência anterior com alimentos estavam 14 pessoas e, entre seis meses e um ano, 27 pessoas. Cerca de $38 \%$ dos participantes afirmaram ter entre 1 a 10 anos de experiência anterior na área de alimentos. Aproximadamente 7\% dos participantes tinham experiência anterior com alimentos entre onze e trinta e cinco anos, sendo apenas uma pessoa que afirmou possuir entre 31-35 anos de experiência pregressa.

Quando indagado sobre o tempo de experiência na empresa em que houve a pesquisa, a maioria dos participantes possuía entre seis meses e dez anos de experiência (72,59\%). O grupo mais representativo dessa maioria tinham 3-5 anos de experiência na empresa $(27,42 \%)$. Os participantes com menos de seis meses de experiência tinham cerca de $4 \%$ de representatividade. Enquanto isso, os que possuíam entre 11-20 anos são 18,02\% da amostra. Os mais experientes na empresa - entre 21 a 30 anos - representavam 4,44\%. Não houve participantes com experiência na empresa acima de 31 anos.

Em relação ao cargo/função e setor em que trabalha, a maioria dos participantes eram OP (84,59\%). Trinta e três participantes eram GC desses operadores de loja (8,61\%). Doze participantes eram ES cursando ensino superior. Sete RTs participaram do estudo e três outros colaboradores de outras áreas da empresa também participaram do estudo, mas como esses colaboradores não estavam envolvidos diretamente com a manipulação de alimentos eles não foram considerados para a análise.

Para visualizar melhor os cargos ou funções e os setores nos quais os participantes ocupavam, seguem as Figuras 7 e 8 abaixo. Houve uma parcela representativa de OP $(17,49 \%)$ e GC (3,39\%) que não identificaram o setor em que trabalhavam. 
Figura 7 - Total de participantes na pesquisa, segundo seu Cargo ou Função - Setor da Empresa - São Paulo, 2018

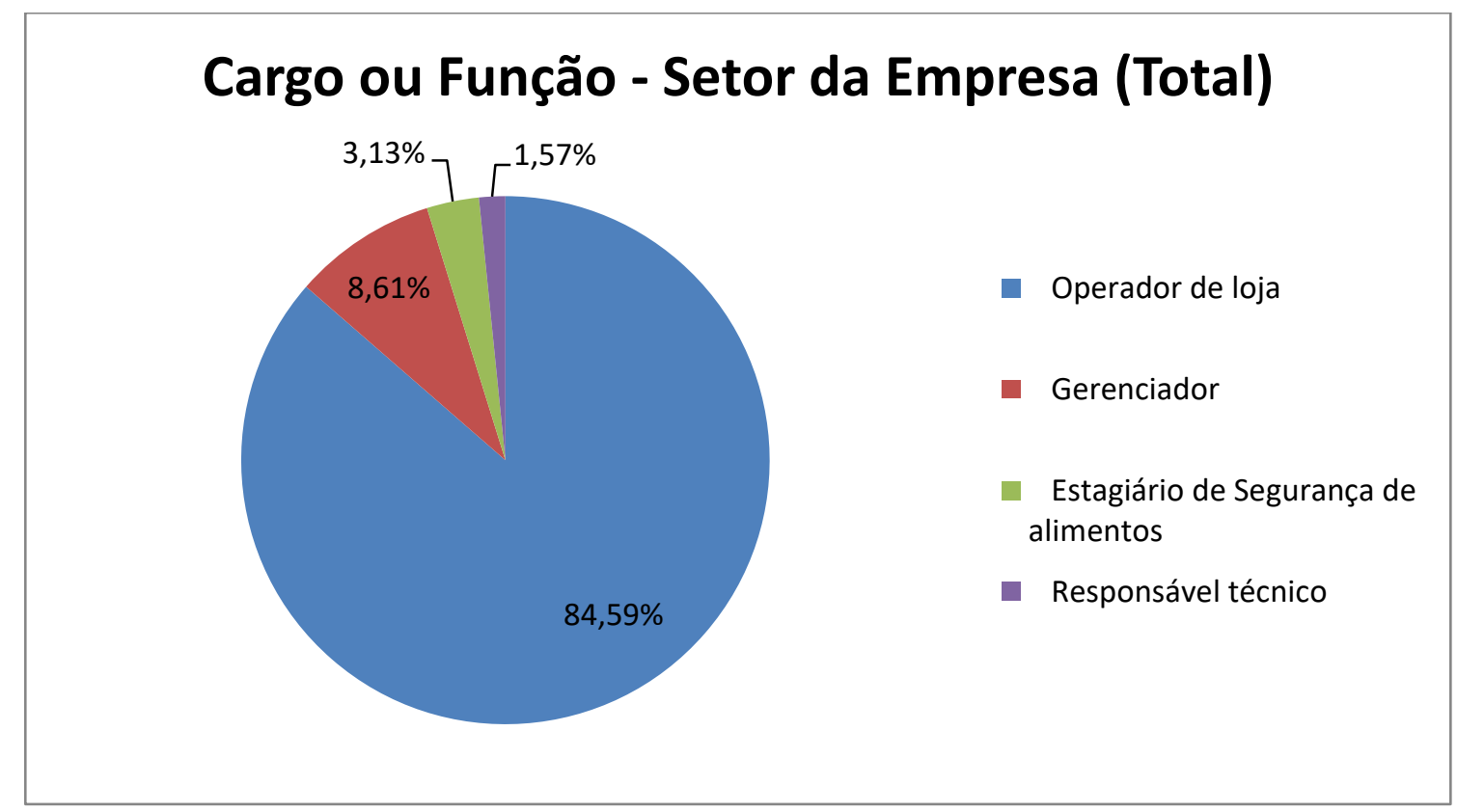

Fonte: (GALVÃO, V. C., 2018).

Figura 8 - Participantes da pesquisa categorizados em Operadores de Loja e Gerenciadores, subdivididos segundo os setores de manipulação de alimentos - São Paulo, 2018

\section{Operadores de loja}

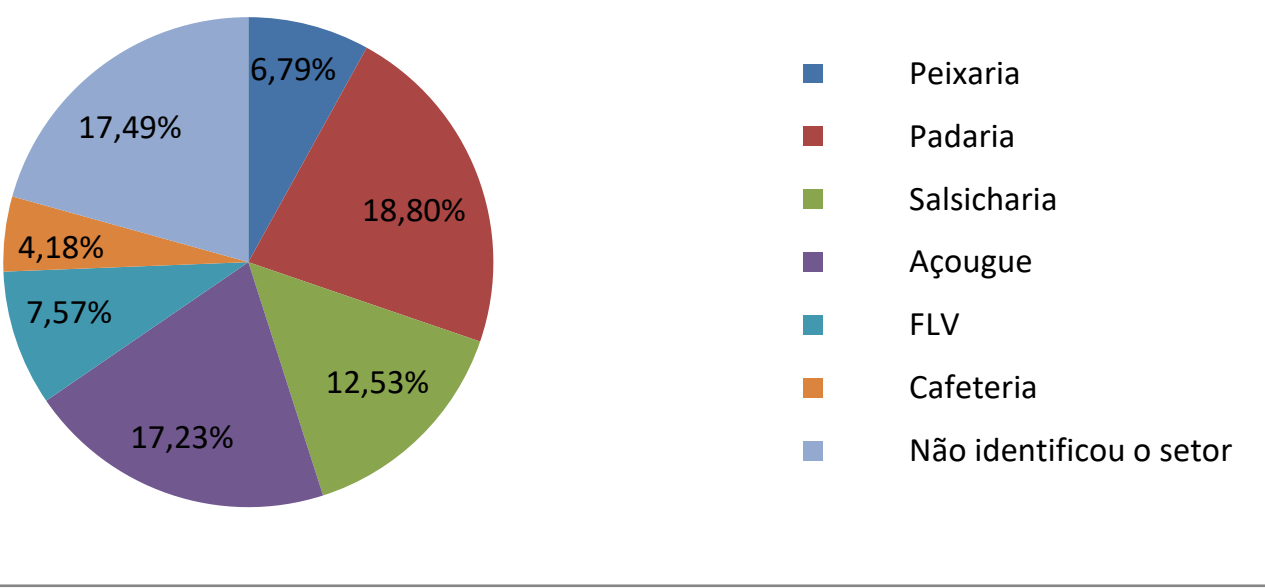


Fonte: (GALVÃO, V. C., 2018).

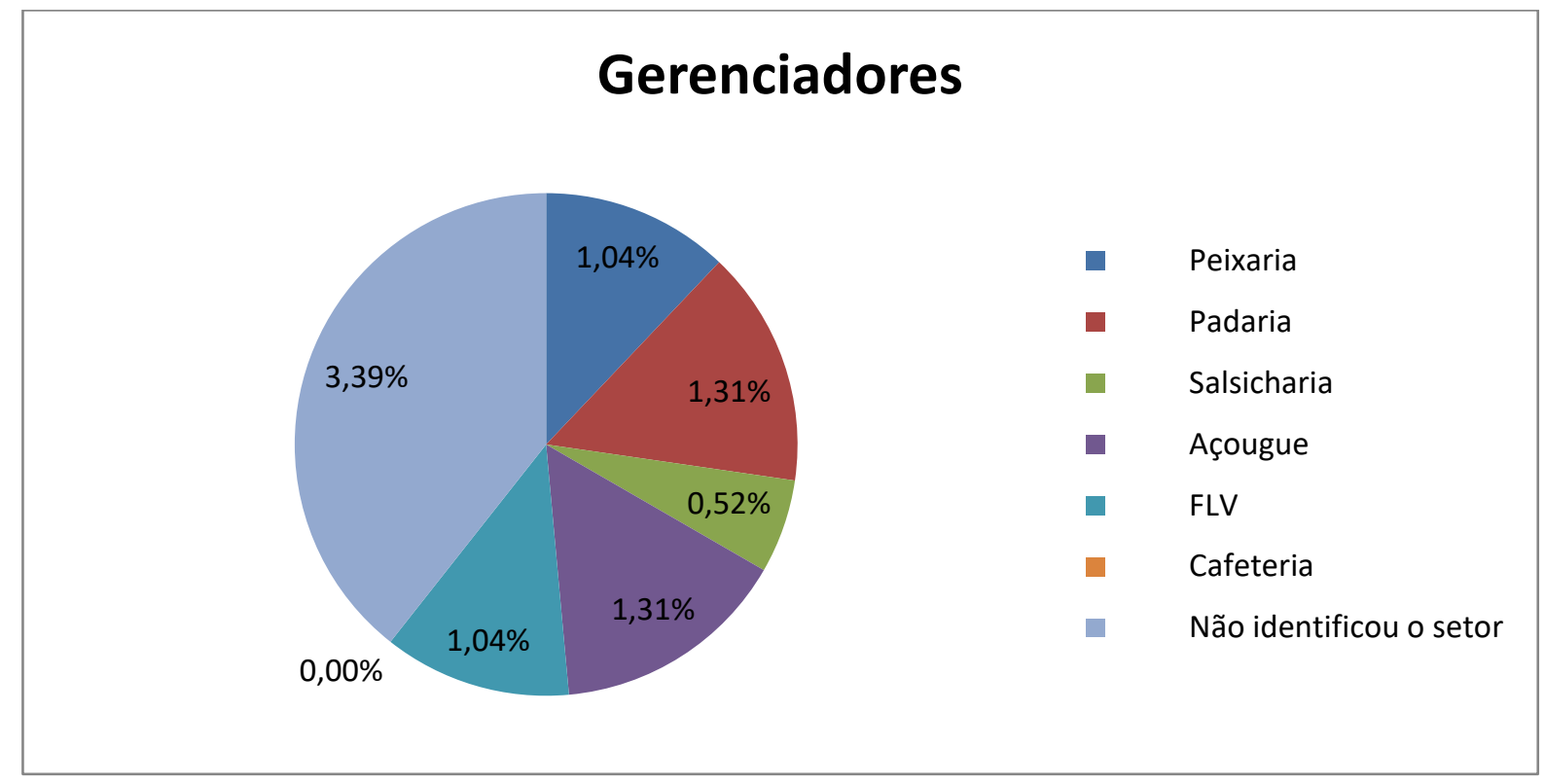

Fonte: (GALVÃO, V. C., 2018). 


\subsection{RESULTADOS DA SEÇÃO SOBRE CSA DO QUESTIONÁRIO}

\subsubsection{Resultados das frequências absolutas e relativas}

O questionário desenvolvido por Ungku Fatimah (2013) foi dividido em duas seções, uma parte demográfica e uma sobre os fatores de CSA. Essa última parte, fora desenvolvida em escala Likert de sete pontos para que os próprios participantes colocassem a sua percepção sobre CSA. Com isso, pode-se analisar os dados de frequência absoluta e relativa através do grau de concordância ou discordância das respostas dos participantes para cada item do questionário (Gráficos 1 e 2).

Os gráficos mostram uma tendência de concordância para a maioria dos itens (1 a 29 e 31). Essa tendência indica CSA positiva para a maioria dos itens. Entretanto, os itens 6 e 30 apresentaram tendência de CSA negativa.

O item 6 foi o que apresentou maior grau de discordância entre os quatro itens. O conteúdo do item 6 - "Acredito que as políticas e os procedimentos de segurança alimentar da empresa são nada mais do que uma obrigação caso haja um problema com a legislação" - mostrou que os participantes entendem a SA como uma obrigação ou um fardo no cotidiano, apenas para que a empresa não tenha conflito com as autoridades.

O item 30, "Quando estamos sob pressão para terminar a produção de alimentos, os gerentes às vezes nos dizem para trabalhar mais rápido, 'pulando' algumas regras de segurança dos alimentos", revelou uma cooperação entre GC e OP contra a segurança dos alimentos em prol da produtividade.

Os resultados de Moda e Mediana foram apresentados na Tabela 5. A moda indica qual das respostas apresentou maior frequência e a mediana é o número no centro de um grupo de números (isto é, metade dos números possui valores que são maiores do que a mediana e a outra metade possui valores menores).

O resultado da Moda para o item 29 apresentou valor 1, ou seja, alto grau de discordância. O conteúdo do referido item foi "O número de funcionários programados em cada turno é adequado para que eu possa fazer meu trabalho e 
manipular alimentos com segurança". Mas, o critério da maioria (conjunto de respostas de concordância) é mais relevante para CSA do que a moda. Por isso, a CSA para esse item foi considerada positiva.

O item 30 apresentou diferença na interpretação do resultado para dois parâmetros (moda e mediana), pois enquanto a moda apresentou resultado 7, a mediana resultou em valor 4. Mas, assim como no caso anterior, prevalece a interpretação pelo conjunto de respostas de concordância. 
Gráfico 1 - Grau de Concordância (Frequência absoluta) de cada item do Questionário sobre Cultura de Segurança de Alimentos - São Paulo, 2018

\section{Grau de Concordância (Frequência absoluta) de cada item do Questionário sobre Cultura de Segurança de Alimentos}

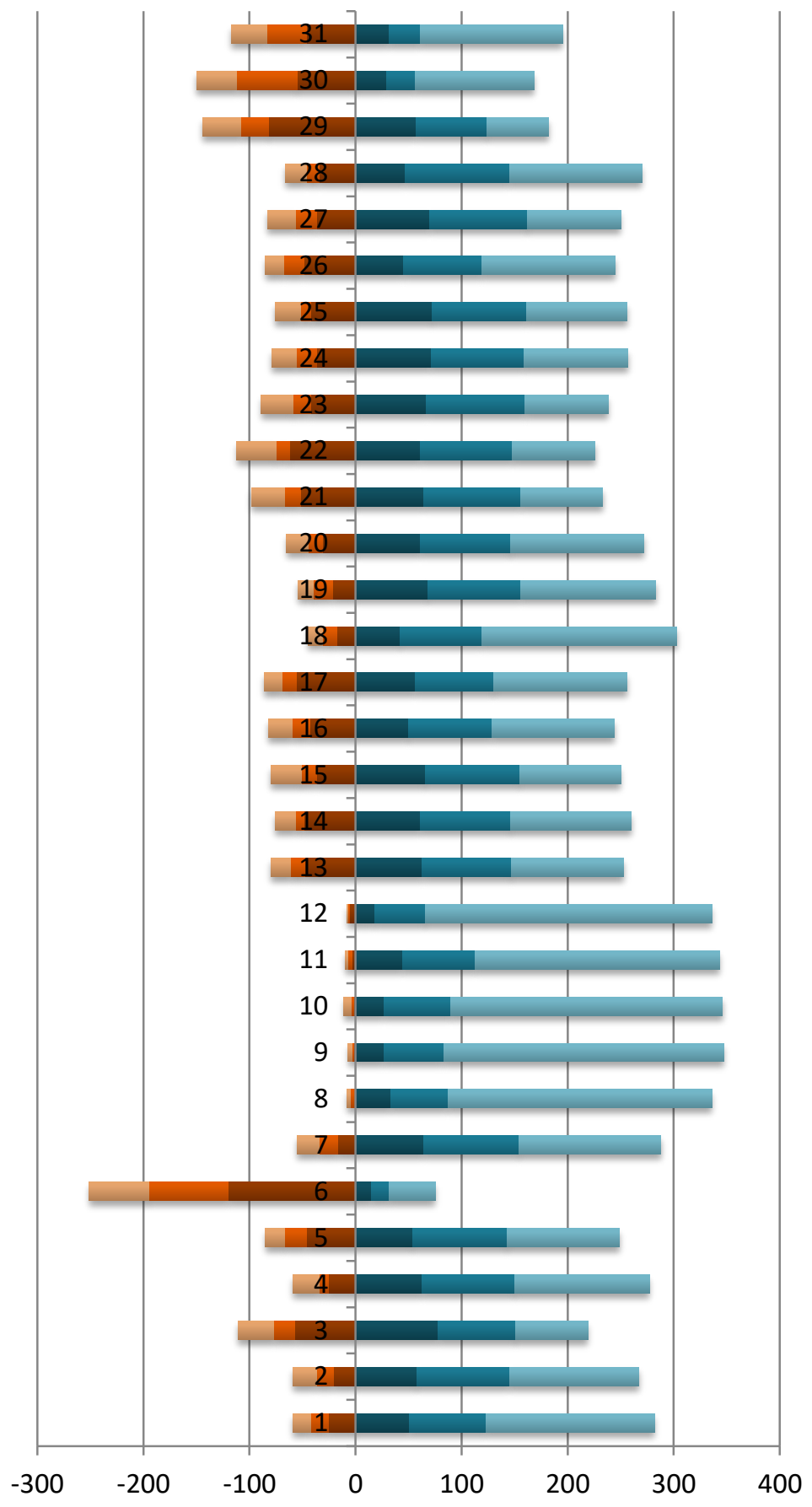

Discordo muito

Discordo moderadamente

Discordo pouco

Concordo pouco

- Concordo moderadamente

Concordo muito

Fonte: (GALVÃO, V. C., 2018). 
Gráfico 2 - Grau de Concordância (Frequência relativa) de cada item do Questionário sobre Cultura de Segurança de Alimentos - São Paulo, 2018

\section{Grau de Concordância (Frquência relativa) de cada item do Questionário sobre Cultura de Segurança de Alimentos}

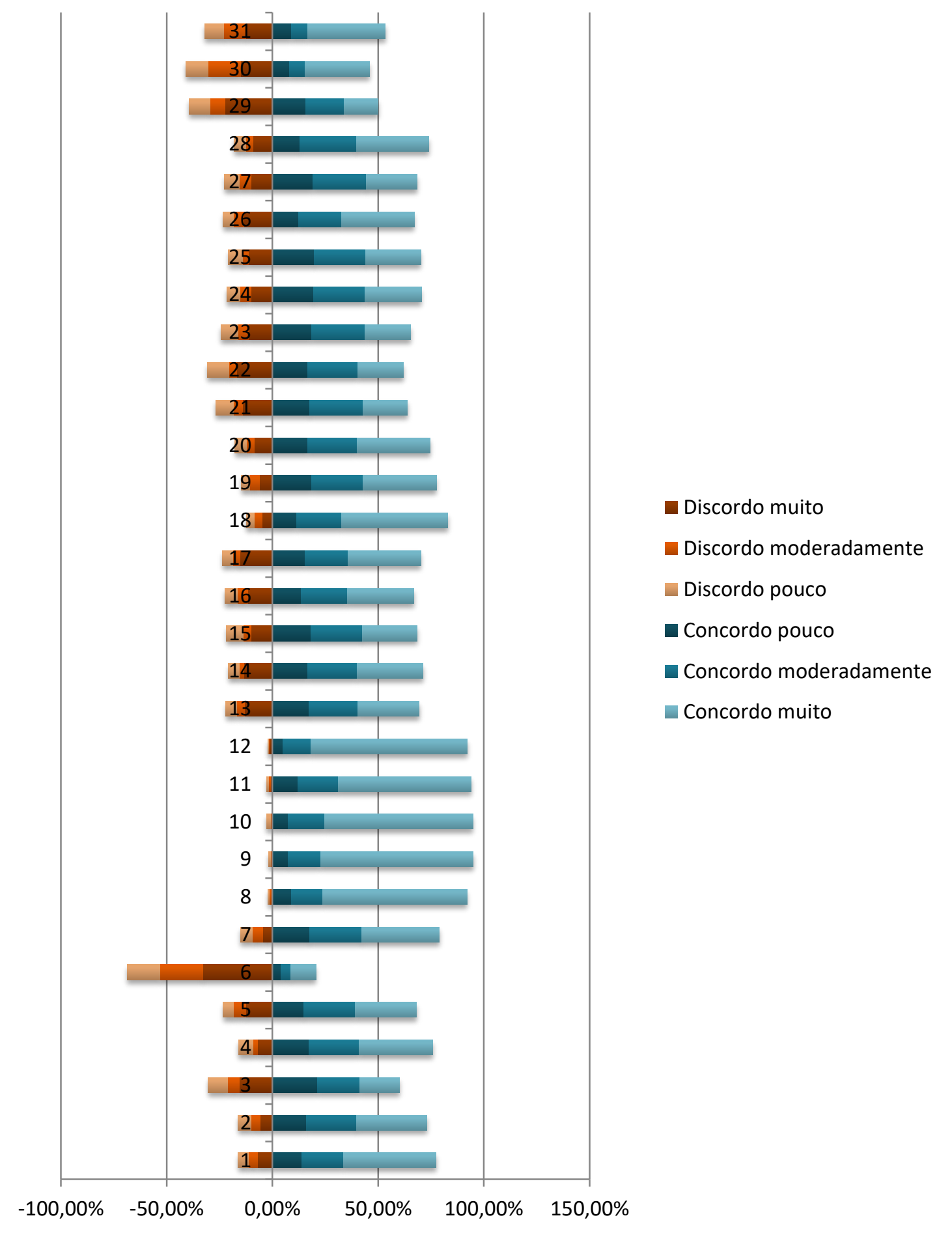

Fonte: (GALVÃO, V. C., 2018). 
Analisando os fatores de CSA individualmente através das frequências absolutas e relativas pode-se observar na Tabela 3 que o Fator 1 - Apoio dos gerentes e colaboradores - possui alta concordância e, portanto, CSA positiva em relação ao apoio mútuo entre os colaboradores para a prática segura de manipulação de alimentos nesse fator; o Fator 2 - Comunicação - também ocorre alta concordância, apesar do item 3 apresentar uma alta frequência de respostas "concordo pouco", revelando que ocorre a transferência de mensagens e conhecimentos sobre SA; o Fator 3 - Auto comprometimento - apresentou alta frequência de respostas "concordo muito", ou seja, mais de $60 \%$ dos participantes se percebem comprometidos com a segurança de alimentos; Fator 4 - Suporte do ambiente - houve alta frequência de concordância para este fator o que revela que há disponibilidade de infraestrutura para ocorrer SA; o Fator 5 - Pressão no trabalho - indicou CSA positiva para os itens 27 e 28, pois há alta frequência de respostas "concordo muito", porém, como já dito, o item 29 apresentou presença de CSA negativa, mas o conjunto de itens "discordo" possui uma frequência absoluta mais baixa do que o conjunto "concordo", assim esse item se caracteriza como CSA positiva; e o Fator 6 - Julgamento baseado em risco - mostrou que o item 6 transparece uma CSA negativa, enquanto que os itens 30 e 31 foram revelados pela amostra como sendo CSA positiva, apesar da frequência absoluta do item 30 tanto do conjunto "discordo" quanto "concordo" serem próximas $(150$ e 168 respectivamente).

A frequência de respostas "Indiferente" (4) ficou abaixo de 10\%, com exceção dos itens 30 e 31 que apresentaram ambos 11,8\%. Isso pode ter ocorrido devido aos conteúdos dos itens induzirem os participantes a uma atitude defensiva para responder as afirmações. 
Tabela 3 - Resultados de Frequência absoluta e relativa, Moda e Mediana para cada ponto da escala Likert - São Paulo, 2018

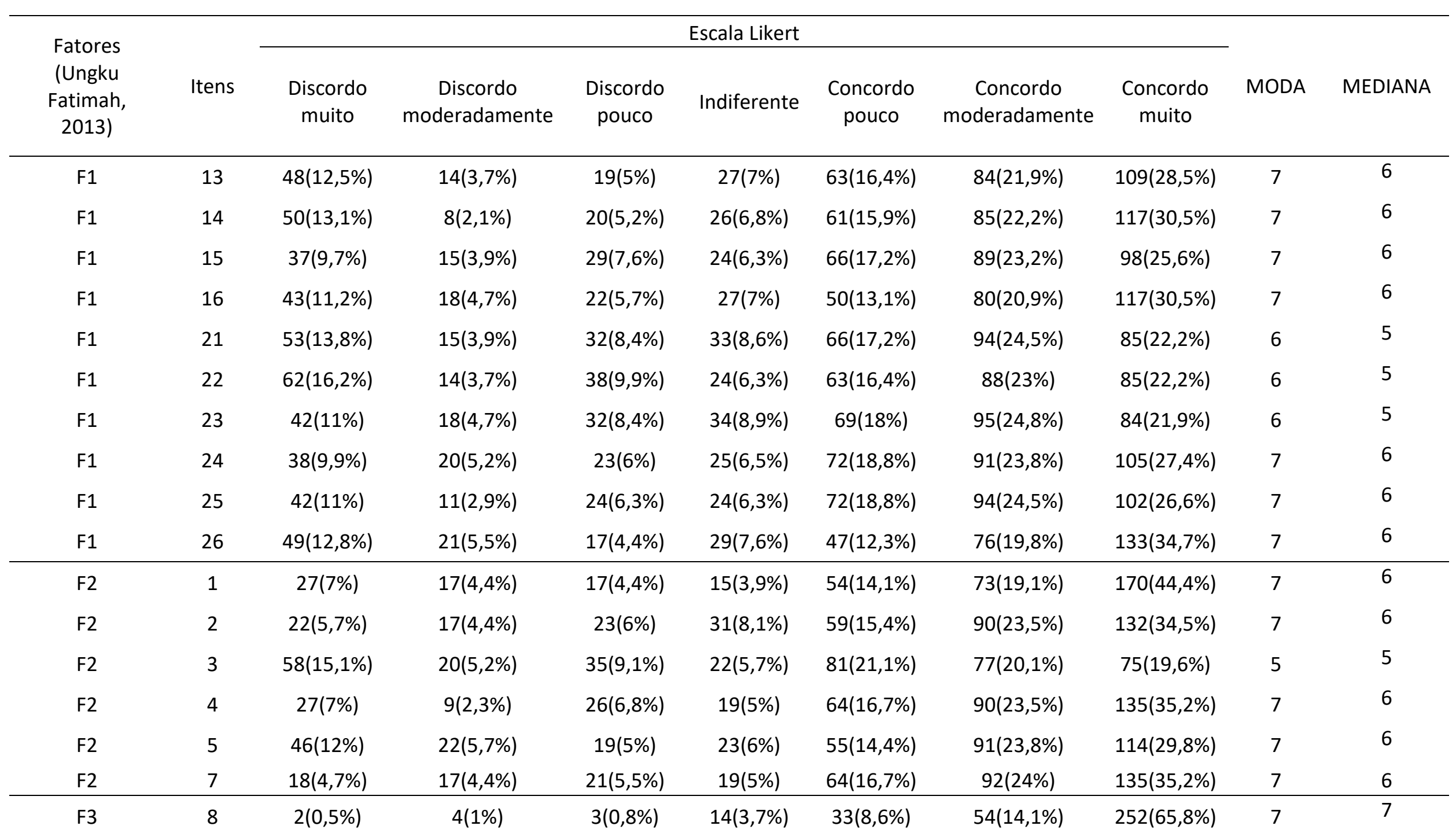




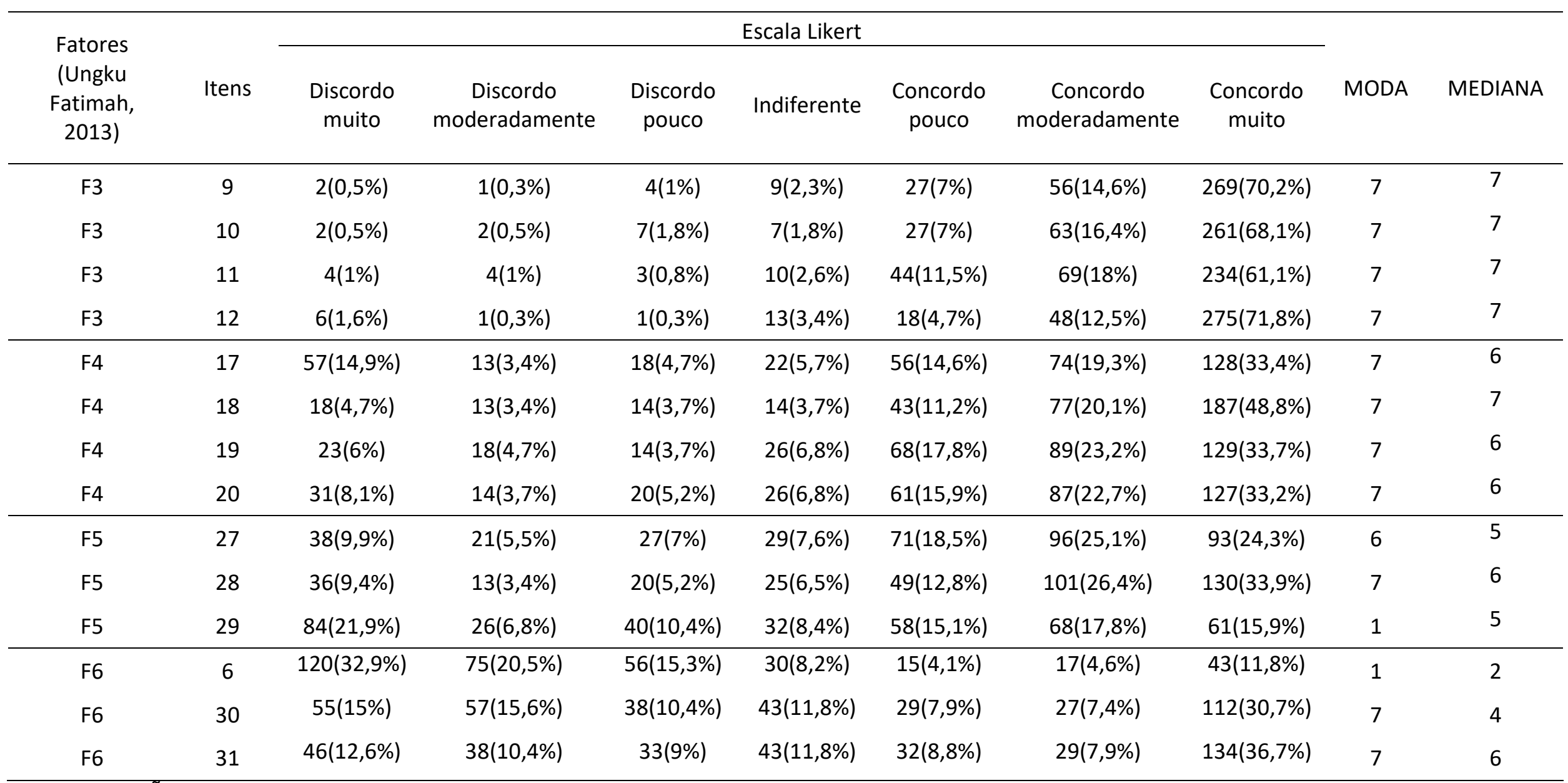

Fonte: GALVÃO (2018). 
A fim de esmiuçar o comportamento dos fatores de CSA em cada loja, os resultados da média da Moda para cada fator foi calculado (Tabela 4). Os resultados mostraram que as lojas 1, 4, 6, 7, 10, 11 e 15 apresentaram as respostas tendendo para a concordância, ou seja, positividade.

As lojas que obtiveram resultados indiferentes ou negativos em um ou mais fatores podem ser interpretados como descrito a seguir.

O Fator 1 - Apoio dos gerentes e colaboradores - demonstrou que as atividades gerenciais e práticas dos colaboradores não estavam adequadas, evidenciando falta de harmonia entre as partes para assegurar alimentos seguros.

A Comunicação (Fator 2) apresentou resultado indiferente em duas lojas. Isso quer dizer que a comunicação não interfere na transferência de informação entre as pessoas. Ou então, os participantes não quiseram se posicionar sobre esse assunto, podendo indicar um ponto crítico na loja.

O Fator 5 - Pressão no trabalho - que resultou valor indiferente pode refletir que esse fator não interfere nem positivamente ou negativamente (indiferente) ou que os colaboradores se sentem pressionados para realizar suas tarefas e isso prejudica a SA (negatividade).

O Fator 4 - Suporte do ambiente - apresentou resultado negativo para a loja 12. A interpretação desse resultado mostrou que os participantes declaram que a qualidade da infraestrutura necessária para realizar a SA é insuficiente.

O Julgamento Baseado em Risco (Fator 6) avalia como no dia a dia o colaborador realiza a avaliação do risco das suas atividades. No caso de negatividade, os colaboradores estavam assumindo um alto risco para SA conforme os itens respectivos a esse fator.

Tabela 4 - Resultado da média da Moda para cada Fator de CSA em cada loja - São Paulo, 2018

\begin{tabular}{ccccccc}
\hline Loja & $F 1$ & $F 2$ & $F 3$ & $F 4$ & $F 5$ & $F 6$ \\
\hline 1 & 7 & 6,8 & 7 & 6,8 & 6,6 & 5 \\
2 & 6,5 & 6,3 & 7 & 7 & 4,3 & 5 \\
3 & 6,4 & 7 & 7 & 7 & 7 & 3,3 \\
4 & 6,3 & 6,6 & 7 & 7 & 7 & 7 \\
5 & 2,6 & 5,1 & 7 & 5,2 & 4,6 & 5 \\
6 & 5,2 & 5,6 & 7 & 6,5 & 5 & 5 \\
7 & 6,4 & 6,8 & 7 & 6,5 & 6,6 & 5 \\
8 & 6,8 & 6,3 & 7 & 6,5 & 5,6 & 1,6 \\
9 & 2,6 & 4,6 & 7 & 7 & 3,6 & 3,6 \\
10 & 6,3 & 5,6 & 7 & 6,5 & 5,6 & 5 \\
11 & 5,3 & 6,5 & 7 & 6,7 & 6 & 5 \\
12 & 1 & 4 & 7 & 2,5 & 3 & 7
\end{tabular}




\begin{tabular}{ccccccc}
\hline Loja & F1 & F2 & F3 & F4 & F5 & F6 \\
\hline 13 & 6,9 & 7 & 7 & 7 & 5 & 3 \\
14 & 5,5 & 5 & 7 & 5 & 5,3 & 3,3 \\
15 & 6,5 & 6,8 & 7 & 7 & 6,3 & 5 \\
\hline
\end{tabular}

Fonte: GALVÃO (2018).

\subsubsection{Resultado dos itens e fatores de CSA por meio de Média e Desvio Padrão}

Segundo Griffith (2010a), é fundamental decidir como os dados sobre CSA serão utilizados e para quem ele será apresentado. Antes da apresentação da discussão dos resultados analisados através da frequência e somatório das escalas Likert, se faz necessário apresentar ao leitor que se pode conduzir a análise dos dados sobre a CSA por medidas de tendência central (média e desvio padrão).

Há uma grande discussão por trás da escala Likert que se estende por mais de 50 anos na literatura (CARIFIO, 2008). Alguns pesquisadores defendem que a escala Likert seja analisada como sendo ordinal. Outros defendem que a análise deve considerar a escala como intervalar. A principal diferença entre elas é que uma escala ordinal considera que os pontos de uma escala são dispostos em ordem de intensidade, mas que as distâncias entre os pontos não são mensuráveis. Enquanto que a intervalar considera que as distâncias entre os pontos são mensuráveis, ou seja, seria possível calcular o quão distante os pontos estão separados (WAKITA, 2004; COELHO, 2007; NORMAN, 2010; WAKITA, 2012; GAIL, 2013).

Por isso, buscou-se analisar os dados do presente estudo considerando a escala de Ungku Fatimah sendo intervalar. No Gráfico 3, está contido os dados de média, desvio padrão e moda dos fatores de CSA. A moda é uma medida da frequência mais alta de um resultado. $O$ intuito de inserir a moda ao lado da média e desvio padrão é comparar as medidas de tendência central com uma medida de frequência.

Ao analisarmos os dados podemos notar que do item 1 ao 28 , os resultados entre média e moda são diferentes, o que corrobora a condução da análise sobre as frequências de respostas. $\mathrm{O}$ item 6 apresenta um comportamento em que o valor da média é superior ao valor da moda. Isso se dá porque as frequências absolutas do conjunto de respostas "discordo" (escala 1, 2 e 3) e o 
conjunto de "concordo" (escala 5, 6 e 7) são próximos. Portanto, quando a média é calculada, o resultado posiciona-se em um valor maior que a moda.

O item 29 apesar da moda ter sido 1 ("Discordo muito") foi categorizado positivo para CSA, como já visto anteriormente. Os itens 30 e 31 apresentaram uma diferença maior entre os respectivos valores de média. Entretanto, o item 30 mostrou equilíbrio entre o conjunto de frequências absolutas "discordo" e "concordo". 
Gráfico 3 - Média, Desvio padrão e Moda das respostas em escala Likert de cada item do questionário sobre Cultura de Segurança de Alimentos São Paulo, 2018

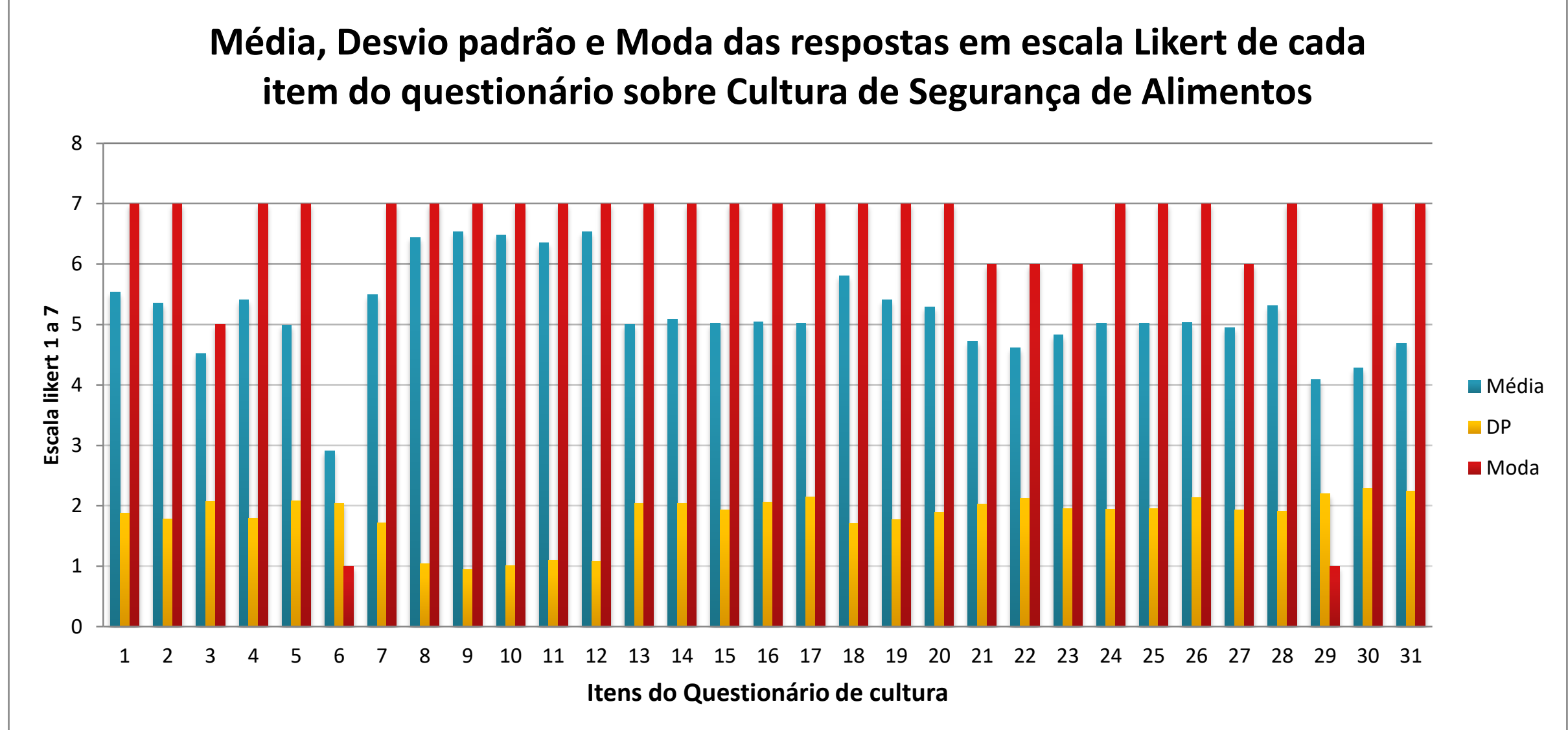

Fonte: (GALVÃO, V. C., 2018). 
Quando se analisa as médias, desvios padrões e moda de cada fator individualmente nota-se diferenças nos valores e que esses valores representam diferentes interpretações para os mesmos fatores. A Tabela 5 apresenta os valores para média, desvio padrão e moda. O Fator 1 apresentou como média das respostas dos participantes do estudo valor de 4,9, ou seja, caracteriza-se como resposta "Indiferente". O Fator 2 a média indicou um padrão de resposta "Concordo pouco". O Fator 3, o padrão de resposta foi "Concordo moderadamente". O Fator 4 a média resultou valor de 5,4 ou "Concordo pouco". Tanto o Fator 5 quanto o Fator 6 apresentaram valores de média ao redor de quatro, ou seja, "Indiferente".

Os valores da Moda de cada fator de CSA mostraram a diferença entre conduzir uma interpretação por frequências e por médias. Apesar dos resultados das frequências serem menos centralizados e com menos poder de generalização para amostra, ele permite nos aproximar daquilo que realmente os participantes relataram nas suas respostas.

Tabela 5 - Média, Desvio Padrão e Moda de cada Fator de Cultura de Segurança de Alimentos - São Paulo, 2018

Fatores Itens correspondentes MÉDIA DP MODA

\begin{tabular}{lcccc}
$\begin{array}{l}\text { F1 - Apoio dos gerentes e } \\
\text { colaboradores }\end{array}$ & $13,14,15,16,21,22,23,24,25,26$ & 4,9 & 1,5 & 7 \\
F2 - Comunicação & $1,2,3,4,5,7$ & 5,2 & 1,4 & 7 \\
F3 - Autocomprometimento & $8,9,10,11,12$ & 6,5 & 0,7 & 7 \\
$\begin{array}{l}\text { F4 - Suporte do ambiente } \\
\text { (ambiente favorável) }\end{array}$ & $17,18,19,20$ & 5,4 & 1,5 & 7 \\
$\begin{array}{l}\text { F5 - Pressão no trabalho } \\
\text { F6 - Julgamento baseado em }\end{array}$ & $27,28,29$ & 4,8 & 1,7 & 5 \\
risco & & & & \\
\hline
\end{tabular}

Fonte: GALVÃO (2018). 


\subsubsection{Resultado da consistência interna do questionário}

Segundo Landis e Koch (1977), os valores de alfa de Cronbach revelam a consistência interna de um instrumento, os quais foram calculados para avaliar a confiabilidade do instrumento de pesquisa. Portanto, a finalidade da mensuração da consistência interna foi verificar se os itens medem o constructo ou o conceito que o questionário pretende diagnosticar. $O$ valor do alfa quanto mais próximo de 1 mais consistente o instrumento será. Conforme a Tabela 6, esses autores definem os valores de alfa que correspondem ao significado da consistência interna do questionário.

O valor de alfa dos 31 itens do questionário foi de 0,7957 caracterizandose como substancial. O valor de alfa dos fatores F1, F3, F4 e F5 foram maiores que 0,80, ou seja, uma consistência interna substancial. Os fatores F2 e F6 obtiveram valores de alfa, respectivamente, 0,78 e 0,59, o que representa para o F2 uma consistência interna substancial enquanto que para F6 a consistência interna foi moderada.

Tabela 6 - Valores de alfa de Cronbach para consistência interna de um questionário - São Paulo, 2018

\begin{tabular}{cc}
\hline Valor de alfa & Consistência interna \\
\hline$>0,8$ & Quase perfeito \\
De 0,8 a 0,61 & Substancial \\
De 0,6 a 0,41 & Moderado \\
De 0,4 a 0,21 & Razoável \\
$<0,21$ & Pequeno \\
\hline
\end{tabular}

Fonte:GALVÃO (2018). 


\subsubsection{Análise Fatorial Exploratória e Confirmatória da escala Likert}

A razão da utilização da análise fatorial exploratória (AFE) foi verificar em quantos fatores os itens do instrumento se dividem para comparar se eles se distribuíam no mesmo número de fatores do que os desenvolvidos pelo autor original do instrumento. Ou seja, essa análise foi aplicada com o objetivo de reduzir as variáveis (itens do instrumento), sintetizando-as e agrupando-as em um certo número de fatores (HAIR, 2009).

A AFE segue uma sequência de etapas de testes estatísticos, iniciandose pelo teste $\mathrm{KMO}$, em seguida, teste de Bartllet's, matriz de comunalidades, matriz de variância total explicada, matriz de componentes e matriz de componente rotacionada (Varimax).

Já a análise fatorial confirmatória (AFC) foi útil para identificar como os itens se distribuem quando se fixa o número de fatores, assim pode-se observar se 0 mesmo conjunto de itens permanece no mesmo fator que o autor do instrumento havia definido como sendo o fator que melhor o explica. A AFC também percorreu o mesmo trajeto que a exploratória, porém fixa-se o número de fatores nos quais se deseja ajustar os itens.

O teste KMO (Kaiser Meyer Olkin) foi utilizado para verificar se análise fatorial é adequada para determinado conjunto de dados. Entende-se por adequado o KMO com resultado mais próximo de 1. O teste de esfericidade de Bartllet's mede se a analise fatorial foi adequada para o fenômeno observado. No teste de Bartlett's quanto mais próximo de zero o resultado, mais adequada a analise fatorial. Tendo em vista a função de ambos os testes pode-se observar no Quadro 3 que o instrumento foi adequado e pode sofrer analise fatorial (HAIR. 2009).

Quadro 3 - Testes KMO e Bartllet's para verificar a adequação dos dados para início da Análise Fatorial Exploratória - São Paulo, 2018

\begin{tabular}{|c|c|c|}
\hline \multicolumn{3}{|c|}{ KMO and Bartlett's Test } \\
\hline Kaiser-Meyer-Olkin Measur & of Sampling Adequacy. & ,916 \\
\hline \multirow[t]{3}{*}{ Bartlett's Test of Sphericity } & Approx. Chi-Square & 5799,199 \\
\hline & df & 465 \\
\hline & Sig. & 000 \\
\hline
\end{tabular}


Fonte: GALVÃO (2018).

A matriz de comunalidade indica a percentagem de variabilidade de uma variável. Para averiguar essa medida, os resultados de comunalidades devem ser superiores a 0,6. Como vemos no Quadro 4, existem valores abaixo do esperado. Porém, cabe ao pesquisador manter ou não as variáveis com valores baixos. A intenção de retirar itens que possuem valores abaixo de 0,6 é diminuir a variabilidade do instrumento. Mas como o objetivo do estudo é validar o instrumento construído por Ungkuh Fatimah, portanto não foram retirados os itens abaixo de 0,6 (HAIR. 2009).

Quadro 4 - Comunalidades para Análise Fatorial Exploratória, segundo software SPSS - São Paulo, 2018

\begin{tabular}{|c|c|c|}
\hline \multicolumn{3}{|c|}{ Communalities } \\
\hline Fator ${ }^{*} /$ Item $^{* *}$ & Initial & Extraction \\
\hline $\mathrm{F} 1 / 13$ & 1,000 & ,763 \\
\hline $\mathrm{F} 1 / 14$ & 1,000 & 837 \\
\hline $\mathrm{F} 1 / 15$ & 1,000 & ,779 \\
\hline $\mathrm{F} 1 / 16$ & 1,000 & 782 \\
\hline $\mathrm{F} 1 / 21$ & 1,000 & ,685 \\
\hline$F 1 / 22$ & 1,000 & ,751 \\
\hline $\mathrm{F} 1 / 23$ & 1,000 & ,756 \\
\hline $\mathrm{F} 1 / 24$ & 1,000 & ,732 \\
\hline $\mathrm{F} 1 / 25$ & 1,000 & 632 \\
\hline $\mathrm{F} 1 / 26$ & 1,000 &, 502 \\
\hline $\mathrm{F} 2 / 1$ & 1,000 & ,495 \\
\hline $\mathrm{F} 2 / 2$ & 1,000 & ,499 \\
\hline $\mathrm{F} 2 / 3$ & 1,000 & 692 \\
\hline $\mathrm{F} 2 / 4$ & 1,000 & ,603 \\
\hline $\mathrm{F} 2 / 5$ & 1,000 & ,722 \\
\hline $\mathrm{F} 2 / 7$ & 1,000 & ,541 \\
\hline $\mathrm{F} 3 / 8$ & 1,000 & ,617 \\
\hline $\mathrm{F} 3 / 9$ & 1,000 & ,638 \\
\hline $\mathrm{F} 3 / 10$ & 1,000 & ,672 \\
\hline$F 3 / 11$ & 1,000 &, 540 \\
\hline$F 3 / 12$ & 1,000 & ,458 \\
\hline $\mathrm{F} 4 / 17$ & 1,000 & ,607 \\
\hline $\mathrm{F} 4 / 18$ & 1,000 & ,629 \\
\hline $\mathrm{F} 4 / 19$ & 1,000 & ,665 \\
\hline $\mathrm{F} 4 / 20$ & 1,000 &, 585 \\
\hline F5/27 & 1,000 & 681 \\
\hline $\mathrm{F} 5 / 28$ & 1,000 & ,643 \\
\hline
\end{tabular}




\begin{tabular}{|l|r|rr|}
\hline \multicolumn{3}{|c|}{ Communalities } \\
\hline \multicolumn{2}{|c|}{ Fator $^{*} /$ Item $^{* *}$} & Initial & Extraction \\
\hline F5/29 & & 1,000 &, 632 \\
F6/6 & 1,000 &, 590 \\
F6/30 & 1,000 &, 780 \\
F6/31 & & &, 822 \\
\hline
\end{tabular}

Fonte: GALVÃO (2018).

Legenda: Extraction Method Principal Component Analysis; *Fator de Ungku Fatimah, 2013; **Itens do questionário desenvolvido por Ungku Fatimah, 2013.

A matriz de variância total explicada apresentada no Quadro 5 indica a percentagem total da variância que é explicada pelos fatores obtidos (HAIR. 2009). As variâncias devem se apresentar acima de 60\%. Na última coluna chamada "rotation sums of squared loadings" observa-se que 65,5\% das variâncias explicam sete fatores.

Quadro 5 - Resultados da variância total explicada para Análise Fatorial Exploratória, segundo software SPSS - São Paulo 2018

\begin{tabular}{|c|c|c|c|c|c|c|c|c|c|}
\hline \multicolumn{10}{|c|}{ Total Variance Explained } \\
\hline \multirow{2}{*}{ Component } & \multicolumn{3}{|c|}{ Initial Eigenvalues } & \multicolumn{3}{|c|}{ Extraction Sums of Squared Loadings } & \multicolumn{3}{|c|}{$\begin{array}{l}\text { Rotation Sums of Squared } \\
\text { Loadings }\end{array}$} \\
\hline & Total & $\begin{array}{c}\% \text { of } \\
\text { Variance }\end{array}$ & $\underset{\%}{\text { Cumulative }}$ & Total & $\begin{array}{c}\% \text { of } \\
\text { Variance }\end{array}$ & Cumulative \% & Total & $\begin{array}{c}\% \text { of } \\
\text { Variance }\end{array}$ & Cumulative \% \\
\hline 1 & 10,652 & 34,362 & 34,362 & 10,652 & 34,362 & 34,362 & 4,715 & 15,211 & 15,211 \\
\hline 2 & 2,350 & 7,580 & 41,942 & 2,350 & 7,580 & 41,942 & 4,135 & 13,340 & 28,551 \\
\hline 3 & 1,970 & 6,355 & 48,298 & 1,970 & 6,355 & 48,298 & 2,640 & 8,515 & 37,067 \\
\hline 4 & 1,700 & 5,485 & 53,783 & 1,700 & 5,485 & 53,783 & 2,435 & 7,854 & 44,920 \\
\hline 5 & 1,449 & 4,674 & 58,457 & 1,449 & 4,674 & 58,457 & 2,346 & 7,567 & 52,487 \\
\hline 6 & 1,163 & 3,752 & 62,209 & 1,163 & 3,752 & 62,209 & 2,327 & 7,507 & 59,994 \\
\hline 7 & 1,045 & 3,371 & 65,581 & 1,045 & 3,371 & 65,581 & 1,732 & 5,587 & 65,581 \\
\hline 8 & 949 & 3,062 & 68,643 & & & & & & \\
\hline 9 & 875, & 2,823 & 71,465 & & & & & & \\
\hline 10 & ,752 & 2,426 & 73,891 & & & & & & \\
\hline 11 & 700 & 2,258 & 76,149 & & & & & & \\
\hline 12 & 632 & 2,039 & 78,188 & & & & & & \\
\hline 13 & ,587 & 1,894 & 80,082 & & & & & & \\
\hline 14 & ,542 & 1,748 & 81,829 & & & & & & \\
\hline 15 & ,536 & 1,729 & 83,559 & & & & & & \\
\hline 16 & ,504 & 1,627 & 85,186 & & & & & & \\
\hline 17 & 483 & 1,559 & 86,745 & & & & & & \\
\hline 18 & 465 & 1,501 & 88,246 & & & & & & \\
\hline
\end{tabular}




\begin{tabular}{|c|c|c|c|c|c|c|c|c|c|}
\hline \multicolumn{10}{|c|}{ Total Variance Explained } \\
\hline \multirow{2}{*}{ Component } & \multicolumn{3}{|c|}{ Initial Eigenvalues } & \multicolumn{3}{|c|}{ Extraction Sums of Squared Loadings } & \multicolumn{3}{|c|}{$\begin{array}{l}\text { Rotation Sums of Squared } \\
\text { Loadings }\end{array}$} \\
\hline & Total & $\begin{array}{c}\% \text { of } \\
\text { Variance }\end{array}$ & $\begin{array}{c}\text { Cumulative } \\
\%\end{array}$ & Total & $\begin{array}{c}\% \text { of } \\
\text { Variance }\end{array}$ & Cumulative \% & Total & \begin{tabular}{|c|}
$\%$ of \\
Variance \\
\end{tabular} & Cumulative \% \\
\hline 19 & 407 & 1,311 & 89,557 & & & & & & \\
\hline 20 & 396 & 1,278 & 90,836 & & & & & & \\
\hline 21 & ,379 & 1,224 & 92,060 & & & & & & \\
\hline 22 & ,343 & 1,106 & 93,166 & & & & & & \\
\hline 23 & ,330 & 1,065 & 94,231 & & & & & & \\
\hline 24 & ,312 & 1,007 & 95,238 & & & & & & \\
\hline 25 & ,293 & ,946 & 96,184 & & & & & & \\
\hline 26 & ,266 & ,857 & 97,041 & & & & & & \\
\hline 27 & ,237 & ,765 & 97,806 & & & & & & \\
\hline 28 & ,226 & ,728 & 98,535 & & & & & & \\
\hline 29 & ,214 & ,691 & 99,226 & & & & & & \\
\hline 30 & 125 & ,403 & 99,629 & & & & & & \\
\hline 31 & 115 & ,371 & 100,000 & & & & & & \\
\hline
\end{tabular}

Fonte: GALVÂO (2018).

A matriz de componentes mostra quais itens estão em cada fator de acordo com suas cargas fatoriais (Quadro 6). A matriz de componente rotacionada (Varimax with Kaiser normalization) fornece um contraste maior entre as variáveis (fatores), discriminando e simplificando as colunas. Pode-se visualizar no Quadro 7 os valores para cada item. Os maiores valores das cargas fatoriais em cada fator foram aqueles considerados pertencentes ao fator correspondente (HAIR. 2009).

Quadro 6 - Matriz de componentes não rotacionados para Análise Fatorial Exploratória, segundo software SPSS - São Paulo, 2018

\begin{tabular}{|l|c|c|c|c|c|c|c|}
\hline \multicolumn{7}{|c|}{ Component Matrix $^{\mathbf{a}}$} \\
\hline \multirow{2}{*}{ Fator $^{*} /$ Item $^{* *}$} & \multicolumn{7}{|c|}{ Component $^{\prime}$} \\
\cline { 2 - 7 } & 1 & 2 & 3 & 4 & 5 & 6 & 7 \\
\hline F1/13 &, 744 &,- 165 &, 279 &, 017 &,- 196 &,- 116 &, 228 \\
F1/14 &, 766 &,- 210 &, 322 &, 003 &,- 196 &,- 163 &, 195 \\
F1/15 &, 774 &,- 151 &, 299 &, 015 &,- 200 &,- 050 &, 157 \\
F1/16 &, 811 &,- 127 &, 237 &, 002 &,- 115 &,- 031 &, 193 \\
F1/21 &, 647 &,- 218 &,- 167 &,- 030 &, 337 &,- 273 &,- 044 \\
F1/22 &, 660 &,- 290 &,- 143 &, 054 &, 377 &,- 255 &, 031 \\
F1/23 &, 713 &,- 182 &,- 204 &,- 006 &, 360 &,- 187 &,- 094 \\
F1/24 &, 754 &,- 110 &,- 119 &,- 081 &, 360 &,- 030 &, 002
\end{tabular}




\begin{tabular}{|l|c|c|c|c|c|c|c|}
\hline \multicolumn{7}{|c|}{ Component Matrix } \\
\hline \multirow{2}{*}{ Fator*/ltem ** } & \multicolumn{7}{|c|}{ Component } \\
\cline { 2 - 7 } & 1 & 2 & 3 & 4 & 5 & 6 & 7 \\
\hline F1/25 &, 714 &,- 107 &,- 235 &, 077 &, 183 &, 117 &,- 045 \\
F1/26 &, 646 &,- 087 &,- 163 &,- 128 &, 170 &,- 048 &,- 045 \\
F2/1 &, 425 &, 289 &, 056 &,- 291 &, 185 &, 328 &,- 038 \\
F2/2 &, 514 &, 158 &, 029 &,- 349 &, 173 &, 238 &, 017 \\
F2/3 &, 637 &,- 138 &, 353 &,- 362 &,- 070 &, 055 &,- 058 \\
F2/4 &, 617 &, 014 &, 344 &,- 241 &,- 142 &, 129 &,- 098 \\
F2/5 &, 719 &,- 139 &, 320 &,- 247 &,- 142 &,- 021 &,- 036 \\
F2/7 &, 612 &, 280 &, 110 &,- 137 &, 162 &, 091 &,- 149 \\
F3/8 &, 369 &, 597 &, 106 &,- 122 &, 187 &,- 050 &,- 245 \\
F3/9 &, 358 &, 698 &,- 056 &, 049 &, 042 &,- 108 &, 061 \\
F3/10 &, 378 &, 669 &,- 080 &, 082 &,- 053 &, 000 &, 257 \\
F3/11 &, 406 &, 544 &, 087 &, 111 &, 063 &,- 209 &, 107 \\
F3/12 &, 239 &, 413 &,- 055 &, 076 &,- 178 &,- 367 &, 234 \\
F4/17 &, 647 &,- 054 &,- 223 &, 301 &,- 206 &,- 018 &, 044 \\
F4/18 &, 574 &, 060 &,- 255 &, 335 &,- 291 &,- 094 &,- 156 \\
F4/19 &, 622 &,- 052 &,- 212 &, 292 &,- 217 &,- 001 &,- 313 \\
F4/20 &, 634 &,- 063 &,- 193 &, 197 &,- 177 &,- 119 &,- 241 \\
F5/27 &, 642 &, 048 &,- 309 &, 180 &,- 039 &, 366 &, 056 \\
F5/28 &, 587 &, 072 &,- 195 &, 162 &,- 156 &, 450 &, 045 \\
F5/29 &, 464 &,- 183 &,- 324 &, 040 &,- 004 &, 361 &, 383 \\
F6/6 &,- 348 &,- 067 &,- 001 &, 175 &, 386 &,- 002 &, 534 \\
F6/30 &,- 005 &,- 008 &, 567 &, 589 &, 257 &, 205 &,- 056 \\
F6/31 &, 109 &, 029 &, 554 &, 621 &, 291 &, 104 &,- 146 \\
\hline
\end{tabular}

Fonte: GALVÃO (2018).

Legenda: Extraction Method: Principal Component Analysis; a: 7 components extracted; ${ }^{*}$ Fator de Ungku Fatimah, 2013; **Itens do questionário desenvolvido por Ungku Fatimah, 2013.

Quadro 7 - Matriz de componentes rotacionados para Análise Fatorial Exploratória, segundo software SPSS - São Paulo, 2018

\begin{tabular}{|c|c|c|c|c|c|c|c|}
\hline \multicolumn{7}{|c|}{ Rotated Component Matrix $^{\mathbf{a}}$} \\
\hline \multirow{2}{*}{ Fator*/tem $^{* *}$} & \multicolumn{7}{|c|}{ Component $^{*}$} \\
\cline { 2 - 8 } & 1 & 2 & 3 & 4 & 5 & 6 & 7 \\
\hline F1/13 &, 777 &, 266 &, 165 &, 199 &, 130 &,- 008 &, 066 \\
F1/14 &, 826 &, 297 &, 137 &, 143 &, 149 &,- 016 &, 076 \\
F1/15 &, 777 &, 249 &, 140 &, 212 &, 184 &, 069 &, 100 \\
F1/16 &, 735 &, 324 &, 170 &, 264 &, 139 &, 107 &, 085 \\
F1/21 &, 237 &, 774 &, 064 &, 058 &, 124 &, 076 &,- 034 \\
F1/22 &, 264 &, 812 &, 035 &, 120 &, 070 &, 006 &, 044
\end{tabular}




\begin{tabular}{|c|c|c|c|c|c|c|c|}
\hline \multicolumn{8}{|c|}{ Rotated Component Matrix ${ }^{a}$} \\
\hline \multirow{2}{*}{ Fator*/Item ${ }^{* *}$} & \multicolumn{7}{|c|}{ Component } \\
\hline & 1 & 2 & 3 & 4 & 5 & 6 & 7 \\
\hline $\mathrm{F} 1 / 23$ & ,208 & ,796 & ,070 & , 132 & ,181 & ,157 &,- 003 \\
\hline $\mathrm{F} 1 / 24$ & ,283 & ,705 & ,096 & ,231 & ,079 & ,294 &, 014 \\
\hline $\mathrm{F} 1 / 25$ & ,196 &, 561 & ,059 & ,405 & ,249 & ,220 & ,035 \\
\hline $\mathrm{F} 1 / 26$ & ,259 &, 543 & ,081 & ,187 & ,169 & ,240 &,- 109 \\
\hline $\mathrm{F} 2 / 1$ &, 141 & ,111 & ,163 & ,200 &,- 029 &, 628 &,- 017 \\
\hline $\mathrm{F} 2 / 2$ & ,254 & ,227 &, 118 & ,200 &,- 040 &, 562 &,- 105 \\
\hline $\mathrm{F} 2 / 3$ & ,686 & ,200 &,- 058 &,- 002 &, 101 & ,408 &,- 043 \\
\hline $\mathrm{F} 2 / 4$ & 609 & ,079 & ,049 & ,059 & , 193 & ,425 & ,037 \\
\hline $\mathrm{F} 2 / 5$ & ,732 & 238 & ,022 & ,041 & ,193 & 299 &,- 022 \\
\hline $\mathrm{F} 2 / 7$ & ,257 & ,278 & ,283 & ,085 & , 168 &, 523 & ,088 \\
\hline $\mathrm{F} 3 / 8$ & ,007 & 128 &, 506 &,- 149 & ,162 &, 536 & ,092 \\
\hline $\mathrm{F} 3 / 9$ &,- 013 & ,061 & ,738 & ,068 & ,105 & 272 & ,018 \\
\hline $\mathrm{F} 3 / 10$ &, 060 &,- 020 & ,747 & ,263 & ,029 & 201 &,- 012 \\
\hline F3/11 & 142 & ,138 & ,676 & ,004 & ,065 & ,158 & ,120 \\
\hline F3/12 & 149 & ,032 & ,627 &,- 017 & ,069 &,- 143 &,- 127 \\
\hline $\mathrm{F} 4 / 17$ & ,288 & ,313 & ,213 & ,431 & ,427 &,- 112 & ,026 \\
\hline $\mathrm{F} 4 / 18$ & 177 & ,235 & 268 & 295 & ,610 &,- 103 & ,018 \\
\hline $\mathrm{F} 4 / 19$ & 188 & 301 & 097 & 273 & 670 & ,023 & ,077 \\
\hline $\mathrm{F} 4 / 20$ & 247 & ,366 & ,136 & 193 & ,579 & ,002 & ,000 \\
\hline $\mathrm{F} 5 / 27$ & 128 & 266 & ,138 & ,663 & 299 & ,214 & ,028 \\
\hline $\mathrm{F} 5 / 28$ & , 190 & ,090 & , 107 & ,654 & 310 & 245 & ,056 \\
\hline F5/29 & 183 & 248 &,- 028 & ,718 &,- 050 & ,033 &,- 130 \\
\hline $\mathrm{F} 6 / 6$ &,- 220 & ,056 & ,023 & 120 &,- 639 &,- 297 &, 163 \\
\hline F6/30 & ,068 &,- 072 &,- 032 & ,007 &,- 069 &,- 018 & ,874 \\
\hline F6/31 & ,085 &, 045 &, 044 &,- 051 & ,034 & ,002 & ,899 \\
\hline
\end{tabular}

Fonte: GALVÃO (2018).

Legenda: Extraction Method Principal Component Analysis with Rotation Method: Varimax with Kaiser Normalization; ${ }^{\text {: }}$ Rotation converged in 12 iterations; *Fator de Ungku Fatimah, 2013; **Itens do questionário desenvolvido por Ungku Fatimah, 2013.

A AFE constatou que os itens devem ser agrupados em sete fatores, diferente do proposto por Ungku Fatimah. Houve também um novo rearranjo dos itens. O Fator I é composto pelos itens 3,4,5,13,14,15 e16. O Fator II possui os itens $21,22,23,24,25$ e 26. O Fator III recebe os itens $9,10,11$ e 12 . O Fator IV é composto pelos itens $17,27,28$ e 29. O Fator V pelos itens 18,19 e 20 . O Fator VI pelos itens 1, 2, 7 e 8 . O Fator VII pelos itens 6, 30 e 31. 
Como o questionário desenvolvido por Ungkuh Fatimah (2013) estava discriminado em seis fatores de CSA, a AFC foi realizada para verificar se os seis fatores e respectivos itens se mantinham os mesmos após a aplicação do questionário no contexto deste trabalho. Foram adotados os mesmos procedimentos da AFE, contudo foram fixados seis fatores nos quais as cargas fatoriais dos itens se ajustariam.

Os valores obtidos nos testes KMO e Barllet's foram idênticos, pois o conjunto de dados é o mesmo. A matriz de comunalidades também apresentou alguns valores abaixo de 0,6 , porém os itens não foram retirados. Na matriz de variância total explicada, $62,2 \%$ dos itens são explicados por seis fatores. A matriz de componente (Quadro 8) e matriz de componente rotacionada (Quadro 9) apresentaram uma composição de cargas fatoriais diferente dos quadros obtidos na análise fatorial exploratória.

Quadro 8 - Matriz de componente não rotacionado para Análise Fatorial Confirmatória, segundo software SPSS - São Paulo, 2018

\begin{tabular}{|c|c|c|c|c|c|c|}
\hline \multicolumn{7}{|c|}{ Component Matrix ${ }^{a}$} \\
\hline \multirow{2}{*}{ Fator $^{*} /$ Item $^{* *}$} & \multicolumn{6}{|c|}{ Component } \\
\hline & 1 & 2 & 3 & 4 & 5 & 6 \\
\hline $\mathrm{F} 1 / 13$ & ,744 &,- 165 & 279 & ,017 &,- 196 &,- 116 \\
\hline $\mathrm{F} 1 / 14$ & ,766 &,- 210 & ,322 & ,003 &,- 196 &,- 163 \\
\hline $\mathrm{F} 1 / 15$ & ,774 &,- 151 & ,299 &, 015 &,- 200 &,- 050 \\
\hline $\mathrm{F} 1 / 16$ & ,811 &,- 127 & ,237 & ,002 &,- 115 &,- 031 \\
\hline $\mathrm{F} 1 / 21$ & ,647 &,- 218 &,- 167 &,- 030 & ,337 &,- 273 \\
\hline $\mathrm{F} 1 / 22$ & ,660 &,- 290 &,- 143 & ,054 & ,377 &,- 255 \\
\hline $\mathrm{F} 1 / 23$ &, 713 &,- 182 &,- 204 &,- 006 &, 360 &,- 187 \\
\hline $\mathrm{F} 1 / 24$ &, 754 &,- 110 &,- 119 &,- 081 & 360 &,- 030 \\
\hline $\mathrm{F} 1 / 25$ & ,714 &,- 107 &,- 235 & ,077 & 183 &, 117 \\
\hline $\mathrm{F} 1 / 26$ & ,646 &,- 087 &,- 163 &,- 128 & 170 &,- 048 \\
\hline F2/1 & ,425 & ,289 & ,056 &,- 291 & , 185 & ,328 \\
\hline$F 2 / 2$ &, 514 &, 158 & ,029 &,- 349 & ,173 & 238 \\
\hline$F 2 / 3$ & ,637 &,- 138 & ,353 &,- 362 &,- 070 & ,055 \\
\hline$F 2 / 4$ & ,617 &, 014 & ,344 &,- 241 &,- 142 & 129 \\
\hline $\mathrm{F} 2 / 5$ &, 719 &,- 139 & ,320 & -,247 &,- 142 &,- 021 \\
\hline F2/7 & ,612 & 280, & 110 &,- 137 & ,162 & ,091 \\
\hline F3/8 & ,369 & ,597 & 106 & -,122 & 187 &,- 050 \\
\hline F3/9 & ,358 & 698 &,- 056 & 049, & ,042 &,- 108 \\
\hline $\mathrm{F} 3 / 10$ & ,378 & 669 &,- 080 & ,082 &,- 053 & ,000 \\
\hline F3/11 & ,406 & ,544 & ,087 & 111 & 063, &,- 209 \\
\hline
\end{tabular}




\begin{tabular}{|c|c|c|c|c|c|c|}
\hline \multicolumn{7}{|c|}{ Component Matrix ${ }^{a}$} \\
\hline \multirow{2}{*}{ Fator ${ }^{*} /$ tem $^{* *}$} & \multicolumn{6}{|c|}{ Component } \\
\hline & 1 & 2 & 3 & 4 & 5 & 6 \\
\hline $\mathrm{F} 3 / 12$ & ,239 &, 413 &,- 055 & ,076 &,- 178 &,- 367 \\
\hline $\mathrm{F} 4 / 17$ & ,647 &,- 054 &,- 223 & ,301 &,- 206 &,- 018 \\
\hline $\mathrm{F} 4 / 18$ &, 574 & ,060 &,- 255 & ,335 &,- 291 &,- 094 \\
\hline $\mathrm{F} 4 / 19$ & ,622 &,- 052 &,- 212 & ,292 &,- 217 &,- 001 \\
\hline $\mathrm{F} 4 / 20$ & ,634 &,- 063 &,- 193 & , 197 &,- 177 &,- 119 \\
\hline $\mathrm{F} 5 / 27$ & ,642 & ,048 &,- 309 & , 180 &,- 039 & ,366 \\
\hline $\mathrm{F} 5 / 28$ & ,587 & ,072 &,- 195 & , 162 &,- 156 & ,450 \\
\hline $\mathrm{F} 5 / 29$ & ,464 &,- 183 &,- 324 &, 040 &,- 004 & ,361 \\
\hline $\mathrm{F} 6 / 6$ &,- 348 &,- 067 &,- 001 & , 175 & ,386 &,- 002 \\
\hline $\mathrm{F} 6 / 30$ &,- 005 &,- 008 &, 567 & ,589 & ,257 & ,205 \\
\hline $\mathrm{F} 6 / 31$ & 109 &, 029 &, 554 & ,621 & ,291 & ,104 \\
\hline
\end{tabular}

Fonte: GALVÃO (2018).

Legenda: Extraction Method: Principal Component Analysis; a: 6 components extracted; ${ }^{*}$ Fator de Ungku Fatimah, 2013; **Itens do questionário desenvolvido por Ungku Fatimah, 2013.

Quadro 9 - Matriz de componentes rotacionados para Análise Fatorial Confirmatória, segundo software SPSS - São Paulo, 2018

\begin{tabular}{|c|c|c|c|c|c|c|}
\hline \multicolumn{7}{|c|}{ Rotated Component Matrix ${ }^{\mathrm{a}}$} \\
\hline \multirow[b]{2}{*}{ Fator $^{*} /$ tem $^{* *}$} & \multicolumn{6}{|c|}{ Component } \\
\hline & 1 & 2 & 3 & 4 & 5 & 6 \\
\hline$\overline{F 1 / 13}$ &, 732 & ,282 & 272 & ,111 &,- 007 & 097 \\
\hline $\mathrm{F} 1 / 14$ & ,789 & 315, & 240, & 093, &,- 038 & , 104 \\
\hline $\mathrm{F} 1 / 15$ & ,753 & ,259 & ,302 & , 109 & 052 & , 121 \\
\hline $\mathrm{F} 1 / 16$ & ,699 & ,334 & ,319 & , 132 & ,116 &, 111 \\
\hline $\mathrm{F} 1 / 21$ & ,230 &, 770 & , 165 & 080 & 041 &,- 035 \\
\hline $\mathrm{F} 1 / 22$ & ,227 & ,810 & , 197 &, 021 & 016 &, 056 \\
\hline $\mathrm{F} 1 / 23$ & ,214 & ,783 & ,251 & , 102 & 124 &,- 012 \\
\hline $\mathrm{F} 1 / 24$ & ,274 & ,699 & ,250 &, 116 & ,304 & 020 \\
\hline $\mathrm{F} 1 / 25$ & , 198 &, 533 & ,485 & 072 & ,256 & 024 \\
\hline $\mathrm{F} 1 / 26$ & ,273 &, 534 & ,257 & , 109 & 220 &,- 116 \\
\hline $\mathrm{F} 2 / 1$ & 181 & , 109 & 083 & ,234 & ,622 &,- 021 \\
\hline $\mathrm{F} 2 / 2$ & ,277 & ,232 & 088 & , 168 & ,568 &,- 097 \\
\hline $\mathrm{F} 2 / 3$ & ,731 & 219 & 019 & ,007 & 324 &,- 040 \\
\hline $\mathrm{F} 2 / 4$ & 670, & ,086 & 119 & 123, & ,327 & ,026 \\
\hline F2/5 & 770 & 252 & 129 & ,068 & 207, &,- 021 \\
\hline $\mathrm{F} 2 / 7$ & 322 & 270 & 140 & 377, & 420 & ,063 \\
\hline F3/8 & 110 & ,118 &,- 052 & ,640 & 342 & ,046 \\
\hline F3/9 & ,011 & ,050 & 129 & ,763 & 181 & ,002 \\
\hline $\mathrm{F} 3 / 10$ & 033, &,- 028 & 245, & ,709 & 204 &,- 002 \\
\hline
\end{tabular}




\begin{tabular}{|c|c|c|c|c|c|c|}
\hline \multicolumn{7}{|c|}{ Rotated Component Matrix ${ }^{\mathrm{a}}$} \\
\hline \multirow[b]{2}{*}{ Fator $^{*} /$ Item $^{* *}$} & \multicolumn{6}{|c|}{ Component } \\
\hline & 1 & 2 & 3 & 4 & 5 & 6 \\
\hline$\overline{F 3 / 11}$ &, 143 & ,137 & 075 & ,682 &, 067 & ,117 \\
\hline$F 3 / 12$ & ,119 & 039 & 080 &, 572 &,- 202 &,- 117 \\
\hline $\mathrm{F} 4 / 17$ & ,276 & ,279 & ,643 & , 172 &,- 094 & 011 \\
\hline $\mathrm{F} 4 / 18$ & ,225 & , 189 & ,634 & ,283 &,- 185 &,- 033 \\
\hline $\mathrm{F} 4 / 19$ & ,271 & ,249 & ,631 &, 160 &,- 086 &, 010 \\
\hline $\mathrm{F} 4 / 20$ & ,314 & ,327 &, 522 & , 186 &,- 110 &,- 053 \\
\hline $\mathrm{F} 5 / 27$ &, 115 & ,225 & ,705 & ,113 & ,322 & 018 \\
\hline $\mathrm{F} 5 / 28$ & , 189 & 051 & ,688 & 089 & 344 & 045 \\
\hline $\mathrm{F} 5 / 29$ & ,073 & ,236 &, 556 &,- 155 & ,291 &,- 080 \\
\hline F6/6 &,- 400 &, 087 &,- 224 &,- 144 &,- 044 & ,254 \\
\hline $\mathrm{F} 6 / 30$ &, 046 &,- 077 &,- 009 &,- 023 &,- 007 & 877 \\
\hline F6/31 & 086, & ,034 & ,014 & 081 &,- 045 & 885 \\
\hline
\end{tabular}

Fonte: GALVÃO (2018).

Legenda: Extraction Method Principal Component Analysis with Rotation Method: Varimax with Kaiser Normalization; a: Rotation converged in 11 iterations; *Fator de Ungku Fatimah, 2013; **Itens do questionário desenvolvido por Ungku Fatimah, 2013.

Após a AFC constatou-se que houve um novo rearranjo dos itens. O Fator I é composto pelos itens 3, 4, 5, 13, 14, 15 e 16. O Fator II possui os itens 21, 22, 23, 24, 25 e 26. O Fator III recebe os itens 17, 18, 19, 20, 27, 28 e 29. O Fator IV é composto pelos itens 8, 9, 10, 11 e 12. O Fator $V$ pelos itens 1, 2 e 7. Por fim, 0 Fator VI pelos itens 6, 30 e 31.

O leitor pode visualizar o cruzamento e rearranjo entre fatores e itens na Tabela 7 em que estão identificados tanto a composição do autor (Ungku Fatimah, 2013) do questionário quanto a composição após análise fatorial no presente estudo.

Tabela 7 - Composição de fatores e itens de Ungku Fatimah e do presente estudo após AFE e AFC São Paulo, 2018 


\begin{tabular}{|c|c|c|c|}
\hline \multicolumn{2}{|c|}{ Ungku Fatimah (2013) } & \multicolumn{2}{|c|}{ Presente estudo } \\
\hline & & $\mathrm{AFE}^{*}$ & $\mathrm{AFC}^{\star *}$ \\
\hline Fatores & Itens correspondentes & Itens & Itens \\
\hline $\begin{array}{l}\text { F1 - Apoio dos } \\
\text { gerentes e } \\
\text { colaboradores }\end{array}$ & $13,14,15,16,21,22,23,24,25,26$ & $3,4,5,13,14,15,16$ & $3,4,5,13,14,15,16$ \\
\hline $\begin{array}{l}\text { F2 - } \\
\text { Comunicação }\end{array}$ & $1,2,3,4,5,7$ & $21,22,23,24,25,26$ & $21,22,23,24,25,26$ \\
\hline $\begin{array}{l}\text { F3 - Auto } \\
\text { comprometimento }\end{array}$ & $8,9,10,11,12$ & $9,10,11,12$ & $17,18,19,20,27,28,29$ \\
\hline $\begin{array}{l}\text { F4 - Suporte do } \\
\text { ambiente } \\
\text { (ambiente } \\
\text { favorável) }\end{array}$ & $17,18,19,20$ & $17,27,28,29$ & $8,9,10,11,12$ \\
\hline $\begin{array}{l}\text { F5 - Pressão no } \\
\text { trabalho }\end{array}$ & $27,28,29$ & $18,19,20$ & $1,2,7$ \\
\hline $\begin{array}{l}\text { F6 - Julgamento } \\
\text { baseado em risco }\end{array}$ & $6,30,31$ & $1,2,7,8$ & $6,30,31$ \\
\hline
\end{tabular}

Fonte: GALVÃO (2018).

Legenda: *Análise Fatorial Exploratória; ** Análise Fatorial Confirmatória.

Observando que houve um novo rearranjo entre os itens decidiu-se comparar os fatores de CSA determinados por Ungku Fatimah com os elementos encontrados na literatura científica sobre o assunto. Foram elaboradas as Tabelas 8 e 9 com o conjunto de itens após a AFE e AFC, respectivamente. É possível correlacionar os conteúdos dos itens com fatores elaborados por outros autores de CSA. Portanto, o conteúdo dos itens de Ungku Fatimah (2013) pode ser considerado capaz de diagnosticar a CSA de um estabelecimento de alimentos. 
Tabela 8 - Resultados de Análise Fatorial Exploratória e rearranjo dos itens conforme os fatores dos autores de Cultura de Segurança de Alimentos São Paulo, 2018

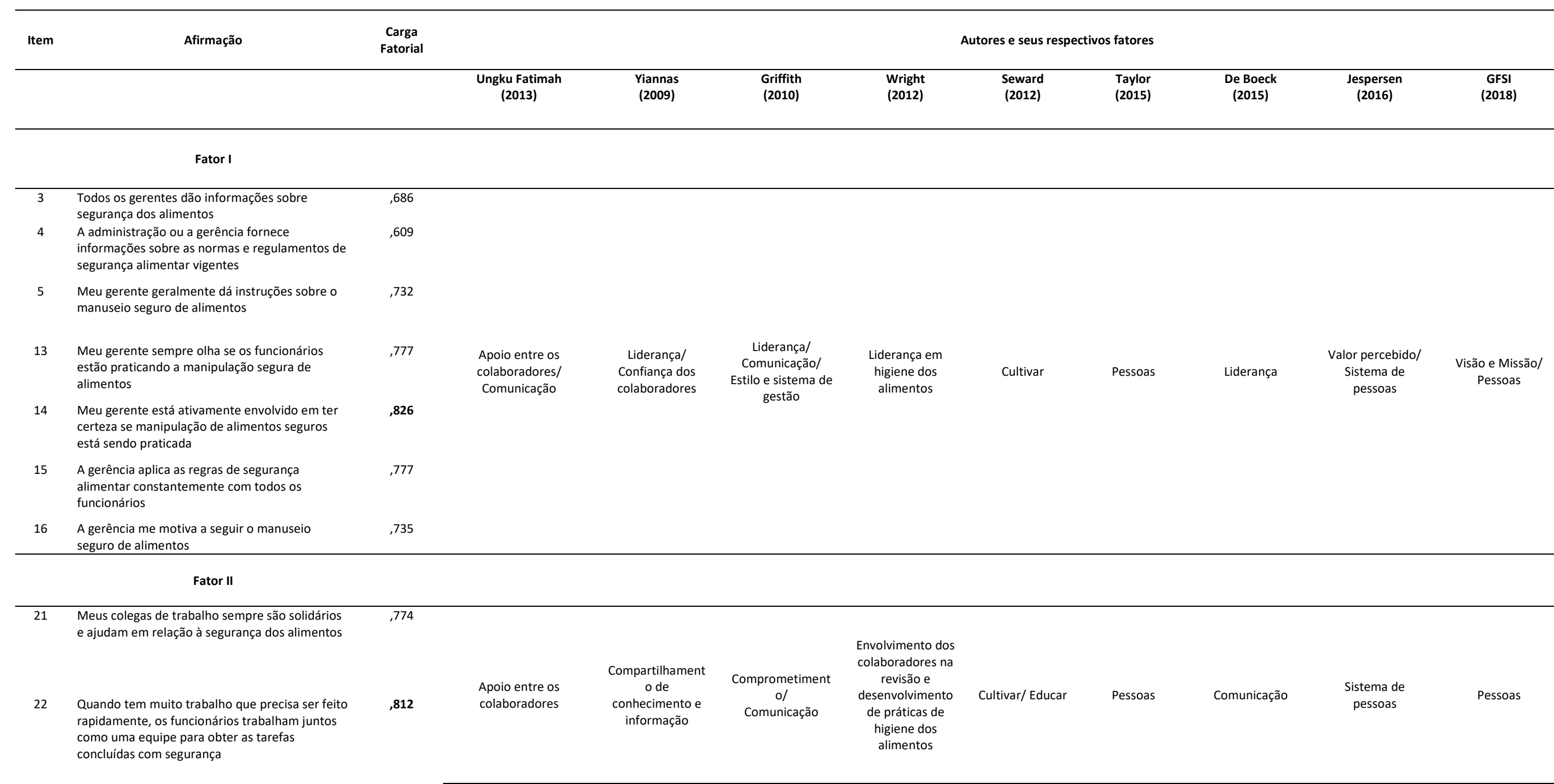




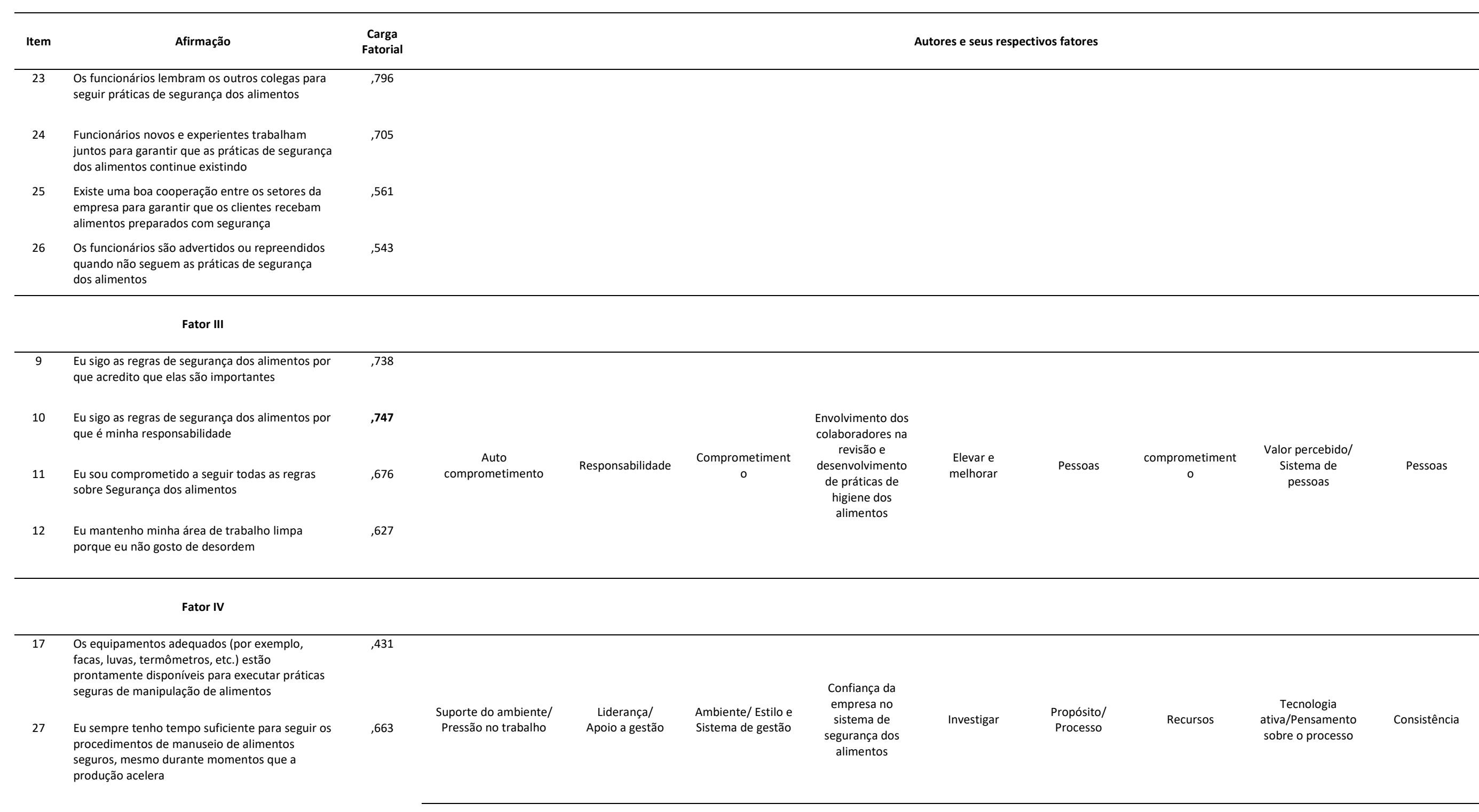




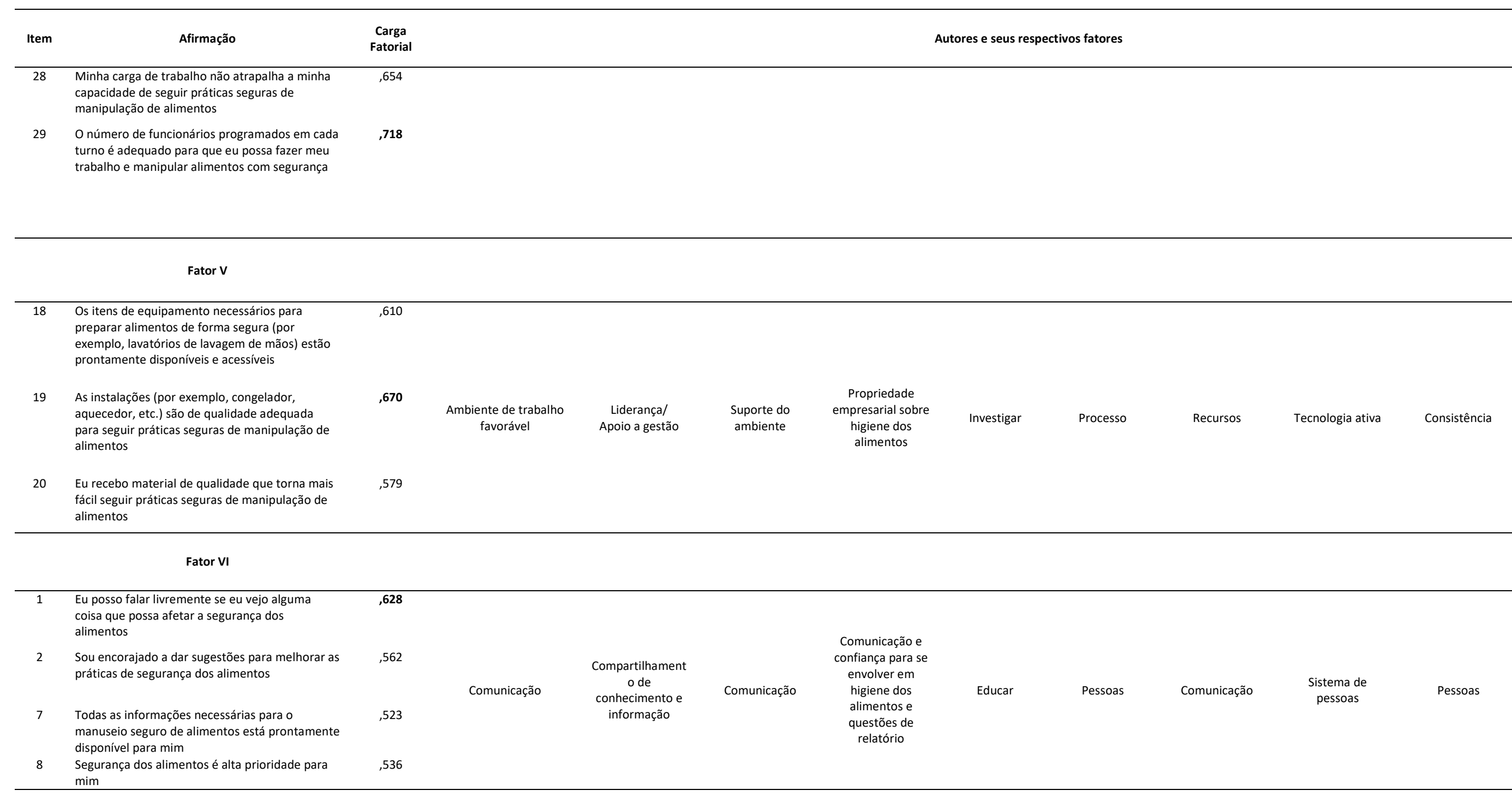

Fator VII 


\begin{tabular}{|c|c|c|c|c|c|c|c|c|c|c|c|}
\hline Item & Afirmação & $\begin{array}{l}\text { Carga } \\
\text { Fatorial }\end{array}$ & & & & & ores e seus re & ivos fatores & & & \\
\hline 6 & $\begin{array}{l}\text { Acredito que as políticas e os procedimentos } \\
\text { escritos de segurança alimentar da empresa não } \\
\text { são nada mais do que umaa proteção caso haja } \\
\text { um problema com a lei. }\end{array}$ & 163 & & & & & & & & & \\
\hline 30 & $\begin{array}{l}\text { Quando estamos sob pressão para terminar a } \\
\text { produção de alimentos, os gerentes às vezes nos } \\
\text { dizem para trabalhar mais rápido, "pulando" } \\
\text { algumas regras de segurança alimentar }\end{array}$ & ,874 & Consciência de risco & Responsabilidade & $\begin{array}{l}\text { Percepção- } \\
\text { Consciência- } \\
\text { comportamento } \\
\text { de risco }\end{array}$ & $\begin{array}{l}\text { Competencia, } \\
\text { aprendizagem, } \\
\text { treinamento, } \\
\text { conhecimento/ } \\
\text { Percepção e } \\
\text { conhecimento de }\end{array}$ & $\begin{array}{l}\text { Elevar e } \\
\text { melhorar }\end{array}$ & Pro-atividade & $\begin{array}{l}\text { Consciência de } \\
\text { risco }\end{array}$ & $\begin{array}{l}\text { Pensamento } \\
\text { sobre os } \\
\text { processos }\end{array}$ & $\begin{array}{l}\text { Adaptabilidade/ } \\
\text { Perigos e } \\
\text { Consciência de } \\
\text { risco }\end{array}$ \\
\hline 31 & $\begin{array}{l}\text { Às vezes me pedem para "cortar caminho" em } \\
\text { relação à segurança dos alimentos durante a } \\
\text { produção dos alimentos para que possamos } \\
\text { economizar custos }\end{array}$ & 899 & & & & $\begin{array}{l}\text { risso em higiene } \\
\text { dos alimentos }\end{array}$ & & & & & \\
\hline
\end{tabular}

Fonte: GALVÃO (2018).

Tabela 9 - Resultados de Análise Fatorial Confirmatória e rearranjo dos itens conforme os fatores dos autores de Cultura de Segurança de Alimentos - São Paulo, 2018

\begin{tabular}{|c|c|c|c|c|c|c|c|c|c|c|c|}
\hline \multirow{2}{*}{ Item } & \multirow{2}{*}{$\begin{array}{c}\text { Afirmação } \\
\text { Fator I }\end{array}$} & \multirow{2}{*}{$\begin{array}{l}\text { Carga } \\
\text { Fatorial }\end{array}$} & \multicolumn{9}{|c|}{ Autores e seus respectivos fatores } \\
\hline & & & $\begin{array}{l}\text { Ungku Fatimah } \\
\text { (2013) }\end{array}$ & Yiannas (2009) & Griffith (2010) & Wright (2012) & $\begin{array}{l}\text { Seward } \\
\text { (2012) }\end{array}$ & Taylor (2015) & De Boeck (2015) & Jespersen (2016) & GFSI (2018) \\
\hline 3 & $\begin{array}{l}\text { Todos os gerentes dão informações sobre } \\
\text { segurança dos alimentos }\end{array}$ & ,686 & & & & & & & & & \\
\hline 4 & $\begin{array}{l}\text { A administração ou a gerência fornece } \\
\text { informações sobre as normas e } \\
\text { regulamentos de segurança alimentar } \\
\text { vigentes }\end{array}$ & ,609 & $\begin{array}{l}\text { Apoio entre os } \\
\text { colaboradores/ } \\
\text { Comunicacão }\end{array}$ & $\begin{array}{l}\text { Liderança/ } \\
\text { Confiança dos } \\
\text { colaboradores }\end{array}$ & $\begin{array}{c}\text { Liderança/ } \\
\text { Comunicação/ } \\
\text { Estilo e sistema de }\end{array}$ & $\begin{array}{l}\text { Liderança em } \\
\text { higiene dos } \\
\text { alimentos }\end{array}$ & Cultivar & Pessoas & Liderança & Valor percebido & $\begin{array}{l}\text { Visão e Missão } \\
\text { Pessoas }\end{array}$ \\
\hline 5 & $\begin{array}{l}\text { Meu gerente geralmente dá instruções } \\
\text { sobre o manuseio seguro de alimentos }\end{array}$ & ,732 & & & & & & & & & \\
\hline
\end{tabular}




\begin{tabular}{|c|c|c|c|c|c|c|c|c|c|c|c|}
\hline \multirow{2}{*}{ Item } & \multirow{2}{*}{$\begin{array}{l}\text { Afirmação } \\
\text { Meu gerente sempre olha se os funcionários } \\
\text { estão praticando a manipulação segura de } \\
\text { alimentos }\end{array}$} & \multirow{2}{*}{$\begin{array}{c}\text { Carga } \\
\text { Fatorial }\end{array}$} & \multicolumn{9}{|c|}{ Autores e seus respectivos fatores } \\
\hline & & & & & & & & & & & \\
\hline 14 & $\begin{array}{l}\text { Meu gerente estáa ativamente envolvido em } \\
\text { ter certeza se manipulacăa de alimentos } \\
\text { seguros está sendo praticada }\end{array}$ & ,826 & & & & & & & & & \\
\hline 15 & $\begin{array}{l}\text { A gerência aplica as regras de segurança } \\
\text { alimentar constantemente com todos os } \\
\text { funcionários }\end{array}$ & ,777 & & & & & & & & & \\
\hline 16 & $\begin{array}{l}\text { A gerência me motiva a seguir o manuseio } \\
\text { seguro de alimentos }\end{array}$ & ,735 & & & & & & & & & \\
\hline \multicolumn{12}{|c|}{ Fator II } \\
\hline 21 & $\begin{array}{l}\text { Meus colegas de trabalho sempre são } \\
\text { solidários e ajudam em relação à segurança } \\
\text { dos alimentos }\end{array}$ & ,774 & \multirow{6}{*}{$\begin{array}{l}\text { Apoio entre os } \\
\text { colaboradores }\end{array}$} & \multirow{6}{*}{$\begin{array}{l}\text { Compartilhamento } \\
\text { de conhecimento e } \\
\text { informação }\end{array}$} & \multirow{6}{*}{$\begin{array}{c}\text { Comprometimento/ } \\
\text { Comunicaçãoo }\end{array}$} & \multirow{6}{*}{$\begin{array}{l}\text { Envolvimento dos } \\
\text { colaboradores na } \\
\text { revisão e } \\
\text { desenvolvimento de } \\
\text { práticas de higiene } \\
\text { dos alimentos }\end{array}$} & \multirow{6}{*}{$\begin{array}{l}\text { Cultivar/ } \\
\text { Educar }\end{array}$} & \multirow{6}{*}{ Pessoas } & \multirow{6}{*}{ Comunicação } & \multirow{6}{*}{$\begin{array}{l}\text { Sistema de } \\
\text { pessoas }\end{array}$} & \multirow{6}{*}{ Pessoas } \\
\hline 22 & $\begin{array}{l}\text { Quando tem muito trabalho que precisa ser } \\
\text { feito rapidamente, of funcionários } \\
\text { trabalham juntos comou uma equipe para } \\
\text { obter as tarefas concluidas com segurançă }\end{array}$ & ,812 & & & & & & & & & \\
\hline 23 & $\begin{array}{l}\text { Os funcionários lembram os outros colegas } \\
\text { para seguir práticas de seguranņ̧a dos } \\
\text { alimentos }\end{array}$ & 796 & & & & & & & & & \\
\hline 24 & $\begin{array}{l}\text { Funcionários novos e experientes trabalham } \\
\text { juntos para garantir que as práticas de } \\
\text { segurança dos alimentos continue existindo }\end{array}$ & ,705 & & & & & & & & & \\
\hline 25 & $\begin{array}{l}\text { Existe uma boa cooperação entre os setores } \\
\text { da empresesa apara garantir rue os colientes } \\
\text { recebam alimentos preparados com } \\
\text { seguranç̧a }\end{array}$ & ,561 & & & & & & & & & \\
\hline 26 & $\begin{array}{l}\text { Os funcionários são advertidos ou } \\
\text { repreendidos quando não seguem as } \\
\text { práticas de segurança dos alimentos }\end{array}$ & ,543 & & & & & & & & & \\
\hline
\end{tabular}

Fator III 


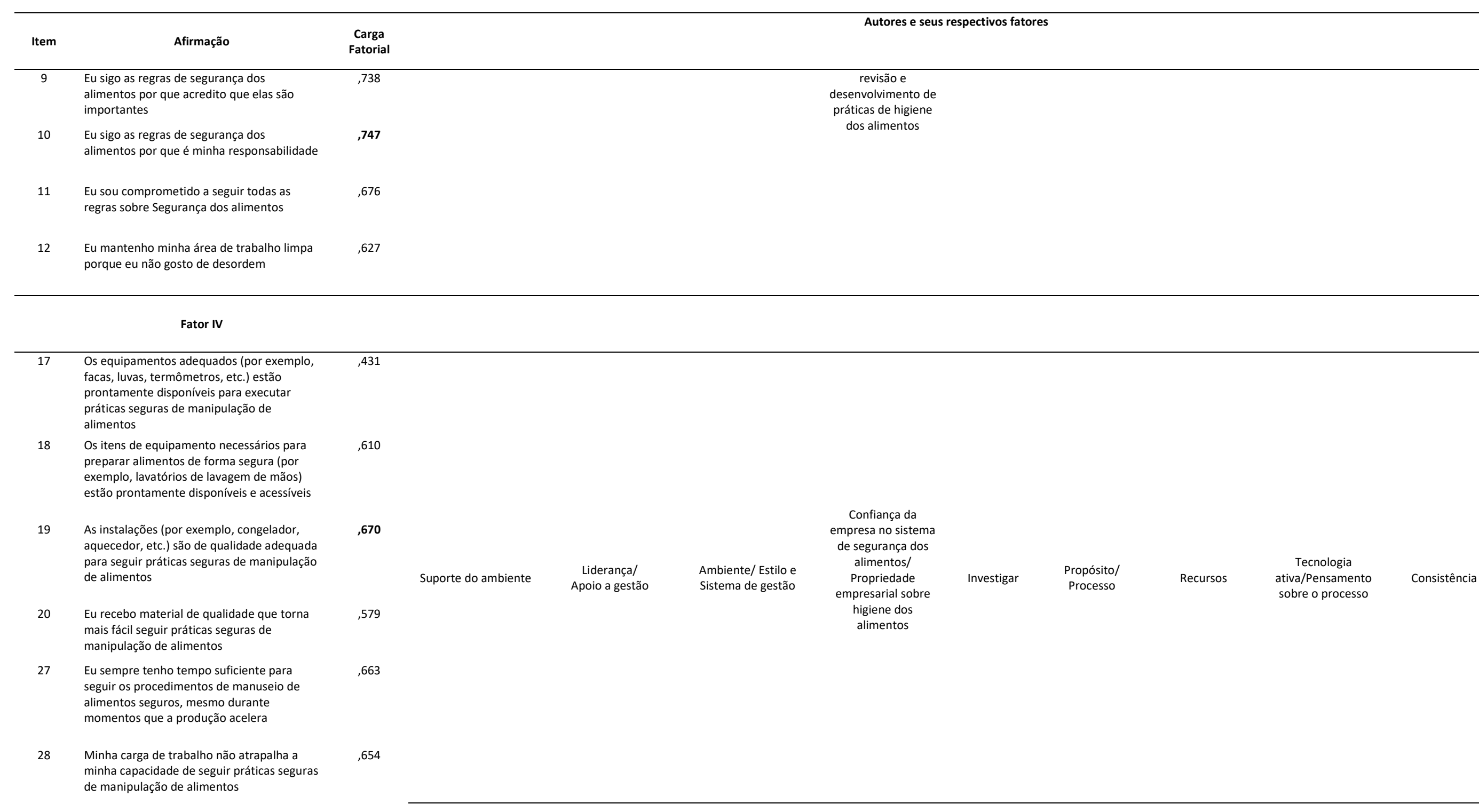




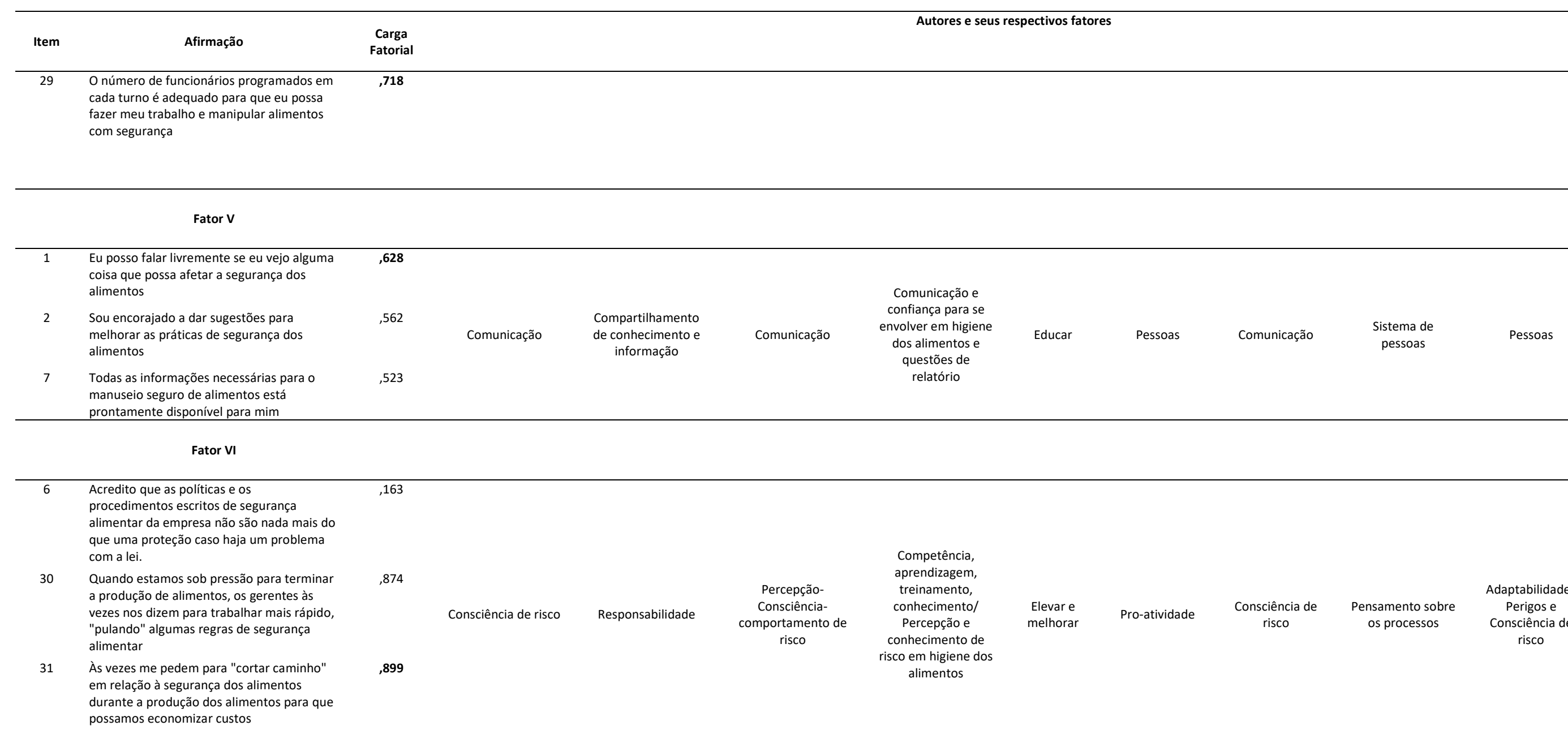

Fonte: GALVÃO (2018). 


\subsubsection{Escores de CSA para cada variável demográfica e para cada loja}

O escore é a somatória da escala Likert que o participante atribuiu para os itens do questionário. Assim, os participantes formaram grupos para variável sexo, idade, etc. Estes resultados foram apresentados com frequências absolutas e escores estratificados por variável demográfica (Tabela 10).

Tabela 10 - Frequência absoluta e Escore para as variáveis demográficas - São Paulo, 2018

\begin{tabular}{lcc} 
Variável & Frequência & Escore \\
\hline Sexo & & \\
F & 176 & 156,6 \\
M & 184 & $\mathbf{1 5 9 , 7}$
\end{tabular}

Origem de nascimento

Norte

156,0

Nordeste

2

155,6

Centro-oeste

139

Sudeste

155,8

DF

221

129,0 *

Estrangeiro

168,3

\section{Escolaridade}

Primário incompleto

183,0

Primário completo

153,5

Fundamental incompleto

157,8

Fundamental completo

145,7

Médio incompleto

159,2

Médio completo

154,1

Superior incompleto

162,5

Superior completo

166,0

Pós-Graduação

143,5

Ensino técnico

155,0

\section{Idade}

18-20

26-30 


\begin{tabular}{lcc} 
Variável & Frequência & Escore \\
\hline $56-60$ & 7 & 166,4 \\
$61-65$ & 3 & $\mathbf{1 7 0 , 3}$ \\
$66-70$ & 1 & $130,0^{*}$ \\
$71-75$ & 0 & 0 \\
$76-80$ & 0 & 0
\end{tabular}

\section{Experiência na área de alimentos}

$<6$ meses

6 meses - 1 ano

159,6

1 - 2 anos

155,8

3 - 5 anos

157,3

6 - 10 anos

158,6

$11-15$ anos

162,5

16 - 20 anos

163,0

$21-25$ anos

173,3

26 - 30 anos

186,5

31 - 35 anos

163,0

\section{Experiência na empresa participante}

$<6$ meses

156,0

6 meses - 1 ano

168,5

1 - 2 anos

148,4

3 - 5 anos

148,4

$6-10$ anos

153,5

$11-15$ anos

155,6

16 - 20 anos

166,4

$21-25$ anos

156,3

$26-30$ anos

158,6

Cargo ou Função - Setor da empresa

Operador de Loja - Peixaria 26

156,7

Operador de loja - Padaria

161,2

Operador de loja - Salsicharia

148,6

Operador de loja - Açougue

151,3

Operador de loja - FLV

154,2

Operador de loja - Cafeteria

$137,3^{*}$

Operador de loja que Não identificou o setor

155,1

Gerenciador - Peixaria

146,3

Gerenciador - Padaria

191,6

Gerenciador - Salsicharia

191,5

Gerenciador - Açougue

154,8

Gerenciador - FLV

164,3

Gerenciador - Cafeteria

Gerenciador de loja que Não identificou o setor 


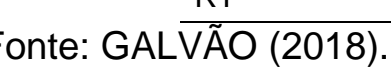

\begin{tabular}{lcc} 
Variável & Frequência & Escore \\
\hline Estagiário & 12 & 155,6 \\
RT & 7 & 169,8 \\
\hline
\end{tabular}

Legenda: *Escore indiferente

Com a finalidade de avaliar os escores das variáveis demográficas, adotou-se neste trabalho o critério de CSA positiva ou negativa conforme o valor do escore, conforme na metodologia no item 4.5 da dissertação.

Conforme o exposto, a maioria das variáveis demográficas apresentaram CSA positiva. Apenas três variáveis apresentaram em sua estratificação uma categoria que apresentou escore Indiferente que são: variável Origem de nascimento - Distrito Federal, variável Idade - entre 61 e 65 anos e variável Cargo ou Função/Setor da empresa - Operador de loja FLV.

No Quadro 10, temos a distribuição dos escores obtidos para cada loja, RT e CR. Nota-se que apenas a loja 12 obteve escore indiferente. $O$ restante das lojas obteve escore acima de 139 pontos, ou seja, CSA positiva.

Os resultados dos escores dos RTs foram correspondentes a uma CSA positiva, exceto o RT6 que apresentou 132,9 pontos. O RT3 apresentou um valor de escore próximo de 139 pontos, porém como o valor foi acima do critério sigma ele foi considerado positivo.

Ambos os CRs obtiveram valor de escore ao redor de 160 pontos. No caso do CR1, das cinco lojas sob sua supervisão, quatro apresentaram resultados acima de 160 pontos e uma loja apresentou valor abaixo desse valor. As lojas do CR2 apresentaram uma amplitude maior de resultados para o escore, variando de cerca de 130 pontos a 176 pontos.

Quadro 10 - Média dos escores em Cultura de Segurança de Alimentos para cada loja, Responsável Técnico (RT) e Coordenador de Região (CR) - São Paulo, 2018

\begin{tabular}{|c|c|c|c|}
\hline CR & RT & Loja & Escore \\
\hline \multirow{4}{*}{ CR1 } & RT1 & 1 & $\mathbf{1 8 1 , 1}$ \\
\cline { 2 - 4 } & \multirow{3}{*}{ RT2 } & 2 & 161,4 \\
\cline { 2 - 4 } & & 3 & 165,8 \\
\cline { 2 - 4 } & & 4 & 168,4 \\
\cline { 2 - 4 } & \multicolumn{2}{c|}{ Média RT2 } \\
\hline
\end{tabular}




\begin{tabular}{|c|c|c|c|}
\hline CR & RT & Loja & Escore \\
\hline & RT3 & 5 & 139,9 \\
\hline \multicolumn{3}{|l|}{ Média CR1 } & 160,3 \\
\hline \multirow{13}{*}{ CR2 } & \multirow{3}{*}{ RT4 } & 6 & 146,8 \\
\hline & & 7 & 169,4 \\
\hline & & 8 & 162,2 \\
\hline & \multicolumn{2}{|l|}{ Média RT4 } & 157,9 \\
\hline & \multirow{3}{*}{ RT5 } & 9 & 140,7 \\
\hline & & 10 & 152,6 \\
\hline & & 11 & 157,9 \\
\hline & \multicolumn{2}{|l|}{ Média RT5 } & 150,0 \\
\hline & RT6 & 12 & 132,9 \\
\hline & \multirow{3}{*}{ RT7 } & 13 & 172,2 \\
\hline & & 14 & 160,2 \\
\hline & & 15 & 176,2 \\
\hline & \multicolumn{2}{|l|}{ Média RT7 } & 169,2 \\
\hline \multicolumn{3}{|l|}{ Média CR2 } & 157,2 \\
\hline \multicolumn{3}{|l|}{ Média Total } & 158,2 \\
\hline
\end{tabular}

Fonte: GALVÃO (2018).

No Gráfico 4, podemos observar os escores de cada região do município de São Paulo e os municípios da Grande São Paulo. Nota-se que os escores foram acima de 139 pontos o que nos leva a CSA positiva em todas as regiões.

Gráfico 4 - Média dos Escores de Cultura de Segurança de Alimentos para cada Zona do Município de São Paulo e Grande São Paulo - São Paulo, 2018

\section{Escore resultante da somatória da escala Likert 7 pontos para cada Região}

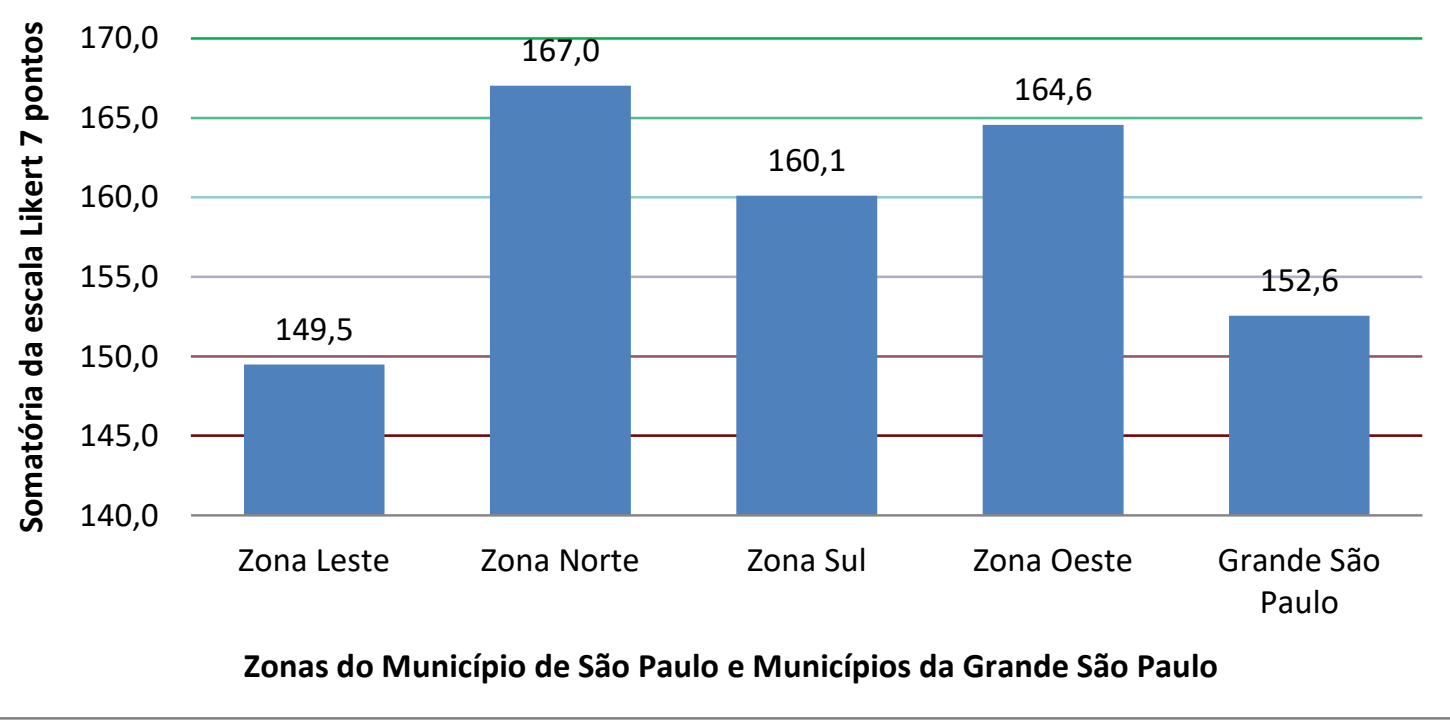

Fonte: (GALVÃO, V. C., 2018). 


\subsubsection{Análise de correlação de Spearman entre as variáveis demográficas e os Escores de CSA}

O coeficiente de Spearman varia entre -1 e 1. Quanto mais próximo estiver destes extremos, maior será a associação entre as variáveis. O sinal negativo da correlação significa que as variáveis variam em sentido contrário, isto é, as categorias mais elevadas de uma variável estão associadas a categorias mais baixas da outra variável (HAIR, 2009).

Foi realizado o teste de correlação de Spearman para verificar se havia associação entre as variáveis demográficas e os escores do questionário de CSA. Conforme os valores contidos na Tabela 11, nota-se uma associação significante $(p \geq 0,05)$ nas variáveis Idade e Experiência na Área de Alimentos em relação ao escore dos fatores.

Tabela 11 - Valores de Correlação de Spearman para Variáveis Demográficas - São Paulo, 2018

\begin{tabular}{|c|c|c|c|c|c|c|c|c|}
\hline & Empresa & Sexo & $\begin{array}{l}\text { Origem de } \\
\text { nascimento }\end{array}$ & Escolaridade & Idade & $\begin{array}{c}\text { Experiência } \\
\text { na área de } \\
\text { alimentos }\end{array}$ & $\begin{array}{l}\text { Experiência } \\
\text { na empresa } \\
\text { participante }\end{array}$ & $\begin{array}{c}\text { Cargo } \\
\text { ou } \\
\text { Função } \\
\text { e Setor } \\
\text { da } \\
\text { Empresa }\end{array}$ \\
\hline $\begin{array}{c}\text { Teste de } \\
\text { Correlação } \\
\text { de } \\
\text { Spearman }\end{array}$ & 0,007 & 0,053 & $-0,035$ & 0,056 & 0,150 & 0,125 & 0,021 & $-0,037$ \\
\hline
\end{tabular}

Fonte: GALVÃO (2018). 


\subsection{ENTREVISTA COM RESPONSÁVEL PELA SEGURANÇA DE ALIMENTOS DA EMPRESA PARTICIPANTE}

\subsubsection{História do departamento de qualidade e segurança de alimentos da empresa participante do estudo}

Para rememorar o leitor, houve uma entrevista com a responsável pelo Departamento de Qualidade e Segurança de Alimentos (DSACQ) da Empresa participante do estudo a fim de rastrear e registrar a relação da empresa com a SA. Trata-se de um profissional Médico Veterinário com mais de dez anos de experiência na área de alimentos e iniciou a sua carreira no momento da inauguração do DSACQ da empresa. Neste subitem do trabalho a responsável pelo DSACQ será identificada como "entrevistada", "gerente" ou "responsável pelo DSACQ". Outros atores derivados da fala da entrevistada serão identificados ao longo do texto.

O DSACQ foi fundado em novembro de 2005 e pertencia a Direção de Prevenção de Risco (DPR). Antes da criação do DSACQ, a Segurança de Alimentos (SA), conhecida como "perecíveis", ficava sob a responsabilidade de apenas uma pessoa subordinada à Direção Comercial (DC) da empresa. Durante a criação do DSACQ foi entendido que o departamento não poderia ficar submetido ao DC, pois poderia haver conflito de interesses e, por isso, o DSACQ foi colocado na DPR que, além da SA, cuidava da parte patrimonial da empresa, da ética e imagem da empresa. $E$ até hoje, entende-se que SA tem a ver com a Imagem da empresa.

A criação do DSACQ se deu por causa de fiscalizações nas lojas, segundo relata a entrevistada. Anterior à criação do departamento houve a publicação da Resolução RDC n²16, de 15 de setembro de 2004, válida para todo o Brasil até o presente momento do estudo, que dispõe sobre o Regulamento Técnico de Boas Práticas para Serviços de Alimentação (BRASIL, 2004). O âmbito de aplicação dessa Resolução, presente no item 1.2 do Anexo, diz que serão fiscalizados os estabelecimentos em que ocorre manipulação, preparação, fracionamento, armazenamento, distribuição, transporte, exposição à venda e entrega de alimentos preparados ao consumo (BRASIL, 2004). Com isso, a empresa notou uma intensificação da fiscalização nas suas lojas, havendo o registro de 
interdições e autuações devido a "não conformidades" - a entrevistada não revelou quais eram as "não conformidades" da época.

O depoimento da entrevistada é corroborado por evidências na história da vigilância sanitária no município de São Paulo, já que a RDC supracitada é de âmbito nacional e a maioria das lojas do presente estudo estão nesse município. Foi criada em 2003 na Secretaria Municipal de Saúde de São Paulo, a Coordenação de Vigilância em Saúde (Covisa) que, dentro de suas atribuições como órgão de saúde, era responsável por coordenar, supervisionar, planejar e avaliar a vigilância sanitária do município (BOANOVA, 2008). A Covisa atua através dos seus agentes fiscalizadores alocados em unidades descentralizadas e distribuídas em todo município, divididos em seis coordenadorias regionais (PREFEITURA DE SÃO PAULO, 2018), como se segue:

- Zona Central (1 unidade);

- Zona Leste (7 unidades);

- Zona Norte (6 unidades);

- Zona Oeste (2 unidades);

- Zona Sul (5 unidades); e

- Zona Sudeste (5 unidades).

Assim, a Covisa desempenha o seu papel na garantia de qualidade dos produtos e dos serviços a eles relacionado através de fiscalizações nos pontos de venda, objetivando a preservação e promoção da saúde da população (BOANOVA, 2008).

No mesmo período o Chefe dos DL (Diretor de Operações) assumiu a problemática das "não conformidades" das lojas, realizando reuniões com a vigilância sanitária para a resolução dos problemas que estavam ocorrendo. Apesar da realização de várias reuniões técnicas com a Vigilância Sanitária, a chefia dos DL não estava sendo capaz de mitigar as "não conformidades" apresentadas pelas lojas. Começava-se a se fazer ver que já existia a necessidade de um profissional do setor de alimentos.

Desde essa época já havia um RT para cada loja. Após as fiscalizações, a empresa questionou-se sobre o trabalho dos RTs e o porquê estava acontecendo tantos problemas, já que as lojas tinham uma pessoa tecnicamente capacitada em alimentos. Constatou-se que o trabalho dos RTs não era padronizado. Isso também 
contribui para a criação do DSACQ que seria responsável pela definição de uma política administrativa para a atuação dos RTs na organização, além de planejar as atividades dos RTs em todas as lojas da empresa.

A entrevistada relatou que, de 2005 até 2010, o DSACQ teve que comprovar para a própria empresa que era necessário supervisionar também a SA e a qualidade dos produtos do Centro de Distribuição - CD. O CD, cuja finalidade dentro da empresa é de receber, selecionar e armazenar todos os produtos da empresa a fim de redistribuí-los às lojas, durante esses cinco anos acima citados pertencia ao DC. Havia conflito de interesse entre o DC e SA quando esta ainda era subordinada aquele. Com isso, o DSACQ ficou responsável pelo CD e passou a receber outros setores em que a SA estava presente, como a "Marca Própria" da empresa (produtos elaborados e vendidos com a marca da empresa). Até 2010 havia grande conflito entre os departamentos, nas palavras do gerente do DSACQ eles tinham que

[...] provar por 'A + B' que a SA era importante para a empresa. Isso não era visto na empresa. A empresa via o DSACQ como um obstáculo para o comercial [...]

Em 2011 aconteceu uma mudança de postura da empresa em relação à SA, representada pelo CEO da empresa no Brasil. CEO é a sigla inglesa de Chief Executive Officer, que significa Diretor Executivo em português. Esta pessoa possui a maior autoridade na hierarquia operacional de uma organização (CFI, 2018; BD, 2018).

Houve uma reunião entre o CEO Brasil e o responsável pelo DSACQ para explicar qual era a função desse departamento e os seus profissionais na empresa. Durante a explicação, o CEO demonstrou conhecimento sobre SA e valorizou o trabalho do DSACQ. Durante o período de atuação do referido CEO, a entrevistada relata que a $S A$ ganhou importância e relevância para os negócios.

Durante a liderança do CEO Brasil, a empresa também possuía outro CEO, desta vez internacional, voltado para a Qualidade e Segurança de Alimentos nos nove países em que a empresa possui lojas operando (América do Sul, Europa e Ásia). O CEO Internacional (CEOint), analisando os fatos ocorridos no Brasil e em outros países nesse período, criou uma padronização global de qualidade $(Q)$ e SA 
para todas as lojas da multinacional. Ele realizou uma avaliação das lojas através de um checklist próprio. Desta forma, a empresa no Brasil passou a prestar contas de desempenho sobre $Q$ e SA para a Sede Internacional da empresa. Além disso, iniciaram-se visitas de auditoria vindas da Sede para avaliar se as lojas estavam alinhadas com o escopo de Q e SA, tanto na parte documental (do DSACQ e das lojas) quanto nas práticas in loco nas lojas. Essas visitas se mantêm até o momento do presente estudo.

O CEOint da empresa ainda é o mesmo da época citado no parágrafo anterior e permanece como responsável pela $Q$ e SA da multinacional. A empresa, globalmente falando, possui uma equipe subordinada ao CEOint para cuidar dos produtos da marca própria e da Higiene e SA em todos os países que a empresa possui lojas. Abaixo dessa equipe internacional estão os DSACQ dos países que possuem lojas da empresa. Na Figura 9 é possível visualizar esse organograma.

Figura 9 - Organograma internacional da Segurança de Alimentos na empresa participante do estudo sobre CSA - São Paulo, 2018

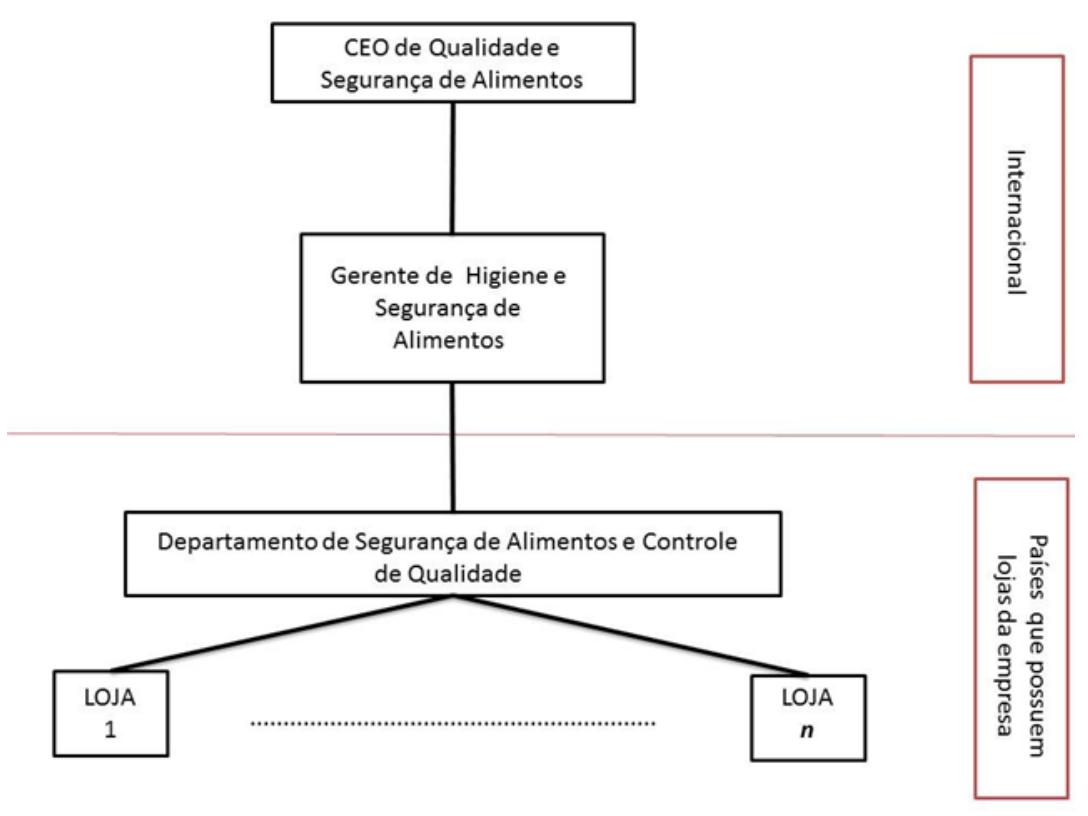

Fonte: (GALVÃO, V. C., 2018).

Os benefícios da implantação do DSACQ para a entrevistada foram processos e produtos mais seguros para o consumidor através de maior controle da higiene, temperatura e recebimento. A empresa se preocupa com análises laboratoriais sobre os produtos. É realizado todo mês uma amostragem aleatória 
sobre as lojas no Brasil para obtenção de resultados físico-químicos e microbiológicos dos alimentos. Além disso, ocorreu uma parceria com o DC e Departamento de Operações (DO) - responsável pelo funcionamento das lojas - em que cada departamento realiza o seu trabalho contribuindo para a SA. A confiança da empresa sobre o DSACQ aumentou tanto que demandas de outros departamentos são destinadas ao DSACQ para serem avaliadas.

Já as dificuldades residem em implantar ações que exigem custos e investimentos, por exemplo a aquisição de equipamentos avançados que possuem maior desempenho em SA ou mudanças de layout dos fluxos de produções para não ocorrer contaminações cruzadas. Outra dificuldade está em o DSACQ não ter certeza se os conteúdos relacionados à SA são assimilados pelas pessoas que trabalham nas lojas, ou nas palavras da entrevistada é necessário "encontrar uma forma de sensibilizar as pessoas" para SA. Pois, ainda ocorrem resultados não satisfatórios em relação à SA perceptíveis através dos relatórios de inspeção dos RTs.

A entrevistada relata que o problema das pessoas que executam a manipulação de alimentos nas lojas, além da formação básica de um indivíduo (doméstica e escolar, segundo ela), é a disciplina de executar as tarefas operacionais de forma segura cotidianamente. Relacionado a isso, a entrevistada mencionou a cultura brasileira como contribuinte para a manipulação incorreta de alimentos. Ela relata que os brasileiros são "emocionais", acarretando em uma sensibilidade das pessoas nos relacionamentos interpessoais, e que isso influencia nas tarefas realizadas no dia a dia. Porém, no ambiente de trabalho da entrevistada ela relata que há uma boa relação com as pessoas dos outros departamentos. Não há ocorrências frequentes de atritos.

As dificuldades enfrentadas quando há custo de produção nas lojas devido à SA está relacionada aos limites ou parâmetros definidos nas legislações. $O$ DSACQ é rígido em relação à legislação. Por exemplo, os dias de validade dos produtos registrados na embalagem pelo fabricante são controlados de maneira a evitar chegar ao seu limite. Assim a empresa possui uma margem de segurança a fim de que o produto não se torne impróprio para a venda e não haja risco excessivo daquele produto causar um mal às pessoas que irão consumi-lo. Entretanto, ao decidir-se em retirar os produtos que estavam para venda, nesse exemplo, 
financeiramente a decisão do DSACQ gera maior custo de produção, causando possíveis atritos.

Ao ser perguntada sobre as perspectivas da rede para os próximos cinco a dez anos, a entrevistada disse que o foco será sobre os aditivos, resíduos e rastreabilidade dos alimentos, através de uma abordagem mais rígida que a legislação sanitária. Assim, a empresa quer ser líder em alimentos frescos. A empresa também priorizará desenvolver processos automatizados para melhorar a produtividade.

\subsubsection{Cultura de segurança de alimentos sobre a perspectiva do departamento de qualidade e segurança de alimentos da empresa participante do estudo}

A entrevistada relata que a missão do departamento é melhorar continuamente a manipulação de alimentos, transporte e armazenamento de alimentos. Já os valores do departamento em relação à SA são: controle de temperatura, controle de pragas, data de validade, rotulagem e higiene.

A entrevistada avaliou a SA da empresa e o DSACQ como sendo nota 9 (de 0 a 10) e declarou que atribui esta nota inferior a dez, pois há necessidade de aprimoramento da SA na empresa. O produto final da empresa, ou seja, aquele que irá à mesa do consumidor, ela avalia em nota 7 porque ainda encontra-se extrapolação de parâmetros laboratoriais microbiológicos e físico-químicos definidos em leis sanitárias (ex: detecção de Listeria, resíduo de agrotóxico).

Segundo a entrevistada encontrar esses parâmetros acima dos limites legais acontece por causa de parte dos fornecedores da rede. Muitos deles, segundo ela, não se preocupam coma SA dentro de sua organização e por isso a $\mathrm{RLH}$ encontra dificuldade de controlar os parâmetros. A entrevistada associa a falta de SA dos fornecedores à nação brasileira não possuir preocupação com a SA, quando comparada a outras nações como Estados Unidos e França.

A entrevistada disse que "trabalhar com SA é ingrato porque ninguém enxerga o seu trabalho, apenas quando acontece algum problema". Porém, a empresa mostra o reconhecimento pelo trabalho realizado através de compensação financeira. Em contrapartida, a entrevistada diz que nos corredores onde ela trabalha não há reconhecimento dos colegas quando há grandes períodos sem problemas nas lojas. A entrevistada comparou o seu trabalho com os mecânicos de 
manutenção de aeronaves, ressaltando que só há reconhecimento do trabalho dos mesmos "quando algum avião cai".

A entrevistada sugere a outras empresas que para manter uma CSA a hierarquia e liderança dentro da empresa. A hierarquia serve para utilizar as atribuições de cada pessoa para exigir SA. A respeito da liderança, um líder que influencia positivamente e da importância à SA diante dos seus liderados impacta diretamente na rotina de trabalho. A entrevistada destaca que um líder preocupado com a SA, quanto mais alto na hierarquia, mais impacto haverá nos níveis hierárquicos abaixo dele em relação à $S A$.

Além disso, no caso de uma rede de lojas no varejo, situação a qual a entrevistada se encontra atualmente, é necessário ter um plano de controle com auditorias internas e externas e análises laboratoriais. Ademais é preciso ter também uma infraestrutura administrativa que auxilie as lojas que estão operando, garantindo os controles sobre SA e, ao mesmo tempo, supervisionar as lojas, pois "não adianta ter controle na ponta e não ter por trás e vice-versa". 


\section{DISCUSSÃO}

A discussão da dissertação está organizada de maneira que conduza o leitor pelos cinco tópicos que cercam os resultados do trabalho. O primeiro tópico abordará os aspectos da adaptação cultural do instrumento. O segundo tópico apresentará os aspectos de validação do instrumento, ou seja, ele mediu de fato o que pretendia medir? O terceiro tópico mostra as vantagens e desvantagens de se utilizar a escala likert. $\mathrm{O}$ quarto tópico analisa os resultados do questionário, qual o estado da CSA naquele momento, naquelas lojas, com aqueles participantes. Por fim, no quinto tópico faz-se uma pequena discussão dos aspectos culturais do Brasil e do conceito de cultura nacional.

\subsection{ADAPTAÇÃO CULTURAL DO INSTRUMENTO}

O propósito dessa discussão sobre adaptação e validação do instrumento utilizado nesse trabalho é mostrar alguns autores da literatura científica sobre o assunto. A finalidade era mostrar metodologias e procedimentos sobre a adaptação cultural e validação.

Brislin (1970) foi um dos primeiros autores que se preocuparam com a questão de tradução de instrumentos (ou questionários) do inglês para outras línguas. $\mathrm{O}$ autor analisou o método chamado de Backtranslation e sugere que múltiplos métodos para realizar a tradução de questionários devem ser usados quando possível.

Brislin demonstrou em seu artigo que mesmo utilizando a combinação de métodos de tradução ocorrem erros que são percebidos em um método que não no outro - o autor utilizou em seu trabalho os seguintes métodos: backtranslation e Teste piloto.

Por isso, ao realizar o backtranslation, Brislin sugeriu que é preciso ser crítico e não apenas avaliar a compreensibilidade dos itens, mas também se a gramática é adequada, se as palavras utilizadas se adequam à realidade dos nativos da língua alvo e se as pessoas teriam algum problema em ler o instrumento e responder os itens. A preocupação com todos esses aspectos se dá porque uma pequena mudança do sentido original do conteúdo em todas as suas nuances pode interferir na caracterização do fenômeno que o instrumento pretende medir. 
Outros autores preocupados com a questão da tradução de instrumentos e seu impacto nas pesquisas científicas se debruçaram sobre o tema. Prieto (1992) adicionou mais dois métodos para agregar na tradução de documentos. Os métodos são Técnica bilíngue e Abordagem de comitê (grupo de bilíngues).

A técnica bilíngue consiste em aplicar 0 instrumento tanto na versão original quanto a traduzida em um grupo de profissionais bilíngues com o intervalo de aplicação de cinco dias entre as versões. A abordagem em comitê consiste em um grupo de profissionais bilíngues realizarem a tradução do texto original para a língua alvo. Prieto destacou em seu artigo que antes de iniciar um projeto científico é preciso compreender quem será o público-alvo da pesquisa, pois conforme a idade, nível educacional e a cultura, a compreensão do instrumento irá variar (PRIETO, 1992).

Segundo Prieto (1992), existem quatro tipos de tradução. Deferente do método de tradução, o tipo de tradução se refere ao momento em que um tradutor está realizando a tradução do documento, ou seja, durante o ato em que o tradutor lê a palavra e realiza a transformação daquele termo em uma palavra no idioma alvo da tradução.

Os tipos são a) Tradução pragmática: tradução do texto com foco na acurácia da informação; b) Tradução Poético-Estética: leva em consideração as qualidades emocionais do texto original (ex.: diálogo dramático ou soneto); c) Tradução Etnográfica: explica o contexto cultural tanto do texto original quanto da língua alvo, ou seja, explica maneira como as palavras são usadas; e d) Tradução Linguística: se preocupa com a equivalência de significado e a forma gramatical tanto do texto original quanto da língua alvo. Desses quatro tipos, Prieto (1992) sugere que sejam utilizadas a pragmática, a etnográfica e a linguística do que a poético-estética.

Guillemin (1993) contribuiu com mais dois métodos para tradução, adaptação e validação de questionários. O primeiro deles é um Comitê de Revisão no qual uma equipe multidisciplinar de profissionais seria encarregada de avaliar a compreensibilidade, aspectos gramaticais, a forma, estrutura, etc., tanto do questionário original quanto da versão traduzida. O segundo método é chamado Ponderação de Pesos em Escores. Esse método consiste em adaptar ao contexto cultural pesos para os escores de cada item. 
A literatura sobre a adaptação e validação de questionários é extensa e não foi objeto desse trabalho vasculhar os trabalhos nessa área do conhecimento. Os autores apresentados anteriormente foram e ainda são uns dos mais respeitados e citados em trabalhos mais recentes. Borsa (2012) ao propor as suas etapas metodológicas para adaptação e validação de questionário baseou-se nesses autores.

A partir dos resultados apresentados sobre o processo de adaptação cultural, o instrumento de Ungku Fatimah não apresentou a necessidade de alteração do conteúdo dos itens, a supressão de itens ou alteração da forma escrita. Houve a necessidade de escolha de palavras que não alterassem o sentido dos itens na etapa de tradução, mas isso se deve às diferenças de conhecimento de palavras/expressões entre os tradutores. Nesse trabalho confirmou-se o que a literatura nos fornece sobre a quantidade de tradutores, ou seja, é necessário possuir no mínimo dois tradutores com a finalidade de diminuir os erros de tradução (SILVA-ROCHA, 2017; CANFIELD, 2015; BRISLIN, 1970; PRIETO, 1992; GUILLEMIN, 1993).

A participação dos experts $(n=2)$ influenciou positivamente na etapa de tradução. Ao analisarem as traduções dos tradutores A e B e comparar com os itens originais em inglês, os experts puderam notar os aspectos descritos na literatura científica sobre o que avaliar nos textos a fim de que as ideias, intenções e conteúdo do texto original não se perdessem (PRIETO, 1992). Nos itens 2, 4, 6, 12, 30 e 31 são exemplos disso, pois por causa de uma palavra traduzida de formas diferentes poderiam ter alterado o sentido do conteúdo dos itens.

Diferente do que Guillemin (1993) sugere, os experts neste estudo são especializados em Cultura de Segurança dos Alimentos, e não uma equipe multidisciplinar. Isto contribuiu para que na análise dos itens traduzidos, os experts pudessem influenciar a síntese dos documentos de maneira positiva, utilizando os conceitos dos tipos de tradução de Prieto (1992), e não interferindo de maneira literal ao sugerirem palavras para os itens que formaram a síntese dos tradutores $A$ e B (ver Apêndice F).

A avaliação pelo público-alvo da síntese das traduções reflete o trabalho, mais uma vez, dos experts. Os itens estavam compreensíveis, as instruções eram claras para o público, a diagramação e formatação do instrumento eram satisfatórias e objetivas. 
Durante a etapa do Backtranslation houve pouca diferença entre as retraduções dos profissionais de inglês. Nota-se que mesmo os retradutores $C$ e $D$ não conhecendo os itens originais os dois profissionais utilizaram palavras idênticas ou semelhantes na maioria dos itens do questionário de Ungku Fatimah (2013), conforme Apêndice F. Mais uma vez, isso reflete a importância dos experts na síntese das traduções devido ao conhecimento do tema de CSA, assim no Backtranslation houve pouca variação entre as retraduções.

A atuação e a importância dos experts durante os procedimentos de Borsa (2012) foi descrito por Silva-Rocha (2017). Os experts foram fundamentais para o refinamento do instrumento do autor.

O estudo piloto, segundo Borsa (2012), refere-se "a uma aplicação prévia do instrumento em uma pequena amostra que reflita as características da amostra/população-alvo". O objetivo dessa etapa foi avaliar a compreensão e o significado dos itens pelos participantes de pesquisa. Como descrito na metodologia, não houve a necessidade de alteração dos itens. Apenas a troca de um enunciado da seção demográfica que foi sugerido pelos participantes. Por isso, decidiu-se não repetir o estudo piloto devido a essa única alteração.

Devido a aplicação do instrumento ocorrer em salas de treinamento fora do local de trabalho pode ter influenciado a motivação dos participantes para responder os itens. Não foi objeto de estudo a relação do local de preenchimento do instrumento e a motivação dos participantes. Por isso, a possibilidade do local onde os participantes realizaram a pesquisa não é descartável. Mas, é necessário estudos para identificar se há alguma relação entre essas variáveis.

A entrega de recompensa (bombom de chocolate) pela participação na pesquisa também pode ter influenciado a motivação dos respondentes. Há evidências na literatura de que recompensar os participantes é benéfico e não prejudica os resultados de pesquisa (CARDINAELS, 2017). Porém, também não foi objeto deste estudo essa relação.

A metodologia de Borsa (2012) se mostrou sistemática e utilizou os conhecimentos disponíveis na literatura para diminuir as chances de erros de tradução. A metodologia do autor foi utilizada em trabalhos recentes (GABARDOMARTINS, 2017; SILVA-ROCHA, 2017; ZANON, 2017; PETRUCCI, 2016; CANFIELD, 2015) e foi considerada fundamental para a finalidade que se propõe. 
Portanto, a metodologia desenvolvida pelo autor foi adequada para adaptação cultural do instrumento.

\subsection{VALIDAÇÃO DO INSTRUMENTO}

O Alfa de Cronbach é a medida de consistência interna das respostas dos participantes. Também se refere à confiabilidade do instrumento utilizado. Segundo Martins (2006), "confiabilidade de um instrumento de medição se refere ao grau em que sua repetida aplicação, ao mesmo sujeito ou objeto, produz resultados iguais".

Os resultados do Alfa de Cronbach obtidos do instrumento de Ungku Fatimah (2013) no contexto brasileiro mostraram que o instrumento foi confiável $(\alpha=0,7957)$. O Fator 6, "Julgamento baseado em risco", apresentou valor de Alfa mais baixo (consistência moderada) em relação aos outros fatores. Landis e Koch (1977) afirmaram que esse valor pode ser explicado pela quantidade de itens ou pela quantidade de participantes do estudo.

Observando os resultados do tamanho da amostra $(n=328)$ e o alcançado pelo pesquisador $(n=383)$, provavelmente a quantidade de participantes não interferiu no resultado desse fator. É possível que o número de itens do Fator 6 (três itens) esteja interferindo na medição sobre a consciência de risco dos participantes.

Além disso, a consistência do Fator 6 pode ter sido mais baixa devido a uma menor consciência do que é risco em SA. Os respondentes da RLH podem adotar práticas no cotidiano que não priorizam a SA. Neste caso, haveria impacto direto na CSA da organização, pressionando os valores e crenças da empresa de que o julgamento de risco dos colaboradores é prejudicial para a SA.

A análise fatorial dos itens do questionário tinha como objetivo verificar como os itens se comporiam quando calculado suas cargas fatoriais. A AFE mostrou que os itens se agruparam em uma quantidade maior de fatores (7 fatores) e a composição dos itens em cada novo fator também foi diferente em relação aos propostos por Ungku Fatimah. Isto significa que os seis fatores do instrumento no contexto brasileiro não explicam o conjunto de itens propostos pelo autor original. 
Por isso, foi realizada a AFC para verificar se o conjunto de itens que pertencia a cada fator determinado por Ungku Fatimah se mantinham constantes. Foi constatado nos resultados que houve um novo rearranjo dos itens após fixar-se seis fatores. Portanto, podemos afirmar que os itens podem se reagrupar de maneira diferente do que havia proposto por Ungku Fatimah.

Reavaliando o conteúdo de cada item do questionário, as Tabelas 8 e 9 mostraram possíveis correlações entre os itens e fatores de CSA da literatura científica sobre o assunto. Taylor (2011) não expôs o conceito de cada fator que ele considera que compõe o constructo de CSA. Porquanto, não estão nas referidas tabelas a comparação entre os fatores e os itens do questionário e, portanto, não foi possível comparar o conteúdo dos itens de Ungku Fatimah com os fatores de Taylor (2011).

As Tabelas supracitadas nos apresentou que os itens de Ungkuh Fatimah (2013) encontram correspondências aos fatores de CSA disponíveis na literatura cientifica sobre $O$ assunto. Os autores propõem nomes diferentes para os fatores formadores da CSA, mas o conteúdo desses fatores se assemelha entre si. Essas diferenças podem ter acontecido por causa da destinação do instrumento. Percebemos no resumo dos fatores formadores de CSA (Quadro 1) que alguns instrumentos foram elaborados para indústrias de alimentos, outros para o Foodservice, etc. Sugere-se que novos estudos apliquem os diferentes instrumentos para verificar se a categoria do estabelecimento interfere nos resultados.

Os itens de Ungku Fatimah (2013) foram desenvolvidos para o Foodservice. Porém, decidiu-se utilizar o instrumento do autor devido à semelhança das atividades em um serviço de alimentação (Foodservice) em relação à realidade de manipulação de alimentos de um hipermercado. Outros estudos são necessários aplicando o questionário de Ungku Fatimah, validado nesse estudo, verificando se os resultados apresentam repetibilidade e consistência.

Os resultados de frequências do questionário revelam que os fatores "Apoio dos Gerentes e Colaboradores", "Comunicação", "Autocomprometimento" e "Suporte do Ambiente" (ambiente favorável) apresentaram tendência positiva de CSA, ou seja, grau de concordância. O fator "Pressão no trabalho" apresentou o item 29 em grau de discordância, embora os itens 27 e 28 apresentaram grau de 
concordância. A organização deve avaliar se o número de funcionários presentes em cada turno é suficiente para a realização das atividades. Caso o número atual de funcionários por turno seja suficiente, a organização pode persuadir suas equipes demonstrando que é possível realizar as tarefas de SA com o tal número de pessoas.

O fator "Julgamento baseado em Risco" mostrou resultado tendendo a CSA negativa. O item 6, "Acredito que as políticas e os procedimentos de segurança alimentar da empresa são nada mais do que uma obrigação caso haja um problema com a legislação", foi o que apresentou maior grau de discordância entre os três itens desse fator. A organização poderia enxergar esse resultado de maneira pessimista, mas poderia realizar um esforço contrário ao pessimismo e utilizar as leis sanitárias como estímulo para ir além do mínimo cobrado por elas. Assim, para os colaboradores provavelmente as leis se tornarão naturais de serem aplicadas no dia a dia e deixarão de ser uma obrigação.

Os itens 30 e 31 do fator "Julgamento baseado em Risco" se referem aos momentos em que os funcionários deixam de lado a SA para economizar. É compreensível que em algumas etapas haja falhas de SA, pois a execução das tarefas é realizada por seres humanos que podem cometer erros. Mas, a empresa precisa implantar em sua cultura que não é uma prática comum nos seus setores a negligência à $S A$. Ambos os itens apontam que na realidade de manipulação nos setores a cobrança ocorre sobre os custos ao invés da SA. A organização precisa incutir nos seus valores, crenças, atitudes e comportamentos que priorizar a SA traz benefícios de economia, como menor desperdício e menor quantidade de alimentos deteriorados. Sugere-se que a organização se debruce em mostrar aos seus colaboradores os riscos de procedimentos inseguros para os alimentos. Pode-se utilizar treinamento em sala ou mostrando na prática de cada setor os procedimentos corretos. Ainda, rever o sistema de recompensas e punições para melhorar os resultados nesse fator. 


\subsection{ESCALA LIKERT DE MENSURAÇÃO}

Conforme apresentado nos resultados, a condução da análise da escala Likert através da Média e Desvio Padrão poderia nos confundir quanto a veracidade dos dados. Nesse tópico da dissertação foi discutido e apresentado ao leitor as razões disso ocorrer.

Os questionários podem ser construídos a partir dos conceitos de questionário aberto, semi-estruturado ou estruturado. Nos questionários abertos, solicita-se que os participantes ofereçam as próprias respostas após a apresentação de um tema. Os questionários semi-estruturados apresentam perguntas ou afirmações que guiam a resposta do participante de pesquisa sobre o assunto alvo que se pretende estudar. Já o questionário estruturado é aquele em que o respondente possui opções de resposta para responder aos itens que o compõe (GIL, 2008).

No caso dos questionários estruturados pode-se utilizar escalas para mensurar as respostas dos participantes. Um dos primeiros a estabelecer os tipos de escala de mensuração foi Stevens em 1946. Ele propôs que existem quatro tipos de escala: nominal, ordinal, intervalar e razão (LUCIAN, 2016).

Escala nominal não apresenta relação numérica entre os pontos da escala. Os números que representam os pontos são um artifício de identificação, e poderiam ser substituídos por nomes, letras ou imagens. A estatística permitida a essa escala são as frequências das respostas (LUCIAN, 2016).

Escala ordinal, como o próprio nome já diz, tem como característica preservar a ordem dos pontos da escala. Esse tipo de escala não preserva os intervalos ou distâncias entre os pontos da escala. $O$ uso de média e desvio-padrão não é permitido para escala ordinal, sendo o posicionamento relativo do objeto da escala definido em graus de intensidade. Portanto, é possível fazer um ranqueamento de posição das frequências das respostas ou pela mediana (LUCIAN, 2016).

Ao contrário da ordinal, na escala intervalar é possível mensurar os intervalos entre os pontos e, portanto, conhecer o quanto cada ponto está distante do outro. Grande parte das estatísticas como média, desvio padrão, variância, etc., podem ser utilizadas (LUCIAN, 2016). 
Por fim, a escala de razão é uma categoria em que as escalas possuem o poder de igualdade, ordenamento gradual e intervalos iguais entre si. Por isso podese fazer a conversão dessas escalas em outras escalas de razão quando estas medirem o mesmo objeto. São exemplos de escala de razão o comprimento e o peso (LUCIAN, 2016).

Dentre as possibilidades que existem para escolher um tipo de escala de mensuração está a escala Likert. $O$ autor que desenvolveu tal escala visou identificar as atitudes das pessoas através de suas opiniões sobre internacionalismo, racismo, economia, política e religião. Likert (1932) desenvolveu uma escala de 5 pontos com afirmativas e graus de concordância. A forma de análise das respostas desenvolvida pelo autor foram a somatória dos pontos marcados por cada respondente e a distância sigma (distância entre os pontos e a média).

Likert (1932) mostra que as duas formas de análise são as únicas possíveis para esse tipo de escala que é ordinal. Lucian (2016) argumenta que no artigo de Likert a média das distâncias

\footnotetext{
"apresentava a atitude do respondente naquela questão e como a atitude é definida por um conjunto de afirmativas, e não apenas uma, o que contaria era a média das médias para cada cluster. No caso da análise por soma de pontos, era considerado o valor da alternativa marcada pelo respondente em cada afirmativa e, ao final, a atitude seria revelada pelo somatório desses pontos e não pela média.
}

Likert (1932) encontrou como resultado de sua pesquisa que tanto a análise pela somatória quanto pelas médias seriam similares e aparentemente não interfeririam na interpretação final. Ficaria a critério do pesquisador que utilizasse a sua escala a forma de análise.

A contribuição de Likert ao desenvolver a sua escala foi identificar e unir num mesmo instrumento o sentido e a intensidade das respostas de um objeto (atitude) latente (LUCIAN, 2016). Desta forma, aplicando a escala Likert conseguimos identificar em qual sentido o respondente está indo - discordando ou concordando com as afirmações - e o grau de intensidade das respostas.

Neste trabalho utilizou-se um questionário misto que possui duas seções, uma com itens semi-estruturados e a outra com itens estruturados (Ugkuh Fatimah, 
2013). O questionário elaborado por Ungkuh Fatimah possui uma seção demográfica (itens semi-estruturados) e seção relativa à CSA em escala Likert (itens estruturados). A seção demográfica possui característica nominal, uma vez que, os respondentes colocaram livremente as suas respostas e essas são convertidas em números que as identificam a fim de obter as suas frequências.

A escala Likert por ser uma escala ordinal possui a característica de ordenar os objetos alvo do estudo segundo certas características (CHISNALL, 1973), além de serem úteis para nomear, identificar ou categorizar pessoas, objetos ou fatos (MATTAR, 1996). Segundo Oliveira (2001), a escala ordinal nos permite distinguir os objetos entre si, por exemplo, se um produto $A$ é melhor do que o $B$, porém não é possível saber o quanto $A$ é melhor que $B$.

Em princípio, neste presente estudo, a condução da análise estatística foi sustentada pelo entendimento da natureza dos itens e a escala de mensuração conforme o autor que a elaborou, ou seja, ordinal. $O$ que nos leva a análise dos dados através das frequências de respostas, tanto absolutas quanto relativas (\%), somatório dos pontos e distância sigma. Pois, segundo Harry (2012), ao não considerarmos a escala Likert como sendo ordinal poderia ocorrer erro na análise estatística, como por exemplo, analisar os dados considerando-os medidas de tendencial central e gerando dados de média, desvio padrão, etc.

A escala Likert pode ser entendida como escala intervalar (LUCIAN, 2016). O problema da condução da análise estatística considerando a escala Likert como intervalar é: sabemos realmente o que estamos medindo? Likert (1932), quando demonstrou pela primeira vez a sua escala pressupôs que as distâncias entre cada um dos cinco pontos (Discordo fortemente, Discordo, etc.) seriam iguais e, portanto, o respondente da escala também consideraria esse pressuposto ao respondê-la. Mas, na literatura científica há uma discussão que permanece por pelo menos 50 anos a respeito dessas distâncias entre os pontos (CARIFIO, 2008).

Em seu editorial sobre como analisar e interpretar dados de escalas Likert, Gail (2013) nos traz o mesmo comentário feito anteriormente, que "em uma escala ordinal, as respostas podem ser avaliadas ou classificadas, mas a distância entre as respostas não é mensurável". Portanto, estatísticas como médias e desviospadrão têm significados pouco claros quando aplicados a respostas de escala Likert. Basta ter um agrupamento de resposta nos extremos alto e baixo, a média pode 
parecer ser a resposta neutra ou intermediária, mas isso pode não caracterizar de maneira justa os dados (GAIL, 2013).

Os resultados (item 5.4 .2 da dissertação) apresentados mostraram que existe diferença quando se decide analisar as respostas da escala Likert por meio de médias e desvios padrão. A condução da análise sobre as respostas pode influenciar as interpretações sobre a CSA, já que foi utilizado um questionário que possuía escala Likert.

Wakita (2004) descreveu um método para estimar as larguras de cada ponto e mostrou que as larguras foram afetadas pelo conteúdo do item. Posteriormente, Wakita (2012) objetivou examinar o número apropriado de pontos para escalas Likert, concentrando-se na distância psicológica entre os pontos e esclarecer como o número de opções de pontos afeta essa distância. Para o propósito do estudo, foram utilizadas escalas de 4, 5 e 7 pontos para o mesmo instrumento. Concluiu-se que o número de pontos não influenciou a estatística descritiva e as estimativas do coeficiente de confiabilidade. Outro achado foi que os questionários usando a escala Likert são afetados pelo viés de desejabilidade social.

Desejabilidade social é a tendência de alguns entrevistados de reportar uma resposta de uma forma que consideram mais socialmente aceitável do que seria sua resposta "verdadeira". A pessoas fazem isso para projetar uma imagem favorável de si mesmas e evitar receber avaliações negativas. O resultado da estratégia é a supernotificação de comportamentos ou atitudes socialmente desejáveis e a subnotificação de comportamentos ou atitudes socialmente indesejáveis. A desejabilidade social é classificada como uma das fontes de erro (viés) relacionadas ao respondente (CALLEGARO, 2008).

Observe que através do estudo da escala Likert se descobriu uma nova variável que poderia influenciar os respondentes. Será que os participantes do presente estudo foram afetados pela desejabilidade social? Provavelmente sim, pois recentemente Jespersen (2017b) elaborou um instrumento de mensuração para essa variável humana. $O$ autor encontrou que avaliar o grau de desejabilidade social em um estabelecimento de alimentos é importante para ter uma visão mais autêntica, válida e contextualizada da CSA (JESPERSEN, 2017b).

No entanto, Gail (2013) cita que ao longo dos anos outros especialistas em escalas afirmam que se houver um tamanho de amostra adequado (pelo menos 5 a 10 observações por grupo) e se os dados estiverem normalmente distribuídos 
(ou quase normais), os testes paramétricos podem ser usados em escalas ordinais como a de Likert. Segundo Norman (2010), as estatísticas paramétricas

podem ser usadas com dados Likert, com amostras pequenas, com variâncias desiguais e com distribuições não normais, sem medo de chegar à 'conclusão errada'. Esses achados são consistentes com a literatura empírica que remonta há quase 80 anos.

Norman (2010) afirma isso devido à robustez dos testes paramétricos, de acordo com os seus estudos em diferentes tipos de escalas Likert. Porém, em seu próprio artigo, Likert (1932) sugere que o somatório dos pontos seja utilizado ao invés da média porque não se conhece o real valor dos intervalos entre os pontos. Por isso, os resultados apresentados (a partir do item 5.4 do trabalho) focaram-se nas diretrizes do trabalho de Likert, ou seja, análise sobre as frequências, somatório e distância sigma.

Outra questão envolvendo a escala Likert reside no ponto "Neutro". O ponto Neutro (ou no caso do presente estudo chamado de "Indiferente") pode ser interpretado pelos respondentes como uma forma de anular a questão ou realmente um posicionamento neutro à afirmação (LUCIAN, 2016).

Se levarmos em consideração o conceito de desejabilidade social e o conteúdo dos itens de Ungku Fatimah, provavelmente o ponto neutro pode ter sido interpretado pelos participantes desta pesquisa como uma maneira de anular as afirmações. Considerando que os respondentes seguiram essa linha de raciocínio, o diagnóstico da CSA fica prejudicado, pois, ao criar um instrumento de mensuração o autor compõe um conjunto de itens que ele julga necessário para identificá-la. Portanto, apesar da frequência de respostas "Indiferente" ter sido baixa (menor que $10 \%$ ), a ausência desse ponto na escala seria mais precisa para identificar o sentido e intensidade das respostas, facilitando a caracterização de CSA positiva ou negativa. Porém, se retirado o ponto Neutro o indivíduo perde a liberdade de não querer se posicionar sobre determinada afirmação. Além disso, todo o caminho descrito a pouco pode não ser real e o indivíduo apenas se posicionou de forma verdadeiramente neutra. Portanto, sugere-se que mantenha o ponto Neutro na escala, mas que se considere as possibilidades de interpretação desse ponto da escala Likert. 
Veja que toda essa discussão sobre a escala Likert se deve a dois fatos: o desconhecimento dos intervalos entre os pontos e o objeto de mensuração. No caso da CSA, o conjunto de fatores que a compõe difere entre os autores sobre o assunto, devido a forma como eles enxergar a CSA por meio de seus estudos. Isto acontece porque cada pessoa "lê" a CSA no seu íntimo através da sua percepção da realidade. Por si só é notável que esse processo de percepção seja único para cada pessoa. As histórias de vida, as experiências sensíveis, o conhecimento, o modo de ver e raciocinar sobre as coisas de um ser humano é muito complexo e individual.

A busca pela análise da CSA enfrentará os obstáculos descritos anteriormente. Segundo Nayak (2017), a CSA é um "moving target", ou seja, a CSA de qualquer organização está em constante mudança. Isso pode ser encarado como um estímulo à comunidade científica para a construção e pesquisa sobre essa variável latente presente nas organizações de alimentos.

\subsection{A CULTURA DE SEGURANÇA DE ALIMENTOS DA EMPRESA PARTICIPANTE}

Griffith (2010a) postulou que a avaliar e diagnosticar a CSA em uma organização é importante para enxergarmos a conjuntura do estado de coisas em relação à SA. Pode-se identificar fraquezas dos processos, desempenho de unidades, promover o compromisso das pessoas inseridas na organização, etc.

O teste de correlação de Spearman nos mostrou que houve correlação significante entre as respostas sobre os fatores de CSA e as variáveis demográficas Idade e Experiência na Área de Alimentos. Ou seja, houve correlação positiva significante na medida em que se aumenta a idade e a experiência dos participantes da pesquisa. Ambas as variáveis encontradas como sendo significativas, encontram respaldo na literatura científica de alta importância para a SA (THAIVALAPPIL, 2018). Assim, colaboradores mais velhos e com experiência anterior na área de alimentos apresentam maior capacidade de influenciar positivamente a CSA. Não houve associação significativa entre as outras variáveis demográficas e as respostas sobre CSA.

Os resultados para idade apresentaram que 95\% dos participantes estão entre 21 e 55 anos de idade, sendo o grupo 21-25 anos o com maior representatividade $(21,15 \%)$. Uma atenção maior da organização sobre essa fatia dos participantes, através de treinamentos e acompanhamento do desempenho 
provavelmente manterá a CSA positiva. A mesma ação vale para as demais pessoas de outras idades para elevarem os escores de CSA. Sabemos que apenas treinamentos não bastam para uma CSA positiva, mas ele é essencial para fornecer conhecimento, atitudes e práticas em SA (POWELL, 2011; ZANIN, 2017).

Houve correlação significante para Experiência na Área de Alimentos conforme o tempo de experiência aumentava. Trabalhadores que apresentam maior experiência anterior na área de alimentos demonstram quais as práticas corretas de SA. Porém, os resultados expõem que cerca de 35\% dos participantes foram incorporados na organização sem experiência com a manipulação de alimentos. Por isso, a organização deveria intervir fornecendo um treinamento específico a esses participantes em relação a CSA, alinhando e supervisionando o recém-ingressante.

Os resultados da correlação de Spearman para a variável Experiência na área de Alimentos se refletem nos escores da mesma. Acima de 11 anos de experiência os valores dos escores de CSA são maiores que as experiências mais baixas. Porém, é necessário certo cuidado com pessoas muito experientes devido a utilização da experiência em favor à práticas inseguras de alimentos (THAIVALAPPIL, 2018).

Os escores dos fatores de CSA das variáveis demográficas apresentaram uma tendência de positividade. Entre os sexos Feminino e Masculino houve pouca diferença nos resultados, demonstrando uma semelhança de conduta entre os sexos nesse aspecto. Os estrangeiros apresentaram maior escore para CSA, porém sua representatividade na amostra foi baixa $(n=3)$, o que pode ter mascarado esse resultado. As regiões mais representativas na amostra são Nordeste e Sudeste, portanto conhecer os hábitos e costumes dessas regiões podem ajudar nos relacionamentos diários na organização. A origem de nascimento pode ter influencia sobre a maneira como essas pessoas enxergam a CSA.

Quanto a Escolaridade, nota-se que o maior escore de CSA foi apresentado por apenas uma pessoa de ensino fundamental incompleto. Deste fenômeno surgem duas hipóteses: ou essa pessoa possui uma alta compreensão de SA adquirida ao longo da vida, ou no momento de responder o questionário ela foi dominada pela desejabilidade social e assinalou "Concordo muito" em grande parte dos itens.

Nota-se também que as pessoas com ensino superior (incompleto ou completo) apresentaram maiores valores para CSA em comparação as demais 
categorias escolares. Isso mostra que quanto maior o conhecimento sobre SA maior o escore. O fenômeno a respeito da existência da associação positiva entre o grau de escolaridade e o grau de conhecimento, atitudes e práticas de manipuladores de alimentos já se confirmou na literatura (ZANIN, 2017). Apesar dos escores das pessoas Pós-Graduadas serem mais baixos do que alguns outros níveis escolares, essas pessoas ( $n=2)$ são RTs e talvez alguns itens do questionário não se enquadraram nas suas realidades do dia a dia, o que levou a diminuição dos seus escores.

Os resultados dos escores de CSA para o tempo de Experiência na Empresa Participante mostram que duas categorias foram mais significativas - de 3 a 5 anos e 6 a 10 anos - apresentaram baixos escores quando comparado às outras categorias. Segundo Thaivalappil (2018), isso pode acontecer devido a problemas motivacionais no cotidiano da manipulação de alimentos. O reforço positivo pelos superiores aos subordinados não precisa ser monetário para causar uma motivação e promover comportamentos seguros para os alimentos.

Os OP e GC compõem a maior parte da amostra. Ambas as categorias apresentaram tendência de CSA positiva. É possível notar que uma parte dos OP e GC não identificaram o setor no qual trabalhavam. Isso pode ter ocorrido devido ao receio de serem identificados pelos superiores e assim receberem uma possível punição. Porém, esse comportamento não se sustenta uma vez que foram apresentados os objetivos da pesquisa e a livre participação, além do caráter anônimo do estudo.

Em relação à distribuição espacial das lojas e os respectivos valores de escore, as lojas da RLH apresentaram tendência de CSA positiva. Apenas uma loja apresentou estado "Indiferente" devido ao seu escore. Vale ressaltar que o pesquisador não pôde realizar uma amostragem aleatória das lojas. Isto causou a diferença de quantidade entre CRs e o conjunto de RTs subordinados a eles. Devido a questão de tempo e recursos disponíveis, a pesquisa não conseguiu completar o número de lojas presentes no município de São Paulo e nos municípios da Grande São Paulo $(n=70)$. Caso a amostragem tivesse sido aleatória e ter acesso a todas as lojas nesses municípios poderíamos enxergar a CSA e generalizar os resultados para toda a RLH.

Observando os resultados da entrevista com a responsável pela DSACQ na RLH, a organização apresentou um caminho com obstáculos para CSA, mas o 
saldo é positivo. Incutir em todas as pessoas da empresa a importância da SA levou tempo, mas apresentou a determinação e valorização da SA pela empresa. Foi preciso equilibrar a balança em que de um lado está a SA e no outro o desempenho econômico, pois a SA não pode ser um empecilho aos lucros, mas um fator que contribui para diminuir os custos de produção (GRIFFITH, 2010a).

É importante notar a figura do líder na organização. Tanto o CEO Brasil quanto o CEO Internacional valorizavam a SA e isso permeou a organização como um todo. O fato de possuir Líderes engajados é demonstrado pela literatura científica que impacta positivamente em toda a organização (YIANNAS, 2009; GRIFFITH, 2010; SEWARD, 2012; WRIGHT, 2012; DE BOECK, 2015; JESPERSEN, 2016; GFSI, 2018).

A empresa apresenta estrutura administrativa e operacional hierarquizada para fazer acontecer a SA. A hierarquia pode ser benéfica ou prejudicial à SA, pois a hierarquia pode ser positiva para a coordenação de processos ou negativa na resolução de conflitos (GREER, 2018). É preciso que as crenças, valores, atitudes e comportamentos em relação à SA comecem pelos líderes e cheguem ao nível operacional de forma comprometida e engajada, evitando os conflitos devido as diferenças culturais entre as pessoas.

A organização possui departamento de qualidade e segurança de alimentos tanto nacional quanto internacional. Possui pessoas coordenando as lojas e responsáveis técnicos in loco realizando inspeção sanitária e orientando os trabalhadores. Há treinamentos mensais, auditorias externas e análise laboratorial dos produtos. Tudo isso demonstra empenho da organização para garantir produtos seguros e, consequentemente, uma CSA positiva. Para atingir escores mais altos em CSA, a organização precisa atingir os valores, crenças, atitudes e comportamentos através de a) um sistema de recompensa tanto monetário quanto de elogios para todos os envolvidos e b) técnicas de treinamento motivacionais (YIANNAS, 2015). Atingir e conquistar as pessoas que estão envolvidas na realidade de manipulação de alimentos sustentará todo o investimento em infraestrutura relacionada à SA.

Tem sido sugerido na literatura que os documentos comprobatórios da existência de SA nas organizações são imprescindíveis para diagnosticar CSA (NYARUGWE, 2016; NYARUGWE, 2017; JESPERSEN, 2017b). Mas, a obtenção desses documentos não foi possível. Entretanto, pode-se supor que a organização 
deve realizar um controle documental de suas ações devido à presença de uma estrutura administrativa específica para isso. Além disso, ações fiscalizatórias de órgãos oficiais requerem esses documentos. Sugere-se que para estudos futuros sobre CSA é necessário a avaliação desses documentos.

É imprescindível que a organização mantenha entremeada a SA dentro do sistema de seus valores, crenças e atitudes, a fim de que ela se expresse pelos comportamentos das pessoas, seja no nível administrativo seja nos setores de manipulação de alimentos (GRIFFITH, 2010b; YIANNAS, 2009).

\subsection{A INFLUÊNCIA DA CULTURA BRASILEIRA E CULTURA NACIONAL SOBRE OS PARTICIPANTES DA PESQUISA}

O questionário é uma ferramenta fundamental de autorrelato da percepção das pessoas inseridas em um processo produtivo de alimentos para diagnosticar a CSA (SEWARD, 2012; NYARUGWE, 2016; NYARUGWE, 2017; JESPERSEN, 2017a). Mas, como no Brasil não há até esse momento uma ferramenta disponível para ser utilizada, justifica-se a adaptação e validação de um instrumento estrangeiro.

O Brasil possui uma cultura e idioma diferente de onde o instrumento foi retirado e, com isso, entender como o contexto brasileiro pode ter influenciado na interpretação e respostas dos participantes recebe o mérito de ser analisado (TAYLOR, 2011; TAYLOR, 2015; NYARUGWE, 2016). Existem trabalhos na literatura que apontam a influencia da Cultura Nacional (CN) na maneira como as pessoas enxergam os valores, crenças, atitudes e comportamentos relacionados à SA (TAYLOR, 2011; TAYLOR, 2015; NYARUGWE, 2016; JESPERSEN, 2017a).

O Brasil possui proporções continentais, diversidade demográfica e contrastes regionais comparáveis aos Estados Unidos da América e Canadá (HILAL, 2006). O Brasil, apesar da sua semelhança com os países ocidentais - fundados em três pilares principais: a filosofia grega, o direito romano e a religião cristã - é um país que mistura a cultura ocidental com outras culturas não ocidentais há séculos. A nação brasileira é formada pela mistura de raças (miscigenação), religiões e culturas (HILAL, 2006).

Segundo Pereira (2013) a sociedade brasileira possui uma cultura híbrida, ou seja, formada por várias culturas. Analisando a cultura brasileira nas 
organizações o autor considera que a cultura brasileira é formada por sete características ou traços: hierarquia, patrimonialismo, personalismo, formalismo, "jeitinho", estrangeirismo e aventureiro (PEREIRA, 2013).

A hierarquia é entendida como a tendência a centralização do poder, o distanciamento nas relações entre os grupos sociais e a passividade/aceitação dos grupos inferiores. Outro traço é o patrimonialismo que se caracteriza pela apropriação privada dos recursos do Estado e as desigualdades sociais (PEREIRA, 2013).

O formalismo representa uma maneira "tácita de aceitar normas e regras, mas com uma prática distorcida, ou seja, cria-se à prática do 'faz de conta', expressa simbolicamente pelo ditado "é para inglês ver" (PEREIRA, 2013).

$O$ personalismo tem a ver com as relações pessoais que orientam 0 comportamento do indivíduo e o coletivo, havendo aí uma diferenciação entre pessoas que estabelecem afeto/respeito/cordialidade/consideração e pessoas em que não há essas relações (PEREIRA, 2013).

$\mathrm{O}$ "jeitinho" brasileiro configura um mecanismo social aprendido no qual o indivíduo se adapta ao contexto em que ele está presente, retirando de outra(s) pessoa(s) o benefício de que ele pretende adquirir, sendo difícil enganar o praticante dessa técnica social (PEREIRA, 2013). Existem estudos que mostram que há indícios de que o jeitinho brasileiro poderia ter variações, mas isso não é o foco dessa dissertação (FERREIRA, 2012).

O estrangeirismo caracteriza a valorização do que é estrangeiro, ou seja, uma abordagem de subestimar ou desvalorizar a cultura nacional, enxergando os valores estrangeiros como a resolução dos problemas nacionais (PEREIRA, 2013).

$\mathrm{O}$ aventureiro é o indivíduo que "dirige seus esforços a recompensas fáceis e imediatas", de maneira que desvaloriza o trabalho metódico e disciplinado, levando a pessoa a enxergar a dificuldade de vencer, ao invés do triunfo a ser conquistado, ou seja, o indivíduo enxerga só a parte e não o todo (PEREIRA, 2013).

Além dos traços apresentados, Hilal (2006) destaca outros que caracterizam a cultura brasileira. Existe no Brasil, segundo o autor, uma Ética Dupla que opera simultaneamente e determina comportamentos diferentes de acordo com os conceitos de "Casa" e "Rua".

$\mathrm{Na}$ Rua o comportamento é livre do senso de lealdade, livre do significado de "nosso", regido pelos critérios do individualismo, pelas leis e pelas regras do 
mercado. Enquanto que em Casa o comportamento é regido por relações pessoais, o senso de lealdade e emoções, por reciprocidade e amizade. Portanto, no Brasil os comportamentos oscilam entre esses dois conceitos dependendo do contexto que as pessoas estão (HILAL, 2006). Essas formatações e suas diferentes consequências irão moldar a mente e os comportamentos dos indivíduos nas organizações em que trabalham.

Os fatores culturais brasileiros abordados até aqui podem influenciar diretamente os indivíduos de uma organização, mas o inverso não se aplica (VAN OUDENHOVEN, 2001). Os fatores formalismo, personalismo, "jeitinho", aventureiro e "rua" são encontrados na fala da responsável pelo DSACQ ao relatar as suas impressões sobre os comportamentos dos manipuladores de alimentos. O estrangeirismo também aparece no discurso da entrevistada quando há comparação Brasil e outras nações em relação à SA.

Os fatores culturais brasileiros levantados da literatura científica podem também ter influenciado as respostas dos participantes, principalmente o fator formalismo e "casa". Pois, a presença do pesquisador na empresa para realizar o estudo pode ter causado uma atitude defensiva dos participantes através de suas respostas. Esse comportamento também pode ser entendido como desejabilidade social. Sugere-se que novos estudos sejam conduzidos para investigar como esses fatores da cultura brasileira influenciam os brasileiros.

O entendimento de como a Cultura Nacional $(\mathrm{CN})$, neste caso cultura a brasileira, influencia a CO por meio dos colaboradores é importante para CSA. Van Oudenhoven (2001) define a diferença entre CN e CO. A cultura nacional refere-se a

profundas crenças, valores e práticas compartilhadas pela grande maioria das pessoas pertencentes a uma determinada nação. Elas são refletidas nos modos como as pessoas se comportam na escola, na família, no trabalho, etc., e são reforçadas por leis nacionais e políticas governamentais com relação à educação, vida familiar, negócios, etc.

O autor segue argumentando que dentro de uma organização as crenças, valores e práticas são compartilhados pela maioria dos membros. E esses fatores formadores da $\mathrm{CO}$ podem ser formados pela regionalidade em que a empresa está 
ou experiências profissionais construídas ao longo do tempo. Por isso, as crenças, valores e práticas de uma organização não podem ser aplicados em uma nação porque estão restritas a convivência social daquelas pessoas naquele ambiente específico (VAN OUDENHOVEN, 2001).

Se em uma nação a CO de unidades de uma mesma empresa irá apresentar diferenças, mais ainda haverá diferença quando organizações de diferentes países são comparadas, pois a $\mathrm{CN}$ irá influenciar a organização até certo ponto. Por exemplo, uma CN que pessoas no poder, como professores ou gerentes, apresentará uma comunicação organizacional na qual os subordinados hesitam em apresentar discordância aos seus líderes (VAN OUDENHOVEN, 2001).

Hofstede (2010) define CN como a "programação coletiva da mente que distingue os membros de um grupo ou categoria de pessoas de outros". O autor, através de um instrumento de diagnóstico, conseguiu identificar quais dos seus seis fatores que caracterizam determinada nação.

Os seis fatores segundo Hofstede (2010) são: a) distância do poder: culturas com alta distância do poder, a tomada de decisão é centralizada e os funcionários estão pouco envolvidos na tomada de decisões (espera-se que "o chefe diga o que seja feito") e culturas de baixa distância do poder a tomada de decisões é descentralizada e os funcionários esperam ser consultados; b) Individualismo vs coletivismo: nas sociedades individualistas, as pessoas devem cuidar de si mesmas e de sua família direta, já nas sociedades coletivistas, as pessoas pertencem a "grupos" que cuidam delas em troca de lealdade; c) masculinidade vs feminilidade: as culturas masculinas têm pessoas que são assertivas e que dificilmente ajudarão os outros, a menos que recebam crédito, enquanto nas culturas femininas as pessoas ajudam os outros e valorizam os relacionamentos e outras pessoas em detrimento do sucesso material; d) evitar a incerteza: tem a ver com a maneira como uma sociedade lida com o fato de que o futuro nunca pode ser conhecido: "devemos tentar controlar o futuro ou simplesmente deixar que isso aconteça?", portanto, os indivíduos em uma cultura com alto nível de "evitar a incerteza" são expressivos e evitam situações ambíguas, enquanto indivíduos em culturas de baixa "evitar a incerteza" são menos expressivos e se sentem seguros assim; e) orientação de longo prazo vs curto prazo: as culturas orientadas para o longo prazo são tipificadas pela paciência, pelos objetivos de longo prazo e pelas recompensas futuras, e as culturas voltadas para o curto prazo se concentram nas questões predominantes; e 
f) a indulgência $v s$ a restrição: as culturas indulgentes são tipificadas pela gratificação livre, ao passo que as culturas restritivas são tipificadas pela gratificação reprimida (autocontrole) regulada pelas normas sociais.

No sítio eletrônico www.hofstede-insights.com é possível avaliar uma nação através dos seis fatores de Hofstede (2010). No fator Distância do Poder, o Brasil reflete uma sociedade que acredita que a hierarquia deve ser respeitada e as desigualdades entre as pessoas são aceitáveis. A distribuição diferente do poder justifica o fato de que os detentores de poder têm mais benefícios que os menos poderosos da sociedade. Nas empresas, há um chefe que assume total responsabilidade. Os símbolos de status do poder são muito importantes para indicar a posição social e "comunicar" o respeito que pode ser mostrado (HOFSTEDE INSIGHTS, 2018).

Os fatores desenvolvidos por Hofstede (2010) podem influenciar os colaboradores da empresa RLH moldando as relações entre as diferentes hierarquias. Os fatores de Ungku Fatimah utilizados nessa dissertação como Comunicação, Apoio entre Colaboradores e Pressão no Trabalho podem ter sofrido influência nas respostas dos participantes.

O Brasil tem presença de Individualismo (segundo fator de Hofstede), o que significa que neste país as pessoas desde o nascimento são integradas em grupos fortes e coesos (especialmente representados pela família) que continuam protegendo seus membros em troca de lealdade. Esse também é um aspecto importante no ambiente de trabalho, onde, por exemplo, espera-se que um membro mais velho e poderoso de uma família "ajude" um sobrinho mais novo a ser contratado para um emprego em sua própria empresa. Nos negócios, é importante construir relacionamentos confiáveis e duradouros. O estilo de comunicação é rico em contexto, de modo que as pessoas falem profusamente e escrevam de maneira elaborada (HOFSTEDE INSIGHTS, 2018).

Unindo esse achado de pesquisa de Hofstede Insights (2018) com o conceito de "casa" de Hilal (2006) pode-se usufruir desses componentes nas organizações de alimentos. Criar um grupo de trabalho coeso e unido estabelece um melhor resultado nos fatores Comunicação, Autocomprometimento, Apoio entre os Colaboradores e Pressão no Trabalho, culminando numa melhor Consciência de Risco. Além disso, a administração da organização demonstrará sua preocupação 
com a sua "família empresarial" promovendo um Suporte do Ambiente/Ambiente Favorável, conforme estabelecem os itens de Ungku Fatimah (2013).

Em relação à Masculinidade e Feminilidade, o Brasil apresenta uma característica intermediária entre os dois fatores. Ora oscilando comportamentos masculinos, ora femininos. O mesmo fenômeno acontece para a orientação de Longo prazo e Curto prazo (HOFSTEDE INSIGHTS, 2018).

O Brasil, como em todas as sociedades de alta tendência de Evitar a Incerteza, a burocracia, leis e regras são muito importantes para tornar o mundo um lugar mais seguro para se viver. Os brasileiros precisam ter momentos bons e relaxantes em seu cotidiano, conversando com colegas, desfrutando de uma longa refeição ou diversão com convidados e amigos. Devido à sua alta pontuação nesse fator, os brasileiros são pessoas muito apaixonadas e demonstrativas: as emoções são facilmente mostradas em sua linguagem corporal (HOFSTEDE INSIGHTS, 2018).

O Brasil apresentou tendência a ser uma sociedade Indulgente. Pessoas em sociedades classificadas por alta pontuação em Indulgência geralmente demonstram disposição para realizar seus impulsos e desejos com relação a aproveitar a vida e se divertir. Eles possuem uma atitude positiva e tendem ao otimismo. Além disso, eles colocam um maior grau de importância no tempo de lazer, agem como bem entenderem e gastam dinheiro como desejarem (HOFSTEDE INSIGHTS, 2018).

Os resultados encontrados tanto no fator Evitar a Incerteza e Indulgência encontram respaldo nas declarações da entrevistada responsável pelo DSACQ quando refere-se aos brasileiros como "emocionais". Mas, se olharmos para o desempenho tanto econômico quanto em SA, essa característica encontrada por Hofstede Insights (2018) pode melhorar a relação de trabalho nos estabelecimentos de alimentos. A organização entendendo como o brasileiro age no cotidiano pode usar isso a seu favor, promovendo lazer e momentos de relaxamento ao brasileiro visando a sua produtividade.

As abordagens sobre a cultura brasileira e $\mathrm{CN}$ descritas anteriormente podem contribuir para novos caminhos de estudo para CSA, pois são a extensão do raciocínio que busca a origem da formação da CSA em uma organização. Uma vez que dentro de um estabelecimento de alimentos haverá pessoas executando ou controlando os processos. Cada pessoa é composta por diferentes aspectos da CN 
que a formou e isso pode influenciar os valores, crenças, atitudes e comportamentos da CSA. 


\section{CONCLUSÃO}

\subsection{CONCLUSÕES GERAIS}

A proposta do trabalho foi validar um instrumento em português do Brasil de avaliação de cultura de segurança de alimentos. Foi selecionado da literatura científica o questionário de Ungku Fatimah (2013) para atingir o objetivo de validar para o português brasileiro. A metodologia de Borsa (2012) foi utilizada para adaptação e validação do instrumento em seis etapas.

Considera-se que a aplicação da metodologia para adaptação e validação do instrumento foi consistente e replicável. A padronização das etapas sugerida pelo autor contribuiu para validação do instrumento de Ungku Fatimah no Brasil.

As análises estatísticas mostraram que 0 instrumento apresenta confiabilidade interna nos 31 itens em cada fator de CSA. As análises fatoriais exploratória e confirmatória apresentaram um rearranjo dos itens de maneira diferente da apresentada por Ungku Fatimah. Novos estudos com o instrumento validado para o Brasil são necessários a fim de verificar se esse comportamento se mantém ou se a composição original do autor estrangeiro é a mais indicada.

Além disso, a comparação dos seis fatores desenvolvidos por Ungku Fatimah com outros fatores de autores diferentes de CSA permite a conclusão que aqueles encontram similaridade de conteúdo com estes. Em outras palavras, o conteúdo dos fatores de Ungku Fatimah são correspondentes a outros fatores disponíveis na literatura.

Os resultados das frequências absolutas e relativas bem como os escores de CSA conduzem à conclusão de que a empresa participante apresenta tendência positiva para CSA. O fator "Julgamento baseado em Risco" apresentou tendência negativa.

O teste de correlação de Spearman nos leva a conclusão que a Idade e a Experiência na área de alimentos são variáveis que interferem na CSA. Quanto maior a idade e experiência maior a positividade da CSA.

Os depoimentos extraídos da entrevista com a responsável pelo DSACQ apresentaram uma organização que se dedicou para implantar a SA. A empresa ao longo do tempo foi se adaptando às necessidades de segurança para os alimentos. Por isso, é possível concluir que a empresa possui uma infraestrutura administrativa 
em SA que se estende até as lojas, com pessoas dedicadas a isso (ex. CR e RT) que supervisionam os comportamentos dos colaboradores. Mas, tudo isso parte da presença de valores e crenças, desde as hierarquias superiores até as mais inferiores, de que a SA é importante para organização, conforme descrito nos resultados da entrevista.

\subsection{REFLEXÕES E LIMITAÇÕES DO ESTUDO}

Os resultados e conclusões aqui obtidos aconteceram em um determinado período do tempo e espaço. Por isso, os resultados não se aplicam a um período posterior à coleta de amostra. $O$ conjunto de pessoas analisado pode ter alterado e, como a CSA é formada por cada indivíduo em uma organização, os resultados também irão ser alterados.

Os resultados obtidos nesse trabalho não podem ser extrapolados para outros estabelecimentos comerciais de alimentos, pois a natureza do estudo não permite essa abrangência (amostra não probabilística). Também não se pode afirmar os resultados e conclusões aqui obtidos para toda a RLH devido ao tamanho da empresa e da variedade de estabelecimentos que ela possui (mais de 70 lojas no município de São Paulo, segundo informação de representante da empresa). Seria necessário para isso uma amostragem aleatória, o que levaria tempo e recursos para concluir o trabalho.

O questionário é útil para aqueles que desejam diagnosticar a CSA de seu estabelecimento de alimentos segundo a percepção dos colaboradores. Porém, o questionário é uma das formas de enxergar a CSA de uma organização. Existem outras formas de verificar a realidade de SA de um estabelecimento de alimentos, conforme destacam Nyarugwe (2017) e Jespersen (2017).

Conforme Nyarugwe (2017) existem quatro aspectos chaves para analisar e identificar CSA de um estabelecimento de alimentos: desempenho de segurança microbiológica dos produtos, comportamento real no local de trabalho, condições de capacitação tecnológica e organizacional e características dos colaboradores. O questionário deste estudo é uma ferramenta de diagnóstico momentâneo ou uma "foto" da percepção dos colaboradores sobre CSA, além de descrever as características dos participantes. Portanto, só atinge um dos quatro aspectos. 
Jespersen (2017) propõe o método de triangulação para identificar a CSA de uma organização (escala de autoavaliação, desempenho documental e entrevista semi-estruturada). Foram coletadas a percepção dos colaboradores e o depoimento do responsável pela SA da organização. Devido aos resultados aqui apresentados, provavelmente, o desempenho documental da empresa seja positivo. Assim, haveria um sinergismo positivo para CSA com a triangulação completa.

Kirezieva (2015) sugere que as diferenças culturais nacionais são observadas na filosofia, estratégias e práticas de governança da SA de um país (por exemplo, legislação, normas públicas e privadas e práticas de fiscalização). Pois, o governo visa o cumprimento das normas e padrões de SA nas organizações. O modo como o governo atua influenciará a CSA das organizações. Não foi analisado neste estudo as características local, estadual e federal governamentais, pois não eram objetivos da pesquisa. Mas, são necessários estudos sobre como essas características influenciam a CSA nas organizações para verificar como as leis sanitárias influenciam nas organizações e qual a intensidade.

Fatores econômicos bem como a situação política nacional não foram considerados como possíveis influenciadores da CSA. Sabe-se, por exemplo, que crises financeiras na organização podem afetar custos de produção ou redução do quadro de funcionários, o que poderia influenciar nos comportamentos dos colaboradores durante o manuseio dos alimentos. Portanto, analisar se os índices econômicos afetam o desempenho da CSA nas organizações pode ser pertinente. 


\section{REFERÊNCIAS}

BALL, B.; WILCOCK, A.; COLWELL, S. Tool For Measuring Food Safety Climate. Journal of Food Protection, United States, v. 73, p. 84, Jan. de 2010.

BEHR, D. Assessing the use of back translation : the shortcomings of back translation as a quality testing method. International Journal of Social Research Methodology, United States, v. 20, n. 6 , p. 573-584, 2016. Disponível em: <http://dx.doi.org/10.1080/13645579.2016.1252188>. Acesso em: 15 ago. 2017.

BOANOVA, A. B. Comércio varejista de alimentos no Município de São Paulo: comparação entre os códigos sanitérios de 1988 e de 2004. 2008. $136 \mathrm{f}$. Dissertação (Mestre em Saúde Pública) - Faculdade de Saúde Pública, Universidade de São Paulo, São Paulo, 2008.

BORSA, J. C.; DAMÁSIO, B. F.; BANDEIRA, D. R. Adaptação e validação de instrumentos psicológicos entre culturas: algumas considerações. Paidéia, Ribeirão Preto, v. 22, n. 53, p.423-432, 2012. Disponível em: < doi:http://dx.doi.org/10.1590/1982-43272253201314>. Acesso em: 20 jul. 2017.

BRASIL. Ministério da Saúde. Secretaria de Vigilância em Saúde. Departamento de Vigilância das Doenças Transmissíveis. Coordenação Geral de Doenças Transmissíveis. Surtos de Doenças Transmitidas por Alimentos no Brasil [apresentação]. [Brasília]: 2018. 16 p. Disponível em: < http://portalarquivos2.saude.gov.br/images/pdf/2018/julho/02/Apresentacao-SurtosDTA-Junho-2018.pdf >. Acesso em: 05 jun. 2018.

BRASIL. Ministério da Saúde. Conselho Nacional de Saúde. Resolução oㅜ 510, de 7 de abril de 2016. Esta Resolução dispõe sobre as normas aplicáveis a pesquisas em Ciências Humanas e Sociais cujos procedimentos metodológicos envolvam a utilização de dados diretamente obtidos com os participantes ou de informações identificáveis ou que possam acarretar riscos maiores do que os existentes na vida cotidiana, na forma definida nesta Resolução. Diário Oficial [da] União, Brasília, DF, 24 maio 2016. Seção 1. p. 44-46. Disponível em: <http://conselho.saude.gov.br/resolucoes/2016/Reso510.pdf>. Acesso em: 13 ago. 2018.

BRASIL. Portaria CVS 5, de 09 de abril de 2013. Aprova o regulamento técnico sobre boas práticas para estabelecimentos comerciais de alimentos e para serviços de alimentação, e o roteiro de inspeção, anexo. Diário Oficial [do] Estado de São Paulo, São Paulo, 19 mar. 2013. № 73, Seção I, p. 32-35. 
BRASIL. Ministério da Saúde. Agência Nacional de Vigilância Sanitária. ResoluçãoRDC n²16, 15 de set. de 2004. Dispõe sobre Regulamento Técnico de Boas Práticas para Serviços de Alimentação. Diário Oficial [da] União, Brasília, 16 de set. 2005. Seção I, p. 25-28.

BRISLIN, R. W. Back-translation for cross-cultural research. Journal of CrossCultural Psychology, United States, v. 1, n 3, p. 185-216, 1970. Disponível em: < https://doi.org/10.1177/135910457000100301>. Acesso em: 22 set. 2018.

BUSINESS DICTIONARY - BD. Chief executive officer (CEO). Texas. 2018. Disponível em: <http://www.businessdictionary.com/definition/chief-executive-officerCEO.html> Acesso em: 10 set. 2018.

CANFIELD, M.; GILVARRY, C.; KOLLER, S. H. Psychometric proprities of the substance use risk profile scale - brazilian version. International Journal of Mental Health Addiction, United States, v. 37, n. 1, p. 204-214, 2015.

CARDINAELS, E.; DIERYNCK, B.; HU, W. Rejections, Incentives, and Employee Creativity: When Chocolate Is Better Than Cash. Georgia Tech Scheller College of Business Research Paper. Georgia, n. 17-32, 16 Ago.2017. Disponível em: <http://dx.doi.org/10.2139/ssrn.3022001 >. Acesso em: 29 set. 2018.

CARIFIO, J.; PERLA, R. Resolving the 50-year debate around using and misusing Likert scales. Medical Education, United States, v. 42, n. 12, p. 1150-1152, 2008. Disponível em: <https://onlinelibrary.wiley.com/doi/full/10.1111/j.13652923.2008.03172.x>. Acesso em: 12 Ago. 2018.

CALLEGARO, M. Social Desirability. In: LAVRASKAS, P. J. Encyclopedia of survey research methods. 1. ed. p. 1000. USA: SAGE Publications, 2008. Online ISBN: 9781412963947.

CENTERS FOR DISEASE CONTROL AND PREVENTION (CDC). Surveillance for foodborne disease outbreaks - United States, 2009-2015. MMWR Surveill Summ Annual Report by Centers for Disease Control and Prevention. vol. 67, n. 10, p. 1-11, 2015. Disponível em:<http://dx.doi.org/10.15585/mmwr.ss6710a1>. Acesso em: 02 Ago. 2017.

CHISNALL, P. M. Marketing research: Analysis and Measurement. Madison: McGrawHill,1973.

COCHRAN, W. Sampling Techniques. 3. ed., New York: John Wiley \& Sons, 1986. $428 \mathrm{p}$. 
CODEX ALIMENTARIUS. Food hygiene basic texts. 4. ed. Rome, Italy: Food and Agriculture Organization of The United Nations - World Health Organization, 2009. $136 \mathrm{p}$.

CORPORATE FINANCE INSTITUTE - CFI. What is a CEO (Chief Executive Officer)? London, 2018. Disponível em

$<$ https://corporatefinanceinstitute.com/resources/careers/jobs/what-is-a-ceo-chiefexecutive-officer/> Acesso em: 10 set. 2018.

CONSELHO REGIONAL DE MEDICINA VETERINÁRIA DE SÃO PAULO (CRMVSP). Conselho regional de Medicina Veterinária de São Paulo. Manual de Responsabilidade Técnica e Legislação. 3. ed. São Paulo: CRMV-SP, 2014. 406 p.

DE BOECK, E.; JACXSENS, L.; BOLLAERTS, M.; VLERICK, P. Food safety climate in food processing organizations: development and validation of a self-assessment tool. Trends in Food Science \& Technology, United States, 29 Set. de 2015. v. 46, n. 2, p. 242-251, 2015. Disponível em: <http://dx.doi.org/10.1016/j.tifs.2015.09.006>. Acesso em: 10 jun. 2017.

EUROPEAN FOOD SAFETY AUTHORITY (EFSA). The European Union Summary Report on Trends and Sources of Zoonoses , Trends and Sources of Zoonoses, Zoonotic Agents and Food-borne Outbreaks in 2012. European Food Safety Authority Journal, 22 Jan de 2014. Vol. 12, N. 2, p. 312, 2014.

FERREIRA, J. A. F. Panorama das doenças transmitidas por alimentos no Brasil entre 2000 e 2015. 2017. 74 f. Dissertação (mestre em ciências). Faculdade de Saúde Pública, Universidade de São Paulo, São Paulo, 2017.

FERREIRA, M. C.; FISCHER, R.; PORTO, J. B.; PILATI, R.; MILFONT, T. L. Unraveling the mystery of brazilian jeitinho: a cultural exploration of social norms.

Personality and Social Psychology Bulletin, United States, v. 38, n.3, p. 331-344, 2012.

FOOD AND DRUG ADMINISTRATION (FDA). Food code. Alexandria, US: UNITED STATES PUBLIC HEALTH SERVICE - FOOD AND DRUG ADMINISTRATION, 2017. Disponível em: < https://www.fda.gov/downloads/Food/GuidanceRegulation/RetailFoodProtection/Foo dCode/UCM595140.pdf>. Acesso em: jun. 2017.

FORSYTHE, S. J. Infecções e intoxicações de origem alimentar. In: FORSYTHE, S. J. Microbiologia da segurança dos alimentos. $2^{a}$ ed. São Paulo: Artmed, 2013. $602 \mathrm{p}$. 
GAIL, M. S.; ARTINO, A. R. Analyzing and Interpreting Data From Likert-Type Scales. Journal of Graduate Medical Education, United States, Dez. de 2013. v. 5, n. 4, p. 541-542, 2013. Disponível em:

<https://www.ncbi.nlm.nih.gov/pmc/articles/PMC3886444/> Acesso em: 12 Ago. 2018.

GABARDO-MARTINS, L. M. D.; FERREIRA, M. C.; VALENTINI, F. Psychometric properties of the multidimensional scale of perceived social support. Trends in Psychology, Ribeirão Preto - BR, v. 25, n. 4, p. 1873-1883, 2017. Disponível em: <http://dx.doi.org/10.9788/tp2017.4-18pt> Acesso em: 20 out. 2018.

GIL, A. C. Métodos e técnicas de pesquisa social. $6^{a}$ ed. São Paulo: Atlas, 2008. $216 \mathrm{p}$.

GREER, L. L.; SCHOUTEN, M. E.; JONG, B. A. de; DANNALS, J. E. Why and when hierarchy impacts team effectiveness: a meta-analytic integration. Journal of Applied Psychology, United States, v. 103, n. 3, p. 591-613, 2018. Disponível em: < http://dx.doi.org/10.1037/apl0000291> Acesso em: 04 Jun. 2018.

GRIFFITH, C. J. Food safety : where from and where to ? British Food Journal, United Kingdom, v. 108, n. 1, p. 6-15, 2006. Disponível em: < http://dx.doi.org/10.1108/00070700610637599> Acesso em: 22 Mai. 2017.

GRIFFITH, C. J.; LIVESEY, K. M.; CLAYTON, D. A. The assessment of food safety culture. British Food Journal, United Kingdom, v. 112, n. 4, p. 439-456, 2010 a. Disponível em: <https://doi.org/10.1108/00070701011034448>. Acesso em: 22 Mai. 2017.

GRIFFITH, C. J.; LIVESEY, K. M.; CLAYTON, D. A. Food safety culture: the evolution of an emerging risk factor? British Food Journal, United Kingdom, v. 112, n. 4, p. 426-438, 2010b. Disponível em: < https://doi.org/10.1108/00070701011034439> Acesso em: 22 Mai. 2017.

GRIFFITH, C. J.; JACKSON, L. M.; LUES, R. The food safety culture in a large South African food service complex: perspectives on a case study. British Food Journal, United Kingdom, v. 119, n: 4, p.729-743, 2017. Disponível em: < http://dx.doi.org/10.1108/BFJ-11-2016-0533> Acesso em: 21 jun. 2017.

GUILLEMIN, F.; BOMBARDIER, C; BEATON, D. Cross-cultural adaptation of healthrelated quality of life measures : literature review and proposed guidelines. Journal Clinical Epidemiology, Great Britain, v. 46, n. 12, p. 1417-1432, 1993.

HAIR, J.; ANDERSON, R.; BABIN, B. Multivariate Data Analysis: a global perspective. 7. ed. Upper Saddle River: Prentice Hall, 2009. 785 p. 
HARRY, N. B.; BOONE, D. A. Analyzing Likert data. Journal of Extension. West Virginia-US, Abr. de 2012. v. 50, n. 2, 2012. Disponível em:

<https://joe.org/joe/2012april/tt2.php>. Acesso em: 12 Ago. 2018.

HEALTH AND SAFETY EXECUTIVE (HSG65). Successful Health and Safety Management. 2. ed. HSE Books: United Kingdom, 2008. 98 p.

HILAL, A. V. G. de. Brazilian National Culture, Organizational Culture and Cultural Agreement - Findings from a Multinational Company. International Journal of Cross Cultural Management, United States, 01 Ago. de 2006. v. 6, n. 2, p. 139-167, 2006. Disponível em: <https://doi.org/10.1177/1470595806066325> Acesso em: 12 Set. 2018.

HOFSTEDE INSIGHTS. What about Brazil? Finland. 2018. Disponível em: < https://www.hofstede-insights.com/country/brazil/> Acesso em: 12 set. 2018.

HOFSTEDE, G.; HPFSTEDE, G. J.; MINKOV, M. Cultures and Organizations Software of mind. 3. ed. New York: McGraw-Hill, 2010. ISBN: 978-0-07-177015-6.

JESPERSEN, L.; WALLACE, C. A. Triangulation and the importance of establishing valid methods for food safety culture evaluation. Food Research International, United States, v. 100, Part 1, p. 244-253, 2017a. Disponível em: < https://doi.org/10.1016/j.foodres.2017.07.009> Acesso em: 23 Set. 2017.

JESPERSEN, L.; MACLAURIN, T.; VLERICK, P. Development and validation of a scale to capture social desirability in food safety culture. Food Control, United States, v. 82, p.42-47, 2017b. Disponível em: <http://dx.doi.org/10.1016/j.foodcont.2017.06.010> Acesso em: 01 out. 2018.

JESPERSEN, L.; GRIFFITHS, M.; MACLAURIN, T.; CHAPMAN, B.; WALLACE, C. A. Measurement of Food Safety Culture using Survey and Maturity Profiling Tools. Food Control, United States, v. 66, p. 174-182, 2016. Disponível em: <http://dx.doi.org/10.1016/j.foodcont.2016.01.030>. Acesso em: 21 jun. 2017.

KIREZIEVA, K.; JACXSENS, L.; HAGELAAR, G. J. L. F.; van BOEKEL, M. A. J. S.; UYTTENDAELE, M.; LUNING, P. A. Exploring the influence of context on food safety management: Case studies of leafy greens production in Europe. Food Policy. United States, v. 51, p. 158-170, 2015. Disponível em: < https://doi.org/10.1016/j.foodpol.2015.01.005> Acesso em: 22 Set. 2018.

KIRK, M. D.; PIRES, S. M.; BLACK, R. E.; CAIPO, M.; CRUMP, J. A.; DEVLEESSCHAUWER, B.; DOPFER, D.; FAZIL, A.; FISCHER-WALKER, C. L.; HALD, T.; HALL, A. J.; KEDDY, K. H.; LAKE, R. J.; LANATA, C. F.; TORGERSON, P. R.; HAVELAAR, A. H.; ANGULO, F. J. World Health Organization estimates of the 
global and regional disease burden of 22 foodborne bacterial, protozoal, and viral diseases, 2010: a data synthesis. PLOS Medicine, United States, v. 12, n. 12, p. 121, 2015. Disponível em: <

https://journals.plos.org/plosmedicine/article id=10.1371/journal.pmed.1001921> Acesso em: 20 Dez. 2017.

LANDIS, J. R.; KOCH, G. G. The measurement of observer agreement for categorical data. Biometrics, United States. v. 33, n. 1, p. 159-174. 1977. Disponível em: < https://www.jstor.org/stable/2529310>. Acesso em: 20 Jul. 2017.

LAKATOS, E. M.; MARCONI, M. D. A. Fundamentos de metodologia científica. $5^{\mathrm{a}}$ ed. São Paulo: Atlas S.A., 2003.

LIKERT, R. A technique for the measurement of attitudes. Archives of Psychology, United States, v. 22, n. 140, p. 5-55, 1932. Disponível em:

<http://psycnet.apa.org/psycinfo/1933-01885-001>. Acesso em: 14 Jun. 2018.

LUCIAN, R. Repensando o uso da escala likert: tradição ou escolha técnica? PMKT - Revista Brasileira de Pesquisas de Marketing, Opinião e Mídia. São Paulo, Abr. 2016, v. 18, p. 13-32, 2016.

MARTINS, G. A. Sobre confiabilidade e validade. Revista Brasileira de Gestão de Negócios, Brasil, 20 Fev. 2006. v. 8, n. 20, p. 1-12, 2006. Disponível em: < http://www.spell.org.br/documentos/ver/6471/sobre-confiabilidade-e-validade/i/pt-br> Acesso em: 05 Set. 2018.

MATTAR, F. N. Pesquisa de Marketing. São Paulo: Atlas,1996.

MUNNICH, K. MAHLER, C. F. FRICKE, K. Pilot Project to introduce simple technical procedures for mechanical biological treatment of waste in Brazil. Waste Management, v. 26, n. 2, p. 150-157. 2006. Disponível em: < http://dx.doi.org/10.1016/j.wasman.2005.07.022>. Acesso 27 dez. 2017.

NAYAK, R.; WATERSON, P. The Assessment of Food Safety Culture: An investigation of current challenges, barriers and future opportunities within the food industry. Food Control. United States, v. 73, part B, p. 1114-1123, 2017. Disponível em: < http://dx.doi.org/10.1016/j.foodcont.2016.10.061> Acesso em: 09 dez 2017.

NEAL, J. A.; BINKLEY, M.; HENROID, D. Assessing factors contributing to food safety culture in retail food establishments. Food Protection Trends, United States, Ago. 2012. v. 32, n. 8, p. 468-476, 2012.

NORMAN, G. Likert scales, levels of measurement and the "laws" of statistics. 
Advances in Health Sciences Education, 10 Fev. de 2010. v. 15, n. 5, p 625-632, 2010. Disponível em: <https://link.springer.com/article/10.1007\%2Fs10459-0109222-y> Acesso em: 12 Ago. 2018.

NYARUGWE, S. P.; LINNEMANN, A.; HOFSTEDE, G. J.; FOGLIANO, V.; LUNING, $P$. A. Determinants for conducting food safety culture research. Trends in Food Science \& Technology, United States, 29 Jul. 2016. v. 56, p. 77-87, 2016. Disponível em: <http://dx.doi.org/10.1016/j.tifs.2016.07.015>. Acesso em: 22 Ago. 2017.

NYARUGWE, S. P.; LINNEMANN, A.; NAYANGA, L. K.; FOGLIANO, V.; LUNING, P. A. Food safety culture assessment using a comprehensive mixed-methods approach: a comparative study in dairy processing organisations in an emerging economy. Food control, United States, 28 Jul. 2017. v. 84, p. 186-196, 2017. Disponível em: < http://dx.doi.org/10.1016/j.foodcont.2017.07.038>. Acesso em: 20 Mar. 2018.

OLIVEIRA, T. M. V. de. Escalas de Mensuração de Atitudes: Thurstone, Osgood, Stapel, Likert, Guttman, Alpert. Administração On Line, Abr/Mai/Jul de 2001. v. 2, n. 2, p. 1-21, 2001.

PARASURAMAN, A. Marketing research. 2. ed. New York: Addison Wesley Publishing Co, 1991.

PAN AMERICAN HEALTH ORGANIZATION (PAHO). Manual para manipuladores de alimentos. 1. ed. Washigton, DC: Pan American Health Organization; World Health Organization, 2016.

PEREIRA, J. R.; CANÇADO, A. C.; RODRIGUES, F. O.; da SILVA, E. E. Cultura organizacional e cultura brasileira: compreendendo as fragilidades do cooperativismo brasileiro. NAU Social, Mai./Out. de 2013. v.4, n.6, p. 61-81, 2013. Disponível em: < http://www.periodicos.adm.ufba.br/index.php/rs/article/viewArticle/225> Acesso em: 12 Set. 2018.

PETRUCCI, G. W.; BORSA, J. C.; DAMÁSIO, B. F.; KOLLER, S. H. Adaptation and preliminary validation evidences of the School Climate Questionnaire - Revised, Elementary and Middle School Version (SCS-MS). Psicologia: reflexão e crítica, Porto Alegre-BR, 20 Jun. 2016. v. 29, n. 25, 2016. Disponível em:

<http://dx.doi.org/10.1186/s41155-016-0037-5 > Acesso 25 out. 2018.

POWELL, D. A.; JACOB, C. J.; CHAPMAN, B. J. Enhancing food safety culture to reduce rates of foodborne illness. Food Control, United States, v. 22, n. 6, p. 817822, 2011. Disponível em: <http://dx.doi.org/10.1016/j.foodcont.2010.12.009>. Acesso em: 21 jun. 2017. 
PREFEITURA DE SÃO PAULO. Relação das UVIS - Unidades de Vigilância em Saúde. In: INSCRIÇÃO para Curso de Boas Práticas de Manipulação de Alimentos. São Paulo. 2018. Disponível em: $<$ https://www.prefeitura.sp.gov.br/cidade/secretarias/saude/vigilancia_em_saude/vigil ancia_sanitaria/index.php?p=253506> Acesso em 05 out. 2018.

PRIETO, A. J. A Method for Translation of Instruments to Other Languages. Adult Education Quarterly, United States, 1 Mar. 2012. v. 43, n. 1, p. 1-14, 1992.

Disponível em: < https://doi.org/10.1177/0741713692043001001 >. Acesso em: 20 Set. 2012.

SEWARD, S.; DOBMEIER, N.; BARON, M. Assessing the food safety culture of a manufacturing facility. Institute of Food Technololy. United States, v. 66, n. 1, p. 44-47, 2012. Disponível em: < http://www.ift.org/Food-Technology/PastIssues/2012/January.aspx>. Acesso em: 27 Set. 2018.

SILVA-ROCHA, V. V.; OSÓRIO, F. de L. Cross-cultural adaptation of the Sport Anxiety Scale-2 (SAS-2) for the Brazilian context. Trends in Psychiatry and Psychotherapy. Porto Alegre-BR, Set. de 2017. v. 39, n. 3, p. 202-206, 2017. Disponível em: <http://dx.doi.org/10.1590/2237-6089-2017-0027> Acesso em: 25 out. 2018.

SCHEIN, E. H. Organizational culture and leadership. $3^{\mathrm{a}}$ ed. San Francisco: Jossey-Bass, 2004. 458 p.

TAYLOR, J. An exploration of food safety culture in a multi-cultural environment: next steps? Worldwide Hospitality and Tourism Themes, United Kindom, v. 3, n. 5, p. 455-466, 2011. Disponível em: < https://www.emeraldinsight.com/doi/full/10.1108/17554211111185836>. Acesso em: 20 Jan. 2017.

TAYLOR, J.; GARAT, J. P.; SIMREEN, S.; SARIEDDINE, G. An industry perspective: a new model of food safety culture excellence and the impact of audit on food safety standards. Worldwide Hospitality and Tourism Themes, United Kindom, v. 7, n. 1, p. 78-89, 2015. Disponível em: < https://www.emeraldinsight.com/doi/full/10.1108/WHATT-12-2014-0041>. Acesso em: 16 out. 2017.

THAIVALAPPIL, A.; WADDELL, L.; GREIG, J.; MELDRUM, R.; YOUNG, R. A systematic review and thematic synthesis of qualitative research studies on factors affecting safe food handling at retail and food service. Food Control, Jul. de 2018. v. 89, p. 97-107, 2018. Disponível em: < https://doi.org/10.1016/j.foodcont.2018.01.028 > Acesso em 15 set. 2018. 
UNGKU FATIMAH, U. Z. A. Measuring food safety culture : insights from onsite foodservice operations. 2013. $186 \mathrm{f}$. Dissertação (doutor em filosofia) - lowa State University, 2013. lowa, 2013.

van OUDENHOVEN, J. P. Do organizations reflect national cultures? A 10-nation study. International Journal of Intercultural Relations, Jan. de 2001. v. 25, n. 1, p. 89-107, 2001. Disponível em: <https://doi.org/10.1016/S0147-1767(00)00044-4> Acesso em: 20 Set. 2018.

WAKITA, T.; UESHIMA, N.; NOGUSHI, H. Psychological distance between categories in the likert scale: comparing different numbers of options. Educational and Psychological Measurement, 12 Jan. de 2012. v. 72, n.4, p. 533-546, 2012. Disponível em: <https://doi.org/10.1177/0013164411431162> Acesso em: 12 ago. de 2018.

WAKITA, T. The distance between categories in rating-scale method: Applying item response model to the assessment process. Japanese Journal of Psychology, $v$. 75, p. 331-338, 2004.

WHITING, M. A.; BENNETT, C. J. Driving Toward " 0 ": best practices in corporate safety and health. The conference board, inc., p. 1-35, 2003.

WORLD HEALTH ORGANIZATION (WHO). Cinco chaves para uma alimentação mais segura: manual. Genebra, SW: 2006. p. 30.

WORLD ORGANISATION FOR ANIMAL HEALTH (OIE). Veterinary public health the role of the veterinary services. In: TERRESTRIAL Animal Health Code. 20. ed. Paris, France: World Organisation for Animal Health, 2011. p. 485, Vol. 1.

WRIGHT, A. M. S.; LEACH, P.; PALMER, G. A tool to diagnose culture in food business operators: report from greenstreet berman Itd. for the Food Standards Agency. Boston: Greenstreet Berman Ltd, 2012. p. 1-110.

YIANNAS, F. Food safety culture: creating a behavior-based food safety management system. New York: Springer-Verlag, 2009. p. 96. eBook ISBN: 978-0387-72867-4.

YIANNAS, F. Food Safety $=$ Behavior: 30 proven techniques to enhance employee compliance. New York: Springer-Verlag, 2015. p. 115. eBook ISBN: 978-1-49392489-9.

ZANIN, L. M.; da CUNHA, D. T.; ROSSO, V. V. de; CAPRILES, V. D.;

STEDEFELDT, E. Knowledge, attitudes and practices of food handlers in food safety: 
an integrative review. Food Research International, Out. de 2017. v. 100, Part 1, p. 53-62, 2017. Disponível em: < https://doi.org/10.1016/j.foodres.2017.07.042 > Acesso em: 25 set. 2018.

ZANON, R. B.; DA SILVA, M. A.; MENDONÇA FILHO, E. J. de; BANDEIRA, D. R.; SANTOS, M. A. dos; HALPERN, R.; BOSA, C. A. Brazilian study of adaptation and psychometric properties of the Coping Health Inventory for Parents. Psicologia: Reflexão e Crítica, Porto Alegre-BR, 01 Jun. de 2017. v. 30, n. 10, p. 1-10, 2017. Disponível em: <http://dx.doi.org/10.1186/s41155-017-0065-9 > Acesso em: 25 out. 2018. 


\section{APÊNDICE A - TERMO DE CONSENTIMENTO LIVRE E ESCLARECIDO}

\section{TERMO DE CONSENTIMENTO LIVRE E ESCLARECIDO}

Título do Projeto: Validação de um instrumento para caracterização de cultura de segurança de alimentos para o português brasileiro.

Pós-graduando Responsável: Victor Chiaroni Galvão

Pesquisador Responsável: Profa. Dra. Simone de Carvalho Balian

Este projeto tem o objetivo de validar um instrumento em português do Brasil de avaliação de cultura de segurança de alimentos.

O presente termo de consentimento livre esclarecido se refere à coleta de dados a partir da aplicação dos Questionários oferecidos aos colaboradores de uma Rede de lojas de Hipermercado que comercializam alimentos prontos para o consumo.

Durante a execução do projeto não haverá nenhum risco à sua saúde e caso haja alguma dúvida estaremos à disposição para prestar esclarecimentos que forem necessários nos telefones: (11) 972389226 ou (11) 30917653.

Após ler e receber explicações sobre a pesquisa, e ter meus direitos de:

1. Receber resposta a qualquer pergunta e esclarecimento sobre os procedimentos, riscos, benefícios e outros relacionados à pesquisa;

2. Retirar o consentimento previamente feito, a qualquer momento durante a entrevista e deixar de participar do estudo;

3. Participar sem ser identificado, mantido o caráter confidencial das informações apresentadas;

4. As informações obtidas através das entrevistas serão utilizadas, exclusivamente, no presente estudo;

5. Procurar esclarecimentos com o Comitê de Bioética em Pesquisa da Faculdade de Medicina Veterinária e Zootecnia da Universidade de São Paulo, no telefone (11) 3091-7676 ou no endereço: Av. Prof. Dr. Orlando Marques de Paiva, 87, CEP 05508-270, Cidade Universitária, São Paulo/SP, Brasil, caso surjam dúvidas ou notificação de acontecimentos não previstos no projeto.

Declaro estar ciente do exposto e desejar participar do projeto.

Nome do Participante:

Telefone para contato: (_) E-mail:

Eu, Médico Veterinário Victor Chiaroni Galvão, declaro que forneci todas as informações sobre o estudo para o participante.

Ass: 


\section{CARTA DE ACEITE}

$\mathrm{Eu}$ abaixo assinado, responsável

pelo estabelecimento , autorizo a realização do estudo, a ser conduzido pelo pesquisador VICTOR CHIARONI GALVÃO, a fim exclusivamente de colaborar com o projeto "Validação de um instrumento para caracterização de cultura de segurança de alimentos para o português brasileiro". Além disso, fui informado pelo mesmo, sobre as características e objetivos da pesquisa, bem como das atividades que serão realizadas no estabelecimento o qual represento.

Sendo certo que em nenhum momento autorizamos a divulgação do nome da empresa e dos colaboradores que estão apoiando o referido projeto. Local 
APÊNDICE C - AUTORIZAÇÃO DE USO DO INSTRUMENTO POR UNGKU FATIMAH

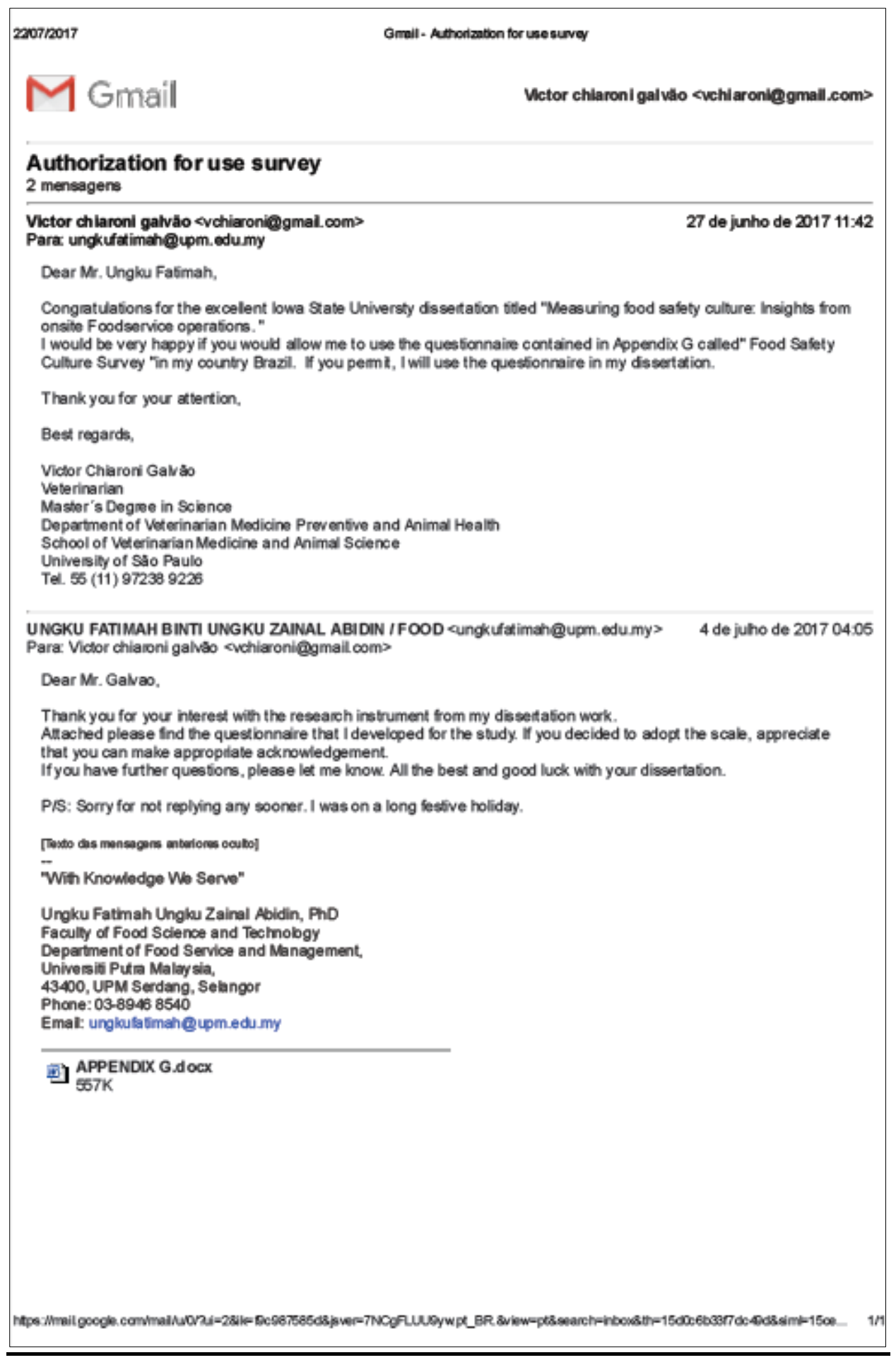




\section{APÊNDICE D - QUESTIONÁRIO ADAPTADO E VALIDADO PARA DIAGNÓSTICO DE CULTURA DE SEGURANÇA DE ALIMENTOS}

\begin{tabular}{|c|c|c|c|c|c|c|c|c|}
\hline \multicolumn{9}{|c|}{ QUESTIONÁRIO CULTURA DE SEGURANÇA DE ALIMENTOS } \\
\hline \multicolumn{9}{|c|}{ Data: } \\
\hline \multicolumn{9}{|c|}{ Empresa (Loja): } \\
\hline \multicolumn{9}{|c|}{ Gênero: } \\
\hline \multicolumn{9}{|c|}{ Origem de nascimento (cidade e estado): } \\
\hline \multicolumn{9}{|c|}{ Escolaridade: } \\
\hline \multicolumn{9}{|c|}{ Idade: } \\
\hline \multicolumn{9}{|c|}{ Experiência na área de alimentos (anos ou meses): } \\
\hline \multicolumn{9}{|c|}{ Experiência na "Empresa X" (anos ou meses): } \\
\hline \multicolumn{9}{|c|}{ Cargo ou Função - Setor da empresa: } \\
\hline \multicolumn{9}{|c|}{$\begin{array}{l}\text { Por favor, leia cada afirmação sobre a Cultura de Segurança dos Alimentos e assinale apenas uma alternativa que } \\
\text { se adequa melhor: Discordo muito (1), Discordo moderadamente (2), Discordo pouco (3), Indiferente (4), } \\
\text { Concordo pouco (5), Concordo moderadamente (6), Concordo muito (7). }\end{array}$} \\
\hline & & 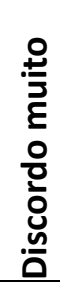 & 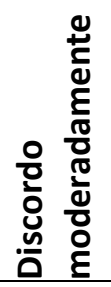 & 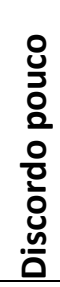 & 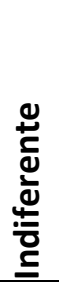 & 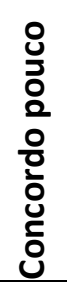 & 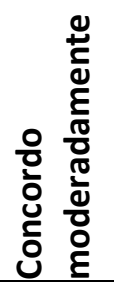 & 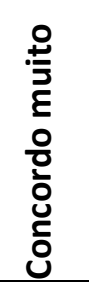 \\
\hline 1 & $\begin{array}{l}\text { Eu posso falar livremente se eu vejo alguma coisa } \\
\text { que possa afetar a segurança dos alimentos }\end{array}$ & 1 & 2 & 3 & 4 & 5 & 6 & 7 \\
\hline 2 & $\begin{array}{l}\text { Sou encorajado a dar sugestões para melhorar as } \\
\text { práticas de segurança dos alimentos }\end{array}$ & 1 & 2 & 3 & 4 & 5 & 6 & 7 \\
\hline 3 & $\begin{array}{l}\text { Todos os gerentes dão informações sobre } \\
\text { segurança dos alimentos }\end{array}$ & 1 & 2 & 3 & 4 & 5 & 6 & 7 \\
\hline 4 & $\begin{array}{l}\text { A administração ou a gerência fornece } \\
\text { informações sobre as normas e regulamentos de } \\
\text { segurança alimentar vigentes }\end{array}$ & 1 & 2 & 3 & 4 & 5 & 6 & 7 \\
\hline 5 & $\begin{array}{l}\text { Meu gerente geralmente dá instruções sobre o } \\
\text { manuseio seguro de alimentos }\end{array}$ & 1 & 2 & 3 & 4 & 5 & 6 & 7 \\
\hline
\end{tabular}


Por favor, leia cada afirmação sobre a Cultura de Segurança dos Alimentos e assinale apenas uma alternativa que se adequa melhor: Discordo muito (1), Discordo moderadamente (2), Discordo pouco (3), Indiferente (4),

Concordo pouco (5), Concordo moderadamente (6), Concordo muito (7).

\begin{tabular}{|c|c|c|c|c|c|c|c|c|}
\hline & & 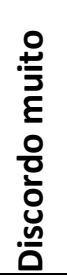 & 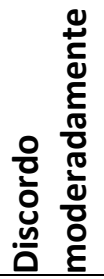 & 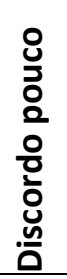 & 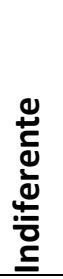 & 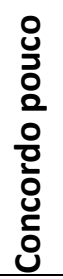 & 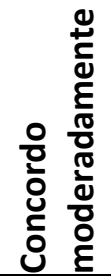 & 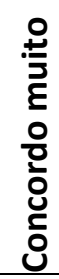 \\
\hline 6 & $\begin{array}{l}\text { Acredito que as políticas e os procedimentos de } \\
\text { segurança alimentar da empresa são nada mais do } \\
\text { que uma obrigação caso haja um problema com a } \\
\text { legislação. }\end{array}$ & 1 & 2 & 3 & 4 & 5 & 6 & 7 \\
\hline 7 & $\begin{array}{l}\text { Todas as informações necessárias para o manuseio } \\
\text { seguro de alimentos está prontamente disponível } \\
\text { para mim }\end{array}$ & 1 & 2 & 3 & 4 & 5 & 6 & 7 \\
\hline 8 & $\begin{array}{l}\text { Segurança dos alimentos é alta prioridade para } \\
\text { mim }\end{array}$ & 1 & 2 & 3 & 4 & 5 & 6 & 7 \\
\hline 9 & $\begin{array}{l}\text { Eu sigo as regras de segurança dos alimentos por } \\
\text { que acredito que elas são importantes }\end{array}$ & 1 & 2 & 3 & 4 & 5 & 6 & 7 \\
\hline 10 & $\begin{array}{l}\text { Eu sigo as regras de segurança dos alimentos por } \\
\text { que é minha responsabilidade }\end{array}$ & 1 & 2 & 3 & 4 & 5 & 6 & 7 \\
\hline 11 & $\begin{array}{l}\text { Eu sou comprometido a seguir todas as regras } \\
\text { sobre Segurança dos alimentos }\end{array}$ & 1 & 2 & 3 & 4 & 5 & 6 & 7 \\
\hline 12 & $\begin{array}{l}\text { Eu mantenho minha área de trabalho limpa } \\
\text { porque eu não gosto de desordem }\end{array}$ & 1 & 2 & 3 & 4 & 5 & 6 & 7 \\
\hline 13 & $\begin{array}{l}\text { Meu gerente sempre olha se os colaboradores } \\
\text { estão praticando a manipulação segura de } \\
\text { alimentos }\end{array}$ & 1 & 2 & 3 & 4 & 5 & 6 & 7 \\
\hline 14 & $\begin{array}{l}\text { Meu gerente está ativamente envolvido em ter } \\
\text { certeza se manipulação de alimentos seguros está } \\
\text { sendo praticada }\end{array}$ & 1 & 2 & 3 & 4 & 5 & 6 & 7 \\
\hline 15 & $\begin{array}{l}\text { A gerência aplica as regras de segurança alimentar } \\
\text { constantemente com todos os colaboradores }\end{array}$ & 1 & 2 & 3 & 4 & 5 & 6 & 7 \\
\hline 16 & $\begin{array}{l}\text { A gerência me motiva a seguir o manuseio seguro } \\
\text { de alimentos }\end{array}$ & 1 & 2 & 3 & 4 & 5 & 6 & 7 \\
\hline 17 & $\begin{array}{l}\text { Os equipamentos adequados (por exemplo, facas, } \\
\text { luvas, termômetros, etc.) estão prontamente } \\
\text { disponíveis para executar práticas seguras de } \\
\text { manipulação de alimentos }\end{array}$ & 1 & 2 & 3 & 4 & 5 & 6 & 7 \\
\hline 18 & $\begin{array}{l}\text { Os itens de equipamento necessários para } \\
\text { preparar alimentos de forma segura (por exemplo, } \\
\text { lavatórios de lavagem de mãos) estão } \\
\text { prontamente disponíveis e acessíveis }\end{array}$ & 1 & 2 & 3 & 4 & 5 & 6 & 7 \\
\hline
\end{tabular}


Por favor, leia cada afirmação sobre a Cultura de Segurança dos Alimentos e assinale apenas uma alternativa que se adequa melhor: Discordo muito (1), Discordo moderadamente (2), Discordo pouco (3), Indiferente (4), Concordo pouco (5), Concordo moderadamente (6), Concordo muito (7).

\begin{tabular}{|c|c|c|c|c|c|c|c|c|}
\hline & & 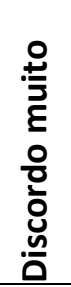 & 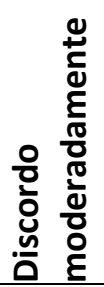 & 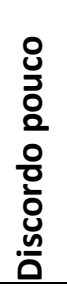 & 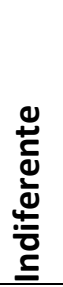 & 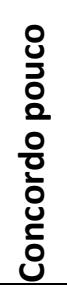 & 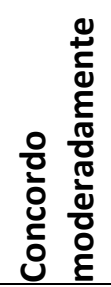 & 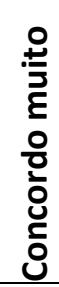 \\
\hline 19 & $\begin{array}{l}\text { As instalações (por exemplo, congelador, } \\
\text { aquecedor, etc.) são de qualidade adequada para } \\
\text { seguir práticas seguras de manipulação de } \\
\text { alimentos }\end{array}$ & 1 & 2 & 3 & 4 & 5 & 6 & 7 \\
\hline 20 & $\begin{array}{l}\text { Eu recebo material de qualidade que tornam mais } \\
\text { fácil seguir práticas seguras de manipulação de } \\
\text { alimentos }\end{array}$ & 1 & 2 & 3 & 4 & 5 & 6 & 7 \\
\hline 21 & $\begin{array}{l}\text { Meus colegas de trabalho sempre são solidários e } \\
\text { ajudam em relação à segurança dos alimentos }\end{array}$ & 1 & 2 & 3 & 4 & 5 & 6 & 7 \\
\hline 22 & $\begin{array}{l}\text { Quando tem muito trabalho que precisa ser feito } \\
\text { rapidamente, os colaboradores trabalham juntos } \\
\text { como uma equipe para obter as tarefas concluídas } \\
\text { com segurança }\end{array}$ & 1 & 2 & 3 & 4 & 5 & 6 & 7 \\
\hline 23 & $\begin{array}{l}\text { Os colaboradores lembram os outros colegas para } \\
\text { seguir práticas de segurança dos alimentos }\end{array}$ & 1 & 2 & 3 & 4 & 5 & 6 & 7 \\
\hline 24 & $\begin{array}{l}\text { Colaboradores novos e experientes trabalham } \\
\text { juntos para garantir que as práticas de segurança } \\
\text { dos alimentos continue existindo }\end{array}$ & 1 & 2 & 3 & 4 & 5 & 6 & 7 \\
\hline 25 & $\begin{array}{l}\text { Existe uma boa cooperação entre os setores da } \\
\text { empresa para garantir que os clientes recebam } \\
\text { alimentos preparados com segurança }\end{array}$ & 1 & 2 & 3 & 4 & 5 & 6 & 7 \\
\hline 26 & $\begin{array}{l}\text { Os colaboradores são advertidos ou repreendidos } \\
\text { quando não seguem as práticas de segurança dos } \\
\text { alimentos }\end{array}$ & 1 & 2 & 3 & 4 & 5 & 6 & 7 \\
\hline 27 & $\begin{array}{l}\text { Eu sempre tenho tempo suficiente para seguir os } \\
\text { procedimentos de manuseio de alimentos } \\
\text { seguros, mesmo durante momentos que a } \\
\text { produção acelera }\end{array}$ & 1 & 2 & 3 & 4 & 5 & 6 & 7 \\
\hline 28 & $\begin{array}{l}\text { Minha carga de trabalho não atrapalha a minha } \\
\text { capacidade de seguir práticas seguras de } \\
\text { manipulação de alimentos }\end{array}$ & 1 & 2 & 3 & 4 & 5 & 6 & 7 \\
\hline 29 & $\begin{array}{l}\text { O número de colaboradores programados em } \\
\text { cada turno é adequado para que eu possa fazer } \\
\text { meu trabalho e manipular alimentos com } \\
\text { segurança }\end{array}$ & 1 & 2 & 3 & 4 & 5 & 6 & 7 \\
\hline 30 & $\begin{array}{l}\text { Quando estamos sob pressão para terminar a } \\
\text { produção de alimentos, os gerentes às vezes nos } \\
\text { dizem para trabalhar mais rápido, "pulando" }\end{array}$ & 1 & 2 & 3 & 4 & 5 & 6 & 7 \\
\hline
\end{tabular}




\begin{tabular}{|c|c|c|c|c|c|c|c|c|}
\hline & algumas regras de segurança dos alimentos & & & & & & & \\
\hline 31 & $\begin{array}{l}\text { Às vezes me pedem para "cortar caminho" em } \\
\text { relação à segurança dos alimentos durante a } \\
\text { produção dos alimentos para que possamos } \\
\text { economizar custos }\end{array}$ & 1 & 2 & 3 & 4 & 5 & 6 & 7 \\
\hline
\end{tabular}

Críticas e Sugestões: 


\section{APÊNDICE E - ROTEIRO DE PERGUNTAS PARA ENTREVISTA COM RESPONSÁVEL PELA SEGURANÇA DE ALIMENTOS DA EMPRESA PARTICIPANTE.}

1. Por quê se decidiu (quem decidiu) criar um departamento relacionado à Segurança de Alimentos na empresa?

2. Quais foram os primeiros passos? Onde teve início e quando chegou ao Brasil?

3. Quais são as dificuldades mais significativas enfrentadas desde a sua criação? Como se tem atuado no sentido de reduzi-las ou elimina-las?

4. Quais foram os benefícios obtidos pela empresa, com a criação do Departamento de Segurança de Alimentos?

5. Qual a relação do Departamento de Segurança de Alimentos com:

a) o cumprimento de Boas Práticas de Manipulação de Alimentos?

b) com as quedas de vendas nas lojas?

c) com o depto. de Análise de Riscos?

6. Quais as perspectivas da empresa para os próximos 5 anos e 10 anos, com relação ao Departamento de Segurança de Alimentos?

7. Quais são os valores e a missão do Departamento de Segurança de Alimentos?

8. Como você avaliaria a maturidade da sua empresa com relação a Segurança de Alimentos como um todo? E do Departamento de Segurança de Alimentos?

9. O que você considera que são os maiores desafios na empresa com relação à construção e manutenção da Cultura de Segurança de Alimentos?

10. Quais sugestões ou dicas você daria para um profissional que pretende desenvolver a Cultura de Segurança de Alimentos na sua própria empresa? 
APÊNDICE F - RESULTADOS DAS ETAPAS DE TRADUÇÃO, BACKTRANSLATION E SÍNTESE DAS VERSÕES DOS AVALIADORES.

\begin{tabular}{|c|c|c|c|c|c|c|c|}
\hline Item & Original & $\begin{array}{l}\text { Avaliador A } \\
\text { (Tradução) }\end{array}$ & $\begin{array}{l}\text { Avaliador B } \\
\text { (Tradução) }\end{array}$ & $\begin{array}{l}\text { Versão } 1 \\
\text { (Síntese) }\end{array}$ & $\begin{array}{c}\text { Avaliador C } \\
\text { (Retradução) }\end{array}$ & $\begin{array}{c}\text { Avaliador D } \\
\text { (Retradução) }\end{array}$ & $\begin{array}{l}\text { Versão } 2 \\
\text { (Síntese) }\end{array}$ \\
\hline 1 & $\begin{array}{c}\text { I can freely } \\
\text { speak up if I see } \\
\text { something that } \\
\text { may affect food } \\
\text { safety }\end{array}$ & $\begin{array}{l}\text { Eu posso falar } \\
\text { abertamente se } \\
\text { ver alguma coisa } \\
\text { que possa afetar } \\
\text { segurança } \\
\text { alimentar? }\end{array}$ & $\begin{array}{l}\text { Eu posso } \\
\text { livremente falar se } \\
\text { eu vir algo que } \\
\text { pode afetar a } \\
\text { segurança da } \\
\text { comida*. }\end{array}$ & $\begin{array}{l}\text { Eu posso falar } \\
\text { livremente se eu } \\
\text { vejo alguma coisa } \\
\text { que possa afetar a } \\
\text { segurança dos } \\
\text { alimentos }\end{array}$ & $\begin{array}{l}\text { I can talk freely if I } \\
\text { see anything that } \\
\text { may affect food } \\
\text { safety. }\end{array}$ & $\begin{array}{c}\text { I can speak } \\
\text { freely if I see } \\
\text { anything that } \\
\text { could affect food } \\
\text { safety. }\end{array}$ & $\begin{array}{l}\text { I can speak } \\
\text { freely if I see } \\
\text { anything that } \\
\text { could affect } \\
\text { food safety. }\end{array}$ \\
\hline 2 & $\begin{array}{l}\text { I am } \\
\text { encouraged to } \\
\text { provide } \\
\text { suggestions for } \\
\text { improving food } \\
\text { safety practices }\end{array}$ & $\begin{array}{c}\text { Sou encorajado } \\
\text { para dar } \\
\text { sugestões de } \\
\text { aprimoramento de } \\
\text { práticas de } \\
\text { segurança } \\
\text { alimentar? } \\
\end{array}$ & $\begin{array}{c}\text { Eu estou } \\
\text { encorajado a dar } \\
\text { sugestões para } \\
\text { melhorar as } \\
\text { práticas de } \\
\text { segurança da } \\
\text { comida. } \\
\end{array}$ & $\begin{array}{l}\text { Sou encorajado a } \\
\text { dar sugestões para } \\
\text { melhorar as } \\
\text { práticas de } \\
\text { segurança dos } \\
\text { alimentos }\end{array}$ & $\begin{array}{l}\text { I am encouraged } \\
\text { to give } \\
\text { suggestions to } \\
\text { improve food } \\
\text { safety practices. }\end{array}$ & $\begin{array}{l}\text { I am encouraged } \\
\text { to give } \\
\text { suggestions to } \\
\text { improve food } \\
\text { safety practices. }\end{array}$ & $\begin{array}{c}\text { I am } \\
\text { encouraged to } \\
\text { give } \\
\text { suggestions to } \\
\text { improve food } \\
\text { safety practices }\end{array}$ \\
\hline 3 & $\begin{array}{l}\text { All managers } \\
\text { give consistent } \\
\text { information } \\
\text { about food } \\
\text { safety }\end{array}$ & $\begin{array}{c}\text { Todos os } \\
\text { gestores dão } \\
\text { informações } \\
\text { consistentes } \\
\text { sobre segurança } \\
\text { alimentar? } \\
\end{array}$ & $\begin{array}{l}\text { Todos os gerentes } \\
\text { dão informações } \\
\text { consistentes sobre } \\
\text { segurança da } \\
\text { comida. }\end{array}$ & $\begin{array}{c}\text { Todos os gerentes } \\
\text { dão informações } \\
\text { sobre segurança } \\
\text { dos alimentos }\end{array}$ & $\begin{array}{l}\text { All managers give } \\
\text { information about } \\
\text { food safety. }\end{array}$ & $\begin{array}{l}\text { All managers } \\
\text { give information } \\
\text { about food } \\
\text { safety. }\end{array}$ & $\begin{array}{l}\text { All managers } \\
\text { give information } \\
\text { about food } \\
\text { safety. }\end{array}$ \\
\hline 4 & $\begin{array}{c}\text { Management } \\
\text { provides } \\
\text { adequate and } \\
\text { timely } \\
\text { information } \\
\text { about current } \\
\text { food safety rules } \\
\text { and regulations }\end{array}$ & $\begin{array}{c}\text { O gerenciamento } \\
\text { fornece } \\
\text { informações } \\
\text { adequadas e } \\
\text { pontuais sobre as } \\
\text { atuais regras e } \\
\text { regulamentações } \\
\text { sobre a } \\
\text { segurança } \\
\text { alimentar? }\end{array}$ & $\begin{array}{l}\text { O gerenciamento } \\
\text { fornece } \\
\text { informações } \\
\text { adequadas e no } \\
\text { tempo certo sobre } \\
\text { regras de } \\
\text { segurança de } \\
\text { comida e } \\
\text { regulamentações. }\end{array}$ & $\begin{array}{l}\text { A administração ou } \\
\text { a gerência fornece } \\
\text { informações sobre } \\
\text { as normas e } \\
\text { regulamentos de } \\
\text { segurança } \\
\text { alimentar vigentes }\end{array}$ & $\begin{array}{c}\text { The } \\
\text { administration or } \\
\text { management } \\
\text { provides } \\
\text { information on } \\
\text { current food } \\
\text { safety standards } \\
\text { and regulations. }\end{array}$ & $\begin{array}{c}\text { The } \\
\text { Administration or } \\
\text { management } \\
\text { provides } \\
\text { information on } \\
\text { current food } \\
\text { safety standards } \\
\text { and regulations. }\end{array}$ & $\begin{array}{c}\text { The } \\
\text { Administration } \\
\text { or management } \\
\text { provides } \\
\text { information on } \\
\text { current food } \\
\text { safety } \\
\text { standards and } \\
\text { regulations. }\end{array}$ \\
\hline 5 & $\begin{array}{l}\text { My manager } \\
\text { generally gives } \\
\text { appropriate }\end{array}$ & $\begin{array}{c}\text { Meu gestor } \\
\text { geralmente dá } \\
\text { instruções }\end{array}$ & $\begin{array}{l}\text { Meu gerente } \\
\text { geralmente dá } \\
\text { instruções }\end{array}$ & $\begin{array}{c}\text { Meu gerente } \\
\text { geralmente dá } \\
\text { instruções sobre o }\end{array}$ & $\begin{array}{c}\text { My manager } \\
\text { usually gives } \\
\text { instructions on }\end{array}$ & $\begin{array}{c}\text { My manager } \\
\text { usually gives us } \\
\text { instructions on }\end{array}$ & $\begin{array}{l}\text { My manager } \\
\text { usually gives } \\
\text { instructions on }\end{array}$ \\
\hline
\end{tabular}




\begin{tabular}{|c|c|c|c|c|c|c|c|}
\hline & $\begin{array}{l}\text { instructions on } \\
\text { safe food } \\
\text { handling }\end{array}$ & $\begin{array}{l}\text { apropriadas de } \\
\text { manuseio da } \\
\text { segurança } \\
\text { alimentar? }\end{array}$ & $\begin{array}{c}\text { apropriadas sobre } \\
\text { manusear comida } \\
\text { segura. }\end{array}$ & $\begin{array}{l}\text { manuseio seguro } \\
\text { de alimentos }\end{array}$ & $\begin{array}{l}\text { safe handling of } \\
\text { food. }\end{array}$ & $\begin{array}{l}\text { safe handling of } \\
\text { food. }\end{array}$ & $\begin{array}{l}\text { safe handling of } \\
\text { food. }\end{array}$ \\
\hline 6 & $\begin{array}{l}\text { I believe that } \\
\text { written food } \\
\text { safety policies } \\
\text { and procedures } \\
\text { are nothing } \\
\text { more than a } \\
\text { cover-up in case } \\
\text { there is a } \\
\text { lawsuit }\end{array}$ & $\begin{array}{l}\text { Acredito que as } \\
\text { políticas e } \\
\text { procedimentos } \\
\text { escritos não são } \\
\text { nada mais que } \\
\text { um acobertas em } \\
\text { caso de uma } \\
\text { ação judicial? }\end{array}$ & $\begin{array}{l}\text { Eu acredito que } \\
\text { políticas e } \\
\text { procedimentos } \\
\text { escritos de } \\
\text { segurança de } \\
\text { comida não são } \\
\text { nada mais do que } \\
\text { uma proteção no } \\
\text { caso de haver um } \\
\text { processo legal. }\end{array}$ & $\begin{array}{l}\text { Acredito que as } \\
\text { políticas e os } \\
\text { procedimentos } \\
\text { escritos de } \\
\text { segurança } \\
\text { alimentar da } \\
\text { empresa não são } \\
\text { nada mais do que } \\
\text { uma proteção caso } \\
\text { haja um problema } \\
\text { com a lei. }\end{array}$ & $\begin{array}{l}\text { I believe that the } \\
\text { company's written } \\
\text { food safety } \\
\text { policies and } \\
\text { procedures are } \\
\text { nothing more than } \\
\text { protection if there } \\
\text { is a problem with } \\
\text { the law. }\end{array}$ & $\begin{array}{l}\text { I believe that the } \\
\text { company's } \\
\text { written food } \\
\text { safety policies } \\
\text { and procedures } \\
\text { are nothing more } \\
\text { than protection if } \\
\text { there is a } \\
\text { problem with the } \\
\text { law. }\end{array}$ & $\begin{array}{l}\text { I believe that } \\
\text { the company's } \\
\text { written food } \\
\text { safety policies } \\
\text { and procedures } \\
\text { are nothing } \\
\text { more than } \\
\text { protection if } \\
\text { there is a } \\
\text { problem with } \\
\text { the law. }\end{array}$ \\
\hline 7 & $\begin{array}{c}\text { All of the } \\
\text { necessary } \\
\text { information for } \\
\text { handling food } \\
\text { safely is readily } \\
\text { available to me }\end{array}$ & $\begin{array}{c}\text { Todas as } \\
\text { informações } \\
\text { necessárias para } \\
\text { a manuseio de } \\
\text { segurança } \\
\text { alimentar está } \\
\text { minha } \\
\text { disposição? }\end{array}$ & $\begin{array}{c}\text { Todas as } \\
\text { informações } \\
\text { necessárias para } \\
\text { manusear comida } \\
\text { com segurança } \\
\text { está prontamente } \\
\text { disponível para } \\
\text { mim. }\end{array}$ & $\begin{array}{c}\text { Todas as } \\
\text { informações } \\
\text { necessárias para o } \\
\text { manuseio seguro } \\
\text { de alimentos está } \\
\text { prontamente } \\
\text { disponível para } \\
\text { mim }\end{array}$ & $\begin{array}{l}\text { All information } \\
\text { necessary for the } \\
\text { safe handling of } \\
\text { food is readily } \\
\text { available to me. }\end{array}$ & $\begin{array}{l}\text { All information } \\
\text { necessary for the } \\
\text { safe handling of } \\
\text { food is readily } \\
\text { available to me. }\end{array}$ & $\begin{array}{l}\text { All information } \\
\text { necessary for } \\
\text { the safe } \\
\text { handling of food } \\
\text { is readily } \\
\text { available to me. }\end{array}$ \\
\hline 8 & $\begin{array}{c}\text { Food safety is a } \\
\text { high priority to } \\
\text { me }\end{array}$ & $\begin{array}{l}\text { Segurança } \\
\text { alimentar é minha } \\
\text { maior prioridade } \\
\text { para mim? }\end{array}$ & $\begin{array}{c}\text { Segurança em } \\
\text { comida é uma } \\
\text { prioridade alta para } \\
\text { mim. }\end{array}$ & $\begin{array}{c}\text { Segurança dos } \\
\text { alimentos é alta } \\
\text { prioridade para } \\
\text { mim }\end{array}$ & $\begin{array}{c}\text { Food safety is } \\
\text { high priority for } \\
\text { me. }\end{array}$ & $\begin{array}{l}\text { The safety of all } \\
\text { food is of high } \\
\text { priority to me. }\end{array}$ & $\begin{array}{c}\text { Food safety is } \\
\text { high priority for } \\
\text { me. }\end{array}$ \\
\hline 9 & $\begin{array}{c}\text { I follow food } \\
\text { safety rules } \\
\text { because I think } \\
\text { they are } \\
\text { important }\end{array}$ & $\begin{array}{c}\text { Sigo as } \\
\text { legislações de } \\
\text { segurança } \\
\text { alimentar por que } \\
\text { penso que são } \\
\text { importantes? }\end{array}$ & $\begin{array}{l}\text { Eu sigo as regras } \\
\text { de segurança em } \\
\text { comida porque eu } \\
\text { penso que são } \\
\text { importantes. }\end{array}$ & $\begin{array}{l}\text { Eu sigo as regras } \\
\text { de segurança dos } \\
\text { alimentos por que } \\
\text { acredito que elas } \\
\text { são importantes }\end{array}$ & $\begin{array}{l}\text { I follow the food } \\
\text { safety rules } \\
\text { because I believe } \\
\text { they are } \\
\text { importante. }\end{array}$ & $\begin{array}{l}\text { I follow the food } \\
\text { safety rules } \\
\text { because I believe } \\
\text { they are } \\
\text { important. }\end{array}$ & $\begin{array}{l}\text { I follow the food } \\
\text { safety rules } \\
\text { because I } \\
\text { believe they are } \\
\text { importante. }\end{array}$ \\
\hline 10 & $\begin{array}{l}\text { I follow food } \\
\text { safety rules } \\
\text { because it is my } \\
\text { responsibility to } \\
\text { do so }\end{array}$ & $\begin{array}{c}\text { Sigo as } \\
\text { legislações de } \\
\text { segurança } \\
\text { alimentar por que } \\
\text { são de minha } \\
\text { responsabilidade? }\end{array}$ & $\begin{array}{c}\text { Eu sigo as regras } \\
\text { de segurança em } \\
\text { comida porque é } \\
\text { minha } \\
\text { responsabilidade } \\
\text { fazer assim. }\end{array}$ & $\begin{array}{c}\text { Eu sigo as regras } \\
\text { de segurança dos } \\
\text { alimentos por que é } \\
\text { minha } \\
\text { responsabilidade }\end{array}$ & $\begin{array}{l}\text { I follow the food } \\
\text { safety rules } \\
\text { because it is my } \\
\text { responsibility. }\end{array}$ & $\begin{array}{l}\text { I follow the food } \\
\text { safety rules } \\
\text { because it is my } \\
\text { responsibility. }\end{array}$ & $\begin{array}{l}\text { I follow the food } \\
\text { safety rules } \\
\text { because it is my } \\
\text { responsibility. }\end{array}$ \\
\hline
\end{tabular}




\begin{tabular}{|c|c|c|c|c|c|c|c|}
\hline 11 & $\begin{array}{l}\text { I am committed } \\
\text { to following all } \\
\text { food safety rules }\end{array}$ & $\begin{array}{l}\text { Estou em } \\
\text { empenhado em } \\
\text { seguir todas as } \\
\text { legislações de } \\
\text { segurança } \\
\text { alimentar? }\end{array}$ & $\begin{array}{c}\text { Eu tenho o } \\
\text { compromisso de } \\
\text { seguir todas as } \\
\text { regras de } \\
\text { segurança de } \\
\text { comida. }\end{array}$ & $\begin{array}{c}\text { Eu sou } \\
\text { comprometido a } \\
\text { seguir todas as } \\
\text { regras sobre } \\
\text { Segurança dos } \\
\quad \text { alimentos } \\
\end{array}$ & $\begin{array}{l}\text { I am committed to } \\
\text { following all the } \\
\text { rules on food } \\
\text { safety. }\end{array}$ & $\begin{array}{l}\text { I am committed } \\
\text { to following all } \\
\text { the rules on Food } \\
\text { Safety. }\end{array}$ & $\begin{array}{l}\text { I am committed } \\
\text { to following all } \\
\text { the rules on } \\
\text { food safety. }\end{array}$ \\
\hline 12 & $\begin{array}{l}\text { I keep my work } \\
\text { area clean } \\
\text { because I do not } \\
\text { like clutter }\end{array}$ & $\begin{array}{c}\text { Mantenho minha } \\
\text { área de trabalho } \\
\text { limpa por que não } \\
\text { gosto de } \\
\text { desordem? }\end{array}$ & $\begin{array}{l}\text { E mantenho minha } \\
\text { área de trabalho } \\
\text { limpa porque eu } \\
\text { não gosto de } \\
\text { talher. }\end{array}$ & $\begin{array}{c}\text { Eu mantenho } \\
\text { minha área de } \\
\text { trabalho limpa } \\
\text { porque eu não } \\
\text { gosto de desordem }\end{array}$ & $\begin{array}{l}\text { I keep my work } \\
\text { area clean } \\
\text { because I do not } \\
\text { like clutter. }\end{array}$ & $\begin{array}{l}\text { I keep my work } \\
\text { area clean } \\
\text { because I do not } \\
\text { like clutter. }\end{array}$ & $\begin{array}{l}\text { I keep my work } \\
\text { area clean } \\
\text { because I do } \\
\text { not like clutter. }\end{array}$ \\
\hline 13 & $\begin{array}{l}\text { My manager } \\
\text { always watches } \\
\text { to see if } \\
\text { employees are } \\
\text { practicing safe } \\
\text { food handling }\end{array}$ & $\begin{array}{c}\text { Meu gestor } \\
\text { sempre } \\
\text { supervisiona se } \\
\text { os empregados } \\
\text { estão praticando } \\
\text { o manuseio de } \\
\text { segurança } \\
\text { alimentar? }\end{array}$ & $\begin{array}{c}\text { Meu gerente } \\
\text { sempre observa } \\
\text { para ver se os } \\
\text { empregados estão } \\
\text { praticando o } \\
\text { manuseio de } \\
\text { comida segura. }\end{array}$ & $\begin{array}{l}\text { Meu gerente } \\
\text { sempre olha se os } \\
\text { funcionários estão } \\
\text { praticando a } \\
\text { manipulação } \\
\text { segura de } \\
\text { alimentos }\end{array}$ & $\begin{array}{l}\text { My manager } \\
\text { always looks at } \\
\text { whether } \\
\text { employees are } \\
\text { practicing safe } \\
\text { food handling. }\end{array}$ & $\begin{array}{l}\text { My manager } \\
\text { always looks at } \\
\text { whether } \\
\text { employees are } \\
\text { practicing safe } \\
\text { food handling. }\end{array}$ & $\begin{array}{l}\text { My manager } \\
\text { always looks at } \\
\text { whether } \\
\text { employees are } \\
\text { practicing safe } \\
\text { food handling. }\end{array}$ \\
\hline 14 & $\begin{array}{l}\text { My manager is } \\
\text { actively involved } \\
\text { in making sure } \\
\text { safe food } \\
\text { handling is } \\
\text { practiced }\end{array}$ & $\begin{array}{c}\text { Meu gerente está } \\
\text { ativamente } \\
\text { envolvido em } \\
\text { certificar se o } \\
\text { manuseio de } \\
\text { segurança } \\
\text { alimentar é } \\
\text { praticado? }\end{array}$ & $\begin{array}{l}\text { Meu gerente está } \\
\text { ativamente } \\
\text { envolvido em se } \\
\text { certificar que o } \\
\text { manuseio de } \\
\text { comida segura é } \\
\text { praticada. }\end{array}$ & $\begin{array}{l}\text { Meu gerente está } \\
\text { ativamente } \\
\text { envolvido em ter } \\
\text { certeza se } \\
\text { manipulação de } \\
\text { alimentos seguros } \\
\text { está sendo } \\
\text { praticada }\end{array}$ & $\begin{array}{l}\text { My manager is } \\
\text { actively involved } \\
\text { in ensuring that } \\
\text { safe food } \\
\text { handling is being } \\
\text { practiced. }\end{array}$ & $\begin{array}{l}\text { My manager is } \\
\text { actively involved } \\
\text { in making sure } \\
\text { that safe food } \\
\text { handling is being } \\
\text { practiced. }\end{array}$ & $\begin{array}{l}\text { My manager is } \\
\text { actively involved } \\
\text { in making sure } \\
\text { that safe food } \\
\text { handling is } \\
\text { being practiced. }\end{array}$ \\
\hline 15 & $\begin{array}{l}\text { Management } \\
\text { enforces food } \\
\text { safety rules } \\
\text { consistently with } \\
\text { all employees }\end{array}$ & $\begin{array}{l}\text { O gerenciamento } \\
\text { aplica a } \\
\text { legislação de } \\
\text { segurança } \\
\text { alimentar } \\
\text { consistentemente } \\
\text { com todos os } \\
\text { empregados? }\end{array}$ & $\begin{array}{l}\text { O gerenciamento } \\
\text { consistentemente } \\
\text { reforça as regras } \\
\text { de segurança de } \\
\text { comida com todos } \\
\text { os empregados. }\end{array}$ & $\begin{array}{l}\text { A gerência aplica } \\
\text { as regras de } \\
\text { segurança } \\
\text { alimentar } \\
\text { constantemente } \\
\text { com todos os } \\
\text { funcionários }\end{array}$ & $\begin{array}{l}\text { The management } \\
\text { consistently } \\
\text { enforces food } \\
\text { safety rules with } \\
\text { all employees. }\end{array}$ & $\begin{array}{c}\text { The } \\
\text { management } \\
\text { consistently } \\
\text { enforces food } \\
\text { safety rules with } \\
\text { all employees. }\end{array}$ & $\begin{array}{c}\text { The } \\
\text { management } \\
\text { consistently } \\
\text { enforces food } \\
\text { safety rules with } \\
\text { all employees. }\end{array}$ \\
\hline 16 & $\begin{array}{c}\text { Management } \\
\text { inspires me to } \\
\text { follow safe food } \\
\text { handling }\end{array}$ & $\begin{array}{l}\text { O gerenciamento } \\
\text { me inspira a } \\
\text { seguir as práticas } \\
\text { de manuseio de }\end{array}$ & $\begin{array}{c}\text { O gerenciamento } \\
\text { me inspira a seguir } \\
\text { práticas de } \\
\text { manuseio de }\end{array}$ & $\begin{array}{c}\text { A gerência me } \\
\text { motiva a seguir o } \\
\text { manuseio seguro } \\
\text { de alimentos }\end{array}$ & $\begin{array}{l}\text { The management } \\
\text { motivates me to } \\
\text { follow the safe } \\
\text { handling of food. }\end{array}$ & $\begin{array}{c}\text { The } \\
\text { management } \\
\text { motivates me to } \\
\text { follow the safe }\end{array}$ & $\begin{array}{c}\text { The } \\
\text { management } \\
\text { motivates me to } \\
\text { follow the safe }\end{array}$ \\
\hline
\end{tabular}




\begin{tabular}{|c|c|c|c|c|c|c|c|}
\hline & practices & $\begin{array}{l}\text { segurança } \\
\text { alimentar? }\end{array}$ & comida segura. & & & handling of food. & $\begin{array}{l}\text { handling of } \\
\text { food. }\end{array}$ \\
\hline 17 & $\begin{array}{c}\text { Adequate } \\
\text { supplies (e.g., } \\
\text { gloves, } \\
\text { thermometers, } \\
\text { etc.) are readily } \\
\text { available to } \\
\text { perform safe } \\
\text { food handling } \\
\text { practices }\end{array}$ & $\begin{array}{c}\text { Materiais } \\
\text { adequados ( } \mathrm{p} . \\
\text { ex.: luvas } \\
\text { termômetros, etc.) } \\
\text { estão } \\
\text { prontamente } \\
\text { disponíveis para } \\
\text { realizar as } \\
\text { práticas de } \\
\text { segurança } \\
\text { alimentar. } \\
\end{array}$ & $\begin{array}{c}\text { Suprimentos } \\
\text { adequados (ex.: } \\
\text { luvas, termômetros, } \\
\text { etc.) estão } \\
\text { prontamente } \\
\text { disponíveis para a } \\
\text { realização de } \\
\text { práticas de } \\
\text { manuseio de } \\
\text { comida segura. }\end{array}$ & $\begin{array}{l}\text { Os equipamentos } \\
\text { adequados (por } \\
\text { exemplo, facas, } \\
\text { luvas, termômetros, } \\
\text { etc.) estão } \\
\text { prontamente } \\
\text { disponíveis para } \\
\text { executar práticas } \\
\text { seguras de } \\
\text { manipulação de } \\
\text { alimentos } \\
\end{array}$ & $\begin{array}{l}\text { The suitable } \\
\text { equipment (for } \\
\text { example, knives, } \\
\text { gloves, } \\
\text { thermometers, } \\
\text { and so on.) is } \\
\text { readily available } \\
\text { to perform safe } \\
\text { food handling } \\
\text { practices. }\end{array}$ & $\begin{array}{c}\text { Suitable } \\
\text { equipment (as, } \\
\text { knives, gloves, } \\
\text { thermometers, } \\
\text { etc.) are readily } \\
\text { available to } \\
\text { perform safe } \\
\text { food handling } \\
\text { practices. }\end{array}$ & $\begin{array}{l}\text { Suitable } \\
\text { equipment (as, } \\
\text { knives, gloves, } \\
\text { thermometers, } \\
\text { etc.) are readily } \\
\text { available to } \\
\text { perform safe } \\
\text { food handling } \\
\text { practices. }\end{array}$ \\
\hline 18 & $\begin{array}{l}\text { Equipment } \\
\text { items needed to } \\
\text { prepare food } \\
\text { safely (e.g., } \\
\text { hand washing } \\
\text { sinks) are } \\
\text { readily available } \\
\text { and accessible }\end{array}$ & $\begin{array}{c}\text { Os itens de } \\
\text { equipamentos } \\
\text { necessários para } \\
\text { o preparo seguro } \\
\text { dos alimentos (p. } \\
\text { ex.: pias para } \\
\text { lavar as mãos) } \\
\text { estão disponíveis } \\
\text { e acessíveis. }\end{array}$ & $\begin{array}{c}\text { Itens de } \\
\text { equipamento } \\
\text { necessários para } \\
\text { preparer comida } \\
\text { com segurança } \\
\text { (ex.: pias para lavar } \\
\text { as mãos) estão } \\
\text { prontamente } \\
\text { disponíveis e } \\
\text { acessíveis. }\end{array}$ & $\begin{array}{c}\text { Os itens de } \\
\text { equipamento } \\
\text { necessários para } \\
\text { preparar alimentos } \\
\text { de forma segura } \\
\text { (por exemplo, } \\
\text { lavatórios de } \\
\text { lavagem de mãos) } \\
\text { estão prontamente } \\
\text { disponíveis e } \\
\text { acessíveis }\end{array}$ & $\begin{array}{l}\text { The items of } \\
\text { equipment } \\
\text { needed to } \\
\text { prepare food } \\
\text { safely (for } \\
\text { example, hand } \\
\text { wash basins) are } \\
\text { readily available } \\
\text { and accessible. }\end{array}$ & $\begin{array}{c}\text { Items of } \\
\text { equipment } \\
\text { needed to } \\
\text { prepare food } \\
\text { safely (as, hand } \\
\text { wash basins) are } \\
\text { readily available } \\
\text { and accessible. }\end{array}$ & $\begin{array}{l}\text { The items of } \\
\text { equipment } \\
\text { needed to } \\
\text { prepare food } \\
\text { safely (for } \\
\text { example, hand } \\
\text { wash basins) } \\
\text { are readily } \\
\text { available and } \\
\text { accessible. }\end{array}$ \\
\hline 19 & $\begin{array}{l}\text { Facilities (e.g., } \\
\text { freezer, warmer, } \\
\text { etc.) are of } \\
\text { adequate quality } \\
\text { to follow safe } \\
\text { food handling } \\
\text { practices }\end{array}$ & $\begin{array}{l}\text { As instalações ( } p \text {. } \\
\text { ex.: freezer, } \\
\text { aquecedores, etc) } \\
\text { tem a qualidade } \\
\text { adequada para } \\
\text { seguir as práticas } \\
\text { manuais da } \\
\text { segurança } \\
\text { alimentar. }\end{array}$ & $\begin{array}{l}\text { Instalações (ex.: } \\
\text { freezer, aquecedor, } \\
\text { etc.) são de } \\
\text { qualidade } \\
\text { adequada para } \\
\text { seguir as práticas } \\
\text { de manuseio de } \\
\text { comida segura. }\end{array}$ & $\begin{array}{l}\text { As instalações (por } \\
\text { exemplo, } \\
\text { congelador, } \\
\text { aquecedor, etc.) } \\
\text { são de qualidade } \\
\text { adequada para } \\
\text { seguir práticas } \\
\text { seguras de } \\
\text { manipulação de } \\
\text { alimentos } \\
\end{array}$ & $\begin{array}{l}\text { The facilities (for } \\
\text { exemple, freezer, } \\
\text { heater, and so } \\
\text { on.) are of } \\
\text { adequate quality } \\
\text { to follow safe food } \\
\text { handling } \\
\text { practices. }\end{array}$ & $\begin{array}{l}\text { The facilities (as, } \\
\text { freezer, heater, } \\
\text { etc.) are of } \\
\text { adequate quality } \\
\text { to follow safe } \\
\text { food handling } \\
\text { practices. }\end{array}$ & $\begin{array}{l}\text { The facilities } \\
\text { (as, freezer, } \\
\text { heater, etc.) are } \\
\text { of adequate } \\
\text { quality to follow } \\
\text { safe food } \\
\text { handling } \\
\text { practices. }\end{array}$ \\
\hline 20 & $\begin{array}{l}\text { I am provided } \\
\text { with quality } \\
\text { supplies that } \\
\text { make it easy for } \\
\text { me to follow }\end{array}$ & $\begin{array}{c}\text { Tenho a } \\
\text { disposição } \\
\text { materiais de } \\
\text { qualidade que me } \\
\text { facilitam seguir as }\end{array}$ & $\begin{array}{l}\text { Estou provido de } \\
\text { suprimentos que } \\
\text { tornam fácil para } \\
\text { mim seguir práticas } \\
\text { de manuseio de }\end{array}$ & $\begin{array}{l}\text { Eu recebo material } \\
\text { de qualidade que } \\
\text { tornam mais fácil } \\
\text { seguir práticas } \\
\text { seguras de }\end{array}$ & $\begin{array}{c}\text { I get quality } \\
\text { material that } \\
\text { makes it easier to } \\
\text { follow safe food } \\
\text { handling }\end{array}$ & $\begin{array}{c}\text { I get quality } \\
\text { material that } \\
\text { makes it easy to } \\
\text { follow safe food } \\
\text { handling }\end{array}$ & $\begin{array}{c}\text { I get quality } \\
\text { material that } \\
\text { makes it easy to } \\
\text { follow safe food } \\
\text { handling }\end{array}$ \\
\hline
\end{tabular}




\begin{tabular}{|c|c|c|c|c|c|c|c|}
\hline & $\begin{array}{l}\text { safe food } \\
\text { handling } \\
\text { practices }\end{array}$ & $\begin{array}{c}\text { práticas manuais } \\
\text { de segurança } \\
\text { alimentar. }\end{array}$ & comida segura. & $\begin{array}{l}\text { manipulação de } \\
\text { alimentos }\end{array}$ & practices. & practices. & practices. \\
\hline 21 & $\begin{array}{l}\text { My coworkers } \\
\text { are always } \\
\text { supportive of } \\
\text { each other } \\
\text { regarding food } \\
\text { safety }\end{array}$ & $\begin{array}{l}\text { Meus colegas de } \\
\text { trabalho estão } \\
\text { sempre se } \\
\text { auxiliando um aos } \\
\text { outros no que se } \\
\text { refere a } \\
\text { segurança } \\
\text { alimentar. }\end{array}$ & $\begin{array}{l}\text { Meus colegas de } \\
\text { trabalho sempre } \\
\text { são apoiadores } \\
\text { entre si com } \\
\text { relação à } \\
\text { segurança de } \\
\text { comida. }\end{array}$ & $\begin{array}{l}\text { Meus colegas de } \\
\text { trabalho sempre } \\
\text { são solidários e } \\
\text { ajudam em relação } \\
\text { à segurança dos } \\
\text { alimentos }\end{array}$ & $\begin{array}{l}\text { My co-workers } \\
\text { are always } \\
\text { supportive and } \\
\text { help with food } \\
\text { safety. }\end{array}$ & $\begin{array}{l}\text { My coworkers } \\
\text { are always } \\
\text { supportive and } \\
\text { help with food } \\
\text { safety. }\end{array}$ & $\begin{array}{l}\text { My coworkers } \\
\text { are always } \\
\text { supportive and } \\
\text { help with food } \\
\text { safety. }\end{array}$ \\
\hline 22 & $\begin{array}{c}\text { When lots of } \\
\text { work needs to } \\
\text { be done quickly, } \\
\text { employees work } \\
\text { together as a } \\
\text { team to get the } \\
\text { tasks completed } \\
\text { safely }\end{array}$ & $\begin{array}{l}\text { Quando muito } \\
\text { trabalho precisa } \\
\text { ser feito } \\
\text { rapidamente, os } \\
\text { empregados } \\
\text { trabalham juntos } \\
\text { como uma equipe } \\
\text { para conseguir } \\
\text { completar as } \\
\text { tarefas em } \\
\text { segurança. }\end{array}$ & $\begin{array}{l}\text { Quando muito } \\
\text { trabalho precisa ser } \\
\text { feito rapidamente, } \\
\text { os empregados } \\
\text { trabalham juntos } \\
\text { como um time para } \\
\text { completar as } \\
\text { tarefas com } \\
\text { segurança. }\end{array}$ & $\begin{array}{l}\text { Quando tem muito } \\
\text { trabalho que } \\
\text { precisa ser feito } \\
\text { rapidamente, os } \\
\text { funcionários } \\
\text { trabalham juntos } \\
\text { como uma equipe } \\
\text { para obter as } \\
\text { tarefas concluídas } \\
\text { com segurança }\end{array}$ & $\begin{array}{c}\text { When there is a } \\
\text { lot of work that } \\
\text { needs to be done } \\
\text { quickly, } \\
\text { employees work } \\
\text { together as a } \\
\text { team to get the } \\
\text { jobs done safely. }\end{array}$ & $\begin{array}{c}\text { When there is a } \\
\text { lot of work that } \\
\text { needs to be done } \\
\text { quickly, } \\
\text { employees work } \\
\text { together as a } \\
\text { team to get the } \\
\text { jobs done safely. }\end{array}$ & $\begin{array}{l}\text { When there is a } \\
\text { lot of work that } \\
\text { needs to be } \\
\text { done quickly, } \\
\text { employees work } \\
\text { together as a } \\
\text { team to get the } \\
\text { jobs done } \\
\text { safely. }\end{array}$ \\
\hline 23 & $\begin{array}{l}\text { Employees } \\
\text { remind each } \\
\text { other about } \\
\text { following food } \\
\text { safety practices }\end{array}$ & $\begin{array}{l}\text { Os empregados } \\
\text { lembram um a } \\
\text { outro de seguir as } \\
\text { práticas de } \\
\text { segurança } \\
\text { alimentar. }\end{array}$ & $\begin{array}{l}\text { Os empregados } \\
\text { lembram uns aos } \\
\text { outros sobre seguir } \\
\text { as práticas de } \\
\text { comida segura. }\end{array}$ & $\begin{array}{c}\text { Os funcionários } \\
\text { lembram os outros } \\
\text { colegas para seguir } \\
\text { práticas de } \\
\text { segurança dos } \\
\text { alimentos }\end{array}$ & $\begin{array}{l}\text { The employees } \\
\text { remind the others } \\
\text { co-workers to } \\
\text { follow food safety } \\
\text { practices. }\end{array}$ & $\begin{array}{l}\text { Employees } \\
\text { remind other } \\
\text { colleagues to } \\
\text { follow food safety } \\
\text { practices. }\end{array}$ & $\begin{array}{l}\text { Employees } \\
\text { remind other } \\
\text { colleagues to } \\
\text { follow food } \\
\text { safety practices. }\end{array}$ \\
\hline 24 & $\begin{array}{l}\text { New employees } \\
\text { and experienced } \\
\text { employees work } \\
\text { together to } \\
\text { ensure food } \\
\text { safety practices } \\
\text { are in place }\end{array}$ & $\begin{array}{l}\text { Os novos e os } \\
\text { empregados mais } \\
\text { experientes } \\
\text { trabalham juntos } \\
\text { para assegurar } \\
\text { que as práticas } \\
\text { de segurança } \\
\text { alimentar estão } \\
\text { em pratica. }\end{array}$ & $\begin{array}{l}\text { Novos empregados } \\
\text { e empregados } \\
\text { experientes } \\
\text { trabalham juntos } \\
\text { para garantir que } \\
\text { práticas de comida } \\
\text { segura estão } \\
\text { apropriadas. }\end{array}$ & $\begin{array}{c}\text { Funcionários novos } \\
\text { e experientes } \\
\text { trabalham juntos } \\
\text { para garantir que } \\
\text { as práticas de } \\
\text { segurança dos } \\
\text { alimentos continue } \\
\text { existindo }\end{array}$ & $\begin{array}{c}\text { New and } \\
\text { experienced } \\
\text { employees work } \\
\text { together to } \\
\text { ensure that food } \\
\text { safety practices } \\
\text { continue to exist. }\end{array}$ & $\begin{array}{l}\text { New and } \\
\text { experienced staff } \\
\text { work together to } \\
\text { ensure that food } \\
\text { safety practices } \\
\text { continue to exist. }\end{array}$ & $\begin{array}{c}\text { New and } \\
\text { experienced } \\
\text { staff work } \\
\text { together to } \\
\text { ensure that food } \\
\text { safety practices } \\
\text { continue to } \\
\text { exist. }\end{array}$ \\
\hline 25 & $\begin{array}{l}\text { There is good } \\
\text { cooperation }\end{array}$ & $\begin{array}{c}\text { Existe uma boa } \\
\text { cooperação entre }\end{array}$ & $\begin{array}{c}\text { Há boa cooperação } \\
\text { entre os }\end{array}$ & $\begin{array}{l}\text { Existe uma boa } \\
\text { cooperação entre }\end{array}$ & $\begin{array}{c}\text { There is good } \\
\text { cooperation }\end{array}$ & $\begin{array}{c}\text { There is good } \\
\text { cooperation }\end{array}$ & $\begin{array}{l}\text { There is good } \\
\text { cooperation }\end{array}$ \\
\hline
\end{tabular}




\begin{tabular}{|c|c|c|c|c|c|c|c|}
\hline & $\begin{array}{l}\text { among } \\
\text { departments to } \\
\text { ensure that } \\
\text { customers } \\
\text { receive safely } \\
\text { prepared food }\end{array}$ & $\begin{array}{l}\text { os departamentos } \\
\text { para assegurar } \\
\text { que os clientes } \\
\text { recebem comida } \\
\text { preparada de } \\
\text { acordo com a } \\
\text { segurança } \\
\text { alimentar. }\end{array}$ & $\begin{array}{l}\text { departamentos } \\
\text { para garantir que } \\
\text { os clientes } \\
\text { recebam comida } \\
\text { preparada } \\
\text { seguramente. }\end{array}$ & $\begin{array}{l}\text { os setores da } \\
\text { empresa para } \\
\text { garantir que os } \\
\text { clientes recebam } \\
\text { alimentos } \\
\text { preparados com } \\
\text { segurança }\end{array}$ & $\begin{array}{l}\text { among the } \\
\text { company's } \\
\text { departments to } \\
\text { ensure that } \\
\text { customers } \\
\text { receive food } \\
\text { safely prepared. }\end{array}$ & $\begin{array}{l}\text { between the } \\
\text { company's } \\
\text { departments to } \\
\text { ensure that } \\
\text { customers } \\
\text { receive food } \\
\text { safely prepared. }\end{array}$ & $\begin{array}{l}\text { between the } \\
\text { company's } \\
\text { departments to } \\
\text { ensure that } \\
\text { customers } \\
\text { receive food } \\
\text { safely prepared. }\end{array}$ \\
\hline 26 & $\begin{array}{l}\text { Employees are } \\
\text { disciplined or } \\
\text { reprimanded } \\
\text { when they fail to } \\
\text { follow food } \\
\text { safety practices }\end{array}$ & $\begin{array}{l}\text { Os empregados } \\
\text { são disciplinados } \\
\text { ou advertidos } \\
\text { quando falham no } \\
\text { seguimento das } \\
\text { práticas de } \\
\text { segurança } \\
\text { alimentar. }\end{array}$ & $\begin{array}{l}\text { Os empregados } \\
\text { são disciplinados } \\
\text { ou repreendidos } \\
\text { quando falham em } \\
\text { seguir práticas de } \\
\text { segurança em } \\
\text { comida. }\end{array}$ & $\begin{array}{l}\text { Os funcionários } \\
\text { são advertidos ou } \\
\text { repreendidos } \\
\text { quando não } \\
\text { seguem as práticas } \\
\text { de segurança dos } \\
\text { alimentos }\end{array}$ & $\begin{array}{l}\text { The employees } \\
\text { are warned or } \\
\text { reprimanded } \\
\text { when they do not } \\
\text { follow food safety } \\
\text { practices }\end{array}$ & $\begin{array}{l}\text { Employees are } \\
\text { warned or } \\
\text { reprimanded } \\
\text { when they do not } \\
\text { follow food safety } \\
\text { practices. }\end{array}$ & $\begin{array}{l}\text { Employees are } \\
\text { warned or } \\
\text { reprimanded } \\
\text { when they do } \\
\text { not follow food } \\
\text { safety practices. }\end{array}$ \\
\hline 27 & $\begin{array}{l}\text { I always have } \\
\text { enough time to } \\
\text { follow safe food } \\
\text { handling } \\
\text { procedures, } \\
\text { even during } \\
\text { rush hours }\end{array}$ & $\begin{array}{l}\text { Tenho sempre } \\
\text { tempo suficiente } \\
\text { para seguir os } \\
\text { procedimentos } \\
\text { manuais de } \\
\text { segurança } \\
\text { alimentar, mesmo } \\
\text { durante os } \\
\text { horários de pico. }\end{array}$ & $\begin{array}{l}\text { Eu sempre tenho } \\
\text { tempo suficiente } \\
\text { para seguir } \\
\text { procedimentos de } \\
\text { manuseio de } \\
\text { comida segura, } \\
\text { mesmo durante as } \\
\text { horas de grande } \\
\text { movimento. }\end{array}$ & $\begin{array}{l}\text { Eu sempre tenho } \\
\text { tempo suficiente } \\
\text { para seguir os } \\
\text { procedimentos de } \\
\text { manuseio de } \\
\text { alimentos seguros, } \\
\text { mesmo durante } \\
\text { momentos que a } \\
\text { produção acelera }\end{array}$ & $\begin{array}{l}\text { I always have } \\
\text { enough time to } \\
\text { follow safe food } \\
\text { handling } \\
\text { procedures, even } \\
\text { during times } \\
\text { when production } \\
\text { accelerates. }\end{array}$ & $\begin{array}{l}\text { I always have } \\
\text { enough time to } \\
\text { follow safe food } \\
\text { handling } \\
\text { procedures, even } \\
\text { during times } \\
\text { when production } \\
\text { accelerates. }\end{array}$ & $\begin{array}{c}\text { I always have } \\
\text { enough time to } \\
\text { follow safe food } \\
\text { handling } \\
\text { procedures, } \\
\text { even during } \\
\text { times when } \\
\text { production } \\
\text { accelerates. }\end{array}$ \\
\hline 28 & $\begin{array}{l}\text { My work load } \\
\text { does not } \\
\text { interfere with my } \\
\text { ability to follow } \\
\text { safe food } \\
\text { handling } \\
\text { practices }\end{array}$ & $\begin{array}{l}\text { Meu trabalho não } \\
\text { interfere com } \\
\text { minha habilidade } \\
\text { de seguir as } \\
\text { práticas manuais } \\
\text { de segurança } \\
\text { alimentar. }\end{array}$ & $\begin{array}{l}\text { Meu trabalho não } \\
\text { interfere na minha } \\
\text { habilidade de } \\
\text { seguir práticas de } \\
\text { manuseio de } \\
\text { comida segura. }\end{array}$ & $\begin{array}{l}\text { Minha carga de } \\
\text { trabalho não } \\
\text { atrapalha a minha } \\
\text { capacidade de } \\
\text { seguir práticas } \\
\text { seguras de } \\
\text { manipulação de } \\
\text { alimentos }\end{array}$ & $\begin{array}{l}\text { My workload does } \\
\text { not disrupt my } \\
\text { ability to follow } \\
\text { safe food } \\
\text { handling } \\
\text { practices. }\end{array}$ & $\begin{array}{l}\text { My workload } \\
\text { does not disrupt } \\
\text { my ability to } \\
\text { follow safe food } \\
\text { handling } \\
\text { practices. }\end{array}$ & $\begin{array}{c}\text { My workload } \\
\text { does not disrupt } \\
\text { my ability to } \\
\text { follow safe food } \\
\text { handling } \\
\text { practices. }\end{array}$ \\
\hline 29 & $\begin{array}{l}\text { The number of } \\
\text { staff scheduled } \\
\text { at each shift is } \\
\text { adequate for me } \\
\text { to get my work } \\
\text { done and }\end{array}$ & $\begin{array}{l}\text { O número de } \\
\text { funcionários } \\
\text { alocados em cada } \\
\text { turno é adequado } \\
\text { para que eu tenha } \\
\text { meu trabalho feito }\end{array}$ & $\begin{array}{l}\text { O número de } \\
\text { funcionários } \\
\text { escalados em cada } \\
\text { turno é adequado } \\
\text { para mim para } \\
\text { realizar o meu }\end{array}$ & $\begin{array}{c}\text { O número de } \\
\text { funcionários } \\
\text { programados em } \\
\text { cada turno é } \\
\text { adequado para que } \\
\text { eu possa fazer meu }\end{array}$ & $\begin{array}{l}\text { The number of } \\
\text { employees } \\
\text { scheduled at } \\
\text { each shift is } \\
\text { adequate so I can } \\
\text { do my job and }\end{array}$ & $\begin{array}{l}\text { The number of } \\
\text { employees } \\
\text { scheduled at } \\
\text { each shift is } \\
\text { adequate so I } \\
\text { can do my job }\end{array}$ & $\begin{array}{l}\text { The number of } \\
\text { employees } \\
\text { scheduled at } \\
\text { each shift is } \\
\text { adequate so I } \\
\text { can do my job }\end{array}$ \\
\hline
\end{tabular}




\begin{tabular}{|c|c|c|c|c|c|c|c|}
\hline & $\begin{array}{l}\text { handle food } \\
\text { safely }\end{array}$ & $\begin{array}{l}\text { e o manuseio } \\
\text { seguro do } \\
\text { alimento. }\end{array}$ & $\begin{array}{c}\text { trabalho e } \\
\text { manusear a comida } \\
\text { de forma segura. }\end{array}$ & $\begin{array}{l}\text { trabalho e } \\
\text { manipular } \\
\text { alimentos com } \\
\text { segurança }\end{array}$ & $\begin{array}{l}\text { safely handle } \\
\text { food. }\end{array}$ & $\begin{array}{c}\text { and safely } \\
\text { handle food. }\end{array}$ & $\begin{array}{l}\text { and safely } \\
\text { handle food. }\end{array}$ \\
\hline 30 & $\begin{array}{l}\text { When there is } \\
\text { pressure to } \\
\text { finish food } \\
\text { production, } \\
\text { managers } \\
\text { sometimes tell } \\
\text { us to work faster } \\
\text { by taking } \\
\text { shortcuts with } \\
\text { food safety }\end{array}$ & $\begin{array}{l}\text { Quando existe } \\
\text { uma pressão para } \\
\text { terminar a } \\
\text { produção de um } \\
\text { alimento, os } \\
\text { gestores, as } \\
\text { vezes, nos pedem } \\
\text { para trabalhar } \\
\text { mais rápido com } \\
\text { pausas com as } \\
\text { práticas de } \\
\text { segurança } \\
\text { alimentar. }\end{array}$ & $\begin{array}{l}\text { Quando há pressão } \\
\text { para terminar a } \\
\text { produção de } \\
\text { comida, os } \\
\text { gerentes às vezes } \\
\text { nos dizem para } \\
\text { trabalhar mais } \\
\text { rápido tomando } \\
\text { atalhos com } \\
\text { segurança da } \\
\text { comida. }\end{array}$ & $\begin{array}{l}\text { Quando estamos } \\
\text { sob pressão para } \\
\text { terminar a } \\
\text { produção de } \\
\text { alimentos, os } \\
\text { gerentes às vezes } \\
\text { nos dizem para } \\
\text { trabalhar mais } \\
\text { rápido, "pulando" } \\
\text { algumas regras de } \\
\text { segurança } \\
\text { alimentar }\end{array}$ & $\begin{array}{l}\text { When we are } \\
\text { under pressure to } \\
\text { finish food } \\
\text { production, the } \\
\text { managers } \\
\text { sometimes tell us } \\
\text { to work faster by } \\
\text { "skipping" some } \\
\text { food safety rules. }\end{array}$ & $\begin{array}{l}\text { When we are } \\
\text { under pressure } \\
\text { to finish food } \\
\text { production, } \\
\text { managers } \\
\text { sometimes tell us } \\
\text { to work faster by } \\
\text { "skipping" some } \\
\text { food safety rules. }\end{array}$ & $\begin{array}{l}\text { When we are } \\
\text { under pressure } \\
\text { to finish food } \\
\text { production, the } \\
\text { managers } \\
\text { sometimes tell } \\
\text { us to work } \\
\text { faster by } \\
\text { "skipping" some } \\
\text { food safety } \\
\text { rules. }\end{array}$ \\
\hline 31 & $\begin{array}{l}\text { I am sometimes } \\
\text { asked to cut } \\
\text { corners with } \\
\text { food safety so } \\
\text { we can save } \\
\text { costs when } \\
\text { preparing food }\end{array}$ & $\begin{array}{l}\text { Às vezes me } \\
\text { pedem para } \\
\text { economizar com } \\
\text { a segurança } \\
\text { alimentar, então } \\
\text { podemos cortar } \\
\text { custos quando } \\
\text { preparamos os } \\
\text { alimentos. }\end{array}$ & $\begin{array}{l}\text { Às vezes me } \\
\text { pedem para } \\
\text { economizar com a } \\
\text { segurança de } \\
\text { comida de forma a } \\
\text { cortar custos ao } \\
\text { preparar comida. }\end{array}$ & $\begin{array}{c}\text { Às vezes me } \\
\text { pedem para "cortar } \\
\text { caminho" em } \\
\text { relação à } \\
\text { segurança dos } \\
\text { alimentos durante a } \\
\text { produção dos } \\
\text { alimentos para que } \\
\text { possamos } \\
\text { economizar custos }\end{array}$ & $\begin{array}{l}\text { Sometimes they } \\
\text { ask me to "cut a } \\
\text { path" to food } \\
\text { safety during food } \\
\text { production so we } \\
\text { can save on } \\
\text { costs. }\end{array}$ & $\begin{array}{l}\text { Sometimes they } \\
\text { ask me to "cut a } \\
\text { path" to food } \\
\text { safety during } \\
\text { food production } \\
\text { so we can save } \\
\text { on costs. }\end{array}$ & $\begin{array}{l}\text { Sometimes they } \\
\text { ask me to "cut a } \\
\text { path" to food } \\
\text { safety during } \\
\text { food production } \\
\text { so we can save } \\
\text { on costs }\end{array}$ \\
\hline
\end{tabular}

